\title{
WestVirginiaUniversity
}

THE RESEARCH REPOSITORY @ WVU

Graduate Theses, Dissertations, and Problem Reports

2009

\section{Fuel economy and emissions benefits from diesel fuel additives}

Geoffrey James Newlin

West Virginia University

Follow this and additional works at: https://researchrepository.wvu.edu/etd

\section{Recommended Citation}

Newlin, Geoffrey James, "Fuel economy and emissions benefits from diesel fuel additives" (2009). Graduate Theses, Dissertations, and Problem Reports. 4507.

https://researchrepository.wvu.edu/etd/4507

This Thesis is protected by copyright and/or related rights. It has been brought to you by the The Research Repository @ WVU with permission from the rights-holder(s). You are free to use this Thesis in any way that is permitted by the copyright and related rights legislation that applies to your use. For other uses you must obtain permission from the rights-holder(s) directly, unless additional rights are indicated by a Creative Commons license in the record and/ or on the work itself. This Thesis has been accepted for inclusion in WVU Graduate Theses, Dissertations, and Problem Reports collection by an authorized administrator of The Research Repository @ WVU. For more information, please contact researchrepository@mail.wvu.edu. 


\title{
Fuel Economy and Emissions Benefits from Diesel Fuel Additives
}

\author{
Geoffrey James Newlin
}

\author{
Thesis submitted to the \\ College of Engineering and Mineral Resources \\ at West Virginia University \\ in partial fulfillment of the requirements \\ for the degree of \\ Master of Science \\ In \\ Mechanical Engineering
}

Gregory Thompson, Ph.D., Chair

Nigel Clark, Ph.D. Mridul Gautam, Ph.D.

Department of Mechanical Engineering

Morgantown, West Virginia 2009

Keywords: Diesel Engines, Additives, Emissions, Fuel Economy Copyright 2009 Geoffrey James Newlin 


\section{Abstract \\ Fuel Economy and Emissions Benefits from Diesel Fuel Additives}

\section{Geoffrey James Newlin}

With the spike in fuel costs during 2008, fuel consumption, and methods to reduce it, has come to the forefront of society, and recognition that inexpensive energy sources for mobile transportation may be a thing of the past. Even though fuel costs did significantly decrease by $75 \%$ after this spike [1], they will most likely continue to rise. Improvements to mobile transportation and the reduction of greenhouse gas emissions are a major agenda item of the United States and many industrialized nations. New and improved technologies will be developed and employed for future transportation needs of society. However, the existing fleet used in the transportation sector will take years, if not decades, to replace, and there is a need to find technologies to implement that could serve to reduce the fuel consumption from these vehicles.

One example of the present fleet is the United States Department of Defense (DoD), which in 2008 purchased approximately 100 million barrels of diesel and jet petroleum fuels totaling more than 12 billion dollars [2]. A $0.1 \%$ reduction in consumption could save millions of dollars for the DoD. Any practical, economical means to reduce the fuel consumption for the DoD may have significant financial rewards. Additionally, reducing battlefield fuel consumption will result in reduction of support troop exposure in combat zones. Enhancing combustion is one way to increase fuel economy in vehicles, and using fuel additives may be an economical means to do this.

This study evaluated the effect five different additives had on the fuel consumption and emissions from three heavy-duty and one medium-duty diesel engines. The testing was completed in an engine dynamometer test cell following a variety of test cycles. None of the additives could reliably show a reduction in brake specific fuel consumption for three of the engines, and one engine demonstrated less than a 1.0\% reduction. Likewise, no significant changes in emissions measurements were identified, with the exception that one additive exhibited reductions in brake specific particulate matter for two of the engines. 


\section{Table of Contents}

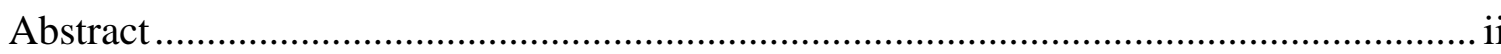

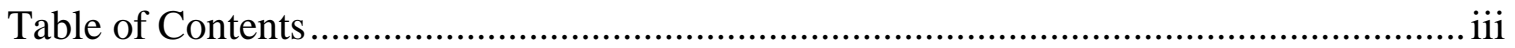

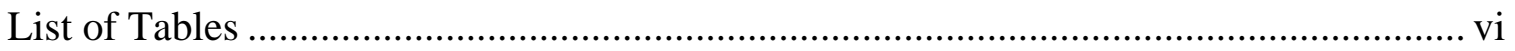

List of Figures ....................................................................................................... ix

1 Introduction and Objectives ............................................................................. 1

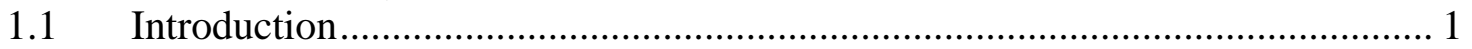

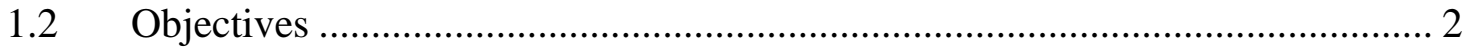

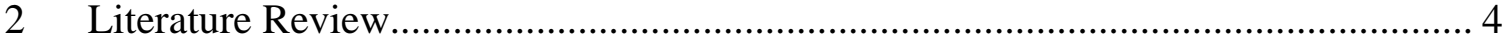

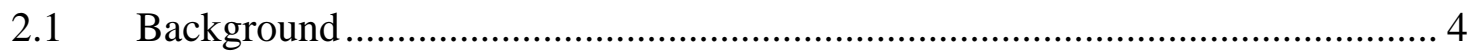

2.1.1 Diesel Fuels...................................................................................... 4

2.2 Diesel Fuel Properties................................................................................. 7

2.2.1 Density and Specific Gravity ................................................................. 7

2.2.2 Cetane Number .................................................................................... 7

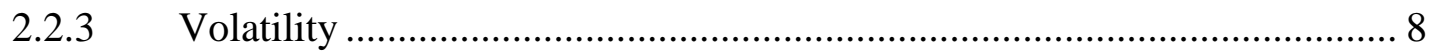

2.2.4 Sulfur Content.............................................................................. 9

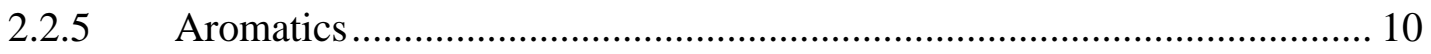

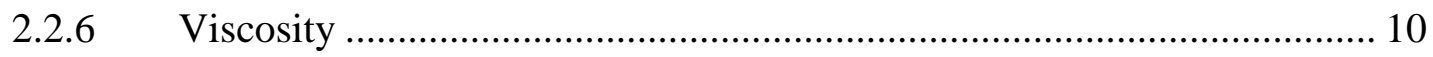

2.2.7 Flash Point ........................................................................................... 11

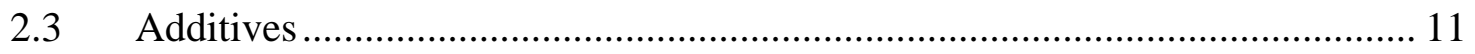

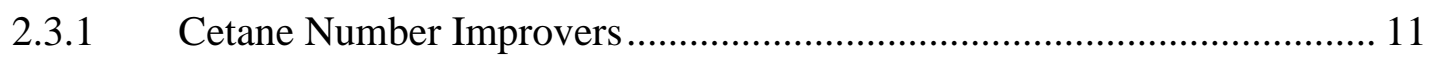

2.3.2 Lubricity Improvers ………………………......................................... 12

2.3.3 Detergents ......................................................................................... 12

2.3.4 Cold Flow Improvers …………………............................................... 13

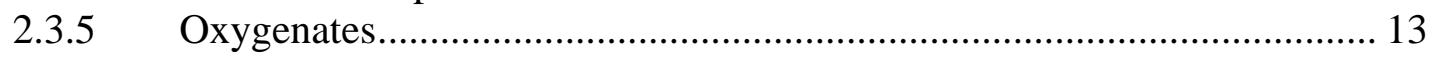

2.3.6 Biodiesel ......................................................................................... 14

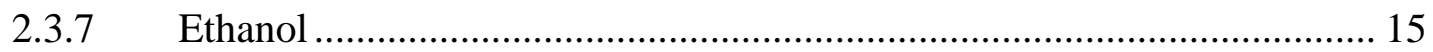

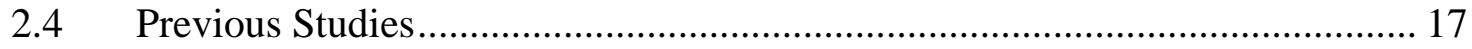

2.4.1 Effect of Fuel Properties on Emissions..................................................... 17

2.4.2 Effect of Additives on Emissions ........................................................ 18

2.4.3 Effect of Engine Model Year on Emissions ……………........................... 19

2.4.4 Test Cycle Development...................................................................... 20

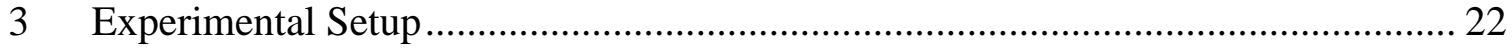

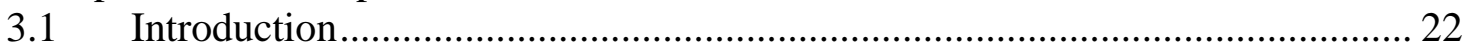

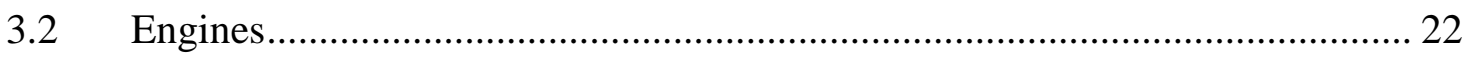

3.2.1 1999 Cummins ISM 370 ESP …………………............................... 22

3.2.2 2004 Mack MP7-355E ....................................................................... 23

3.2.3 1992 Rebuilt Detroit Diesel Series 60 .............................................. 24

3.2.4 1998 General Engine Products................................................................. 25

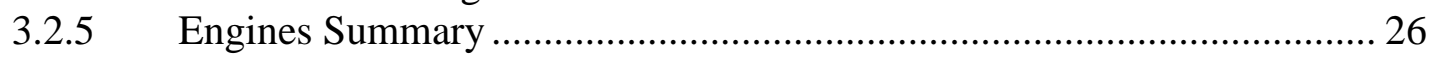

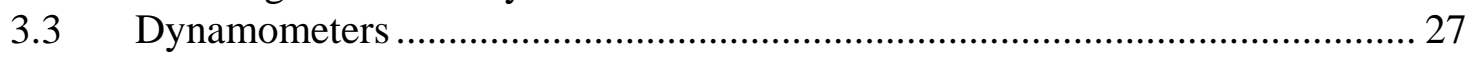

3.3.1 General Electric $800 \mathrm{hp}$...................................................................... 28

3.3.2 General Electric $550 \mathrm{hp} \mathrm{......................................................................} 29$ 


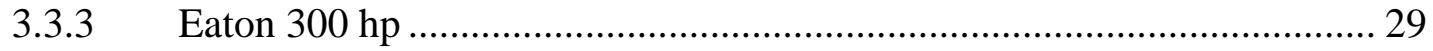

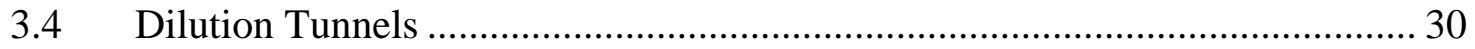

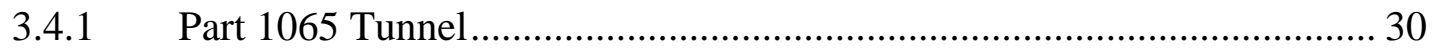

3.4.2 Part 86 Tunnel.................................................................................. 32

3.5 Exhaust Gas Analyzers ................................................................................... 34

3.5.1 Hydrocarbon Analyzers ......................................................................... 35

3.5.2 Carbon Dioxide and Carbon Monoxide Analyzers...................................... 35

3.5.3 Oxides of Nitrogen Analyzers .............................................................. 36

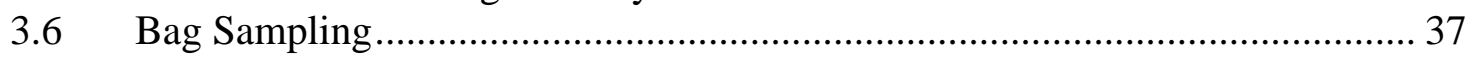

3.7 Particulate Matter Sampling ………………................................................... 37

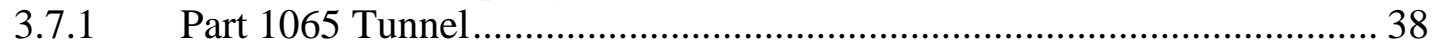

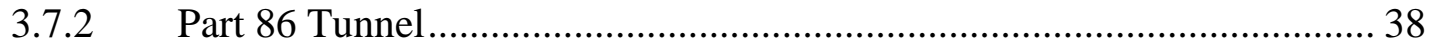

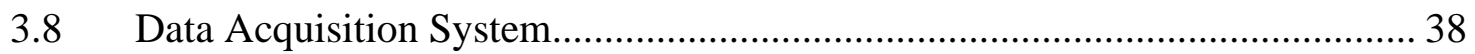

3.9 In-Cylinder Pressure Measurement.............................................................. 40

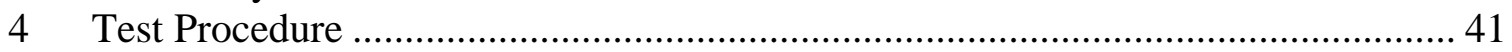

4.1 Analyzer Operation .................................................................................... 41

4.2 Particulate Matter Weighing ......................................................................... 41

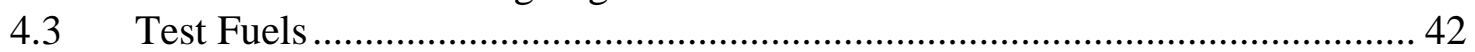

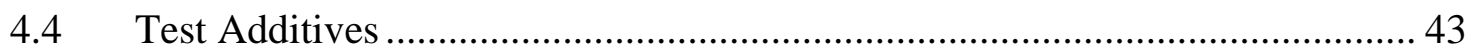

$4.5 \quad$ Test Fuel Preparation .................................................................................. 44

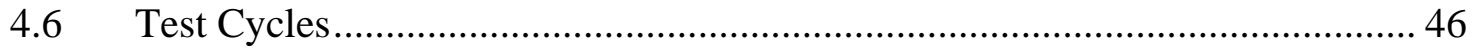

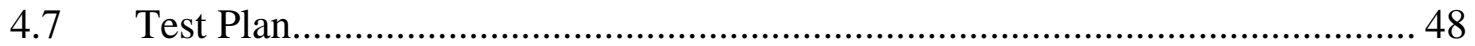

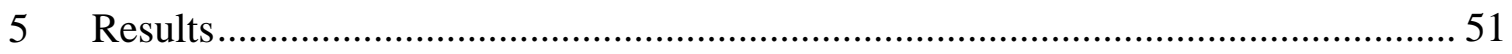

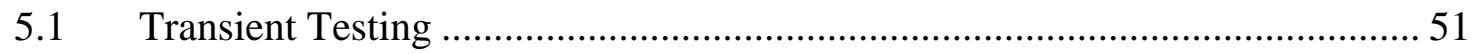

5.1.1 Fuel Consumption and Carbon Dioxide Emissions ................................... 52

5.1.2 Oxides of Nitrogen Emissions .............................................................. 58

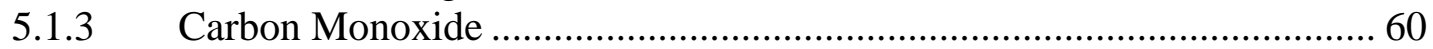

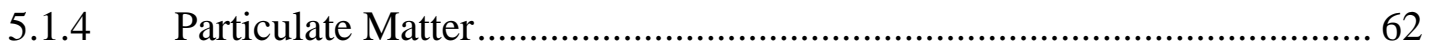

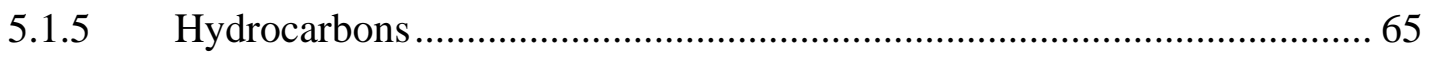

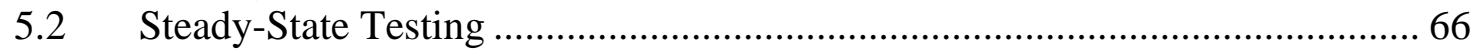

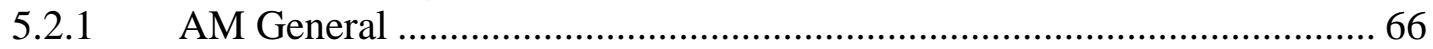

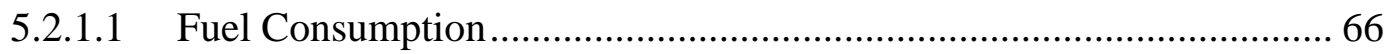

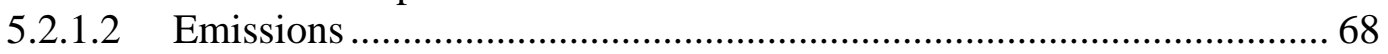

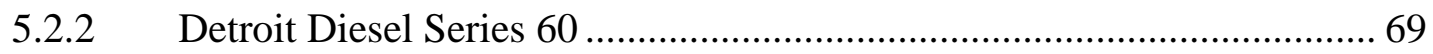

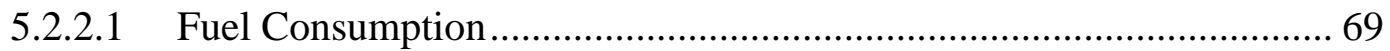

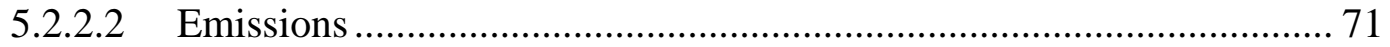

5.2.2.3 In-Cylinder Pressure .................................................................... 72

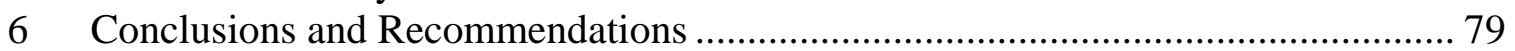

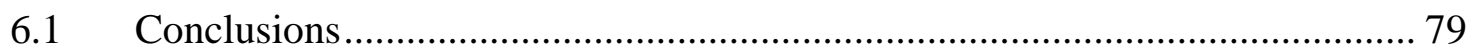

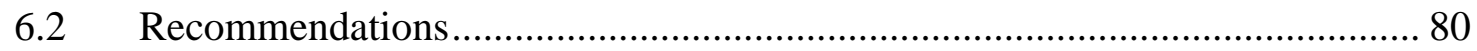

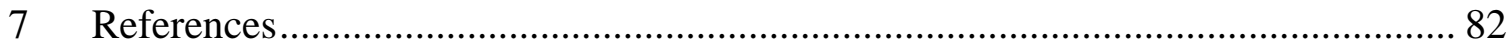

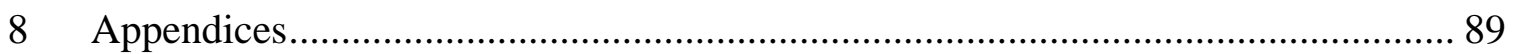

8.1 Set Points for Steady-State Testing of 1992 DDC ............................................. 89

8.2 Set Points for Steady-State Testing of AM General ............................................ 90

8.3 AM General Test Cycle Creation Procedure ...................................................... 90

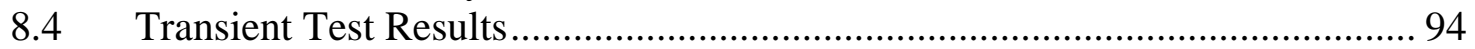


8.4.1 Transient Testing Averages and Variation Results.................................. 94

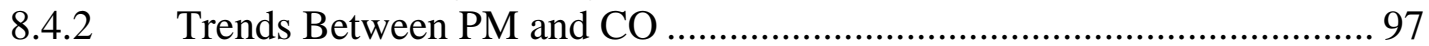

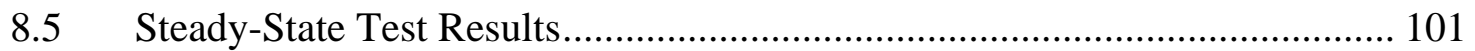

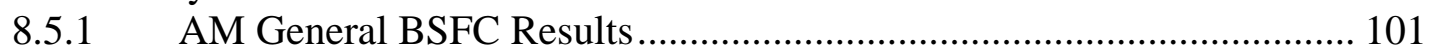

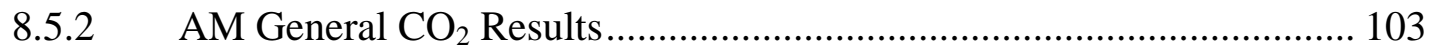

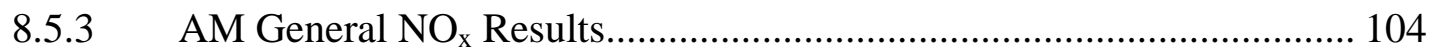

8.5.4 AM General CO Results ................................................................ 106

8.5.5 AM General PM Results ................................................................. 107

8.5.6 AM General HC Results .................................................................... 109

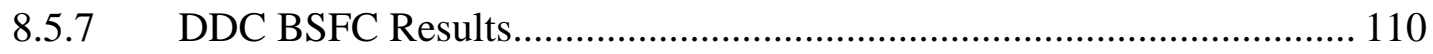

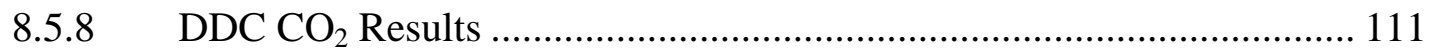

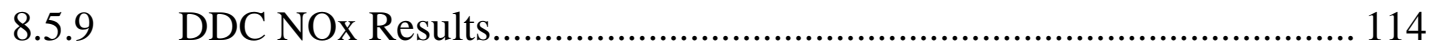

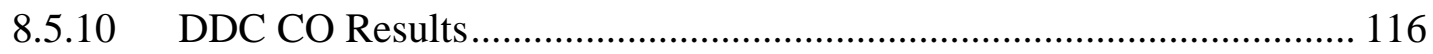

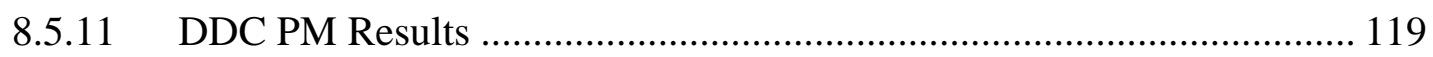

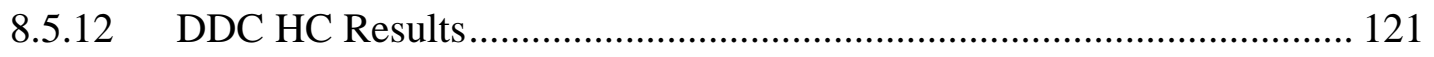

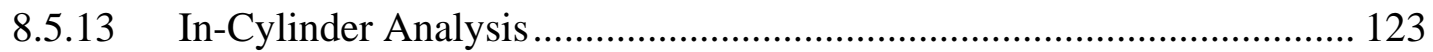

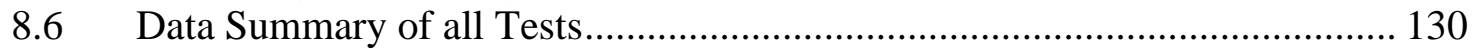

8.6.1 Averages of Transent Tests............................................................ 130

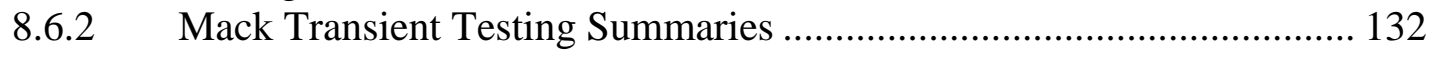

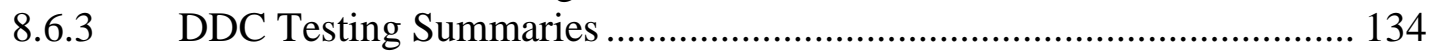

8.6.4 Cummins Testing Summaries ......................................................... 150

8.6.5 AM General Testing Summaries ..................................................... 153 


\section{List of Tables}

Table 2-1 Examples of Hydrocarbons Found in Petroleum [9,13].................................... 5

Table 2-2 Properties of Common Hydrocarbons Found in Petroleum [15,16] ................... 6

Table 2-3 Properties of Different Common Biodiesels [47]............................................. 14

Table 2-4 Emulsifier Manufacturers and Blending Levels [56] ....................................... 16

Table 2-5 Average Percent Change Between E-diesel and Neat No. 2 Diesel [57] ......... 16

Table 3-1 Engines Summary................................................................................. 27

Table 3-2 Hydrocarbon Analyzers used for Testing........................................................ 35

Table 3-3 Carbon Monoxide and Carbon Dioxide Analyzers used for Testing ................ 36

Table 3-4 Analyzers used for Oxides of Nitrogen Measurement ........................................ 37

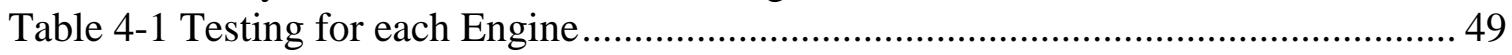

Table 5-1 p-values for Student's t-test for BSFC ............................................................. 56

Table 5-2 p-values for Student's t-test for $\mathrm{BSCO}_{2}$ and BSFC ......................................... 58

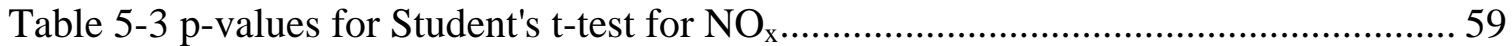

Table 5-4 Comparison of Change in $\mathrm{BSNO}_{\mathrm{x}}$ with Variations Between Test-to-Test....... 60

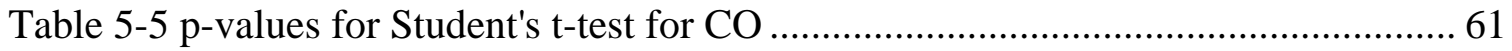

Table 5-6 Comparison of Change in BSCO with Variations Between Test-to-Test......... 62

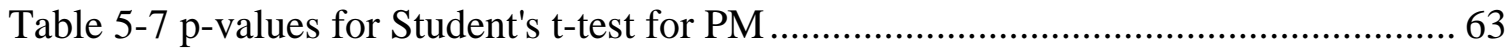

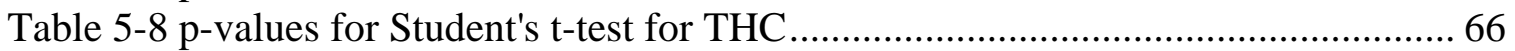

Table 5-9 p-values for BSFC of AM General Steady-State .............................................. 67

Table 5-10 p-values for BSFC of DDC Steady-State …………...................................... 71

Table 5-11 Comparison of Change in BSFC with Variations Between Test-to-Test....... 71

Table 8-1 Speed and Load Points for 13 Mode Steady-State Testing ............................... 89

Table 8-2 Set Points for 6 Mode Steady-State Testing....................................................... 89

Table 8-3 Set Points for Steady-State Testing of 1998 AM General Engine ................... 90

Table 8-4 Transient BSFC Variation Results ................................................................... 94

Table 8-5 Transient $\mathrm{CO}_{2}$ Variation Results ................................................................. 95

Table 8-6 Transient NOx Variation Results ………….................................................. 95

Table 8-7 Transient CO Variation Results.................................................................... 96

Table 8-8 Transient PM Variation Results .............................................................. 96

Table 8-9 Transient HC Variation Results..................................................................... 97

Table 8-10 Percent Change in bsPM and bsCO for Transient Testing............................. 97

Table 8-11 AM General Steady-State BSFC p-values …………………........................ 102

Table 8-12 AM General Steady-State BSFC Variation Results ....................................... 102

Table 8-13 AM General Steady-State $\mathrm{CO}_{2}$ p-values .................................................... 104

Table 8-14 AM General Steady-State $\mathrm{CO}_{2}$ Variation Results .......................................... 104

Table 8-15 AM General Steady-State $\mathrm{NO}_{\mathrm{x}} \mathrm{p}$-values ....................................................... 105

Table 8-16 AM General Steady-State $\mathrm{NO}_{\mathrm{x}}$ Variation Results......................................... 105

Table 8-17 AM General Steady-State CO p-values........................................................... 107

Table 8-18 AM General Steady-State CO Variation Results ........................................... 107

Table 8-19 AM General Steady-State PM p-values ....................................................... 108

Table 8-20 AM General Steady-State PM Variation Results .......................................... 108

Table 8-21 AM General Steady-State HC p-values........................................................... 110

Table 8-22 AM General Steady-State HC Variation Results ....................................... 110 
Table 8-23 p-Values for $\mathrm{CO}_{2}$ for DDC Steady State Testing ...................................... 112

Table 8-24 $\mathrm{BSCO}_{2}$ Variation Results of DDC for Steady State Testing ........................ 112

Table 8-25 p-values for NOx for DDC Steady State Testing ...................................... 114

Table 8-26 BSNOx Variation Results of DDC for Steady State Testing ....................... 115

Table 8-27 p-values for CO for DDC Steady State Testing ........................................ 117

Table 8-28 BSCO Variation Results of DDC for Steady State Testing ......................... 117

Table 8-29 p-values for PM for DDC Steady State Testing ....................................... 119

Table 8-30 BSPM Variation Results of DDC for Steady State Testing ....................... 120

Table 8-31 p-values for PM for DDC Steady State Testing ......................................... 122

Table 8-32 BSHC Variation Results of DDC for Steady State Testing ........................ 122

Table 8-33 Averages and Standard Deviations for all Transient Tests ........................ 130

Table 8-34 Continuation of Averages and Standard Deviations for all Transient Tests 131

Table 8-35 Summary of Guttman testing for Mack.................................................... 132

Table 8-36 Summary of Cerion 1 Testing for Mack..................................................... 132

Table 8-37 Summary of Baseline of Cerion 1 Testing for Mack .................................. 133

Table 8-38 Summary of Cerion 2 Testing for Mack.................................................... 133

Table 8-39 Summary of Baseline for Cerion 2 Testing for Mack ................................. 134

Table 8-40 Summary of Baseline Testing for DDC Transient ..................................... 134

Table 8-41 Summary of Baseline for H2Oil 1 Testing for DDC Transient.................... 135

Table 8-42 Summary for H2Oil 1 for DDC Transient................................................ 135

Table 8-43 Summary of Baseline of Cerion 1 for DDC Transient ................................ 136

Table 8-44 Summary of Cerion 1 for DDC Transient ................................................ 136

Table 8-45 Summary of Baseline of NanoBonus for DDC Transient ........................... 137

Table 8-46 Summary of NanoBonus for DDC Transient ........................................... 137

Table 8-47 Summary of Baseline for H2Oil 1 for DDC Steady State........................... 138

Table 8-48 Summary of Baseline for H2Oil 1 for DDC Steady State........................... 138

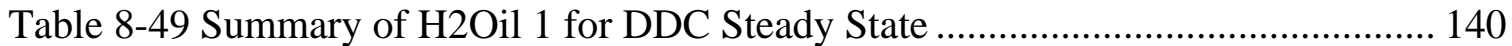

Table 8-50 Summary of H2Oil 1 for DDC Steady State ............................................. 140

Table 8-51 Summary of Baseline of DDC Steady State............................................. 142

Table 8-52 Summary of Baseline of Cerion 1 of DDC Steady State............................. 143

Table 8-53 Summary of Cerion 1 for DDC Steady State ........................................... 144

Table 8-54 Summary of Cerion 1 for DDC STeady State .......................................... 145

Table 8-55 Summary of NanoBonus for DDC Steady State ....................................... 146

Table 8-56 Summary of NanoBonus for DDC Steady State ...................................... 147

Table 8-57 Summary of Baseline for NanoBonus for DDC Steady State ...................... 148

Table 8-58 Summary of Baseline for NanoBonus for DDC Steady State..................... 149

Table 8-59 Summary of Baseline Testing on Mack .................................................... 150

Table 8-60 Summary of Cerion 1 Testing on Mack ..................................................... 150

Table 8-61 Summary of Baseline for Cerion 1 Testing on Mack .................................. 151

Table 8-62 Summary of Baseline for H2Oil 1 Testing on Mack.................................... 151

Table 8-63 Summary of H2Oil 1 Testing on Mack ...................................................... 152

Table 8-64 Summary of Baseline for NanoBonus Testing on Mack............................ 152

Table 8-65 Summary of NanoBonus Test on Mack .................................................... 153

Table 8-66 Summary of Baseline for NanoBonus Test on AM General........................ 153

Table 8-67 Summary of NanoBonus Test on AM General ......................................... 154

Table 8-68 Summary of Baseline for H2Oil 2 Test on AM General .............................. 154 
Table 8-69 Summary of H2Oil 2 Test on AM General ............................................... 155

Table 8-70 Summary of Baseline Test on AM General ............................................... 155

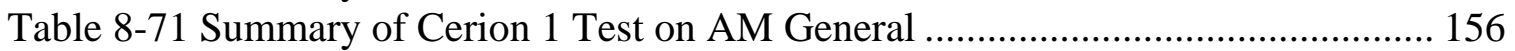

Table 8-72 Summary of Baseline for Cerion 1 Test on AM General............................. 156

Table 8-73 Mode A Baseline for NanoBonus Steady State Test on AM General.......... 157

Table 8-74 Mode A NanoBonus Steady State Test on AM General .............................. 157

Table 8-75 Mode A Baseline for H2Oil 2 Steady State Test on AM General................ 157

Table 8-76 Mode A H2Oil 2 Steady State Test on AM General .................................. 158

Table 8-77 Mode A Baseline for Cerion 1 Steady State Test on AM General................ 158

Table 8-78 Mode A Cerion 1 Steady State Test on AM General .................................. 158

Table 8-79 Mode B Baseline for NanoBonus Steady State Test on AM General.......... 159

Table 8-80 Mode B NanoBonus Steady State Test on AM General ............................ 159

Table 8-81 Mode B Baseline for H2Oil 2 Steady State Test on AM General................ 159

Table 8-82 Mode B H2Oil 2 Steady State Test on AM General ................................... 160

Table 8-83 Mode B Baseline for Cerion 1 Steady State Test on AM General............... 160

Table 8-84 Mode B Cerion 1 Steady State Test on AM General ................................. 160 


\section{List of Figures}

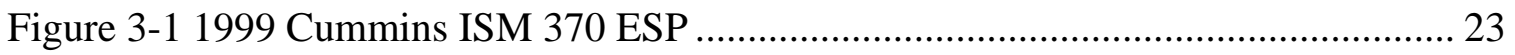

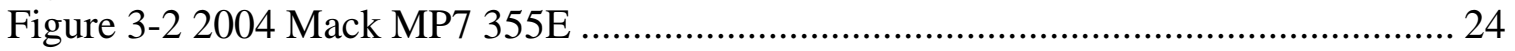

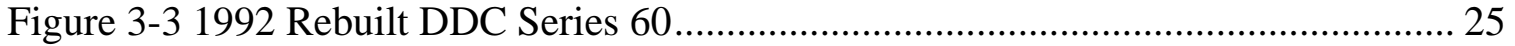

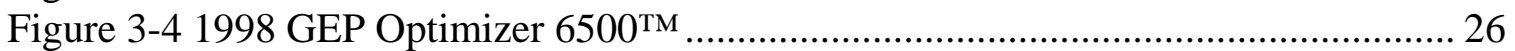

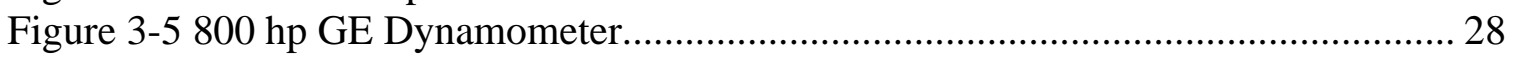

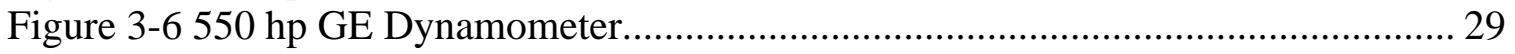

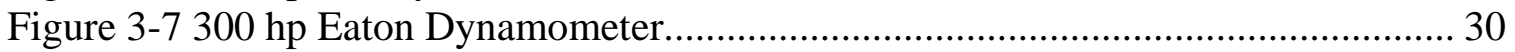

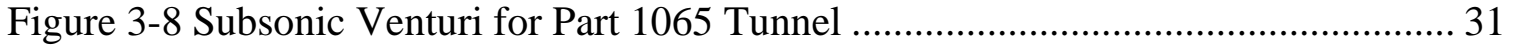

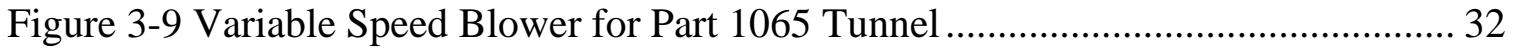

Figure 3-10 Critical Flow Venturis for Part 86 Tunnel .................................................. 33

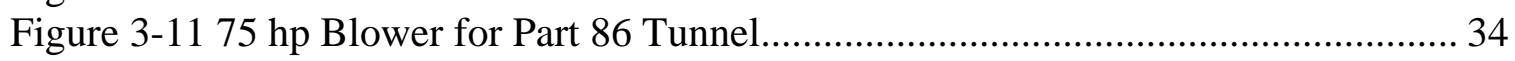

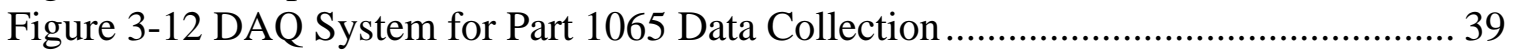

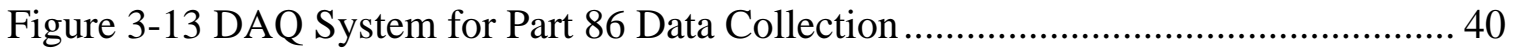

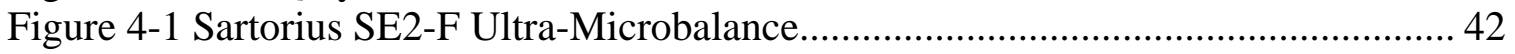

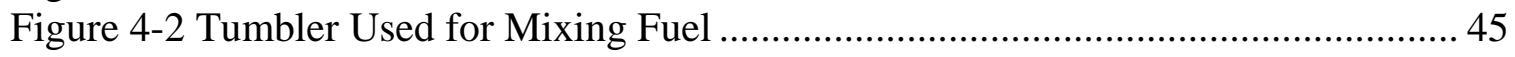

Figure 4-3 Set Points for Supplemental Emissions Test................................................ 47

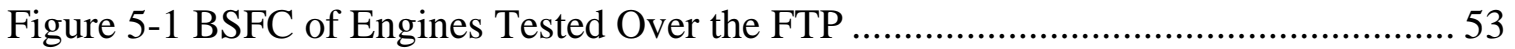

Figure 5-2 BSFC of AM General for Transient Testing.................................................. 54

Figure 5-3 Percent Change in BSFC from Baseline ....................................................... 55

Figure 5-4 Percent Change in $\mathrm{BSCO}_{2}$ Emissions from Baseline................................... 57

Figure 5-5 Percent Change in BSNOx Emissions from Baseline ................................... 59

Figure 5-6 Percent Change in BSCO Emissions from Baseline ...................................... 61

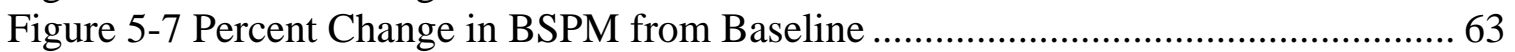

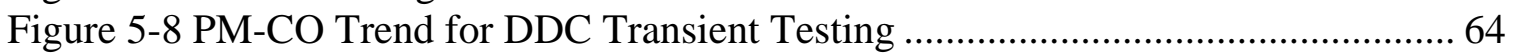

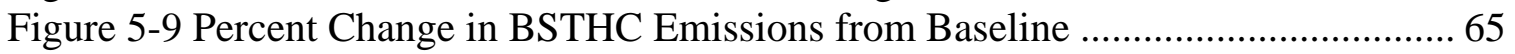

Figure 5-10 Percent Change in BSFC from Baseline for AM General Steady State ....... 67

Figure 5-11 Percent Change in BSFC from Baseline for DDC Steady-State.................. 70

Figure 5-12 Average Maximum In-Cylinder Pressure .............................................. 74

Figure 5-13 Average Maximum In-Cylinder Pressure of Mode 5................................. 75

Figure 5-14 Location of Average Start of Combustion .............................................. 76

Figure 5-15 Average Start of Combustion for Mode 3............................................... 77

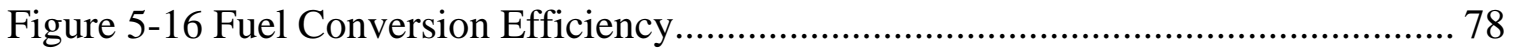

Figure 8-1 Time Versus Speed Set Points for AM General Engine Created Cycle ......... 92

Figure 8-2 Time Versus Speed Set Points for AM General Engine Created Cycle ......... 93

Figure 8-3 PM-CO Trend for Cummins Transient Testing ............................................ 98

Figure 8-4 PM-CO Trend for Mack Transient Testing.................................................. 99

Figure 8-5 PM-CO Trend for AM General Transient Testing...................................... 100

Figure 8-6 Average BSFC Steady-State Test Results for AM General......................... 101

Figure 8-7 Percent Change in BSFC from Baseline ................................................... 102

Figure 8-8 Average $\mathrm{BSCO}_{2}$ Steady-State Test Results for AM General....................... 103

Figure 8-9 Percent Change in $\mathrm{BSCO}_{2}$ from Baseline for AM General .......................... 103

Figure 8-10 Average BSNO $_{x}$ Steady-State Test Results for AM General...................... 104

Figure 8-11 Percent Change in $\mathrm{BSNO}_{\mathrm{x}}$ from Baseline for AM General ....................... 105 
Figure 8-12 Average BSCO Steady-State Test Results for AM General ...................... 106

Figure 8-13 Percent Change in BSCO from Baseline for AM General......................... 106

Figure 8-14 Average BSPM Steady-State Test Results for AM General ........................ 107

Figure 8-15 Percent Change in BSPM from Baseline for AM General ......................... 108

Figure 8-16 Average BSHC Steady-State Test Results for AM General ...................... 109

Figure 8-17 Percent Change in BSHC from Baseline for AM General.......................... 109

Figure 8-18 BSFC for Modes 2 and 5 of DDC Steady State Testing ............................ 110

Figure 8-19 BSFC for Modes 3, 4, and 5 of DDC Steady State Testing ....................... 111

Figure 8-20 Percent Change in $\mathrm{BSCO}_{2}$ for DDC Steady State Testing......................... 111

Figure 8-21 $\mathrm{BSCO}_{2}$ for Modes 2 and 5 of DDC Steady State Testing .......................... 113

Figure 8-22 $\mathrm{BSCO}_{2}$ for Modes 3, 4, and 5 of DDC Steady State Testing ..................... 113

Figure 8-23 Percent Change in BSNOx for DDC Steady State Testing........................ 114

Figure 8-24 BSNOx for Modes 2 and 5 of DDC Steady State Testing .......................... 115

Figure 8-25 BSNOx for Modes 3, 4, and 5 of DDC Steady State Testing ..................... 116

Figure 8-26 Percent Change in BSCO of DDC For Steady State Testing...................... 116

Figure 8-27 BSCO for Modes 2 and 5 of DDC Steady State Testing ........................... 118

Figure 8-28 BSCO for Modes 3, 4, and 5 of DDC Steady State Testing ...................... 118

Figure 8-29 Percent Change in BSPM of DDC for Steady State Testing ..................... 119

Figure 8-30 BSPM for Modes 2 and 5 of DDC Steady State Testing ........................... 120

Figure 8-31 BSPM for Modes 3, 4, and 5 of DDC Steady State Testing ....................... 121

Figure 8-32 Percent Change in BSHC of DDC for Steady State Testing...................... 121

Figure 8-33 BSHC for Modes 2 and 5 of DDC Steady State Testing ........................... 123

Figure 8-34 BSHC for Modes 3, 4, and 5 of DDC Steady State Testing ...................... 123

Figure 8-35 Location of Maximum Pressure ........................................................... 124

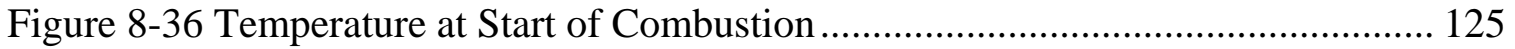

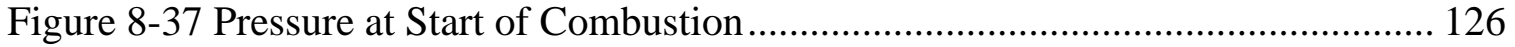

Figure 8-38 Location of 90\% Mass Fraction Burned .................................................. 127

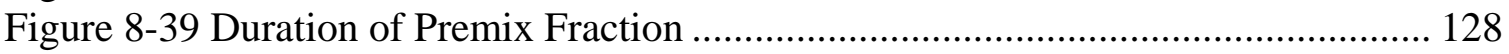

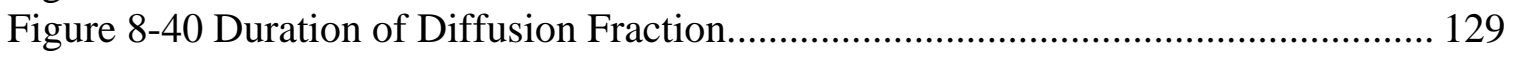




\section{Introduction and Objectives}

\subsection{Introduction}

There has been concern throughout the United States regarding the energy security of our country. The country's dependency on foreign oil imports could be reduced by increasing fleet fuel economy of on-road vehicles. One indication of this desire was the implementation of corporate average fuel economy (CAFE) standards in the 1970s. Currently, standards are set to increase ratably each year and, at a minimum, be set sufficiently high to ensure that average fuel economy of the combined industrywide fleet of all new passenger cars and light trucks sold in the United States during MY 2020 is at least $35.0 \mathrm{mpg}$ [3]. This is a noticeable change from today's current standards of $27.5 \mathrm{mpg}$ [4]. There are presently no fuel economy standards for on-road heavy-duty engines, but this does not mean these standards will not arise in the future.

Several factors affect the fuel economy of a vehicle, including driver habits, fuel quality, and engine design and technology. Heavy-duty engine manufactures are required to meet the strict emissions standards set by the EPA, which often requires strategies or technologies that inhibit high fuel economy. For example, to reduce $\mathrm{NO}_{\mathrm{x}}$, manufacturers often use delayed injection timing, which reduces combustion efficiency and, hence, increases fuel consumption or decreases fuel economy. Exhaust gas recirculation (EGR) has become a prevalent technology to meet $\mathrm{NO}_{\mathrm{x}}$ requirements for the 2004 (actually, October 2002) and newer on-road engine technologies, but can also result in losses associated with throttling or driving a larger fan. A possible method for increasing fuel economy is using fuel additives to increase the quality, or enhance certain properties, of the fuel.

Conversely, engines and vehicles used by the United States military can be excused from Federal, or individual state, emissions or fuel economy requirements by a national security exemption, per 40 CFR 85-1708 [5], and from the Clean Air Act [6]. By not having to meet fuel and emissions standards, the military is able to specify design 
requirements for engines and vehicles to meet battlefield requirements (i.e. performance) to maintain national security. Although there is increased emissions produced from these engines compared to an equivalent on-road engine, fuel economy from these military engines have come to the forefront of concern due to the cost of delivering fuel to these engines in the battlefield. In 2007 for the U.S. military, nearly 80 percent of all material transported on the battlefield was fuel [7]. Also, in a report addressed by the Center for Naval Analyses, a study found that in Iraq, during 2003, a Marine task force used $90 \%$ of its fuel to protect and deliver the other $10 \%$ to vehicles used for "lethal force" [8]. Because of the recent wars going on in Iraq and Afghanistan, and the resulting cost of delivering fuel to the battlefield, there is great interest in developing technologies to increase the present fleets' fuel economy. Although engine and combustion chamber design will most likely be the greatest gain in fuel economy improvements, these changes will take time to penetrate the military engine inventory. In the short term, to maximize potential benefits for the existing fleet, fuel additives may be one solution to improving the military engines’ fuel economy.

To try to aid in the military's needs to improve fuel economy, this research effort explored the effect of potential diesel engine additives that could improve fuel economy. Specifically, five fuel-borne-catalysts were examined to study their effect on the fuel efficiency of on-road vehicle engines and a tactical vehicle engine with the ultimate goal leading to the determination of the additive(s) with the greatest potential to improve fuel economy. Four different engines (one military, three commercial on-road) were exercised over prescribed cycles on an engine dynamometer test stand to evaluate the performance of the additives relative to the neat diesel fuel. Three different baseline diesel fuels were also examined. It is noted that not all of the fuels and additives were tested on each engine.

\subsection{Objectives}

The primary objective of this study was to evaluate the effect of different additives on the fuel consumption and emissions emitted from electronically controlled 
heavy-duty engines and from a mechanically controlled medium-duty engine. A secondary objective was to examine the in-cylinder pressure data for one of those engines to discern changes in combustion phenomena. Parameters such as maximimum incylinder pressure, injection timing, and premix and diffusion durations were to be analyzed. 


\section{Literature Review}

\subsection{Background}

Military engines are designed for rugged use and for multi-fueled applications. Experimental military vehicles with CI engines having compression ratios as high as 50:1 have been tested with the idea that at such high compression ratios, nearly any liquid is combustible. This could be advantageous in that when supplies are interrupted many different fuel types could be used [9]. For the military, it is desirable to have all engines and vehicles running on the same fuel for logistical reasons. Jet propulsion fuel type 8 (JP-8) is used in many military engines and vehicles and typically consists of at least 99\% kerosene by weight. Requirements for fuel properties such as aromatics, sulfur content, and viscosity are laid out by the military [10].

\subsubsection{Diesel Fuels}

Conventional diesel oil is a fuel derived from petroleum and consists mainly of aliphatic hydrocarbons containing 8-28 carbon atoms with boiling points in the range of $130-370^{\circ} \mathrm{C}$. It is a blend of hydrocarbon fractions, heavier than those found in gasoline, with a lower hydrogen/carbon mass ratio than that of gasoline [11]. The three main categories of hydrocarbons found in petroleum are: paraffins, cycloparaffins (or naphthenes), and aromatics. Paraffinic hydrocarbons are saturated hydrocarbons with straight or branched chains, but without any ring structure. Naphthenic hydrocarbons are also saturated with one or more rings, each of which may have one or more paraffin sidechains. Aromatic hydrocarbons contain one or more ring systems that may be linked up with naphthalene rings or paraffin side-chains [12]. Table 2-1 shows example structures of the three different types of hydrocarbons. Note that although methane is shown in this table, it is not a structure found in conventional petroleum-derived diesel fuel, and is only included to represent the simplest molecule in the paraffin hydrocarbon category. 


\section{Table 2-1 Examples of Hydrocarbons Found in Petroleum [9,13]}

\section{Hydrocarbon}

Example Chemical Structures

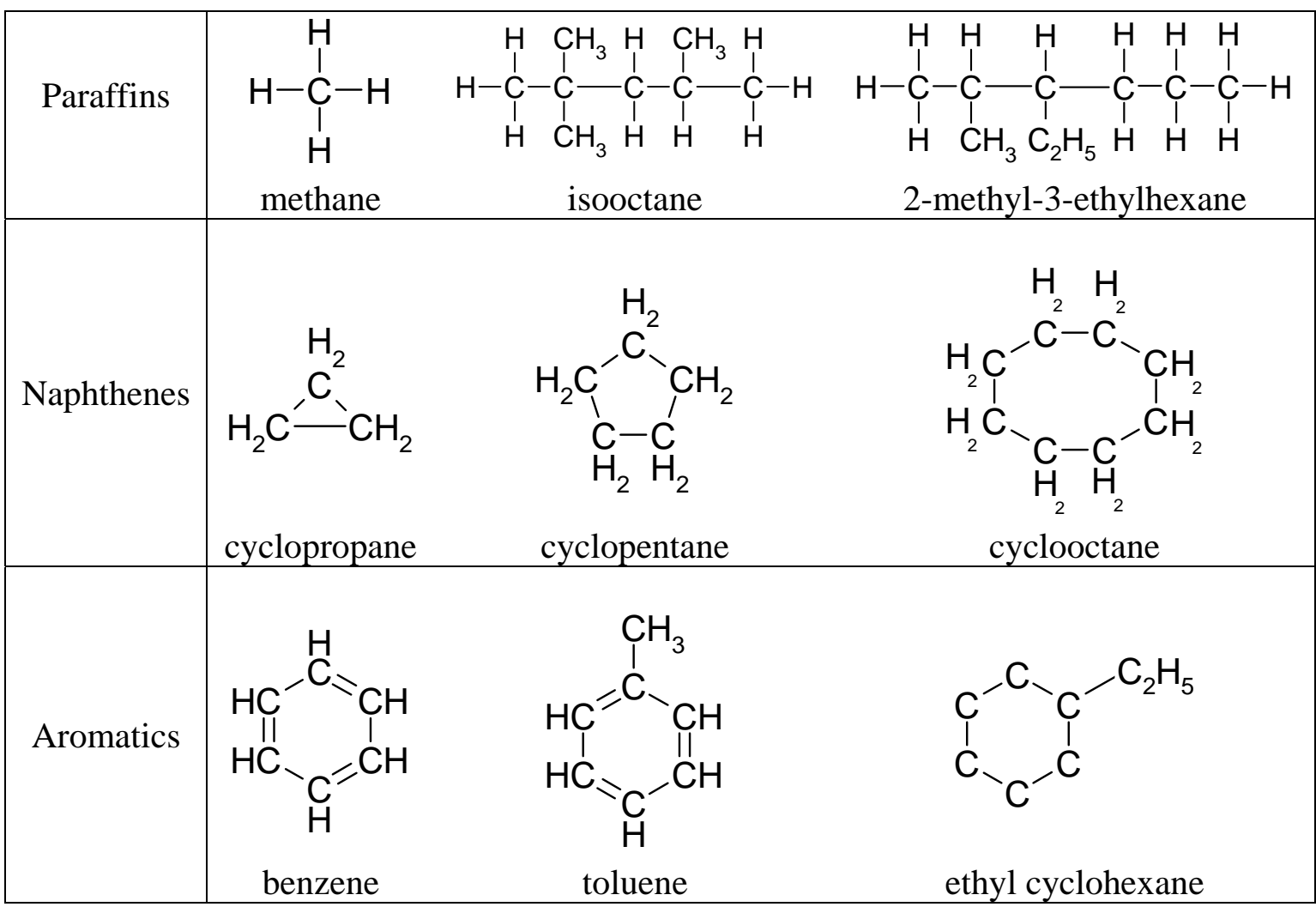

Atoms in paraffinic hydrocarbons are connected by single bonds. They have the general chemical formula of $\mathrm{C}_{n} \mathrm{H}_{2 n+2}$, where $n$ is any integer. Paraffins have good stability to oxidation or chemical change and are clean burning. They have a high hydrogen content, thus a high calorific value. The spontaneous ignition points are fairly low, compared to the other two types of hydrocarbons, which is a desired property for a fuel intended for diesel engines [14].

The atoms within naphthenes are also connected by single bonds. The two types of hydrocarbons differ because naphthenes may contain one or more cyclic structures. They have the general chemical formula of $\mathrm{C}_{n} \mathrm{H}_{2 n}$. Cyclopropane is the simplest napthenic molecule. In most cases, naphthenes are the most stable of the three 
hydrocarbon classes. Compared to paraffins, they have higher melting and boiling points, and also higher densities [13]. Because they have a slightly lower hydrogen to carbon ratio than paraffins, they often have lower calorific values.

Aromatics contain at least one ring structure similar to its simplest molecule, benzene. The atoms are connected by single and double bonds. The general chemical formula is $\mathrm{C}_{2} \mathrm{H}_{2 \mathrm{n}-6}$. Aromatics have the highest density, melting point, and boiling point of the three hydrocarbon types. Because they contain a low hydrogen to carbon ratio, they have the lowest calorific value of the three hydrocarbons, and a tendency to cause smoke. This characteristic makes them somewhat undesirable for diesel fuel [14]. Table 2-2 shows melting points, boiling points, and densities of common molecules within the paraffinic, naphthenic, and aromatic hydrocarbons.

Table 2-2 Properties of Common Hydrocarbons Found in Petroleum [15,16]

\begin{tabular}{|c|c|c|c|c|}
\hline Component & Formula & $\begin{array}{c}\text { Melting } \\
\text { Point }\left({ }^{\circ} \mathbf{C}\right)\end{array}$ & $\begin{array}{c}\text { Boiling } \\
\text { Point }\left(^{\circ} \mathbf{C}\right) \\
\text { at 1 atm }\end{array}$ & $\begin{array}{c}\text { Density at 1 } \\
\text { atm and 15 } \\
\left(\mathbf{g} / \mathbf{c m ~ m}^{\circ} \mathbf{C}\right.\end{array}$ \\
\hline Paraffins & & & & \\
\hline Methane & $\mathrm{CH}_{4}$ & -184 & -161.5 & - \\
\hline n-Butane & $\mathrm{C}_{4} \mathrm{H}_{10}$ & -135 & -0.6 & - \\
\hline Iso-Butane & $\mathrm{C}_{4} \mathrm{H}_{10}$ & -145 & -10.2 & - \\
\hline n-Pentane & $\mathrm{C}_{5} \mathrm{H}_{12}$ & -131.5 & 36.2 & 0.626 \\
\hline n-Hexane & $\mathrm{C}_{6} \mathrm{H}_{14}$ & -94.3 & 69.0 & 0.659 \\
\hline Iso-octane & $\mathrm{C}_{8} \mathrm{H}_{18}$ & -107.4 & 99.3 & 0.692 \\
\hline n-Decane & $\mathrm{C}_{10} \mathrm{H}_{22}$ & -30 & 174.0 & 0.730 \\
\hline Tetradecane & $\mathrm{C}_{14} \mathrm{H}_{30}$ & 5.9 & 253.5 & - \\
\hline Octadecane & $\mathrm{C}_{18} \mathrm{H}_{38}$ & 28.2 & 316.1 & - \\
\hline Naphthenes & & & & \\
\hline Cyclopentane & $\mathrm{C}_{5} \mathrm{H}_{10}$ & -93.3 & 49.5 & 0.745 \\
\hline Methyl cyclopentane & $\mathrm{C}_{6} \mathrm{H}_{12}$ & -142.4 & 71.8 & 0.754 \\
\hline Cyclohexane & $\mathrm{C}_{6} \mathrm{H}_{12}$ & 6.5 & 81.4 & 0.779 \\
\hline Aromatics & & & & \\
\hline Benzene & $\mathrm{C}_{6} \mathrm{H}_{6}$ & 5.51 & 80.1 & 0.885 \\
\hline Toluene & $\mathrm{C}_{7} \mathrm{H}_{8}$ & -95 & 110.6 & 0.867 \\
\hline o-Xylene & $\mathrm{C}_{8} \mathrm{H}_{10}$ & -29 & 144.4 & 0.880 \\
\hline Naphthalene & $\mathrm{C}_{10} \mathrm{H}_{8}$ & 80.2 & 217.9 & 0.971 \\
\hline
\end{tabular}




\subsection{Diesel Fuel Properties}

\subsubsection{Density and Specific Gravity}

Density is the mass to volume ratio of a material. It is important with respect to volumetric fuel economy and maximum power. Higher density fuels have increased volumetric energy content and produce more power than lower density fuels [17]. Research has shown that lower density fuels produce lower $\mathrm{NO}_{\mathrm{x}}$ and $\mathrm{PM}$ emissions [18].

Density is often specified through a specific gravity value. The specific gravity is the ratio of the density of the material to the density of water at a specific temperature. This ratio is useful because it is unitless, and can give an immediate indication of the relative density differences between fuels. One method of measurement is by placing a standard hydrometer in a cylinder filled with a liquid and allowing the hydrometer to stabilize. The hydrometer is designed such that the stem of the hydrometer is immersed in the liquid and calibrated with division marks that correspond to different specific gravities [14]. The standard procedure used for fuels is listed in ASTM D287 [19]. Specific gravity suffers from the disadvantage that only a very narrow range of values applies to a wide range of petroleum feedstocks. Thus, the American Petroleum Institute (API) devised a wider scale named the API gravity that is calculated through the equation [20]:

$$
{ }^{\circ} A P I=\left(\frac{141.5}{S G} \frac{60^{\circ}}{60^{\circ} \mathrm{F}}\right)-131.5 .
$$

\subsubsection{Cetane Number}

Diesel engine ignition quality is attributed to the ignition delay of the fuel and is expressed as the cetane number. A larger cetane number indicates a shorter ignition delay which yields improved ignition quality. ASTM D613 is used to measure the cetane number of a fuel [19]. The method involves comparing the test fuel to two standard reference fuels. The unbranched fuel component n-cetane (hexadecane), $\mathrm{C}_{16} \mathrm{H}_{34}$, is given a cetane number value of 100 , while the highly branched alkane heptamethylnonane 
(HMN), $\mathrm{C}_{12} \mathrm{H}_{34}$, is given a value of 15 . The cetane number is then found by comparing the ignition delay of the test fuel to the ignition delay of a mixture of the two reference fuels with the equation [9]:

$$
C N=\% C_{16} H_{34}+0.15\left(\% C_{12} H_{34}\right) .
$$

The testing takes place with the Cooperative Fuels Research (CFR) engine that can actively change the compression ratio during testing.

A high concentration of paraffins tends to increase the cetane number. Conversely, aromatics and branched chain paraffins weaken the ignition quality and lower the cetane number [17]. Shorter ignition delay times have been directly correlated with faster startup in cold weather, and smoother engine operation [21]. Many studies have found that $\mathrm{NO}_{\mathrm{x}}$ emissions decrease significantly with increasing cetane number. This reduction is attributed to the shorter ignition delay [22].

\subsubsection{Volatility}

Volatility is the readiness of a liquid to vaporize as expressed by distillation. Using distillation to determine volatility is the general procedure of vaporizing a liquid through heating at atmospheric pressure or a reduced pressure and recording data for any/all of the following items: initial boiling point, distillation temperature, end point, dry point, percent distillate, percent residue, percent total recovery, sum of the liquids and residue, percent distillation loss, and percent evaporated at a specific thermometer reading or other distillation temperatures [20]. ASTM D86 is the accepted method for measuring distillation points in diesel fuel [19].

Volatility is often spoken of as front-end or back-end distillation temperatures. Front-end volatility refers to the lower temperatures at which the fuel begins to vaporize such as the $10 \%, 15 \%$, or $20 \%$ distillation temperatures. Back-end volatility refers to the higher temperatures where the fuel is near complete vaporization such as the $85 \%, 90 \%$, or $95 \%$ distillation temperatures. Several studies have shown that the back end volatility had no significant effect on emissions [23, 24]. It was apparent that engine design 
differences were much more important than volatility differences with regards to emissions. It is often difficult to determine the direct effect of volatility on emissions because it affects many other fuel properties including viscosity, flash point, cetane number, and density.

\subsubsection{Sulfur Content}

Sulfur content was the first fuel property to be controlled as a means of limiting harmful diesel exhaust emissions [25]. These emissions include sulfur dioxide and PM. Along with these harmful emissions, exposure to certain amounts of sulfur is known to poison aftertreatment devices. These factors led to the requirement in 2006 that on-road diesel fuel have a sulfur content no greater than $15 \mathrm{ppm}$. This type of fuel is labeled ultra low sulfur diesel (ULSD). One study found that decreasing sulfur content from roughly 2000 ppm to 500 ppm showed significant reductions in engine-out PM emissions [26]. Another study showed that lowering sulfur content from roughly $500 \mathrm{ppm}$ to 30 ppm showed nearly no change in engine-out PM emissions for a 2001 Navistar 7.6L engine [27]. However, when the engine was equipped with an oxidation catalyst, significant reductions in PM emissions were found when the sulfur content was reduced. These studies suggest that the reduction from high sulfur diesel to low sulfur diesel can directly reduce PM emissions. The change from low sulfur diesel to ULSD is related to PM emission reduction mainly through enabling the operation of aftertreatment devices. For instance, large amounts of sulfur can poison catalysts drastically reducing their effectiveness.

Hydrodesulfurization is the most commonly used process for removing sulfur from heavy oils. This is a catalytic process where a crude oil fraction is passed with hydrogen over a catalyst bed at elevated temperatures and pressure [28]. The problem with such low concentrations of sulfur in diesel fuel is the lack of lubrication. The low

levels of sulfur can cause damage to fuel injection equipment as well as increase engine wear [25]. Fuel suppliers rely more and more on lubricity additives to replace the natural lubricity lost by the process of removing sulfur [17]. 


\subsubsection{Aromatics}

Aromatic compounds are those containing one or more benzene rings or similar ring structures. Common aromatic fractions are benzene, toluene, xylene, and ethylbenzene [12]. Increasing the aromatic content is known to lower the cetane number of a given fuel [13], thus bringing the emission impacts of a lower cetane number. It is difficult to distinguish the effects of individual fuel properties on emissions, because altering one property often leads to the change of another property. This inability to separate individual fuel properties often leads to mixed emissions results in the literature when researchers attempt to de-couple fuel properties. Several studies show that decreasing aromatic content reduces either $\mathrm{NO}_{\mathrm{x}}, \mathrm{PM}$, or both [29, 30, 31]. Early regulations used test method ASTM D1319, which utilizes fluorescent indicator adsorption. With this method, a liquid petroleum sample is placed in a glass column that has been packed with activated silica gel and also fluorescent dyed gel. Alcohol is then added to desorb the sample and separate the hydrocarbons. The different layers of hydrocarbons are visible under ultraviolet light, and the volume percentage of each different layer is representative of the content in the sample [32]. More recent regulations use test method ASTM D5186 to determine aromatic content. This method uses supercritical fluid chromatography. A sample is passed through a column of supercritical fluid where the two form a mixture with separate layers. These layers are identified with any number of detectors to determine the samples content.

\subsubsection{Viscosity}

Viscosity is the measure of resistance of flow of a fluid. A change in engine performance, due to changing viscosity, is seen primarily in the fuel injection equipment. Since the injection process takes place over a relatively short period of time, small changes in viscosity require changes in the injection timing and duration. For a given pressure and injector nozzle configuration, the viscosity will influence the quantity of fuel injected [25]. The increased viscosity of biodiesel compared to on-road diesel can create problems with injection timing if the issue is not dealt with. As an explanation of $\mathrm{NO}_{\mathrm{x}}$ increase with biodiesel, most researchers suggest that the combustion process is advanced due to an advanced injection derived from physical properties such as viscosity 
[33]. The accepted method for measuring viscosity is ASTM D445 [19], which consists of measuring the time it takes for a fixed volume of fluid to flow, under gravity, through a capillary tube viscometer in a thermally controlled bath [25].

\subsubsection{Flash Point}

The fuel temperature at which vapor concentration is sufficient to support combustion upon the application of some form of ignition is denoted the flash point of the fuel. This point provides an indication of fire risk in storage under ambient conditions [13]. The flash point is not believed to have a direct impact on emissions, but is important for safety procedures [17]. ASTM D445 is the method used in testing the flash point of diesel fuel.

\subsection{Additives}

Diesel fuel additives can be any chemical added to base petroleum diesel fuel that enhances the properties of that fuel for combustion performance and or emissions reduction. The benefits of additives seem to fall naturally into four main areas: energy conservation, air quality improvement, cost saving during manufacture, and added value and quality to the user [34]. As legislation pushes for lower emissions from diesel engines, additives will be increasingly relied upon to meet the new standards [21]. The following sections review several common additives used in the diesel fuel arena.

\subsubsection{Cetane Number Improvers}

The cetane number of diesel fuel can be increased in two different ways: naturally or through additives [35]. Natural methods are through the refining process by using different cuts of the distillation process or through other refining processes. Cetane improving additives can be used to avoid difficulties in cold starting and other performance problems associated with low cetane numbers [11]. They may also be used solely to meet the EPA's minimum limit of 40 for the cetane number of a fuel [19]. 
Several types of chemicals have proven to be effective cetane improvers; these include alkyl nitrates, ether nitrates, nitroso compounds and certain peroxides [25]. The most widely used cetane improver in the industry is 2-ethylhexyl nitrate (EHN). Much research has been completed analyzing the effects of EHN on the cetane number of a fuel and on combustion and emissions. Another additive often used, mainly due to the absence of nitrogen, is di-tert-butyl peroxide (DTBP). This peroxide is commonly used in diesel fuels in California due to the lower required nitrogen levels set forth by the California Air Resources Board (CARB) [21]. Several studies have concluded that $\mathrm{NO}_{\mathrm{x}}$ emissions from nitrate-based cetane improvers are higher than those from peroxide based cetane improvers [36, 37]. Other studies have shown that $\mathrm{NO}_{\mathrm{x}}$ emissions are independent of the type of cetane improver $[38,39]$. As with most fuel properties, the effects may differ for different engines.

\subsubsection{Lubricity Improvers}

As sulfur and aromatic content in diesel fuels has decreased, lubrication has become a problem. The role of lubricity additives are to serve as lubricants for the fuel injection system to slow wear on injectors and pumps. The additives work because the molecules are attracted to metal surfaces and form a thin film thus increasing the boundary lubricity [21]. Currently, proprietary ashless longchain polar compounds are used for lubricity enhancement [34]. Also, fatty acid methyl esters found in biodiesel have successfully been used as lubricity improvers. Problems such as fuel injector fouling, water separation and filter plugging may come about if excess amounts of lubricity additives are used [40].

\subsubsection{Detergents}

Excessive coke deposits from diesel fuel can disrupt the fuel pattern from an injector thus degrading atomization resulting in higher emissions, noisier engines, and a reduction in fuel economy [34]. Detergents are used either to prevent this buildup of deposit, or clean an existing problem. Typical substances used as detergents are amines, imidazolines, amides, succinimides, polyalkyl succinimides, and polyetheramines [41]. 
Detergent additive rates around 100 to $200 \mathrm{ppm}$ are used to maintain clean injectors while greater concentrations are used to clean up fouled injectors [25].

\subsubsection{Cold Flow Improvers}

The flow characteristics of a fuel become important in a low temperature environment. As a diesel fuel temperature decreases, there is a temperature at which crystals form and interlock causing flow restriction through filters. Commonly used additives in industry are copolymers such as polyacrylates, polymethacrylates, and ethylene vinyl acetate (EVA) [11]. They work by modifying the size and shape of the wax crystals by blocking off growth faces and forcing new crystal nuclei to form [34]. Additives that fall under the cold flow improver category are sometimes called cold-filter plugging point additives, pour point depressants, middle distillate flow improvers, and wax anti-settling additives to name several. Although not discussed in Section 2.2, pour point is a measured and reported parameter for diesel fuels and is determined with test method ASTM D97.

\subsubsection{Oxygenates}

Oxygenates are used to increase the oxygen content within a fuel. Common oxygenates are alcohols, esters, and ethers. Increasing the oxygen content in the fuel can have varying effects on emissions depending on the base fuel. Oxygenated additives are thought to reduce the ignition temperature of particulates thus reducing the PM emissions [11]. Studies have shown conflicting results for $\mathrm{NO}_{\mathrm{x}}$ emissions. Several studies show that with increasing oxygen content comes a decrease in $\mathrm{NO}_{\mathrm{x}}$ [42, 43], while others show an increase in $\mathrm{NO}_{\mathrm{x}}$ [30,31], and others show no significant change [44, 45, 46]. It appears as if the $\mathrm{NO}_{\mathrm{x}}$ response is highly dependent on the base fuel, specific oxygenate used, and engine type. Biodiesel and ethanol are popular oxygenates that are discussed in the following sections. 


\subsubsection{Biodiesel}

Biodiesel is a fuel comprised of mono-alkyl esters of long chain fatty acids derived from vegetable oils or animal fats. It has become a popular source of alternative fuel because it is considered a renewable energy source with similar characteristics of petroleum diesel fuel. Not only is it a renewable energy source, but it can reduce dependence on imported oil and support agricultural subsidies in certain regions [11].

Biodiesel can be used as a neat fuel or as a blending additive. Nomenclature often denotes it as BXX where the $\mathrm{B}$ stands for biodiesel and the $\mathrm{XX}$ represents the percentage of biodiesel in the blend. Therefore, neat biodiesel is denoted B100 while a 30\% blend of biodiesel with 70\% petroleum diesel is designated B30.

The similarities of biodiesel to petroleum-based diesel are what make it an attractive fuel source. The following table shows the properties of five different biodiesels as well as a conventional diesel fuel used in a study. The fuels shown are: diesel fuel (D160), cottonseed methyl ester (CME), soybean methyl ester (SME), rapeseed methyl ester (RME), palm oil methyl ester (PME) and waste cooking oil methyl ester (WME).

Table 2-3 Properties of Different Common Biodiesels [47]

\begin{tabular}{|c|c|c|c|c|c|c|c|c|c|c|}
\hline $\begin{array}{l}\text { Fuel } \\
\text { Type }\end{array}$ & $\begin{array}{c}\text { Cetane } \\
\text { Number }\end{array}$ & $\begin{array}{c}\text { Sulfur } \\
\text { Content } \\
(\mathrm{ppm})\end{array}$ & $\begin{array}{l}\text { Density } \\
\text { (kg/m3) }\end{array}$ & $\begin{array}{l}\text { T90 } \\
\left({ }^{\circ} \mathrm{C}\right)\end{array}$ & $\begin{array}{c}\text { Boili } \\
\text { ng } \\
\text { Poin } \\
t \\
\text { ( } \mathrm{C})\end{array}$ & $\begin{array}{c}\text { Lower } \\
\text { Heating } \\
\text { Value } \\
(\mathbf{k J} / \mathrm{kg})\end{array}$ & $\begin{array}{c}\text { Viscosity } \\
\left(\mathrm{mm}^{2} / \mathrm{s}\right)\end{array}$ & $\begin{array}{l}\text { Oxygen } \\
\text { Content } \\
\text { (Wt. \%) }\end{array}$ & $\begin{array}{l}\text { Carbon } \\
\text { Content } \\
\text { (Wt. \%) }\end{array}$ & $\begin{array}{l}\text { Hydro- } \\
\text { gen } \\
\text { Content } \\
\text { (vol \%) }\end{array}$ \\
\hline D160 & 55 & 160 & 830 & 318.5 & 341 & 43140 & 3.763 & 0.00 & 86.4 & 13.6 \\
\hline CME & 54 & 5 & 880 & 343.0 & -- & 39787 & 6.381 & 10.6 & -- & -- \\
\hline SME & 51 & 1 & 873 & 343.5 & -- & 39950 & 6.624 & -- & -- & -- \\
\hline RME & 53 & 6 & 873 & 341.5 & -- & 39837 & 6.380 & 10.5 & -- & -- \\
\hline PME & 64 & 1 & 878 & 334.9 & -- & 40063 & 7.114 & 11.2 & 76.6 & 12.4 \\
\hline WME & 56 & 7 & 870 & 342.5 & -- & 40055 & 6.897 & 11.3 & 76.3 & 12.2 \\
\hline
\end{tabular}

As can be seen in Table 2-3, biodiesel enjoys a relatively high cetane number and near zero sulfur content concentration. Some disadvantages include a lower heating value and larger viscosity than conventional diesel. The lower heating value typically 
results in an increase in fuel consumption. The specific fuel consumption when using a neat biodiesel fuel is expected to increase by around 14\% in relation to the consumption with diesel fuel [33].

Nearly all of the literature reviewed shows the addition of biodiesel causing a reduction in $\mathrm{PM}$ and an increase in $\mathrm{NO}_{\mathrm{x}}$ emissions [47, 48, 49, 50, 51, 52]. The increased oxygen content of biodiesel may explain the decrease in PM emissions. The $\mathrm{NO}_{\mathrm{x}}$ increase however, can most likely be attributed to injection related issues. Most researchers say the combustion process is advanced due to the advanced injection derived from the physical properties of biodiesel (viscosity, density, compressibility, sound velocity) [33]. The higher sound velocity of biodiesel causes the pressure wave from the fuel pump to the fuel injector to travel faster, resulting in advanced fuel injection.

\subsubsection{Ethanol}

Ethanol has been an attractive blending agent with gasoline for many years, while more recently research has been performed on ethanol-diesel blends. Adding ethanol to diesel (often called e-diesel) has shown to result in significant reductions in PM emissions, as is the case with most oxygenates, while $\mathrm{NO}_{\mathrm{x}}$ emissions are not as conclusive [54]. There are several challenges confronted with diesel-ethanol blends including: flash point, lubricity, durability, cost, distribution system, cetane quality, and stability [55]. Several of these issues are addressed through the use of other additives.

The blending cetane number of ethanol is 8 [56] which means e-diesels often require a cetane improving additive to meet the minimum cetane number of 40 . Another inherent problem with e-diesel is stability. Over time, a mixture of diesel and ethanol will separate into two distinct layers with the lighter ethanol settling on top of the diesel. This is unacceptable for an engine as it would cause high variability in performance. In response, an emulsifier or co-solvent is used to deter this separation. An emulsifier acts to suspend ethanol droplets within the diesel and the co-solvent acts as a linking agent through molecular bonding [54]. Table 2-4 shows several emulsifier producers as well as appropriate blending levels. 
Table 2-4 Emulsifier Manufacturers and Blending Levels [56]

\begin{tabular}{|l|c|c|}
\hline \multicolumn{1}{|c|}{ Emulsifier Producer } & $\begin{array}{c}\text { Prefemed Ethanol } \\
\text { Level \% volume }\end{array}$ & $\begin{array}{c}\text { Emulsifier } \\
\text { Level } \\
\text { volume }\end{array}$ \\
\hline $\begin{array}{l}\text { AAE Technologies, Inc/Octel } \\
\text { Sta reon, } \amalg C\end{array}$ & 7.7 or 10 & 0.5 \\
\hline Akzo-Nobel & 10 or 15 & 1 to 4 \\
\hline Betz-Dearbom, Inc. & 5,10 or 15 & $\begin{array}{c}0.25,0.35-0.75, \\
\text { or } 1\end{array}$ \\
\hline Pure Energy Comporation & 5 to 15 & 1 to 5 \\
\hline Biodiesel & 10 & 10 \\
\hline
\end{tabular}

Often, these additives are included in packages that consist of properties to enhance cetane number, flash point, and other properties. A study completed by Southwest Research Institute on e-diesel with an additive produced by the Pure Energy Corporation, Puranol, found large reductions in emissions compared to neat diesel in a 12.7 L Series 60 Detroit Diesel engine, as shown in Table 2-5.

Table 2-5 Average Percent Change Between E-diesel and Neat No. 2 Diesel [57]

\begin{tabular}{|l|c|c|}
\hline & $15 \%$ Ehanol Blend & $10 \%$ Ehanol Blend \\
\hline $\mathrm{PM}$ & $-41 \%$ & $-27 \%$ \\
\hline $\mathrm{NO}_{\mathrm{x}}$ & $-5 \%$ & $-4 \%$ \\
\hline $\mathrm{O}$ & $-27 \%$ & $-20 \%$ \\
\hline $\mathrm{HC}$ & Neutral & Neutral \\
\hline
\end{tabular}

Table 2-5 shows that large reductions in $\mathrm{PM}, \mathrm{NO}_{\mathrm{x}}$, and $\mathrm{CO}$ were found while using different blends of the e-diesel. Though work and fuel economy were not reported, a rough calculation was carried out predicting a 7\% loss in performance and/or fuel economy while using the $15 \%$ ethanol blend. 


\subsection{Previous Studies}

\subsubsection{Effect of Fuel Properties on Emissions}

In a study conducted by the Coordinating Research Council (CRC), testing was performed on a 1994 Navistar DTA-466 engine equipped with a catalytic converter [31]. The engine was tuned at a $5 \mathrm{~g} / \mathrm{hp}-\mathrm{hr} \mathrm{NO}_{\mathrm{x}}$ calibration, compliant to 1994 regulations, and a $4 \mathrm{~g} / \mathrm{hp}-\mathrm{hr} \mathrm{NO}_{\mathrm{x}}$ calibration. Ten fuel sets were made varying in cetane number, aromatic, and oxygen content to determine the effects of these fuel properties on emissions using the EPA transient Federal Test Procedure.

Testing showed that an increase in cetane number significantly reduced HC, CO, and $\mathrm{NO}_{\mathrm{x}}$ emissions at both $\mathrm{NO}_{\mathrm{x}}$ calibrations. Increased cetane number only showed an effect on $\mathrm{PM}$ emissions at the $4 \mathrm{~g} / \mathrm{hp}-\mathrm{hr} \mathrm{NO}_{\mathrm{x}}$ calibration, a significant reduction, and no effect at the $5 \mathrm{~g} / \mathrm{hp}-\mathrm{hr}$ calibration point. Decreasing aromatics resulted in reduced HC and $\mathrm{NO}_{\mathrm{x}}$ at the $5 \mathrm{~g} / \mathrm{hp}-\mathrm{hr} \mathrm{NO}_{\mathrm{x}}$ calibration only, and no effect at the lower calibration point. PM, however, showed a reduction with decreasing aromatic content at both calibration points. An increase in oxygen content lowered PM, but increased HC at both $\mathrm{NO}_{\mathrm{x}}$ calibrations. $\mathrm{NO}_{\mathrm{x}}$ only showed an increase with greater oxygen content at the 5 g/hp-hr calibration point.

Within the project conducted by the CRC, similar testing was completed on a 1994 DDC Series 60 engine [30] using the same 4 and $5 \mathrm{~g} / \mathrm{hp}$-hr $\mathrm{NO}_{\mathrm{x}}$ limits. In this testing, HC levels were extremely low (on the level of background concentrations), thus no fuel parameter was correlated with a significant change in the HC emissions. On the Navistar engine, PM showed responses to changes in both aromatics and cetane number, this was not so for the DDC. PM did show a similar response to oxygen content for both engines. Another difference between the two engines was the $\mathrm{CO}$ emission response. For the Navistar engine, cetane number explained the change in $\mathrm{CO}$ emissions, while for the DDC, the oxygen content was the most significant fuel property in explaining CO emissions (an increase in oxygen content decreased $\mathrm{CO}$ emissions). $\mathrm{NO}_{\mathrm{x}}$ emissions responded similarly to each fuel property change for both engines. 
The previous two studies show that different engines respond differently to fuel property changes. Therefore, the notion that a change in certain fuel properties will result in a given change in emissions must be considered with caution.

\subsubsection{Effect of Additives on Emissions}

A study conducted by Ethyl Petroleum Additives Inc. sought to determine the effects of two common cetane number improvers, EHN and DTBP, on regulated exhaust emissions from a 1993 Detroit Diesel Series 60 engine [38]. Two low sulfur base fuels were tested on the EPA transient Federal Test Procedure. For comparing the additives on a specific fuel, the cetane numbers were made equivalent, rather than adding equal amounts on a volume or mass basis of each additive.

With increased concentrations of both additives, $\mathrm{NO}_{\mathrm{x}}, \mathrm{CO}$, and $\mathrm{PM}$ emissions were reduced with HC showing little to no response. The effects of both additives were nearly identical, with differences being attributed to experimental error. The similarity in $\mathrm{NO}_{\mathrm{x}}$ reduction led to the conclusion that the nitrogen content within EHN does not contribute to any $\mathrm{NO}_{\mathrm{x}}$ emission, but rather the cetane number drives these emission levels.

In a study by Pennsylvania State University, an oxygenated additive, CETANER $^{\mathrm{TM}}$, was tested on a 1998 Navistar T444E 7.3L engine to determine the emission reduction benefits [42]. CETANER ${ }^{\mathrm{TM}}$, developed by Air Products and Chemicals Inc., is a combination of glycol ethers with a cetane number around 125 . The oxygenate was added to an Emissions Certification Diesel - Low Sulfur (ECD-LS) base fuel to increase the fuel by 2 wt. \% oxygen. The blend was then tested over the AVL 8mode steady state test procedure.

Using weighting factors for emissions calculations, $\mathrm{NO}_{\mathrm{x}}$ and $\mathrm{HC}$ emissions were reduced by $5.4 \%$ and $5.5 \%$, respectively, over the complete test cycle. CO emissions, however, showed no clear trend with certain loads causing mixed results. Overall, the CO emissions increased by less than 1\%. PM emissions saw significant reductions due to the addition of the additive. 
A study conducted at the University of California, Berkeley found no correlation between the amount of CETANER ${ }^{\mathrm{TM}}$ added versus $\mathrm{NO}_{\mathrm{x}}$ formation [44]. In this study a Cummins B5.9 engine was tested with a CARB-certified number 2 diesel fuel as the baseline, and test fuels were blended with $10 \%$ to $40 \%$ CETANER $^{\mathrm{TM}}$ by volume. The results showed that total $\mathrm{NO}_{\mathrm{x}}$ varied from a $5 \%$ decrease to a $2 \%$ increase with no clear trend on CETANER ${ }^{\mathrm{TM}}$ blend. The results from the previous two studies suggest that the engine configuration must play a significant role in the response to the oxygenate on $\mathrm{NO}_{\mathrm{x}}$ emissions.

In 2003, the EPA composed a report analyzing the effects on $\mathrm{NO}_{\mathrm{x}}$ emissions due to cetane improvers [35]. The report was constructed from pre-existing data from various sources such as journal articles and conference papers. From the data, a model was created for predicting $\mathrm{NO}_{\mathrm{x}}$ reduction due to cetane number increase from additives. The model shows that as the natural cetane number of the base fuel increases, the impact from a cetane improver on $\mathrm{NO}_{\mathrm{x}}$ emissions diminishes. In other words, a base fuel with a natural cetane number of 40 would see greater benefits from a cetane improver compared to that of a base fuel with a natural cetane number of 45 .

\subsubsection{Effect of Engine Model Year on Emissions}

In a study conducted at West Virginia University, emissions due to fuel effects on two different model year heavy-duty engines were analyzed [58]. The two engines (a 1992 DDC S60 and 2004 Cummins ISM 370) were tested on the transient FTP, the steady state supplemental emissions test (SET) test cycle, and two different on-road cycles. All fuels tested were commercially available low sulfur diesel.

The older 1992 engine showed a greater response to changes in cetane number for all emissions. Density changes in the fuel affected $\mathrm{NO}_{\mathrm{x}}$ and $\mathrm{PM}$ emissions in the newer engine more so than the older engine. Neither engine showed a considerable response to changes in sulfur content, sulfur content ranged from $455.0 \mathrm{ppm}$ to $166.0 \mathrm{ppm}$ for the test fuels. The fuel property that showed the strongest difference between engines was total aromatic content. The newer 2004 engine had an overall stronger response to changes in aromatic content. This large impact may be attributed to the fact that it is difficult to 
decouple specific fuel properties. For example, a higher aromatic content may often mean a lower cetane number unless an additive is used.

Another study completed at West Virginia University examined the effect of cetane number improvers on early and recent production heavy-duty engine models [59]. Testing was performed through both the transient FTP and the steady state SET cycles. The older engine models consisted of a 1991 DDC S60, 1992 DDC S60, and a rebuilt 1992 DDC S60. The newer engines were a 1999 and 2004 Cummins ISM 370. The additives reduced $\mathrm{NO}_{\mathrm{x}}$ emissions more for the older technology engines, while a negative impact was seen on the newer technology engines. The additives were most effective at lower loads. An average reduction in $\mathrm{NO}_{\mathrm{x}}$ was seen for both new and old models below around 250 bhp, however once past this point, $\mathrm{NO}_{\mathrm{x}}$ production increased. This effect was seen more severely on the newer engines.

\subsubsection{Test Cycle Development}

A dynamometer test cycle was developed at Southwest Research Institute that combined activities for three off-road heavy duty diesel vehicles [60]. A crawler tractor, backhoe loader, and agricultural tractor were instrumented and monitored during their typical activities. The data analysis included defining speed and torque characteristics for each activity, then assembling small segments of data, microtrips, to represent the entire activity. Before a microtrip was considered valid, parameters based on speed, torque, and power were sorted into bins that covered the complete range of operation of the activity. The frequency that the vehicle operated in these ranges of bins for the microtrip was compared to the frequency at which the vehicle operated in those bins for the entire population of data. A chi-square statistic was computed to compare the two sets of data and determine if the microtrip was representative of the population of data for the specific activity. These microtrips were combined for each activity and vehicle to form a complete cycle.

At West Virginia University a dynamometer test cycle was created that was representative of real-world heavy-duty engine activity in the not-to-exceed (NTE) zone of operation [61]. A new test cycle was desired because the majority of engine activity in 
the NTE zone is not represented in the transient Federal Test Procedure cycle. The process for building a test cycle was similar to that of the previous study. A microtrip was selected by taking in-use vehicle data that was within the NTE zone as well as small durations in the non-NTE zone that represented activities such as gear shifting. This was completed for three vehicles on two different road categories at two different loads. Engine operation characteristics for these microtrips were compared to the population of data with a chi-square goodness-of-fit test. After validating that a microtrip was representative of the population, it was combined with other microtrips to make up the cycle.

Members of West Virginia University conducted work on developing a Heavy Heavy-Duty Diesel Engine (HHDDE) test schedule to be used on a dynamometer [62]. The test schedule was to be representative of the existing Heavy Heavy-Duty Diesel Truck chassis cycle. Torque and speed data was organized from existing ECU data from seven engines ran on the chassis cycle. Because each engine had different characteristics (power and torque rating) the data was transformed into \%speed and \%torque using CFR Title 40 Part 86-type procedures. This data was then separated into four operating modes, namely creep, transient, cruise, and high-speed cruise. To ensure that a created mode did not use data from only one engine, at least four different microtrips were required to compose a mode. A Matlab program was created to try all possible combinations of the microtrips to create a single mode. The software statistically analyzed (average \%speed, average \%speed squared, average \%torque, average \%torque squared) each mode of data and compared that to the statistics of the original population data. The top representative modes were analyzed further until a single mode was selected. Testing was conducted on the transient mode to determine engine behavior over a part of the cycle. It was discovered that not all Federal Test Procedure regression limits could be met with the created cycle and that several new regression parameters would be needed. 


\section{Experimental Setup}

\subsection{Introduction}

The majority of the research completed for this study was performed at West Virginia University's Center for Alternative Fuels, Engines, and Emissions (CAFEE). Four test engines were used to obtain a diverse range of engine technologies to attempt to capture the effect of the additives. Three different dynamometers were used mainly due to their availability at the time of testing. Two separate full-scale dilution tunnels were used, also because of their availability. The following sections further describe the testing setup.

\subsection{Engines}

\subsubsection{Cummins ISM 370 ESP}

A turbocharged, direct injection, inline six cylinder 1999 Cummins ISM 370 ESP engine was used for a portion of the research. This engine complies to 1998 EPA onroad emissions regulations and was used to represent a median between a newer and older on-road engine technology. Figure 3-1 shows a picture of the engine. More detailed characteristics of the engine can be found in Table 3-1 of Section 3.2.5 


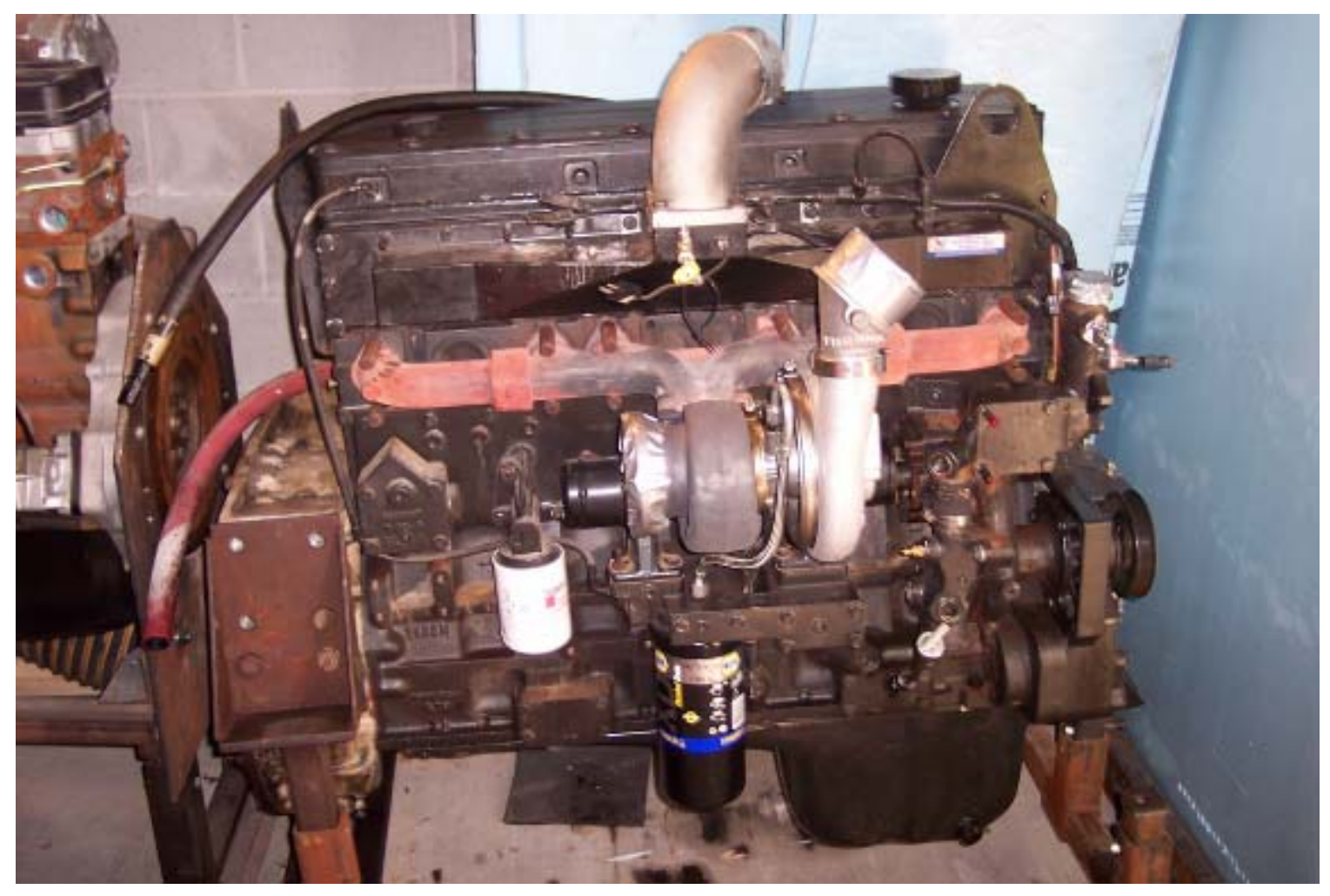

Figure 3-1 1999 Cummins ISM 370 ESP

\subsubsection{Mack MP7-355E}

A turbocharged, direct injection, inline six cylinder 2004 Mack MP7-355E was used for testing. This engine is typically used in heavy duty on-road, refuse trucks. It was selected to represent a newer technology engine as compared to the older electronically controlled engines. Figure 3-2 shows a picture of the engine and Table 3-1 of Section 3.2.5 gives more detailed characteristics. 


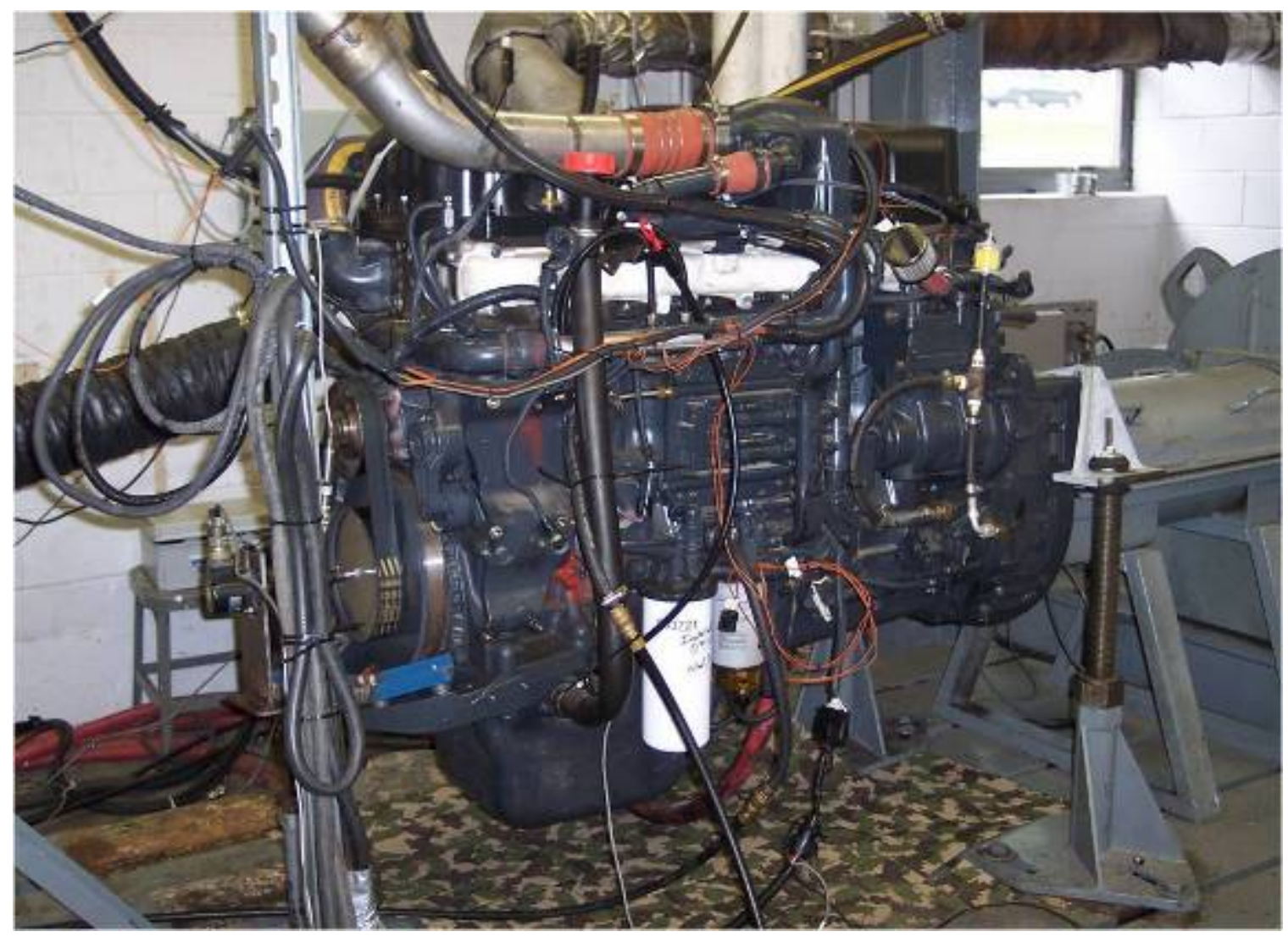

Figure 3-2 2004 Mack MP7 355E

\subsubsection{Rebuilt Detroit Diesel Series 60}

A turbocharged, direct injection, inline six cylinder 1992 DDC series 60 engine was used for part of the testing. The engine has been rebuilt and complies with 1991 EPA emissions standards and was used to represent an older on-road, electronicallycontrolled engine technology. This engine was used for the in-cylinder pressure research. In Figure 3-3 a picture of the engine can be seen along with the encoder connected at the front pulley. The encoder provided the DAQ system with the crank angle of the driveshaft. Table 3-1 of Section 3.2.5 gives further characteristics of the engine and Section 3.9 gives further description of the in-cylinder pressure measurement setup. 


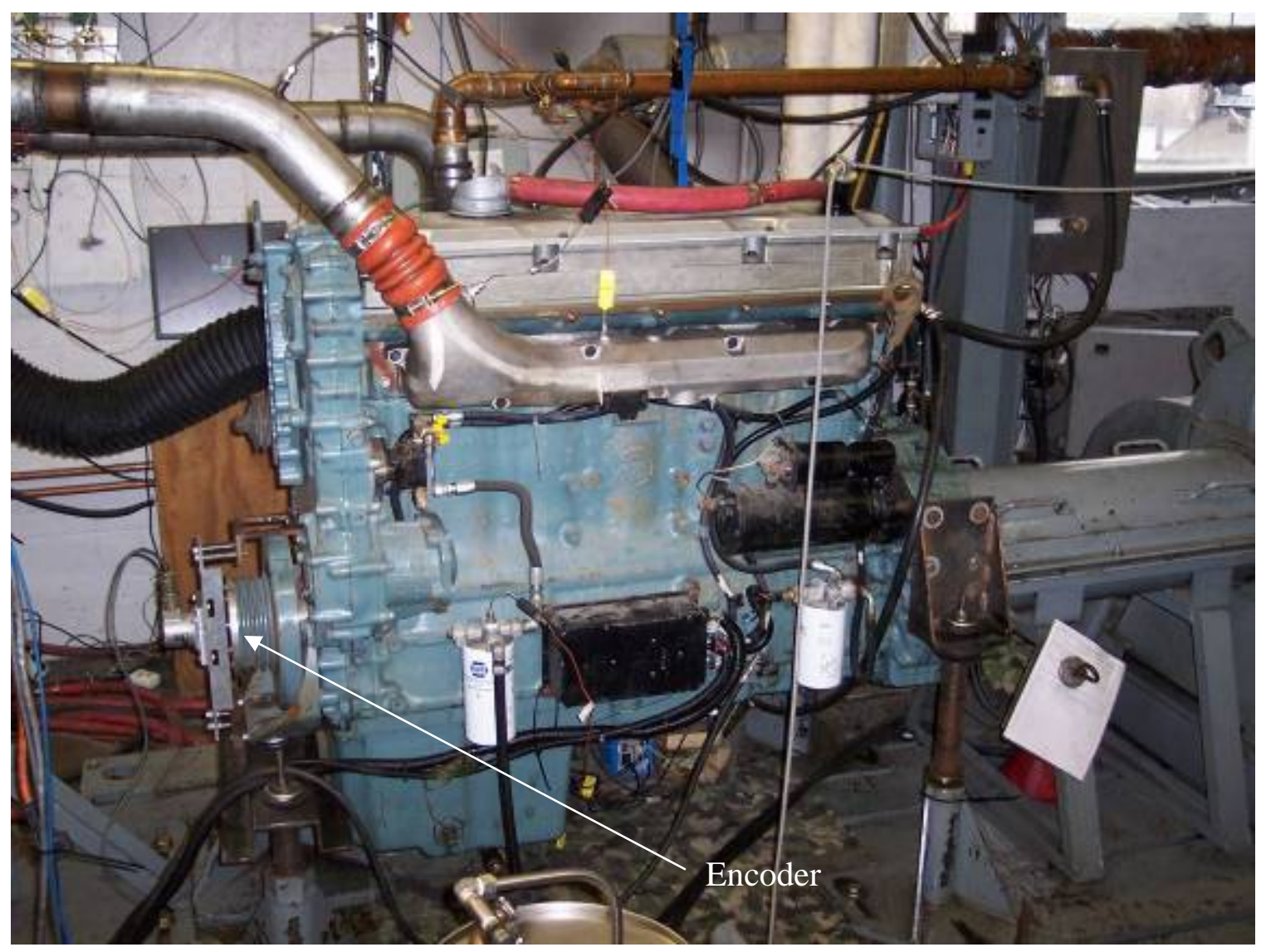

Figure 3-3 1992 Rebuilt DDC Series 60

\subsubsection{General Engine Products}

A turbocharged, indirect injection, mechanically controlled, V8 1998 General Engine Products (GEP) Optimizer $6500^{\mathrm{TM}}$ engine was used for part of the testing. This engine is used in new high mobility multipurpose wheeled vehicles (HMMWV). West Virginia University CAFEE received the engine brand new from the Army, therefore a break-in was required. The engine was loaded on the Eaton AC dynamometer, explained in detail in Section 3.3, and was run with a cyclic load. Carbon dioxide and carbon monoxide emissions were analyzed and the engine was considered suitable for emissions testing once these stabilized. This engine has been exempted from U.S. EPA heavy-duty engine emission regulations by a national security exemption per 40 CFR 85-1708, and section 203 (B) (1) of the Clean Air Act. This engine was selected as representative of 
the present DoD fleet. Figure 3-4 shows a picture of the engine prior to break in and Table 3-1 of Section 3.2.5 gives further characteristics of the engine.

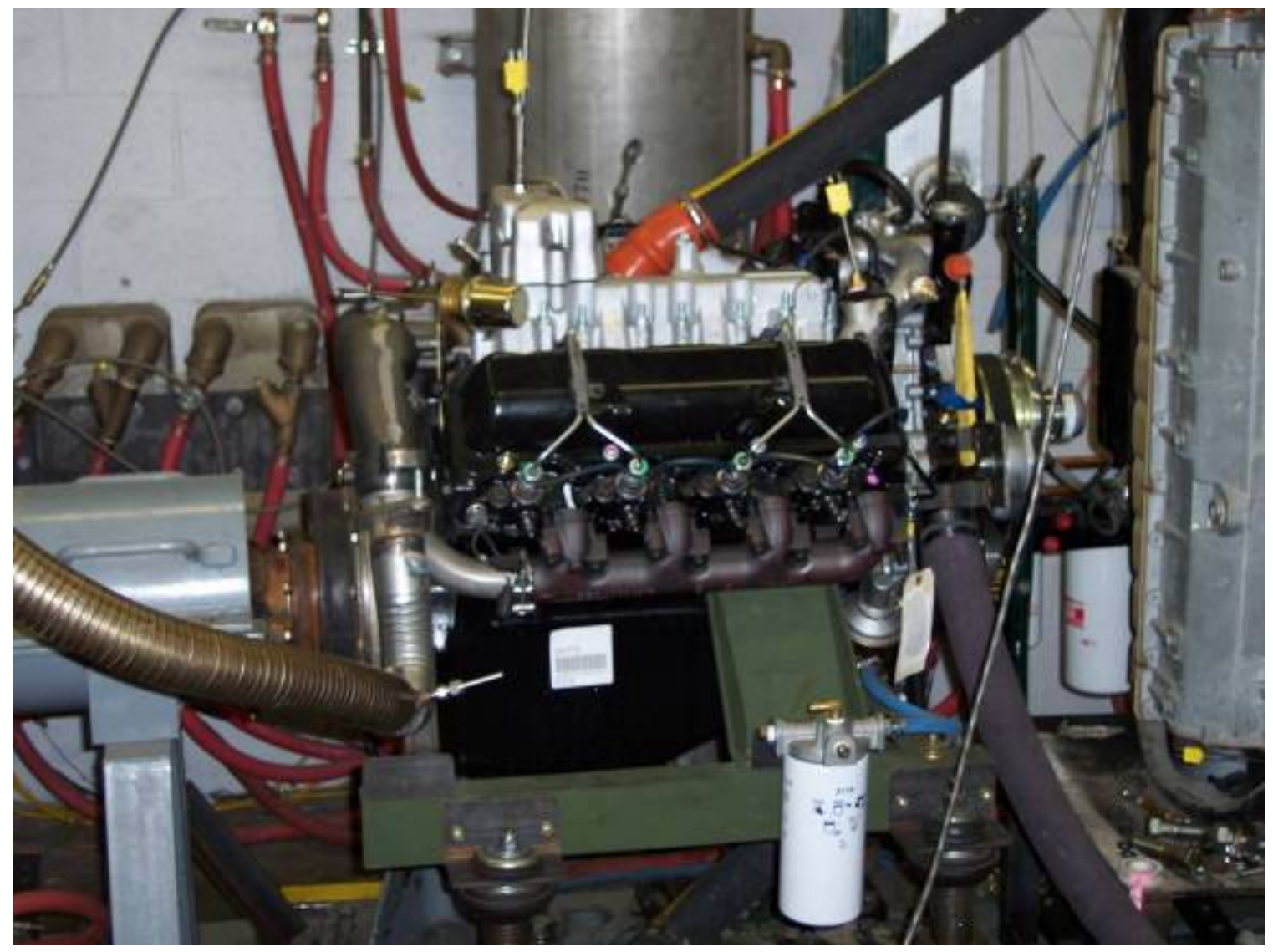

Figure 3-4 1998 GEP Optimizer $6500^{\mathrm{TM}}$

\subsubsection{Engines Summary}

Table 3-1 shows a summary of characteristics for the four engines used for testing. The major differences between engines were the model years. This implies a broad range of technologies covered in the testing. The newest engine of the four, the 1998 AM General, however, had relative primitive technology in that fuel injection was controlled mechanically, as opposed to the electronic control that is employed by existing on-road and many off-road heavy-duty engines found in the commercial fleets. The eight cylinder AM general engine had considerably lower displacement at $6.5 \mathrm{~L}$ opposed to the six cylinder heavy-duty engines that were all above $10 \mathrm{~L}$. All four engines were 
turbocharged and the post turbo intake charge air was circulated through a liquid to air intercooler prior to entering the intake manifold on the three larger engines but not for the AM General engine. The 2004 Mack also had cooled EGR while the other engines did not. The application of the engines also differed. The 1998 AM General is a tactical vehicle used by the military with different operating requirements than the other three which were on-road engines. The three heavy-duty engines were used due to their availability at the time of testing, it is recognized that their applications and performance are different than that of the AM General engine.

Table 3-1 Engines Summary

\begin{tabular}{|c|c|c|c|c|}
\hline Engine & 1999 Cummins & 2004 Mack & $\begin{array}{l}1992 \text { Detroit } \\
\text { Diesel }\end{array}$ & 1998 AM General \\
\hline Configuration & Inline 6 cylinder & Inline 6 cylinder & Inline 6 cylinder & V-shaped 8 cylinder \\
\hline Fuel Delivery & $\begin{array}{l}\text { Electronic; Direct } \\
\text { Injection }\end{array}$ & $\begin{array}{l}\text { Electronic; Direct } \\
\text { Injection }\end{array}$ & $\begin{array}{l}\text { Electronic; Direct } \\
\text { Injection }\end{array}$ & $\begin{array}{c}\text { Mechanical; } \\
\text { Indirect Injection }\end{array}$ \\
\hline Displacement Volume (L) & 10.7 & 11 & 12.7 & 6.5 \\
\hline Compression Ratio & 16.5 & 16 & 15.1 & 20.2 \\
\hline Power Rating (hp) & 370 @ 2100 rpm & $355 @ 1800$ rpm & $360 @ 1810$ rpm & $190 @ 3400$ rpm \\
\hline Torque Rating (ft-lb) & $1450 @ 1200$ rpm & $1360 @ 1200$ rpm & $1450 @ 1200$ rpm & $380 @ 1800$ rpm \\
\hline Aspiration & $\begin{array}{l}\text { Non-wastegated } \\
\text { Turbocharger }\end{array}$ & $\begin{array}{l}\text { Non-wastegated } \\
\text { Turbocharger; } \\
\text { Cooled EGR }\end{array}$ & $\begin{array}{l}\text { Non-wastegated } \\
\text { Turbocharger }\end{array}$ & $\begin{array}{l}\text { Wastegated } \\
\text { Turbocharger }\end{array}$ \\
\hline
\end{tabular}

\subsection{Dynamometers}

The operating points for each test engine were controlled in the same manner. A dynamometer was used to bring the engine to set speed which is measured with a digital encoder. The engine fueling was then controlled via a proportional-integral-derivative controller which sends a signal to the engines fuel injection controller. The GEP engine was controlled via a mechanical actuator that is connected to the fuel pump actuator through a cable. The resulting engine torque was measured on the dynamometer lever arm through a strain gauge load cell. The CFR requires the engine speed readout be accurate to within \pm 2 percent of the absolute standard value and the engine flywheel torque readout be accurate to within \pm 3 percent of the NBS true value torque. The dynamometers load cells were calibrated prior to the beginning of testing according to 
Title 40 CFR Part 86 procedures. Note that although the 1998 General Engine Products engine was not certified for on-road use, the Title 40 CFR Part 86 procedures were used to evaluate this engine's emissions. The calibration consisted of placing known weights on the lever arm a known horizontal distance from the center axis of revolution.

\subsubsection{General Electric $800 \mathrm{hp}$}

The 1999 Cummins engine operated on an 800 hp General Electric type TLC243 dynamometer. The DC dynamometer is capable of both delivering and absorbing $800 \mathrm{hp}$. The flywheel was connected to the dynamometer through a Vulkan`C coupler. Figure 3-5 shows a picture of the dynamometer.

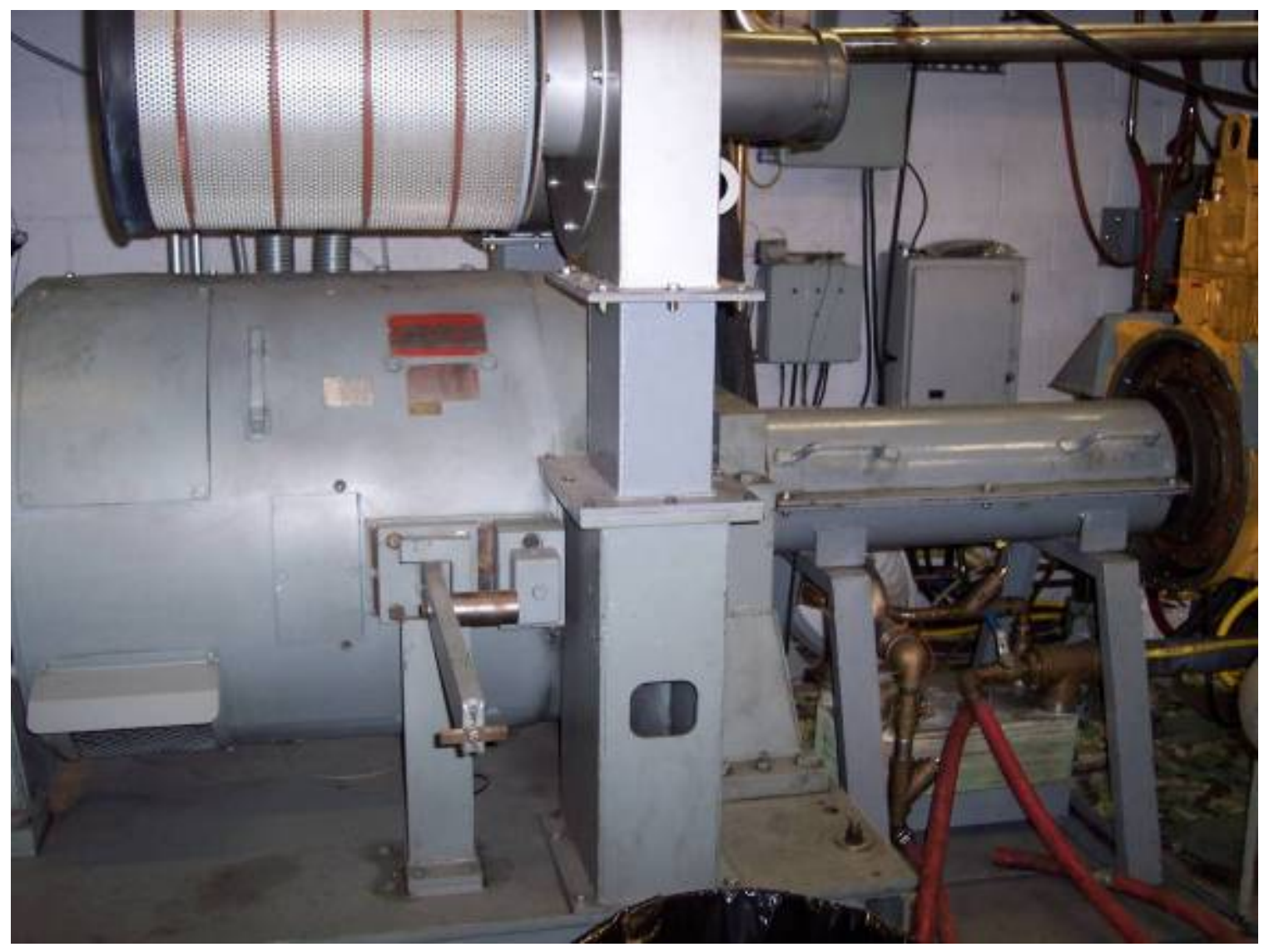

Figure 3-5 800 hp GE Dynamometer 


\subsubsection{General Electric $550 \mathrm{hp}$}

The 2004 Mack and 1992 Detroit Diesel engines were run on a 550 hp General Electric type DYC243 dynamometer. This dynamometer is capable of delivering $500 \mathrm{hp}$ and absorbing $550 \mathrm{hp}$. The engines' flywheels were connected to the dynamometers drive shaft through a Vulkan@ coupling. Figure 3-6 shows a picture of the dynamometer.

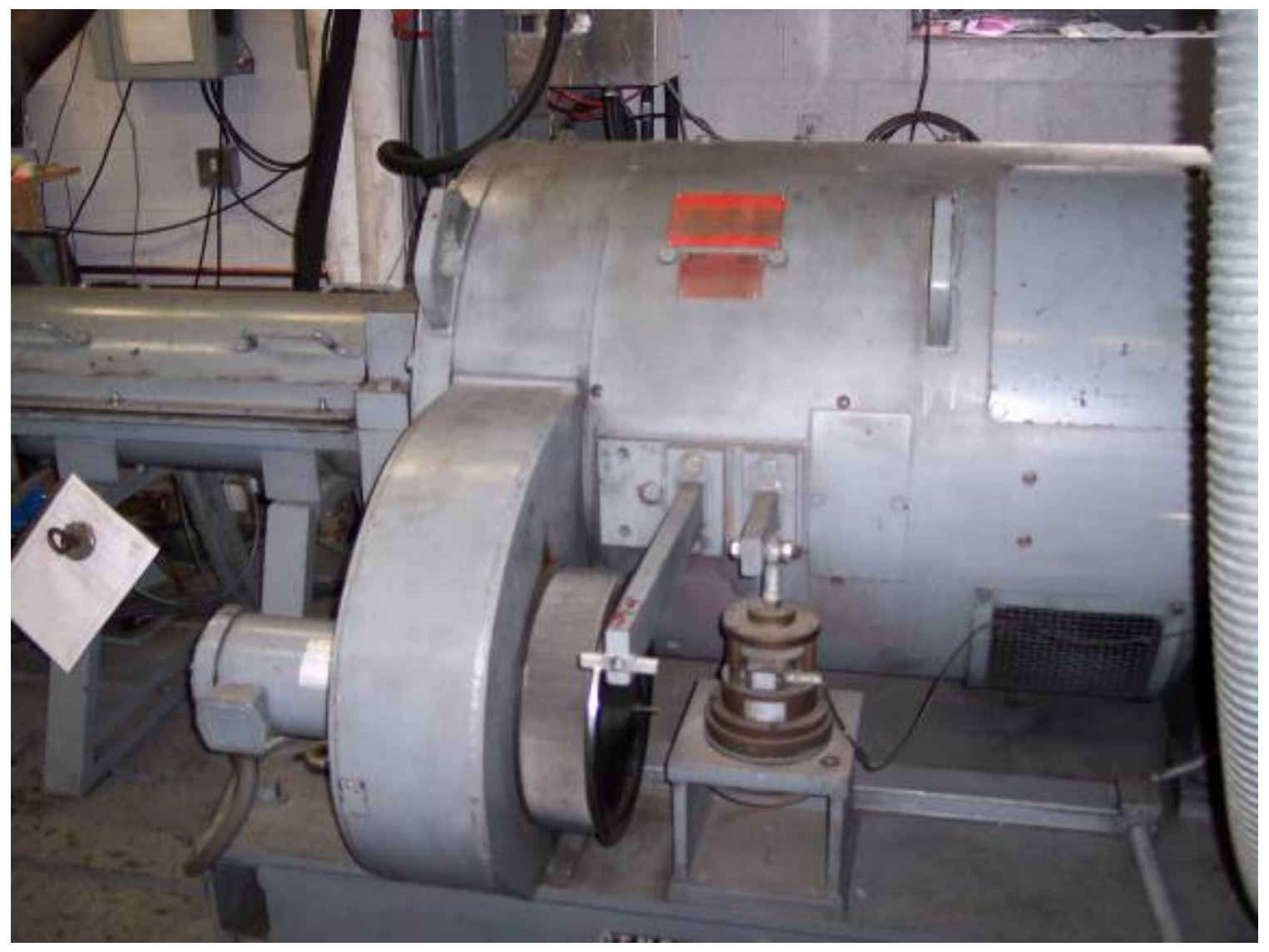

Figure 3-6 550 hp GE Dynamometer

\subsubsection{Eaton $300 \mathrm{hp}$}

The American General engine was run on a 300 hp AC Eaton dynamometer. The dynamometer is capable of absorbing $300 \mathrm{hp}$ and delivering $225 \mathrm{hp}$. As with the previous setups, the engine’s flywheel was connected to the driveshaft with a Vulkan( coupling. Figure 3-7 shows a picture of the Eaton dynamometer. 


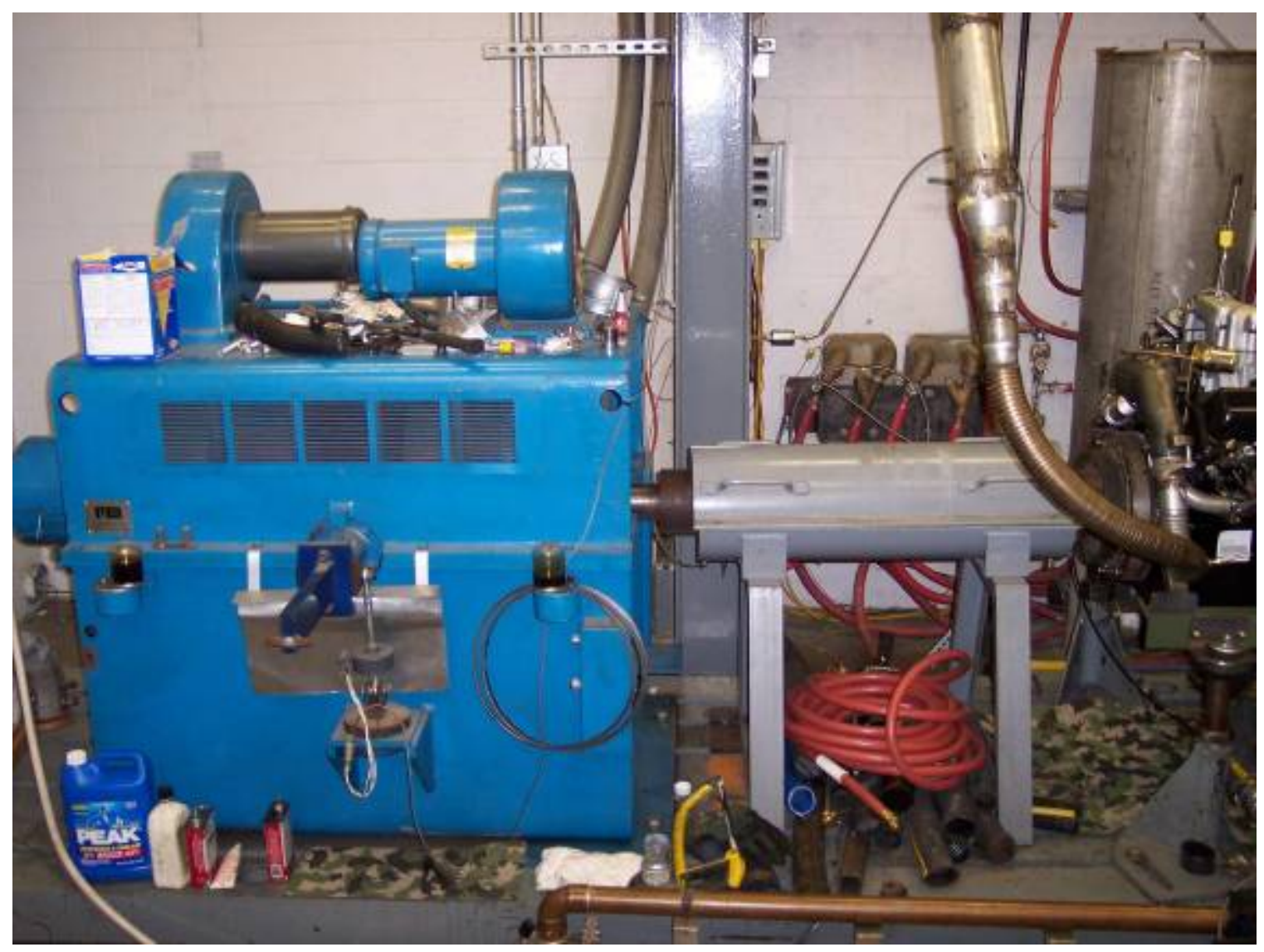

Figure 3-7 300 hp Eaton Dynamometer

\subsection{Dilution Tunnels}

West Virginia University’s CAFEE has two separate full-scale dilution tunnels for emissions testing. The purpose of a dilution tunnel is to mimic the reactions of exhaust gases coming out of the tailpipe of a vehicle and entering the atmosphere, thus allowing mixing of ambient air with the exhaust gases where they can then be sampled and analyzed. The following sections describe the two tunnels used for this study.

\subsubsection{Part 1065 Tunnel}

The emissions testing on the 1999 Cummins and 1998 GEP engines used a fullscale dilution tunnel designed to adhere to title 40 CFR part 1065 standards. Airflow through the tunnel is regulated by a subsonic venturi which allows measurement of the 
volumetric (or mass) flow rate by using known parameters of the venturi and the air temperature and pressure before and after the throat. The air/exhaust through the tunnel is driven by a $30 \mathrm{hp}$ variable speed blower. A subsonic venturi has the advantage of being able to regulate the flow rate at which the air/exhaust is below sonic velocity at the throat. For this particular system, that flow rate is approximately $2500 \mathrm{scfm}$. Figure 3-8 and Figure 3-9 show a picture of the subsonic venturi and the variable speed blower.

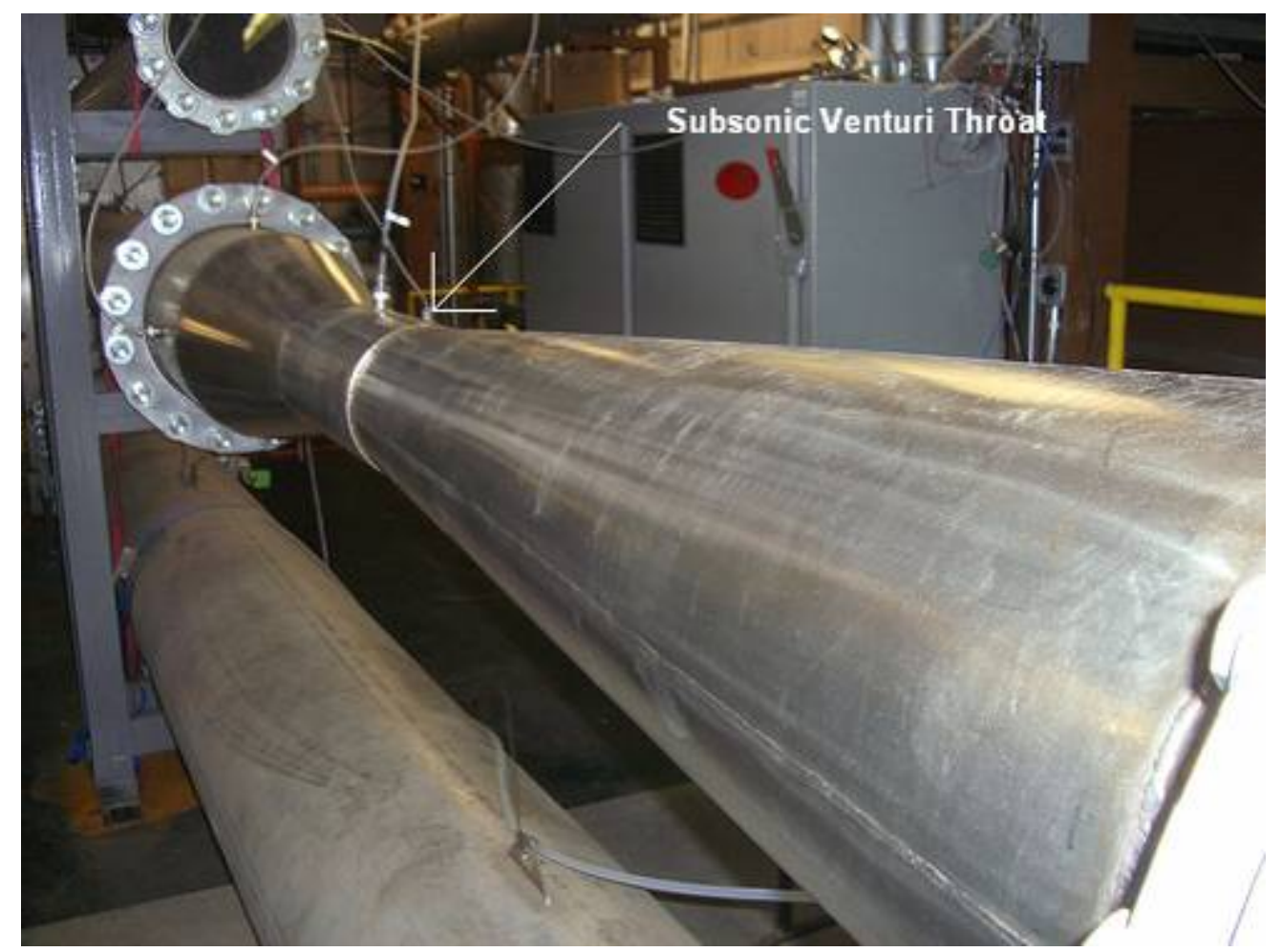

Figure 3-8 Subsonic Venturi for Part 1065 Tunnel 


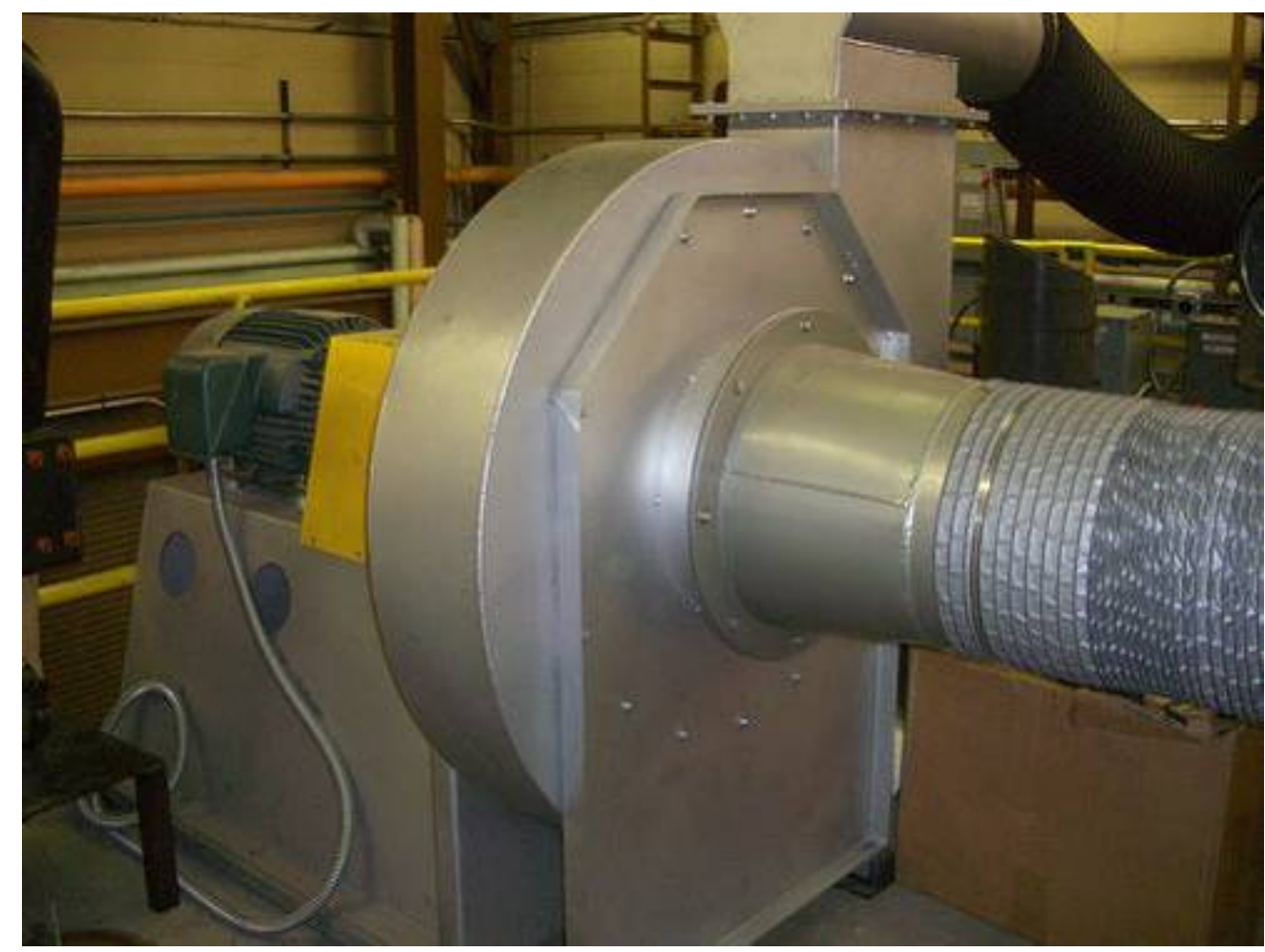

Figure 3-9 Variable Speed Blower for Part 1065 Tunnel

\subsubsection{Part 86 Tunnel}

The emissions testing completed on the 2004 Mack and the 1992 DDC used a full-scale dilution tunnel designed to adhere to title 40 CFR part 86 standards. Tunnel flow can be regulated by any combination of four critical flow venturis (CFV). For this testing, three of the venturis (two $1000 \mathrm{scfm}$ and one $400 \mathrm{scfm}$ ) were used to measure approximately $2400 \mathrm{scfm}$. The flow rate through the venturi is calculated by using a constant unique to the geometry of the venturi and also the pressure and temperature of the air upstream in the flow. The air/exhaust through the tunnel is driven by a $75 \mathrm{hp}$ blower. A CFV has the disadvantage of only being capable of measuring the flow rate when the throat velocity is sonic. This limits the flow rate through the tunnel to only discrete values. Figure 3-10 shows a picture of the piping for the critical flow venturi and Figure 3-11 shows a picture of the 75 hp blower. 


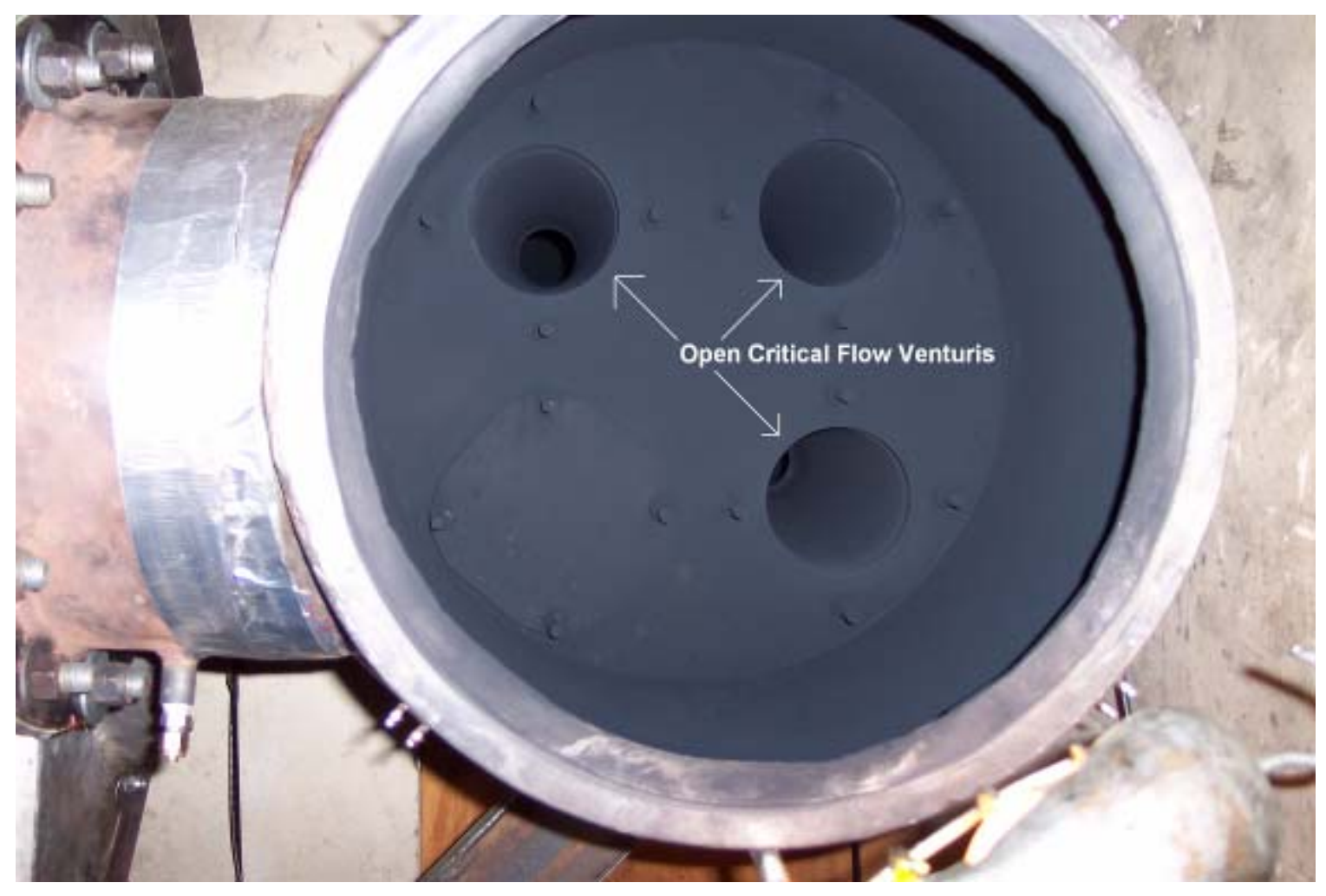

Figure 3-10 Critical Flow Venturis for Part 86 Tunnel 


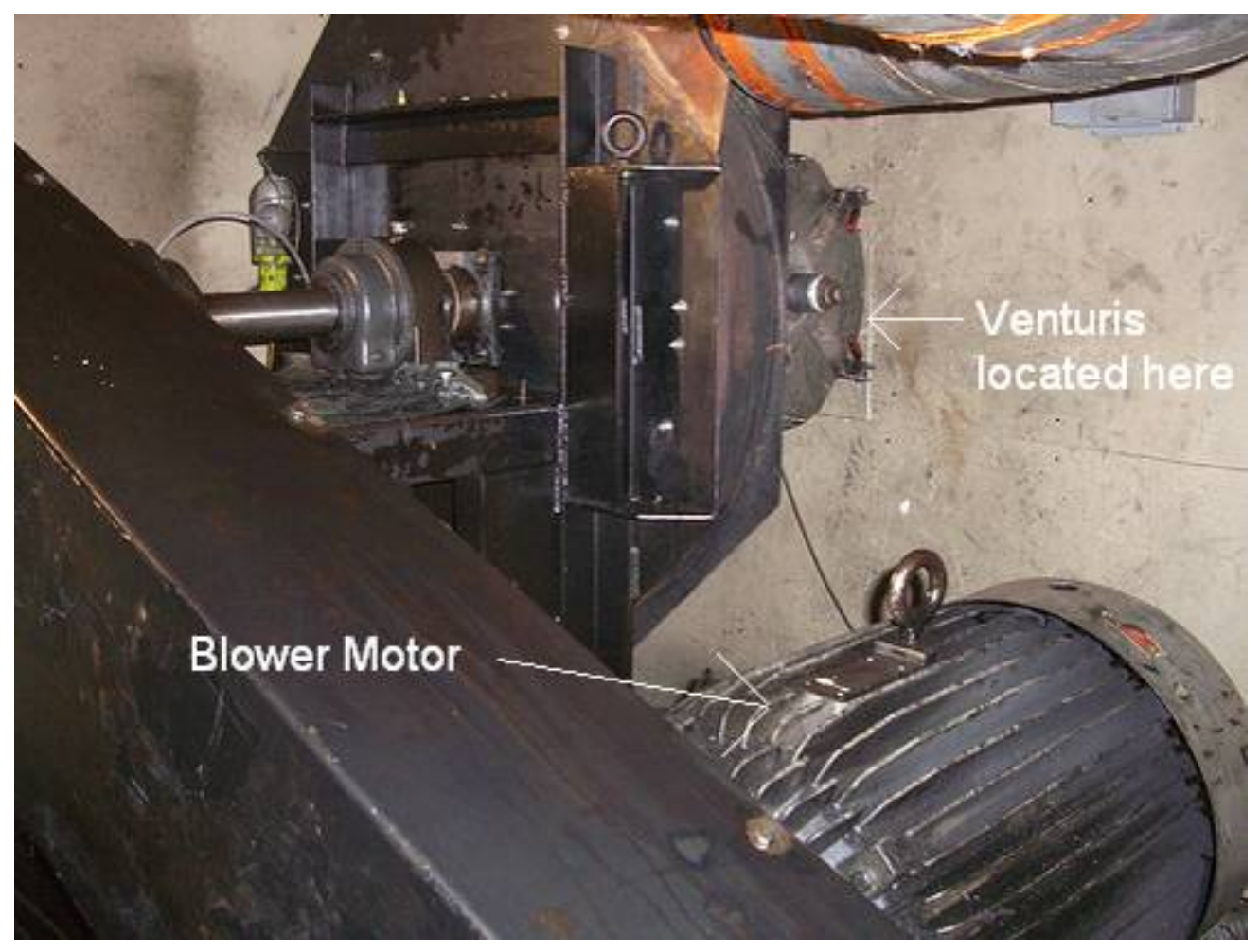

Figure 3-11 75 hp Blower for Part 86 Tunnel

\subsection{Exhaust Gas Analyzers}

A sampling plane is located downstream of where the exhaust gases and ambient air mix. Its purpose is to direct the diluted exhaust gases to the analyzers. Heated pumps and lines are used to transfer the samples from the sampling probe to the analyzers. The heated lines serve to prevent condensation of the sampled gas. Total hydrocarbons, carbon dioxide, carbon monoxide, and oxides of nitrogen were measured in this study. For the testing completed on the AM General engine, a Horiba exhaust gas analyzer (MEXA) model 7200D was used. This device contains the same gaseous measurement capability in one unit. Use of the MEXA is highly automated, for instance, pre- and posttest zero and spanning, as well as calibrations, are all automated. The following sections describe the analyzer equipment. 


\subsubsection{Hydrocarbon Analyzers}

Hydrocarbon concentrations were measured by heated flame ionization detection (HFID). The exhaust gas is introduced into a hydrogen flame, the heat energy from the combustion causes it to undergo ionization. Two electrodes are fitted on either side of the flame, then a DC voltage is applied between the electrodes, which causes a flow of ions proportional to the number of carbon atoms within the hydrocarbon. This current is converted into a voltage which is representative of the hydrocarbon concentration [63, 64]. All the analyzers used the HFID principle for HC measurements. Table 3-2 gives a summary of the specific analyzers used for the testing.

Table 3-2 Hydrocarbon Analyzers used for Testing

\begin{tabular}{|c|c|c|}
\hline Test Engine & $\begin{array}{c}\text { Analyzer } \\
\text { Manufacturer }\end{array}$ & Model \\
\hline 1999 Cummins & Horiba & FIA-236 \\
\hline 2004 Mack & CAl & $600 M-H F I D$ \\
\hline \multirow{2}{*}{1992 DDC } & Horiba & FIA-236 \\
\cline { 2 - 3 } & CAl & $600 M-H F I D$ \\
\hline 1998 AM General & Horiba & FIA-725A \\
\hline
\end{tabular}

The CAI analyzer was used as the primary THC analyzer for the testing completed on the 2004 Mack and was used as a secondary THC analyzer for the testing completed on the 1992 DDC. A Horiba FIA-236 was used as the primary THC measurement for testing on the 1992 DDC.

\subsubsection{Carbon Dioxide and Carbon Monoxide Analyzers}

The carbon dioxide and carbon monoxide analyzers function according to the principle of selective absorption of infrared energy in order to determine gas concentrations. This process is called non-dispersive infrared (NDIR) detection. A molecule consisting of different atoms absorbs infrared energy of specific wavelengths, and the degree of this absorption is proportional to the concentration at constant pressure. The analyzer works by using a detector cell to measure the intensity of infrared light after 
being passed through the sample. The intensity of the light is an indicator of the concentration of gas within the measurement cell $[65,66]$. Table 3-3 shows a summary of the specific analyzers used for measuring $\mathrm{CO}$ and $\mathrm{CO}_{2}$.

Table 3-3 Carbon Monoxide and Carbon Dioxide Analyzers used for Testing

\begin{tabular}{|c|c|c|c|}
\hline Test Engine & $\begin{array}{c}\text { Measured } \\
\text { Emissions }\end{array}$ & $\begin{array}{c}\text { Analyzer } \\
\text { Manufacturer }\end{array}$ & Model \\
\hline 1999 Cummins & $\mathrm{CO}, \mathrm{CO}_{2}$ & Horiba & AIA-210 \\
\hline 2004 Mack & $\mathrm{CO}$ & Horiba & AIA-210LE \\
& $\mathrm{CO}_{2}$ & Horiba & AIA-210 \\
\hline \multirow{2}{*}{1992 DDC } & $\mathrm{CO}($ high $)$ & Horiba & AIA-210 \\
& $\mathrm{CO}($ low $)$ & Horiba & AIA-210LE \\
& $\mathrm{CO}_{2}$ & Horiba & AIA-210 \\
\hline 1998 AM General & ${\mathrm{CO}, \mathrm{CO}_{2}}$ & & AIA-72X \\
\hline
\end{tabular}

The purpose of using two different analyzers to measure CO for the 1992 DDC is to have the ability to measure a wide range of concentrations. Only one CO analyzer was used while testing the 2004 Mack because it was known that CO would not exceed 500 ppm, which was a narrow enough range for a single analyzer to satisfy measurement accuracy requirements.

\subsubsection{Oxides of Nitrogen Analyzers}

For oxides of nitrogen the analyzer measured both $\mathrm{NO}$ and $\mathrm{NO}_{\mathrm{x}}$ on the principle of chemiluminescence. The detection of $\mathrm{NO}$ is based on its reaction with ozone $\left(\mathrm{O}_{3}\right)$ to produce nitrogen dioxide and oxygen $\left(\mathrm{O}_{2}\right)$. As $\mathrm{NO}$ and $\mathrm{O}_{3}$ mix in the reaction chamber, the chemiluminescent reaction produces light emission that is directly proportional to the concentration of $\mathrm{NO}$ which is measured by a photomultiplier tube. The $\mathrm{NO}_{\mathrm{x}}$ determination is identical to the NO determination except that prior to entry into the reaction chamber, the sample is routed through a converter where the $\mathrm{NO}_{2}$ component is dissociated to form NO [67,68]. Table 3-4 shows the manufacturer and model of analyzers used for measuring $\mathrm{NO}_{\mathrm{x}}$. 
Table 3-4 Analyzers used for Oxides of Nitrogen Measurement

\begin{tabular}{|c|c|c|}
\hline Test Engine & $\begin{array}{c}\text { Analyzer } \\
\text { Manufacturer }\end{array}$ & Model \\
\hline 1999 Cummins & Eco Physics & CLD 822 CM h \\
\hline 2004 Mack & Eco Physics & CLD 822 CM h \\
\hline 1992 DDC & $\begin{array}{c}\text { Eco Physics } \\
\text { Rosemount } \\
\text { Analytical }\end{array}$ & CLD 822 CM h \\
& Horiba & CLA-720MA \\
\hline 1998 AM General & \multicolumn{2}{c}{} \\
\hline
\end{tabular}

The major difference between the two tunnels measuring $\mathrm{NO}_{\mathrm{x}}$ is that the part 1065 tunnel, or Horiba CLA-720MA analyzer, has a chiller between the sample and the analyzers to remove moisture giving a "dry" sample, while the part 86 tunnel, or Eco Physics CLD 822 CM h and Rosemount Analytical 955, gives a “wet” sample.

\subsection{Bag Sampling}

Throughout testing, 80 liter Tedlar bags were used to collect the exhaust gases for an integrated measurement of the test. To take into consideration the concentrations of gases within the dilution air, a background bag was also collected, sampled upstream of where the dilution air and exhaust gases mix. After testing, the air in the bags was fed into the analyzer bench for measurement of emissions. The background concentrations were subtracted from the diluted exhaust gas to account for background emissions.

\subsection{Particulate Matter Sampling}

A gravimetric based approach was used in collecting TPM emissions for both tunnels. A stream of dilute exhaust was taken at the sampling plane and introduced into a secondary dilution tunnel and passed over filters, where the PM was collected. The CFR requires that the exhaust stream after dilution not exceed $125^{\circ} \mathrm{F}$ for PM measurement. The following sections describe the differences in the TPM collection for both tunnels. 


\subsubsection{Part 1065 Tunnel}

For the part 1065 tunnel, the exhaust slipstream was diluted with secondary air to ensure the sample not exceed the $125^{\circ} \mathrm{F}$ limit. The twice diluted exhaust was introduced into a temperature controlled box that contained a pre-classifier which permited only PM of nominal sizes smaller than $2.5 \mu \mathrm{m}$. The diluted exhaust sample was then passed through the filter where the PM was collected. A mass flow controller was used to control and measure the flowrate through the filter and the secondary dilution air. The type of filter used was a single $47 \mathrm{~mm}$ Teflo filter.

\subsubsection{Part 86 Tunnel}

For the part 86 tunnel, no secondary dilution air was required to keep the PM sample below $125^{\circ} \mathrm{F}$. The slipstream was pulled into a temperature controlled box but no cyclone was used to alter the PM sizes introduced across the filter. A mass flow controller was also used to monitor the flow across the filter face. Two T60A20, $70 \mathrm{~mm}$ fluorocarbon glass coated filters in series were used to collect the PM.

\subsection{Data Acquisition System}

The data acquisition (DAQ) system used for conditioning signals for the part 1065 tunnel used National Instruments data acquisition cards and a SCXI 1001 signal conditionin system. The part 86 tunnel used RTI data acquisition cards and a 3B series signal conditioning system. Each DAQ system takes a current or voltage from a transducer and converts the signal into engineering units with a calibration file. Figure 3-12 and Figure 3-13 show the two DAQ systems. Both the data collection and the data reduction software were written and maintained by WVU personnel. 


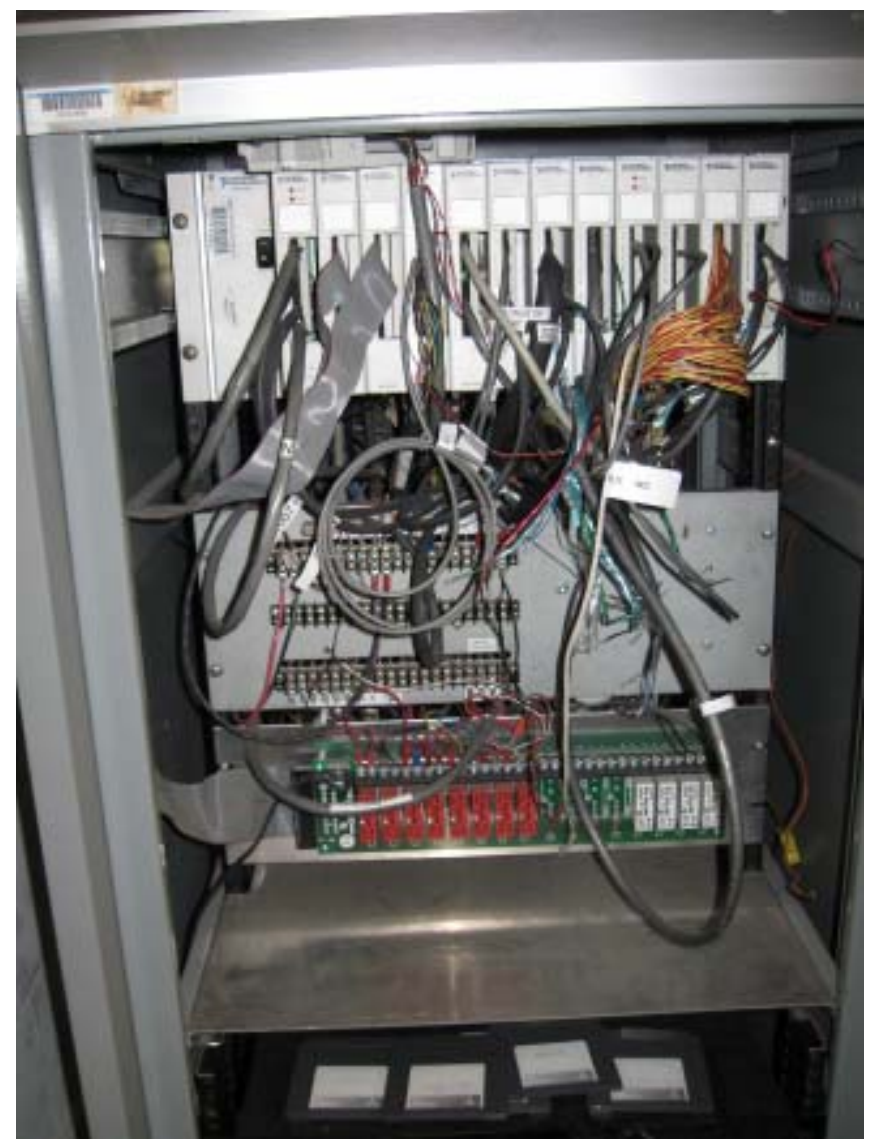

Figure 3-12 DAQ System for Part 1065 Data Collection 


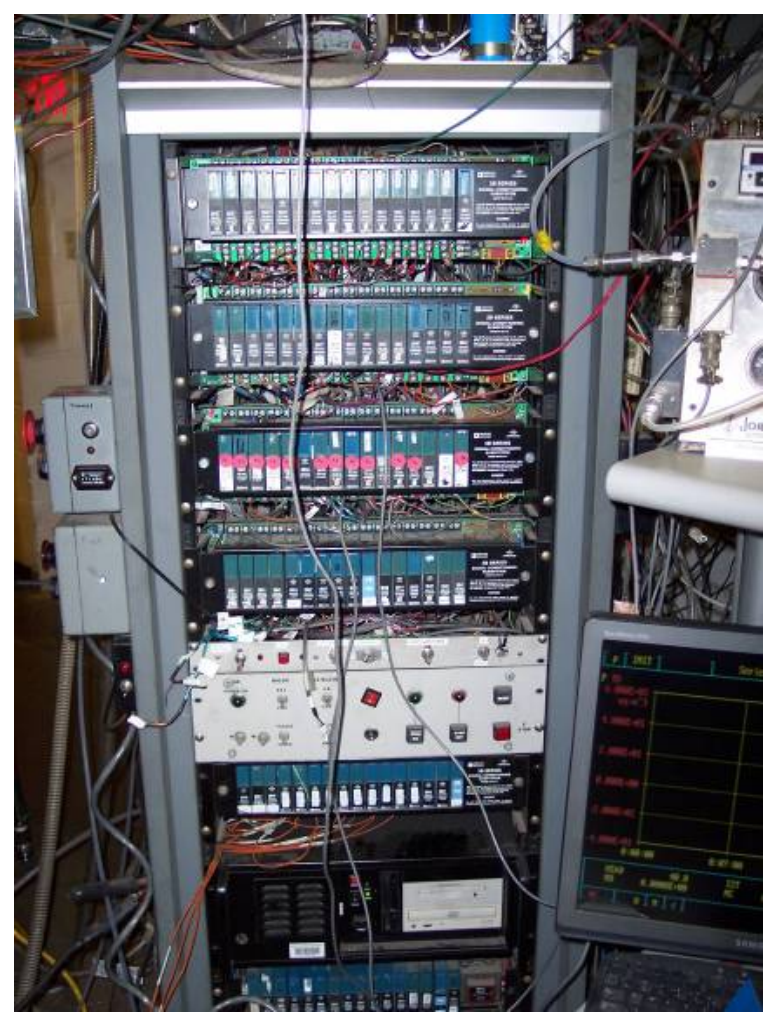

Figure 3-13 DAQ System for Part 86 Data Collection

\subsection{In-Cylinder Pressure Measurement}

In-cylinder pressure data was desired to attempt to distinguish the effects the different additives had on the combustion process. The 1992 DDC had piezoelectric pressure transducers installed in two of the cylinders (cylinders 3 and 5). The transducers emit a charge which is proportional to the pressure. This charge was then converted to a voltage and sent to the data acquisition system. The data acquisition software used was developed in another study and more information on this and the testing setup can be found in that paper [69]. 


\section{Test Procedure}

The procedures completed to acquire data to be used for analysis are outlined in this chapter. As mentioned previously, testing was completed by adhering to Title 40 Part 1065 or Part 86 of the CFR. Test fuels, additives, and test cycles are also explained in detail.

\subsection{Analyzer Operation}

Calibrations were performed prior to testing on each analyzer. It consisted of supplying a known concentration of gas to the analyzer. An 11 point calibration curve was created by using different concentrations of the gas through use of a gas divider and a balance gas. The $\mathrm{HC}$ and $\mathrm{NO}_{\mathrm{x}}$ analyzers had a linear fit while the $\mathrm{CO}$ and $\mathrm{CO}_{2}$ analyzers had a second or third order polynomial curve fit.

Between each test, the analyzers were zeroed and spanned. This consisted of supplying the analyzer with $100 \%$ concentration of the measured gas as well as $100 \%$ concentration of the balance gas $\left(\mathrm{N}_{2}\right.$ for $\mathrm{NO}_{\mathrm{x}}, \mathrm{CO}$, and $\mathrm{CO}_{2}$ and zero air for $\left.\mathrm{HC}\right)$. A potentiometer on the analyzer or an electronic setting was then adjusted to give the appropriate output voltage according to the calibration curve. The MEXA did not require adjustment of a potentiometer as the zero and spanning process was automated internally through electronic signals.

\subsection{Particulate Matter Weighing}

The filters used for particulate matter measurement were preconditioned in a clean room prior to initial weighing. The clean room maintained a temperature of $22^{\circ} \mathrm{C} \pm$ $3^{\circ} \mathrm{C}$ and a dew point of $9.5^{\circ} \mathrm{C} \pm 1^{\circ} \mathrm{C}$. The initial reading of the filter(s) prior to testing, the tare weight, was recorded. The filter(s) was/were then stored in a covered petri dish until it was transferred to the PM filter housing to be used for testing. After the emissions test, 
the filter(s) was/were removed from the housing and placed in a petri dish to be conditioned to the clean room specifications for a minimum of one hour. After at least one hour, the filter(s) was/were weighed and recorded as the gross weight. The net particulate weight on the filter(s) was the gross weight minus the tare weight. A background filter, or filter set, was taken during each testing period to account for particulates in the ambient air or dilution tunnel so that ambient air quality would not alter the results. Figure 4-1 shows the Sartorius SE2-F ultra-microbalance used for weighing PM filters. The user can record measurements out to $0.1 \mu \mathrm{g}$.

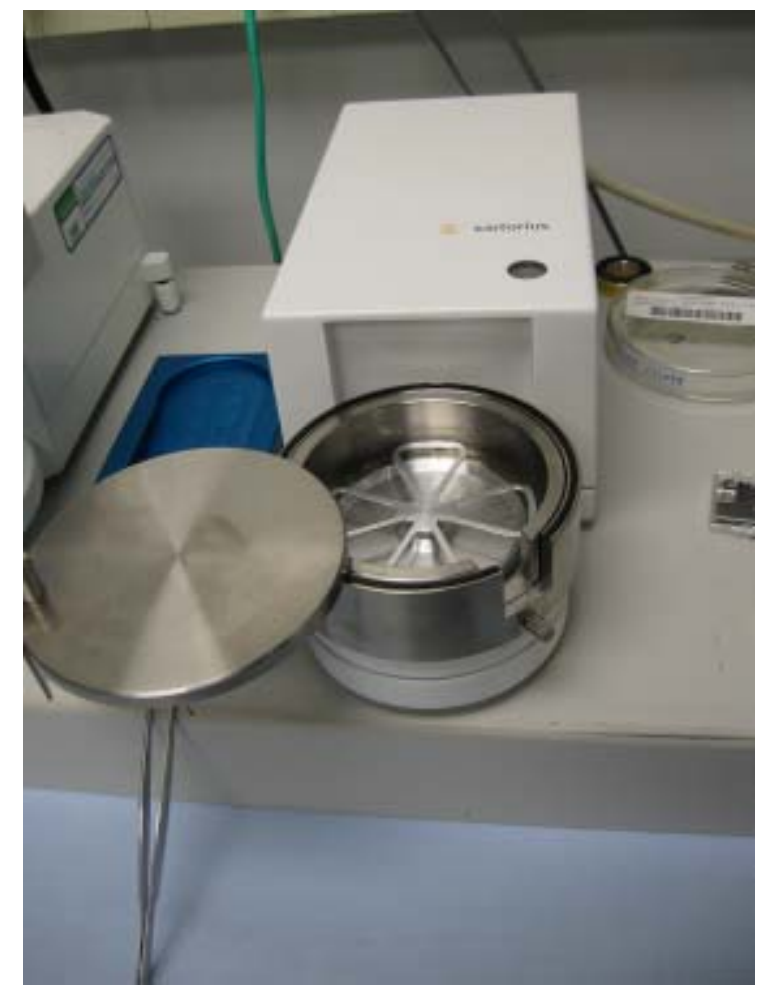

Figure 4-1 Sartorius SE2-F Ultra-Microbalance

\subsection{Test Fuels}

Three different baseline fuels were used during testing. An ultra low sulfur number 2 diesel (Guttman, named for the oil company) was used as the baseline fuel for 
the 1999 Cummins and 2004 Mack testing. This diesel fuel was delivered to WVU CAFEE from Bulk Terminal Storage in Star City, WV. A Haltermann products reference fuel (Halt) was used for testing on the 1992 DDC. This fuel had been in WVU CAFEE inventory from prior testing. Jet propulsion fuel (JP-8), which consists mainly of kerosene, was used during testing of the AM General engine. Since the results of different additives were only compared to other additives of the same engine and base fuel, the use of different base fuels for each engine was deemed acceptable.

\subsection{Test Additives}

Five additives were used during the testing, though not all were used on each engine. The additives fall into the category of fuel borne catalysts. These additives are primarily intended to enhance combustion with the desired result of better fuel economy, though they may serve as other multipurpose additives as well.

Nano-Coat ${ }^{\mathrm{TM}}$ (Cerion 1), a Cerion Energy Inc. product [70], was used in testing of all four engines. The company claims the additive can produce an increase in fuel economy as well as reduce PM emissions. The company’s suggested application rate was $0.71 \mathrm{ml} / \mathrm{gal}$. A second additive from Cerion Energy Inc. (Cerion 2) was a slight alteration of the first. This additive had been altered to have a greater oxygen storage capacity than the first. Cerion 2 was only used in testing on the 2004 Mack engine.

F2-21® NanoTech eeFuel® (H2Oil 1), an H2Oil Corporation product [71], was used in testing of the 1999 Cummins, 1992 DDC, and 1998 AM General engines. This additive claims to improve fuel economy, increase engine power, reduce harmful emissions and clean combustion chamber deposits. The company's suggested application rate was $0.76 \mathrm{ml} /$ gal. A second additive from H2Oil Corporation, F2-21® NanoTech (H2Oil 2), was used only for testing on the 1998 AM General Engine. The suggested application rate for H2Oil 2 was $1.00 \mathrm{ml} / \mathrm{gal}$.

Nano Bonus ${ }^{\circledR}$ (Nano Bonus), a Nano Bonus Ltd. Product, was used in testing of the 1999 Cummins, the 1992 DDC, and the 1998 AM General Engines. This additive 
claims to reduce fuel consumption, increase engine power, reduce exhaust emissions, and reduce engine deposits by creating a second atomization of the fuel for more complete combustion. The company's suggested application rate was $0.76 \mathrm{ml} / \mathrm{gal}$.

\subsection{Test Fuel Preparation}

The baseline test fuels were stored in either 16 or 30 gallon stainless steel drums from where they were supplied to the engine. The Guttman fuel was drawn from a 500 gallon tank at WVU CAFEE and put into a 55 gallon steel drum. From there, the fuel was placed into 16 gallon stainless steel drums. The Haltermann fuel was taken from 55 gallon steel drums from WVU CAFEE inventory and put into both 16 and 30 gallon stainless steel drums. The JP-8 fuel was taken from 55 gallon steel drums and placed into 16 gallon stainless steel drums. The fuels were prepared no more than one week prior to the beginning of testing.

The fuel was measured on a mass basis but the additive dosage rate was on a volume basis, therefore the specific gravity of the fuel must be known to determine the volume of the fuel. A sample from each 55 gallon drum was taken and the specific gravity was measured with a hydrometer at the WVU CAFEE laboratory using hydrometers that conform to the ASTM D287 requirements. Additionally, the temperature of each fuel sample was recorded and the resulting specific gravity, or API gravity, was corrected back to $60^{\circ} \mathrm{F}$ using the ASTM correction procedure. Note that although the ASTM D287 equipment and procedures were followed as close as possible there are no claims being made that the measurements were made per ASTM D287. However, the resulting measurements were assumed to be acceptable for this research program. The amount of additive to use was then known from the suggested dose rate. The additives were first placed from their original container into a $1000 \mathrm{ml}$ beaker where they were transferred into a $25 \mathrm{ml}$ graduated cylinder with a plastic syringe. The syringe was purged with the additive several times prior to use to ensure no carryover from previous fuels or additives. The graduated cylinder had a readability of $0.2 \mathrm{ml}$. Once the proper amount of additive was measured into the graduated cylinder, it was transferred 
into the drum containing the base fuel. The additives were then admixed to the remaining neat diesel fuel drum and mixed for 20 minutes using a mechanical drum tumbler. The additized fuels were then stored for at least 24 hours between when the fuels were mixed and when testing began. This was due to preparation procedures for the H2Oil additives which stated that storage for 24 hours allows the nano-cluster lattices time to become fully established in the body of the fuel. Since no other additive had a preparation limitation as such, they were all treated in this manner. Figure 4-2 shows the tumbler used for mixing the fuels.

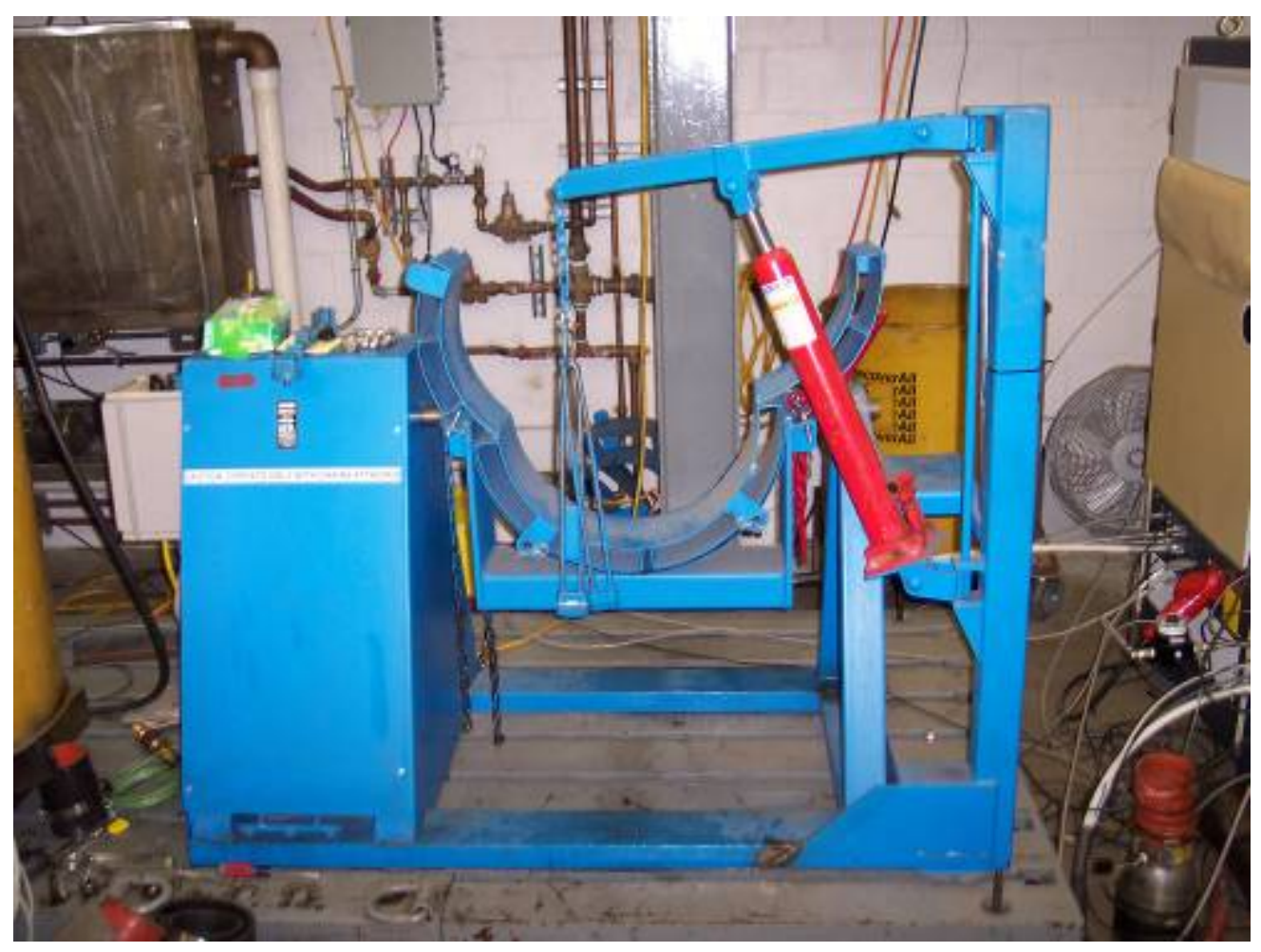

Figure 4-2 Tumbler Used for Mixing Fuel

The barrel was placed in the tumbler and locked down with chain lever binders. The tumbler was then used to rotate the barrel at approximately $20 \mathrm{rpm}$ for 20 minutes. 


\subsection{Test Cycles}

Five test cycles were used in this study. They include the Federal Test Procedure (FTP), a rearrangement of the Supplemental Emissions Test (SET), a 6-mode steady-state cycle, a 3-mode steady-state cycle, and a created transient cycle representing in use data.

The FTP is a transient cycle created to represent three different driving scenarios within New York and Los Angeles. The distinct segments consist of New York freeway, Los Angeles freeway, and Los Angeles non-freeway. On-road, heavy-duty diesel engine manufactures are required to test their engines over the FTP within certain emissions limits to become certified.

The SET is also a required test cycle for heavy-duty engine manufacturers to certify their engines. This cycle consists of 13 different modes. Except for idle, each mode falls on one of three speeds at $25 \%, 50 \%, 75 \%$, or $100 \%$ load. Looking at a speed versus load plot, the set points create a "box" (A-25, A-100, C-25, C-100) as can be seen in Figure 4-3. 


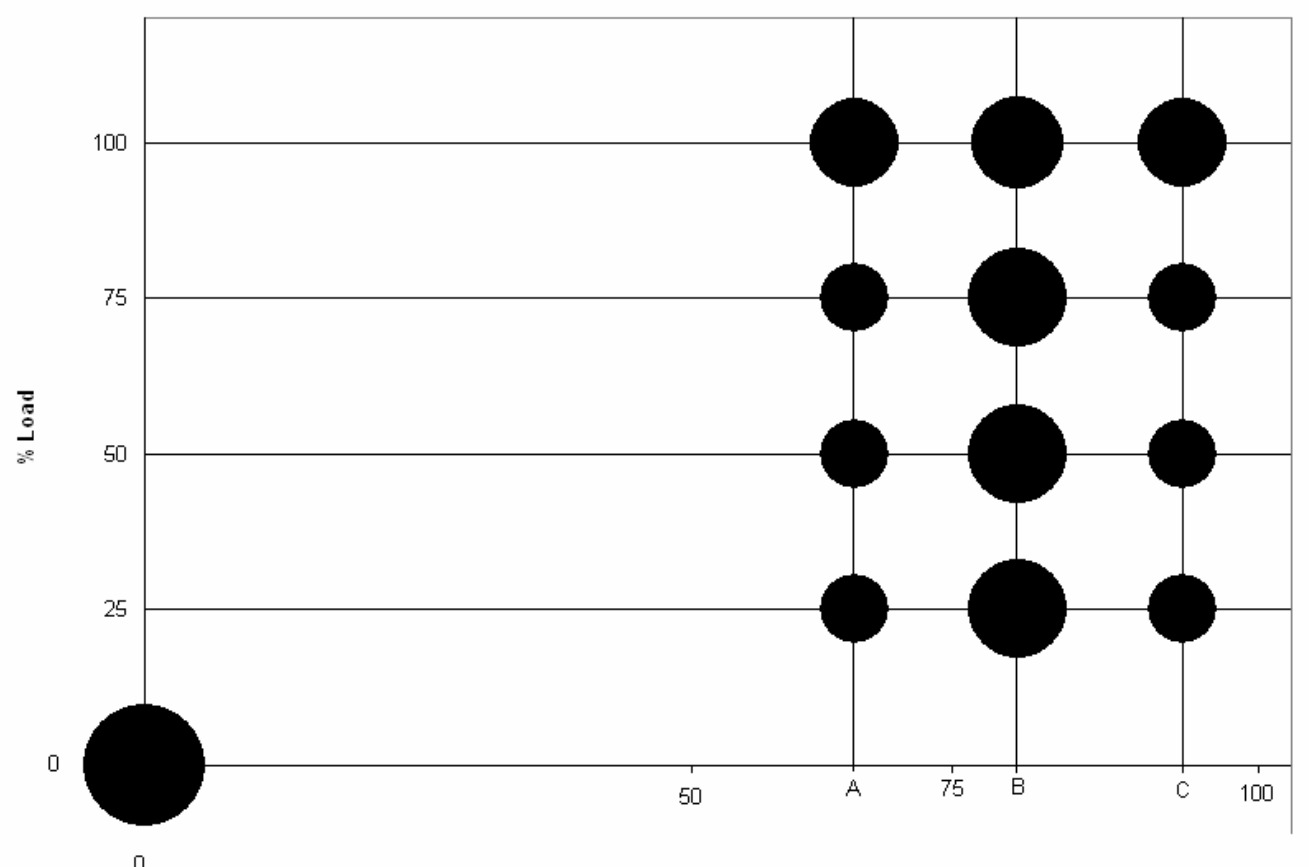

$\%$ Speed

Figure 4-3 Set Points for Supplemental Emissions Test

Speeds $A, B$, and $C$ are determined after mapping the engine. Emissions are collected throughout the test in sections of each mode, and weighting factors are applied to obtain integrated emission results. PM filters can be treated the same way, or a filter can be changed between each mode. In this study, the filters were changed between each mode. The same set points were utilized in this study, except the order was rearranged. Reason being, the engine had difficulty obtaining thermal equilibrium in certain high load modes after low power modes for the 1992 DDC, therefore an intermediate load mode was used prior to entering the high load modes to provide time for the engine to reaching thermal equilibrium within the 2 minutes. Also, it was known prior to testing that a 6mode cycle would be desired to conserve fuel and time. Therefore, the first 6 modes of the created 13 mode cycle cover the idle section as well as the four corners and one point within the set point "box." 
The created 6-mode cycle includes the first 6 modes of the altered SET points. A smaller mode cycle that incorporated the spectrum of operating points from the SET was created due to limited time and fuel. Also, these modes could be compared to the first 6 modes of the 13-mode created cycle because they were completed in the same order, and therefore should obtain the same thermal history. The engine speed and load set points can be found in Appendix 8.1.

The 3-mode steady state cycle consisted of a segment of idle, a segment of intermediate speed at 50\% load, and a segment of rated speed at 50\% load. This short cycle was created to look at fuel consumption differences between additives and was again used to conserve time and fuel. These modes will be labeled A, B, and C to avoid confusion with the steady state modes used for the DDC testing. The set points can be found in Appendix 8.2.

The final cycle was created based on in-use data from a HMMWV driven over a fuel consumption course at the Aberdeen Proving Grounds [74]. The cycle was developed by grouping the frequency of set points at which the vehicle operated. Then

pieces of data were selected and placed together to create a dynamometer cycle that was statistically representative of the in-use data. This test cycle was termed as the Tactical Support cycle. Appendix 8.3 gives a detailed explanation on the creation of this cycle.

\subsection{Test Plan}

A test plan was designed to determine the effects the additives would have on a diesel engine. The availability of the test cell, engines, fuels, and additives were all taken into consideration. Initial research began with the 1999 Cummins engine in January 2009 and ended with testing of the 1998 AM General engine in May 2009.

The suggested application rates of each additive were used except on the 1992 DDC engine where 1.5 times the suggested rate was used due to results observed from previous testing. Table 4-1 shows the number of tests ran on each engine. 
Table 4-1 Testing for each Engine

\begin{tabular}{|c|c|c|c|c|c|c|}
\hline Engine & Base Fuel & $\begin{array}{l}\text { Testing } \\
\text { Month of } \\
2009\end{array}$ & Additive/Blend & $\begin{array}{l}\text { Number } \\
\text { of Hot } \\
\text { FTP } \\
\text { Tests }\end{array}$ & $\begin{array}{l}\text { Number of } \\
\text { Steady } \\
\text { State Tests }\end{array}$ & $\begin{array}{c}\text { Number } \\
\text { of } \\
\text { Tactical } \\
\text { Support } \\
\text { Tests }\end{array}$ \\
\hline \multirow[t]{4}{*}{1999 Cummins } & \multirow[t]{4}{*}{ Guttman } & \multirow[t]{4}{*}{ January } & Neat & 15 & 0 & 0 \\
\hline & & & $0.71 \mathrm{ml} / \mathrm{gal}$ Cerion 1 & 6 & 0 & 0 \\
\hline & & & 0.76 ml/gal H2Oil 1 & 5 & 0 & 0 \\
\hline & & & $0.76 \mathrm{ml} / \mathrm{gal}$ NanoBonus & 5 & 0 & 0 \\
\hline \multirow[t]{3}{*}{2004 Mack } & \multirow[t]{3}{*}{ Guttman } & \multirow[t]{3}{*}{ February } & Neat & 11 & 0 & 0 \\
\hline & & & $0.71 \mathrm{ml} / \mathrm{gal}$ Cerion 1 & 4 & 0 & 0 \\
\hline & & & $0.71 \mathrm{ml} / \mathrm{gal}$ Cerion 2 & 5 & 0 & 0 \\
\hline \multirow[t]{4}{*}{1992 DDC } & \multirow[t]{4}{*}{ Halt } & \multirow[t]{4}{*}{ March } & Neat & 13 & $6^{a}$ & 0 \\
\hline & & & $1.07 \mathrm{ml} / \mathrm{gal}$ Cerion 1 & 3 & $2^{b}$ & 0 \\
\hline & & & 1.14 ml/gal H2Oil 1 & 3 & $2^{a}$ & 0 \\
\hline & & & $1.14 \mathrm{ml} / \mathrm{gal}$ NanoBonus & 3 & $2^{b}$ & 0 \\
\hline \multirow[t]{4}{*}{1998 AM General } & \multirow[t]{4}{*}{ JP-8 } & \multirow[t]{4}{*}{ April/May } & Neat & 0 & $13^{c}$ & 9 \\
\hline & & & $0.71 \mathrm{ml} / \mathrm{gal}$ Cerion 1 & 0 & $3^{c}$ & 3 \\
\hline & & & 1.00 ml/gal H2Oil 2 & 0 & $3^{c}$ & 3 \\
\hline & & & $0.76 \mathrm{ml} / \mathrm{gal}$ NanoBonus & 0 & $3^{c}$ & 3 \\
\hline \multicolumn{7}{|c|}{$\begin{array}{l}\text { a - Includes both } 6 \text { mode and } 13 \text { mode steady state tests } \\
\text { b - } 6 \text { mode steady state tests } \\
\text { c- } 3 \text { mode steady state tests }(1-50, R-50, \text { Idle })\end{array}$} \\
\hline
\end{tabular}


The test plan in Table 4-1 shows the number and kind of tests ran on each engine as well as the additives used. For statistical analysis, the greater the sample size the more power the statistical test has. However, three hot-starts were chosen as the minimum required to compare emissions for transient tests (FTP, Tactical Support Cycle) for a single fuel. Baseline testing of the neat fuel was coupled with additive testing each day so that the emissions could be compared without day to day variation interfering with the results. In the case that the emission results were highly variable from run to run, additional hot-starts were run.

The steady-state testing was completed on the 1992 DDC to utilize the in-cylinder pressure measurement capabilities. Observing the in-cylinder pressure of steady-state operation, as opposed to transient operation, allows a better chance of deciphering differences in combustion of each type of fuel. The steady-state testing was completed on the 1998 AM General engine to give a different perspective on emissions and fuel consumption compared to the Tactical Support Cycle. Because the engine was mechanically controlled, repeatability of the fuel injector actuating cable position over transient testing is more difficult to obtain compared to steady-state testing. The additives used during testing were selected because of their availability at the time of testing. 


\section{Results}

The results have been presented based on transient test results and on steady-state test results. The overall objective of this work was to evaluate the effect of different additives on the fuel consumption and emissions from mechanically and electronically controlled heavy-duty engines. This objective was met by examining the fuel consumption and emissions changes through transient and steady state emissions evaluations. A secondary objective was to examine and evaluate the in-cylinder pressure data for one of these engines to discern changes in combustion phenomena. This was accomplished through steady state evaluation. For all additive evaluations, repeat testing was performed to provide an indication of statistical significance between the neat fuel and the addititized fuel. Note that not all additives were evaluated on all engines and that different neat fuels were used through this research effort.

\subsection{Transient Testing}

The transient testing consisted of FTP tests for the 1999 Cummins, 2004 Mack, and 1992 DDC and the Tactical Support Cycle for the 1998 AM General. At least three hot starts were completed for each additive and engine that was tested. A hot start is defined as a test cycle that was initiated following an engine off condition after a $20 \pm 1$ minute soak period from the prior test. In order to run the first hot start, a "warm" start test was executed to start the engine thermal aging history, however, the warm start emissions data were not reported. The results that follow are the averages of the combined hot starts for each particular fuel/engine combination. A statistical analysis was performed to uncover any effect on fuel consumption or emissions between the neat and additized fuels; the effectiveness of the additives against one another was not performed. Student's t-test with an alpha level of 0.05 was used to determine statistical significance between the means of the hot starts for a particular additive and the baseline. In other words, a p-value of 0.05 or less suggests that the averages of the two fuels being compared are not equal, rejecting the null hypothesis that the averages of the two fuels 
are not significantly different. In avoidance of a Type I error (rejecting the null hypothesis when it is actually true) the tests were analyzed further to see if day-to-day or run-to-run variation was affecting the difference.

\subsubsection{Fuel Consumption and Carbon Dioxide Emissions}

Determining the effect the additives had on fuel consumption was a main objective of this study. Thus fuel economy was obtained through two different methods. All the engines used the carbon balance method. This method used the carbon content in the exhaust analysis to determine the amount of fuel consumed. Knowing the fuel's hydrogen to carbon ratio and the $\mathrm{HC}, \mathrm{CO}_{2}$, and $\mathrm{CO}$ mass in the exhaust allowed calculation of the fuel consumption. The result of an uncertainty analysis showed that the maximum uncertainty for total fuel consumed by the DDC for an FTP is $0.52 \mathrm{lb}$ for testing on the part 86 tunnel. The uncertainty in the mass fuel consumed for the carbon balance method is a function of the uncertainties in the measurements of $\mathrm{HC}(2 \%), \mathrm{CO}_{2}$ (2\%), CO (2\%), and the fuels atomic hydrogen to carbon content (2\%). This is most likely an overestimate because it combines the maximum uncertainties in each measurement. Fuel consumption for the 1992 DDC was also measured using a fuel counter with a resolution of approximately 0.1 grams. The counter used the fuel's specific gravity and temperature to determine the fuel flow rate. The continuous fueling rate was then integrated to give the total fuel consumed during the test.

Figure 5-1and Figure 5-2 show the brake specific fuel consumption (BSFC) of the engines tested with the FTP and the Tactical Support Cycle, respectively. For each additive there is a baseline labeled "Neat" which is seen prior to the additive in the figures. The bars are one standard deviation of back-to-back repeat hot start tests. 


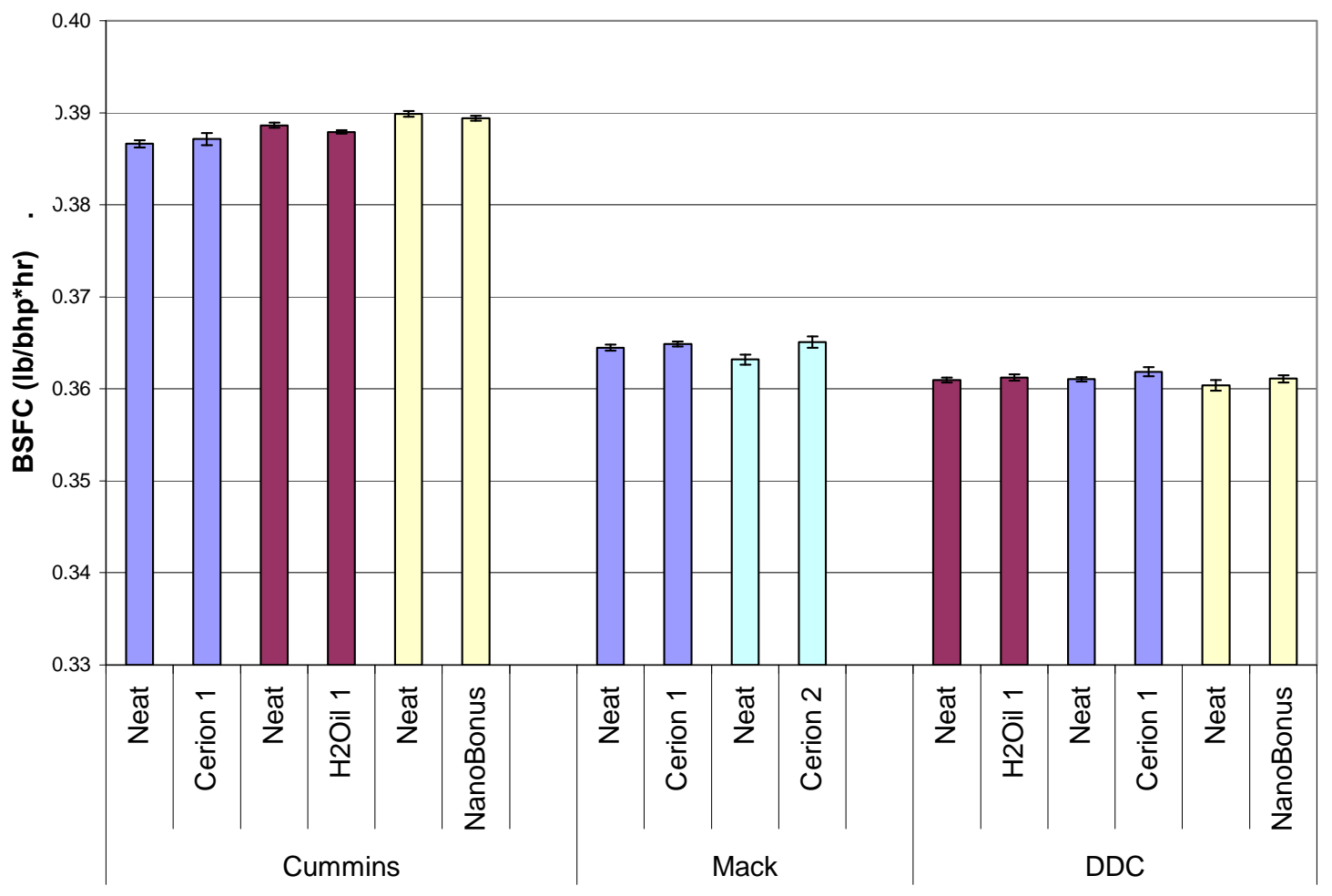

Figure 5-1 BSFC of Engines Tested Over the FTP 


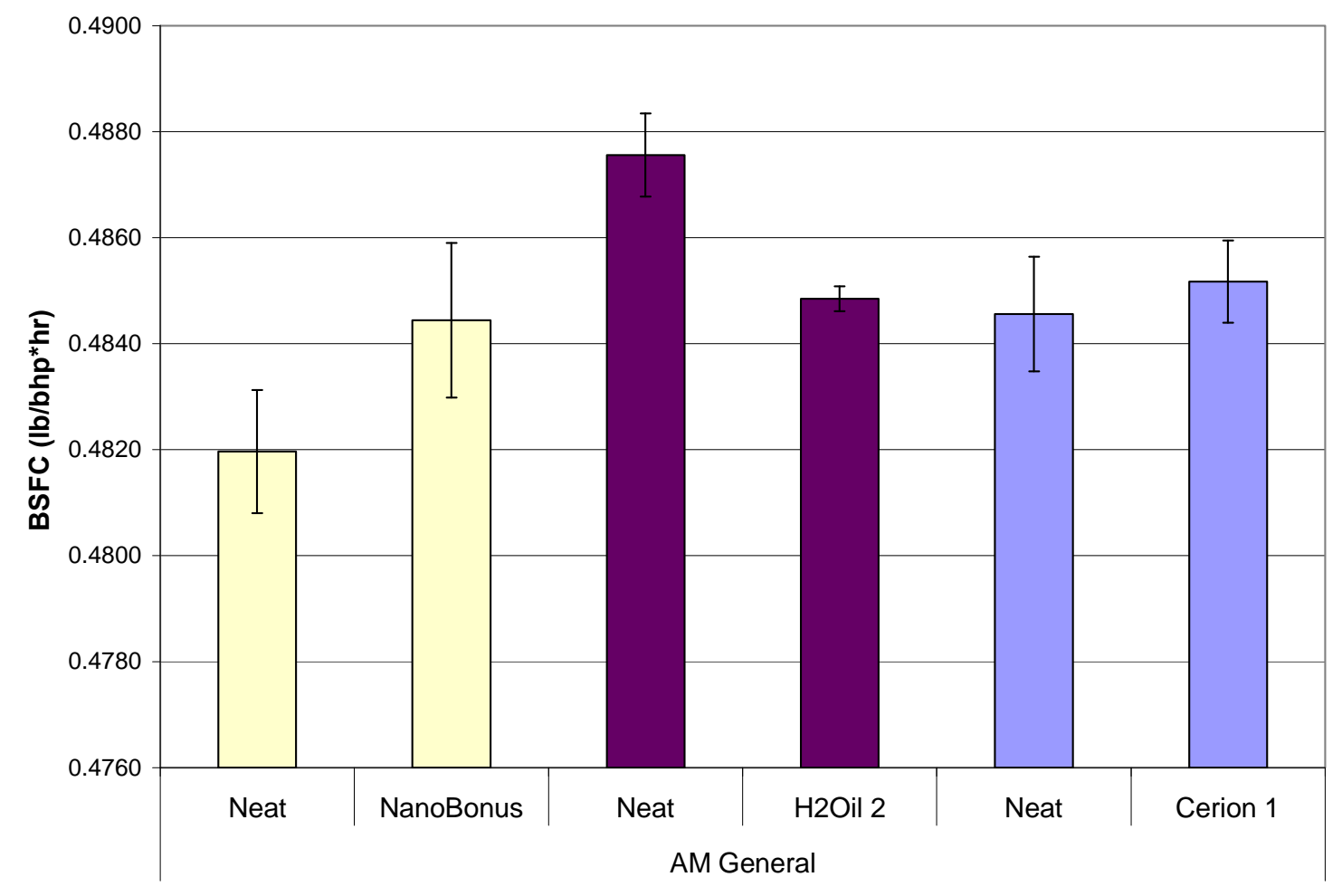

Figure 5-2 BSFC of AM General for Transient Testing

As is seen in Figure 5-2 there are day-to-day variations. For example, the baseline testing with NanoBonus had an average BSFC of $0.4820 \mathrm{lb} / \mathrm{bhp} * \mathrm{hr}$, whereas the baseline testing for H2Oil 2 was nearly $0.4880 \mathrm{lb} / \mathrm{bhp} * \mathrm{hr}$ (1.2\% difference). These variations were accounted for by testing baseline fuels with each additive. However, this was not always the case with the AM General testing. Along with the results presented herein, there were other cycles tested that were completed over the same time period. Baseline and additized fuels could not always be run on the same day due to the inconvenience of switching fuels between each test cycle. Therefore, when significant differences were identified from the AM General engine, the test day was noted.

Figure 5-3 shows the percentage change in brake specific fuel consumption for all the additives with their respective baselines using the carbon balance method. For all the accompanying bar charts, diagonal lines across the bars (cross-hatched lines) indicate changes that were statistically different according to Student's t-test. 


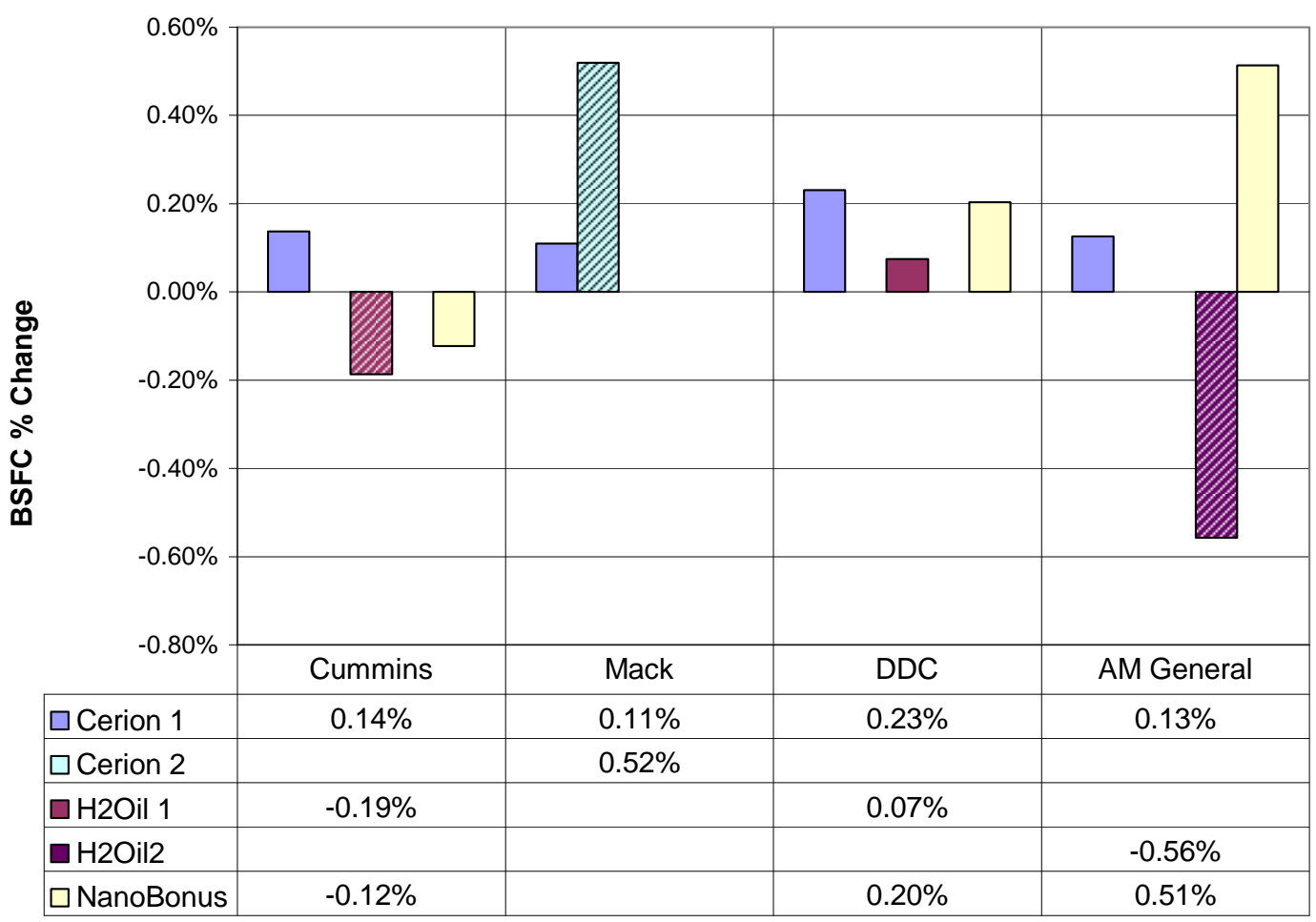

Figure 5-3 Percent Change in BSFC from Baseline

The greatest differences from the baselines occurred with Cerion $2(+0.52 \%)$, with the Mack, and H2Oil 2 (-0.56\%) and NanoBonus (+0.51\%), with the AM General. Table 5-1 shows the p-values from Student's t-test. 
Table 5-1 p-values for Student's t-test for BSFC

\begin{tabular}{|l|l|c|}
\hline Engine & Additive & p-value \\
\hline 1999 Cummins & Cerion 1 & 0.254 \\
\cline { 2 - 3 } & H2Oil 1 & $\mathbf{0 . 0 0 4}$ \\
\cline { 2 - 3 } & NanoBonus & 0.060 \\
\cline { 2 - 3 } & \multicolumn{2}{|c|}{} \\
\hline 2004 Mack & Cerion 1 & 0.112 \\
\cline { 2 - 3 } & Cerion 2 & $\mathbf{0 . 0 0 2}$ \\
\cline { 2 - 3 } & \multicolumn{2}{|}{} \\
\hline 1992 DDC & H2Oil 2 & 0.345 \\
\cline { 2 - 3 } & Cerion 1 & 0.062 \\
\cline { 2 - 3 } & NanoBonus & 0.142 \\
\cline { 2 - 3 } & \multicolumn{2}{|}{} \\
\hline \multirow{3}{*}{$\begin{array}{l}\text { 1998 AM } \\
\text { General }\end{array}$} & NanoBonus & 0.083 \\
\cline { 2 - 3 } & H2Oil 2 & $\mathbf{0 . 0 0 5}$ \\
\cline { 2 - 3 } & Cerion 1 & 0.470 \\
\hline
\end{tabular}

Values listed in bold in Table 5-1 indicate p-values less than the predetermined alpha value of 0.05 . H2Oil 1 showed a $0.19 \%$ decrease in fuel consumption, for the Cummins testing, and H2Oil 2 showed a 0.56\% decrease, for the AM General testing. Cerion 2 showed a $0.52 \%$ increase in fuel consumption with testing of the Mack engine. These values are considered statistically significant based on the t-test. However, such small changes may not prove that the additives, in fact, altered the fuel consumption. The baseline testing and H2Oil 1 testing on the Cummins had variations of $0.15 \%$ and $0.10 \%$ between their respective maximum and minimum measurements. The combination of these variations adds up to more than the observed difference in fuel consumption with the additive ( $0.25 \%$ variation compared to $0.19 \%$ difference in fuel consumption). This also occurred with Cerion 2 with its baseline on the Mack engine $(0.77 \%$ variation compared to $0.52 \%$ difference in fuel consumption). The variation analysis is found in Appendix 8.4.

The one additive that distinctively showed significant difference in bsfc was H2Oil 2 with a $0.56 \%$ reduction (from 0.4876 to $0.4848 \mathrm{lb} / \mathrm{bhp} * \mathrm{hr}$ ) on the AM General 
engine. The baseline tests were run two days prior to testing of the additive which could account for some of the difference.

Carbon dioxide emissions are an indicator of fuel consumption as was the case during this testing. Figure 5-4 shows the percent change in $\mathrm{bsCO}_{2}$ emissions from the baseline testing.

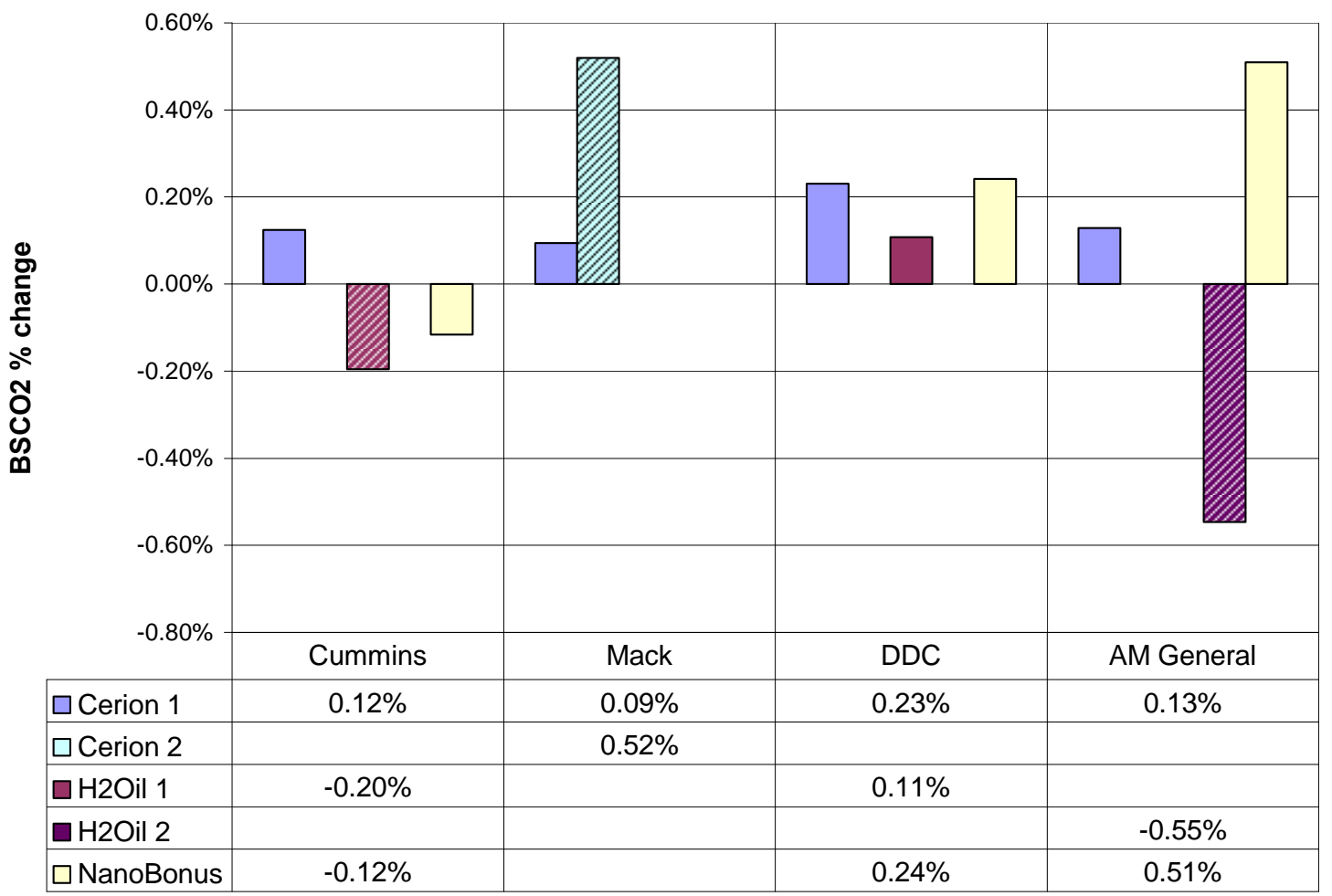

Figure 5-4 Percent Change in $\mathrm{BSCO}_{2}$ Emissions from Baseline

If Figure 5-3 and Figure 5-4 were overlaid they would appear nearly identical, as the difference between bsfc percent change and $\mathrm{bsCO}_{2}$ percent change for any one test did not vary more than $0.04 \%$. The results of Student's t-test were also similar for the $\mathrm{CO}_{2}$ as can be seen in Table 5-2, which shows the bsfc results for comparison. 
Table 5-2 p-values for Student's t-test for $\mathrm{BSCO}_{2}$ and BSFC

\begin{tabular}{|c|c|c|c|}
\hline Engine & Additive & $\begin{array}{c}\text { p-value for } \\
\mathrm{CO}_{2}\end{array}$ & $\begin{array}{c}\text { p-value for } \\
\text { BSFC }\end{array}$ \\
\hline \multirow[t]{3}{*}{1999 Cummins } & Cerion 1 & 0.288 & 0.254 \\
\hline & H2Oil 1 & 0.003 & 0.004 \\
\hline & NanoBonus & 0.074 & 0.060 \\
\hline \multirow{2}{*}{2004 Mack } & Cerion 1 & 0.131 & 0.112 \\
\hline & Cerion 2 & 0.002 & 0.002 \\
\hline \multirow[t]{3}{*}{1992 DDC } & H2Oil 1 & 0.277 & 0.345 \\
\hline & Cerion 1 & 0.062 & 0.062 \\
\hline & NanoBonus & 0.090 & 0.142 \\
\hline \multirow[t]{3}{*}{$\begin{array}{l}1998 \text { AM } \\
\text { General }\end{array}$} & NanoBonus & 0.082 & 0.083 \\
\hline & H2Oil 2 & 0.005 & 0.005 \\
\hline & Cerion 1 & 0.456 & 0.470 \\
\hline
\end{tabular}

As can be seen from Table 5-2 the results for statistical significance are nearly the same. The discussion about the test-to-test variation for H2Oil 1 and Cerion 2 being greater than the difference in fuel consumption for baselines also applies for the $\mathrm{CO}_{2}$ emissions. With that argument, H2Oil 2 used with the AM General engine was the only significant difference (0.55\% reduction) for $\mathrm{CO}_{2}$ emissions.

\subsubsection{Oxides of Nitrogen Emissions}

All $\mathrm{NO}_{\mathrm{x}}$ emissions were analyzed together as opposed to separating $\mathrm{NO}$ and $\mathrm{NO}_{2}$. Although $\mathrm{NO}_{\mathrm{x}}$ includes other compounds, other oxides of nitrogen were not documented. The percent difference in $\mathrm{bsNO}_{\mathrm{x}}$ emissions from the baselines are shown in Figure 5-5 and the accompanying p-values are found in Table 5-3. For the Cummins engine, H2Oil 1 showed a $0.33 \%$ reduction and NanoBonus showed a $0.40 \%$ increase in $\mathrm{NO}_{\mathrm{x}}$ emissions which were both significantly different. Cerion 1 showed a significant increase, 3.46\%, in $\mathrm{NO}_{\mathrm{x}}$ compared to the baselines for the AM General. All three significantly different averages however, had combined variations between their baselines and additive tests greater than the reduction or increase observed. This is shown in Table 5-4. 


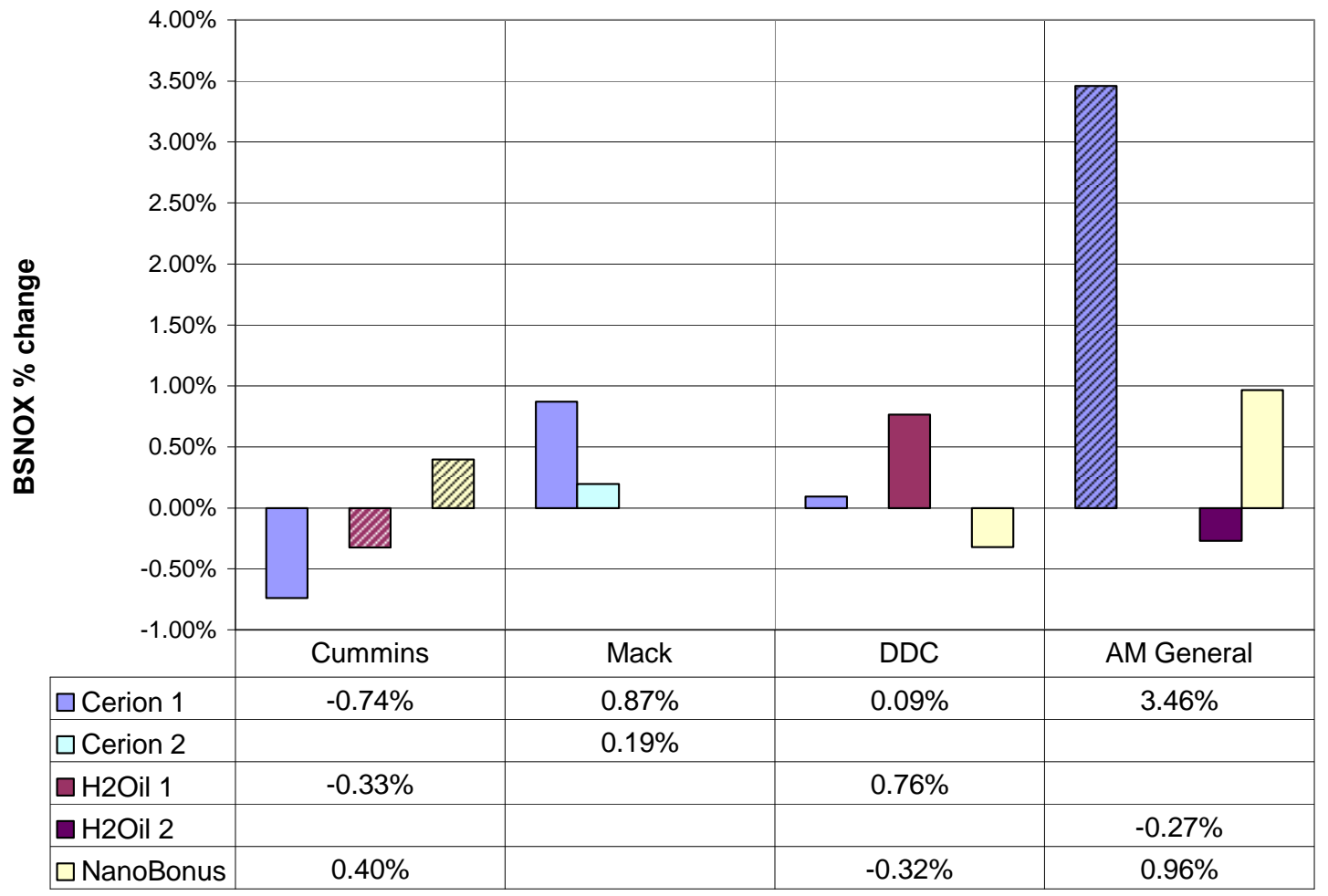

Figure 5-5 Percent Change in BSNOx Emissions from Baseline

Table 5-3 p-values for Student's t-test for $\mathrm{NO}_{\mathrm{x}}$

\begin{tabular}{|l|l|c|}
\hline Engine & Additive & p-value \\
\hline 1999 Cummins & Cerion 1 & 0.054 \\
\cline { 2 - 3 } & H2Oil 1 & $\mathbf{0 . 0 3 8}$ \\
\cline { 2 - 3 } & NanoBonus & $\mathbf{0 . 0 4 2}$ \\
\cline { 2 - 3 } & \multicolumn{2}{|}{} \\
\hline 2004 Mack & Cerion 1 & 0.351 \\
\cline { 2 - 3 } & Cerion 2 & 0.813 \\
\cline { 2 - 3 } & \multicolumn{2}{|}{} \\
\hline 1992 DDC & H2Oil 1 & 0.144 \\
\cline { 2 - 3 } & Cerion 1 & 0.643 \\
\cline { 2 - 3 } & NanoBonus & 0.323 \\
\cline { 2 - 3 } & \multicolumn{2}{|}{} \\
\hline 1998 AM & NanoBonus & 0.605 \\
\cline { 2 - 3 } General & H2Oil 2 & 0.600 \\
\cline { 2 - 3 } & Cerion 1 & $\mathbf{0 . 0 2 0}$ \\
\hline
\end{tabular}


Table 5-4 Comparison of Change in $\mathrm{BSNO}_{\mathrm{x}}$ with Variations Between Test-to-Test

\begin{tabular}{|l|l|c|c|}
\hline \multirow{3}{*}{ Engine } & Additive & $\begin{array}{c}\text { Difference in } \\
\text { Average }\end{array}$ & $\begin{array}{c}\text { Combined } \\
\text { Variations }\end{array}$ \\
\hline \multirow{2}{*}{ 1999 Cummins } & H2Oil 1 & $-0.33 \%$ & $0.72 \%$ \\
\cline { 2 - 4 } & NanoBonus & $0.40 \%$ & $0.95 \%$ \\
\cline { 2 - 4 } & \multicolumn{3}{|c|}{} \\
\hline 1998 AM General & Cerion 1 & $3.46 \%$ & $4.25 \%$ \\
\hline
\end{tabular}

\subsubsection{Carbon Monoxide}

The change in bsCO from the baseline tests are shown in Figure 5-6, and their respective p-values are shown in Table 5-5. As can be seen in Table 5-5, all but four sets of tests showed significant difference from their respective baseline tests. Reductions were seen with Cerion 1 and H2Oil 1 with the Cummins, NanoBonus with the DDC, and H2Oil 2 with the AM General. Table 5-6 shows that for nearly all of the tests, the combined variations were greater than the differences between neat and additized fuels. The bold values indicate a significantly different average based on the Student's t-test. Apart from the health effects associated with CO, CO levels have been shown to be a useful indicator to PM trends [72,73]; PM is discussed below. 


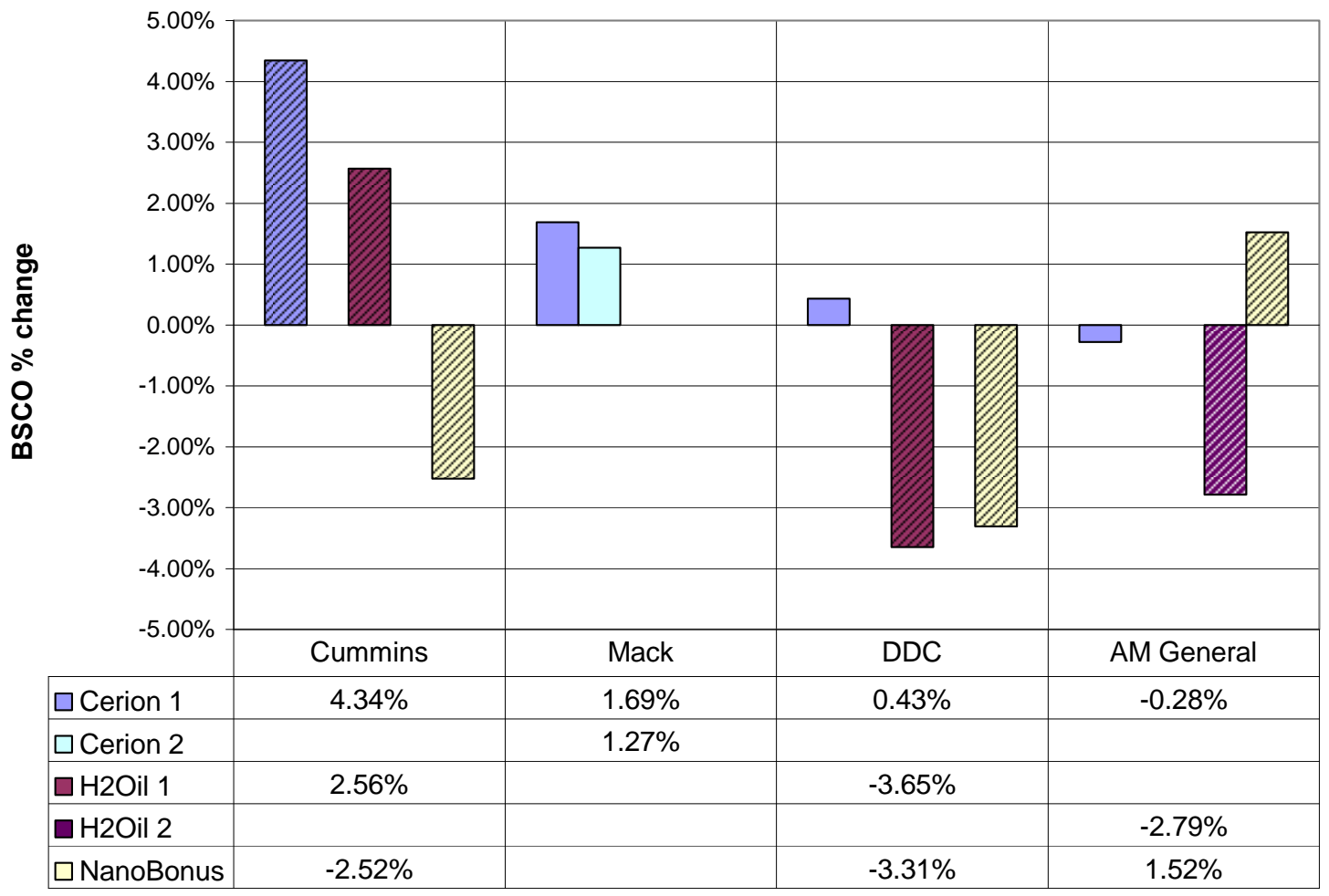

Figure 5-6 Percent Change in BSCO Emissions from Baseline

Table 5-5 p-values for Student's t-test for CO

\begin{tabular}{|l|l|c|}
\hline Engine & Additive & p-value \\
\hline 1999 Cummins & Cerion 1 & $\mathbf{0 . 0 1 0}$ \\
\cline { 2 - 3 } & H2Oil 1 & $\mathbf{0 . 0 0 1}$ \\
\cline { 2 - 3 } & NanoBonus & $\mathbf{0 . 0 1 1}$ \\
\cline { 2 - 3 } & \multicolumn{2}{|}{} \\
\hline 2004 Mack & Cerion 1 & 0.094 \\
\cline { 2 - 3 } & Cerion 2 & 0.458 \\
\cline { 2 - 3 } & \multicolumn{2}{|}{} \\
\hline 1992 DDC & H2Oil 1 & $\mathbf{0 . 0 4 1}$ \\
\cline { 2 - 3 } & Cerion 1 & 0.536 \\
\cline { 2 - 3 } & NanoBonus & $\mathbf{0 . 0 1 4}$ \\
\cline { 2 - 3 } & \multicolumn{2}{|}{} \\
\hline 1998 AM & NanoBonus & 0.402 \\
\cline { 2 - 3 } General & H2Oil 2 & $\mathbf{0 . 0 2 2}$ \\
\cline { 2 - 3 } & Cerion 1 & 0.852 \\
\hline
\end{tabular}


Table 5-6 Comparison of Change in BSCO with Variations Between Test-to-Test

\begin{tabular}{|c|c|c|c|}
\hline Engine & Additive & $\begin{array}{c}\text { Difference in } \\
\text { Average }\end{array}$ & $\begin{array}{l}\text { Combined } \\
\text { Variations }\end{array}$ \\
\hline \multirow[t]{3}{*}{1999 Cummins } & Cerion 1 & $4.34 \%$ & $5.28 \%$ \\
\hline & H2Oil 1 & $2.56 \%$ & $2.46 \%$ \\
\hline & NanoBonus & $-2.52 \%$ & $4.18 \%$ \\
\hline \multirow[t]{2}{*}{2004 Mack } & Cerion 1 & $1.69 \%$ & $4.96 \%$ \\
\hline & Cerion 2 & $1.27 \%$ & $11.30 \%$ \\
\hline \multirow[t]{3}{*}{1992 DDC } & H2Oil 1 & $-3.65 \%$ & $5.40 \%$ \\
\hline & Cerion 1 & $0.43 \%$ & $2.62 \%$ \\
\hline & NanoBonus & $-3.31 \%$ & $3.85 \%$ \\
\hline \multirow[t]{3}{*}{$\begin{array}{l}1998 \text { AM } \\
\text { General }\end{array}$} & NanoBonus & $1.52 \%$ & $6.89 \%$ \\
\hline & H2Oil 2 & $-2.79 \%$ & $3.52 \%$ \\
\hline & Cerion 1 & $-0.28 \%$ & $6.17 \%$ \\
\hline
\end{tabular}

\subsubsection{Particulate Matter}

Figure 5-7 shows percent change in bsPM emissions from the respective baseline tests. The only tests that showed a significant change in PM emissions were NanoBonus on the DDC, with a 5.19\% reduction, and Cerion 1 on the AM General, with a $7.47 \%$ increase. The PM gravimetric collection method inherently has higher variability due to the nature of PM formation, sampling nuances, methodology, and the number of human variables involved with handling and weighing filters. Table 5-7 shows the p-values from the Student's t-test. Assuming the PM measurement techniques employed in this work is an indicator of visible soot levels, a decrease in visible soot levels is desired from a tactical standpoint so as to minimize visible recognition from enemy forces. Therefore, an additive that reduces visible soot would provide additional protection to the personnel. However, it is recognized that this is a simplistic assessment and that the makeup of the exhaust plume, and methods to recognize it, are beyond this thesis. 


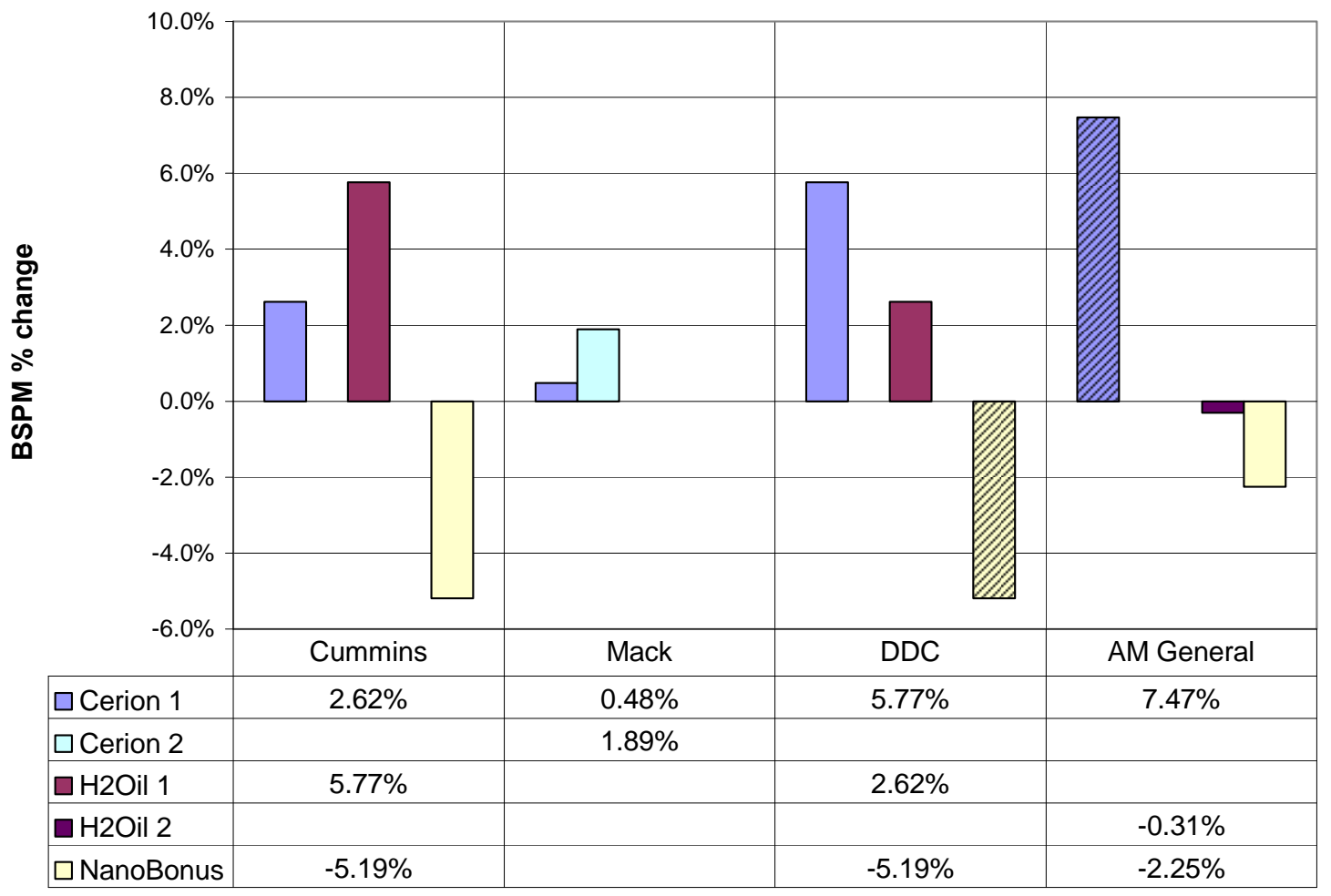

Figure 5-7 Percent Change in BSPM from Baseline

Table 5-7 p-values for Student's t-test for PM

\begin{tabular}{|l|l|c|}
\hline Engine & Additive & p-value \\
\hline 1999 Cummins & Cerion 1 & 0.620 \\
\cline { 2 - 3 } & H2Oil 1 & 0.067 \\
\cline { 2 - 3 } & NanoBonus & 0.238 \\
\cline { 2 - 3 } & \multicolumn{2}{|c|}{} \\
\hline 2004 Mack & Cerion 1 & 0.826 \\
\cline { 2 - 3 } & Cerion 2 & 0.617 \\
\cline { 2 - 3 } & \multicolumn{2}{|}{} \\
\hline 1992 DDC & H2Oil 1 & 0.201 \\
\cline { 2 - 3 } & Cerion 1 & 0.204 \\
\cline { 2 - 3 } & NanoBonus & $\mathbf{0 . 0 1 0}$ \\
\cline { 2 - 3 } & \multicolumn{2}{|}{} \\
\hline 1998 AM & NanoBonus & 0.595 \\
\hline General & H2Oil 2 & 0.931 \\
\cline { 2 - 3 } & Cerion 1 & $\mathbf{0 . 0 2 6}$ \\
\hline
\end{tabular}


As can be seen from Table 5-7, the only additives that had a significant difference was NanoBonus, on the DDC, and Cerion 1, on the AM General with p-values of 0.010 and 0.026 , respectively. H2Oil $1(\mathrm{p}=0.067)$ on the Cummins had a $\mathrm{p}$-value near the predetermined significance level of 0.05 .

From run-to-run within the same test fuel, PM and $\mathrm{CO}$ had a positive correlation for most fuels for each engine. Figure 5-8 shows this relationship for the DDC. Appendix 8.4.2 shows plots of bsPM versus bsCO for the other 3 engines.

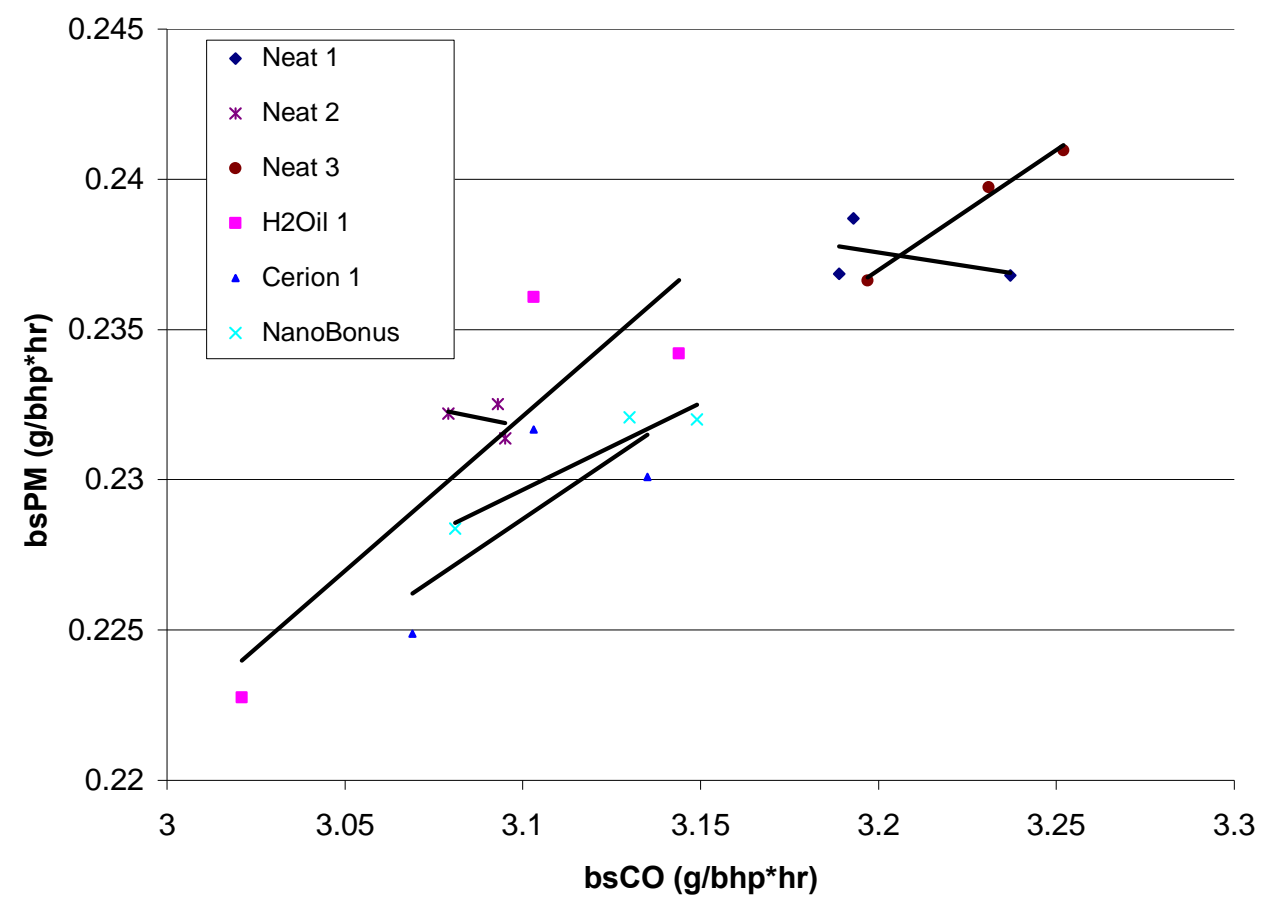

Figure 5-8 PM-CO Trend for DDC Transient Testing

This relationship does not consistently occur, however, when considering a change attributed to an additive. For example, H2Oil 1 for the DDC showed an increase in bsPM (+2.62\%) and a decrease in bsCO (-3.65\%) from the baseline. This contradiction to the PM-CO positive correlation existed for AM General testing of 
NanoBonus and Cerion 1. Table 8-10 shows the percent changes in bsPM and bsCO for all the transient testing.

\subsubsection{Hydrocarbons}

Figure 5-9 shows the percent change in bsTHC from the respective baseline tests and Table 5-8 shows the p-values from Student's t-test. Table 5-8 shows that six additive tests appeared to have a significant difference in THC emissions. The variation analysis shows that only Cerion 1 on the Cummins (2.44\% increase in bsTHC) proved to have a larger change in bsTHC between the baseline than the variation between each individual test. Cerion 1 also showed a significant difference with the Mack, according to Student's t-test. However, the variation analysis shows that this may not be significant.

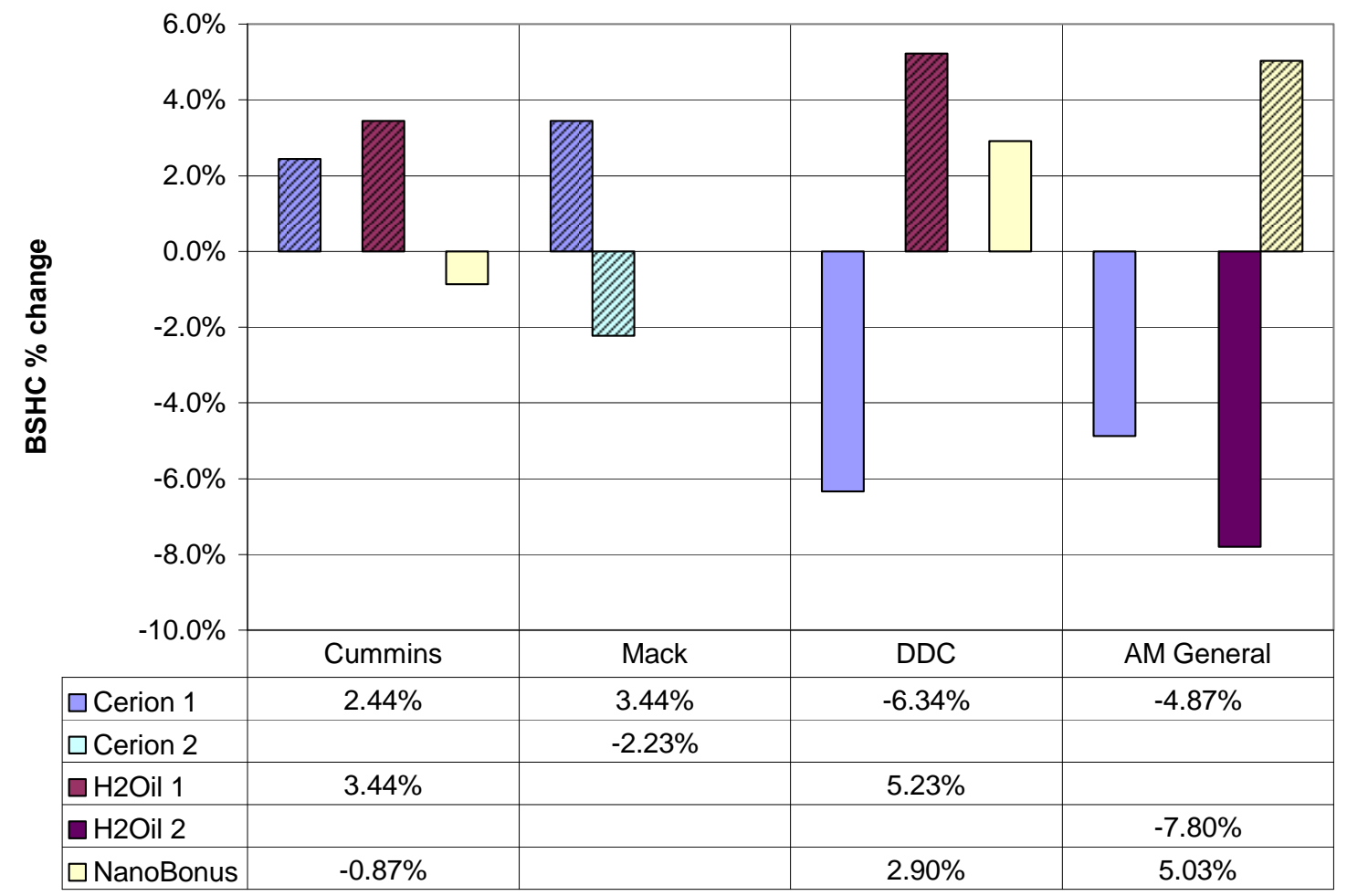

Figure 5-9 Percent Change in BSTHC Emissions from Baseline 
Table 5-8 p-values for Student's t-test for THC

\begin{tabular}{|l|l|r|}
\hline Engine & Additive & p-value \\
\hline 1999 Cummins & Cerion 1 & $\mathbf{0 . 0 0 0}$ \\
\cline { 2 - 3 } & H2Oil 1 & $\mathbf{0 . 0 2 7}$ \\
\cline { 2 - 3 } & NanoBonus & 0.497 \\
\cline { 2 - 3 } & \multicolumn{2}{|}{} \\
\hline 2004 Mack & Cerion 1 & $\mathbf{0 . 0 9 3}$ \\
\cline { 2 - 3 } & Cerion 2 & $\mathbf{0 . 0 3 0}$ \\
\cline { 2 - 3 } & \multicolumn{2}{|}{} \\
\hline 1992 DDC & H2Oil 1 & $\mathbf{0 . 0 2 3}$ \\
\cline { 2 - 3 } & Cerion 1 & 0.149 \\
\cline { 2 - 3 } & NanoBonus & 0.156 \\
\cline { 2 - 3 } & \multicolumn{2}{|}{} \\
\hline 1998 AM & NanoBonus & $\mathbf{0 . 2 0 9}$ \\
\cline { 2 - 3 } General & H2Oil 2 & 0.136 \\
\cline { 2 - 3 } & Cerion 1 & 0.163 \\
\hline
\end{tabular}

\subsection{Steady-State Testing}

Steady-state testing was completed on the 1992 DDC and the 1998 AM General engines. Both engines were tested over different cycles explained in Section 4.6. The set points for DDC testing can be found in Table 8-1 and Table 8-2, and the set points for the AM General testing can be found in Table 8-3. The goal for this testing was, again, to determine any effect the additives had on fuel consumption and emissions. For the DDC testing, the emissions provided a "macroscopic" analysis of the additives, while the incylinder pressure data provided a "microscopic” analysis. Wherever possible, a Student's t-test was completed to help determine statistical difference between the additives and their baseline tests. Whenever sufficient data was not available due to the limited number of tests, the results were plotted with standard deviation bars to aid in determining a difference.

\subsubsection{AM General}

\subsubsection{Fuel Consumption}

The fuel consumption during each mode was calculated with the carbon balance method and the percent change from the baseline for modes A and B can be found in 
Figure 5-10 and their accompanying p-values in Table 5-9. Note that mode A was intermediate speed with 50\% load (1826 rpm, $176 \mathrm{ft}-\mathrm{lb}$ ) and mode B was rated speed with $100 \%$ load (3471 rpm, $137 \mathrm{ft}-\mathrm{lb}$ ).

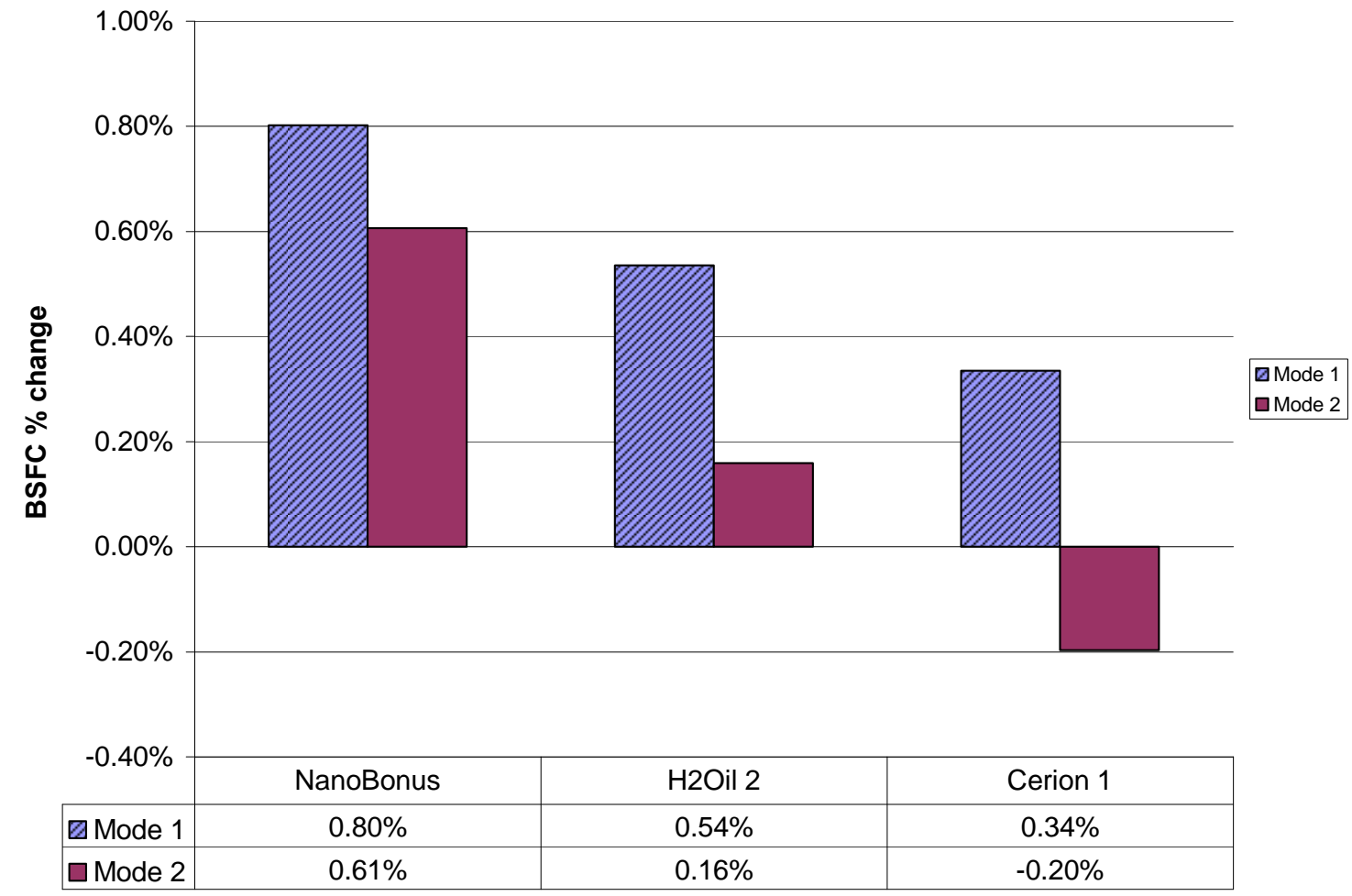

Figure 5-10 Percent Change in BSFC from Baseline for AM General Steady State

Table 5-9 p-values for BSFC of AM General Steady-State

\begin{tabular}{|l|r|c|}
\hline Additive & Mode A & Mode B \\
\hline NanoBonus & $\mathbf{0 . 0 3 9}$ & 0.289 \\
\hline H2Oil 2 & $\mathbf{0 . 0 2 1}$ & 0.659 \\
\hline Cerion 1 & $\mathbf{0 . 0 4 4}$ & 0.380 \\
\hline
\end{tabular}

Figure 5-10 shows that all three additives increased the fuel consumption except for Cerion 1, in mode B. All three additives in mode 1 showed a significant increase in bsfc from their respective baselines, the greatest being NanoBonus with a $0.80 \%$ increase. The transient testing showed an increase in bsfc for NanoBonus and Cerion 1 which agrees with these steady-state results. However, H2Oil 2 showed a significant 
decrease in the transient testing (0.56\% reduction), whereas, an increase was seen in the steady-state testing $(0.54 \%$ increase), difference being that the increase may not be statistically significant because the variations from test to test were at the same magnitude as the bsfc increase observed. The variation results of the steady state testing are found in Appendix 8.5.

\subsubsection{Emissions}

Carbon dioxide emissions, as expected, reflected the bsfc results. All three additives increased the $\mathrm{bsCO}_{2}$ in mode $\mathrm{A}$ and no significant difference was seen in mode B for any additive. As with the bsfc, the reduction with Cerion 1 during mode $\mathrm{C}$ was greater than the variations for $\mathrm{H} 2 \mathrm{Oil}$ and its baseline. The steady state $\mathrm{bsCO}_{2}$ results can be found in Appendix 8.5.2.

There were no significant differences between the additives and their baselines for $\mathrm{bsNO}_{\mathrm{x}}$ emissions. With a p-value of 0.058 , Cerion 1 was nearly significant showing an increase of $4.13 \%$ in mode B. The transient testing was somewhat similar in that Cerion 1 showed a statistically significant increase in $\mathrm{NO}_{\mathrm{x}}(+3.46 \%$, p-value $=0.020)$. The steady state $\mathrm{bsNO}_{\mathrm{x}}$ results can be found in Appendix 8.5.3.

Cerion 1 showed a significant difference in bsCO emissions with a 22\% increase in mode 2 , the $3.46 \%$ increase in mode 1 was not statistically different. The transient testing showed no difference with the Cerion 1 additive. It should be noted that there was high variability in $\mathrm{CO}$ emissions during mode $\mathrm{B}$, exemplified by the fact that NanoBonus showed an $18.29 \%$ decrease in bsCO and was not considered statistically significant. This can be seen in Figure 8-12 by noticing the large bars in the results for mode B, and again in the variation results found in Table 8-18. The steady state bsCO results can be found in Appendix 8.5.4.

The only significant difference found in bsPM for the steady state testing was an 11.94\% reduction using NanoBonus during mode B. There were only 2 valid PM samples from each of the three tests ran for both the NanoBonus and the baseline. With only 2 valid tests for each, it is difficult to clearly say that the additive made a significant reduction in PM. NanoBonus also showed a 2.26\% reduction in PM with the transient 
testing, however this was not a statistically significant difference. The steady state bsPM results can be found in Appendix 8.5.5

There were no significant differences in bsHC emissions for any additive or mode for the steady-state testing of the AM General engine. Again, this may be the result of the high variability from test-to-test due to low concentrations. For example, NanoBonus showed a 14.28\% increase in bsHC during mode 1, but this was not considered statistically significant. The transient testing showed a significant 5.03\% increase in bsHC for NanoBonus. The steady-state bsHC results can be found in Appendix 8.5.6.

\subsubsection{Detroit Diesel Series 60}

The steady-state testing of the DDC consisted of both a 13 mode arrangement of the SET test and the first 6 modes of the same test. Only 6 mode test results are presented, as the 13 mode test was not conducted for all additives. Listings of the set points for these tests are shown in Appendix 8.1. Emissions and in-cylinder pressure data were collected over each test to try and discern any difference between the additives and the baseline fuel. Two valid steady-state tests did not exist for Cerion 1 or for its baseline testing.

\subsubsection{Fuel Consumption}

The bsfc was averaged over two tests for both the additive and its respective baseline test. Figure 5-11 shows the percent change in bsfc from the baseline tests. The crosshatches on the bars represent averages that are significantly different from their baselines. Note that Mode 1, idle, is not present here due to low resolution afforded by the sampling system; the sampling system was configured to provide maximum full scale values under the highest emissions production, and idle emissions suffer because of this. It is recognized that two tests are not optimal for performing a statistical comparison but only two tests could be performed in light of available resources allocated for this program. 


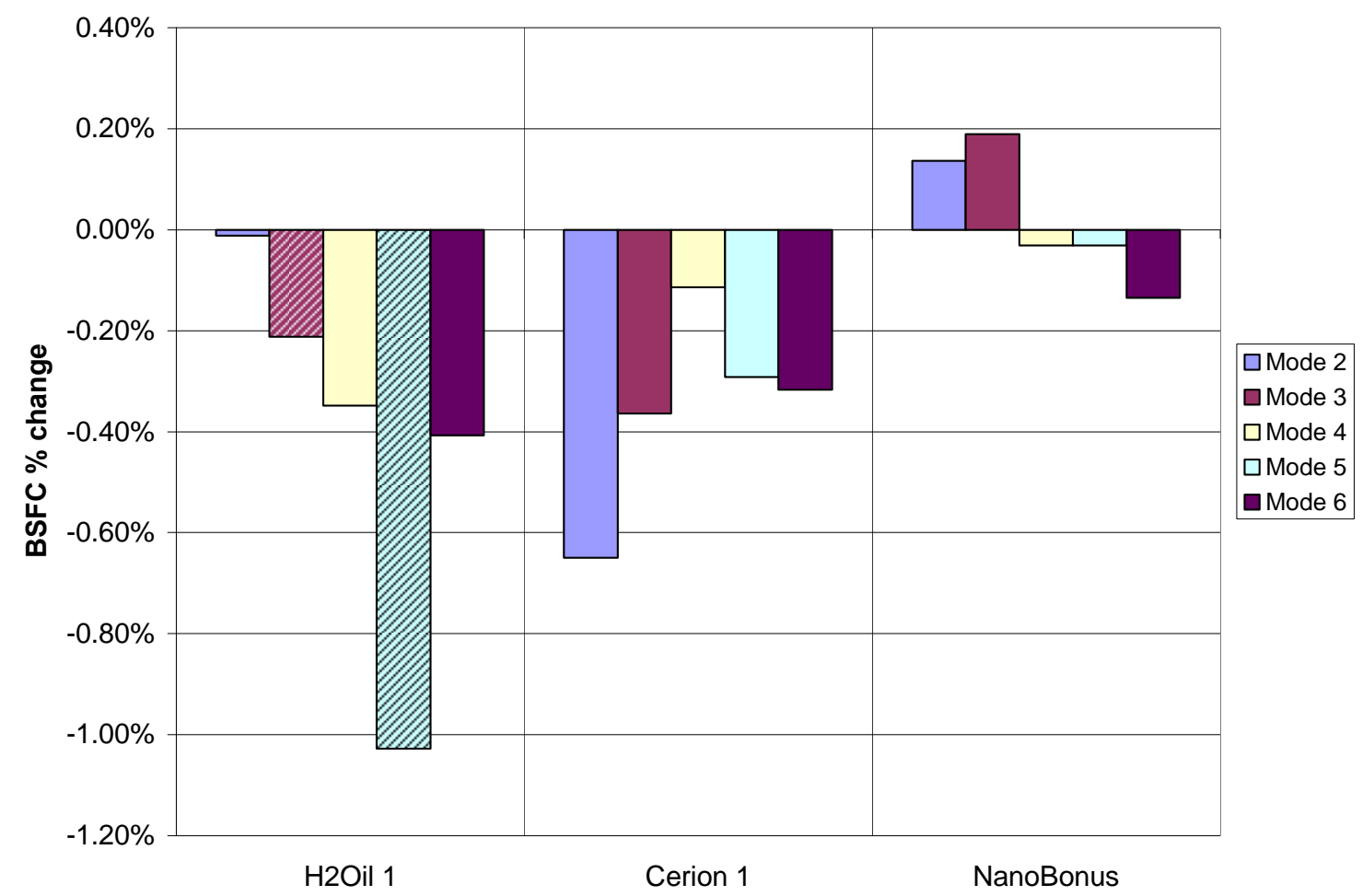

Figure 5-11 Percent Change in BSFC from Baseline for DDC Steady-State

It can be seen from Figure 5-11 that H2Oil 1 was the only additive to show a significant change in fuel consumption. In modes 3 and 5 it reduced the bsfc by $0.21 \%$ and $1.03 \%$, respectively. Mode 3 was at $1420 \mathrm{rpm}$ at 50\% load and mode 5 at $1644 \mathrm{rpm}$ at $25 \%$ load. The additive did not appear to show a significant effect on higher power modes. NanoBonus did not show any significant change in bsfc over the 6 modes. The Student t-test could not be used on Cerion 1, because only 1 valid run was available for it and its baseline. However, if the combined variations for NanoBonus and its baseline for each mode are used as a simple threshold for significance, it appears that Cerion 1 may have an effect. Mode 3 shows a reduction of $0.36 \%$ in bsfc while the variations for NanoBonus were $0.22 \%$. Mode 3 was the only instance of this scenario. The results of Student's t-test are shown in Table 5-10, and the averages and variations are found in Table 5-11. Appendix 8.5.1 shows the modes plotted with modes 2 and 5 grouped together and modes 3, 4, and 6 together. The bars for Cerion 1 came from the NanoBonus results to give some perspective in the magnitude of variation. 
Table 5-10 p-values for BSFC of DDC Steady-State

\begin{tabular}{|l|c|c|c|c|c|}
\hline Additive & Mode 2 & Mode 3 & Mode 4 & Mode 5 & Mode 6 \\
\hline H2Oil 1 & 0.964 & $\mathbf{0 . 0 3 1}$ & 0.367 & $\mathbf{0 . 0 3 1}$ & 0.348 \\
\hline Cerion 1 & - & - & - & - & - \\
\hline NanoBonus & 0.649 & 0.133 & 0.878 & 0.923 & 0.188 \\
\hline
\end{tabular}

Table 5-11 Comparison of Change in BSFC with Variations Between Test-to-Test

\begin{tabular}{|l|l|c|c|}
\hline & & $\begin{array}{c}\text { Difference from } \\
\text { Baseline }\end{array}$ & $\begin{array}{c}\text { Combined } \\
\text { Variations }\end{array}$ \\
\hline Mode 2 & H2Oil 1 & $-0.01 \%$ & $0.56 \%$ \\
\hline & Cerion 1 & $-0.65 \%$ & - \\
\hline & NanoBonus & $0.14 \%$ & $0.70 \%$ \\
\hline Mode 3 & H2Oil 1 & $-0.21 \%$ & $0.11 \%$ \\
\hline & Cerion 1 & $-0.36 \%$ & - \\
\hline & NanoBonus & $0.19 \%$ & $0.22 \%$ \\
\hline & & & \\
\hline Mode 4 & H2Oil 1 & $-0.35 \%$ & $0.74 \%$ \\
\hline & Cerion 1 & $-0.11 \%$ & - \\
\hline & NanoBonus & $-0.03 \%$ & $0.40 \%$ \\
\hline & & & \\
\hline Mode 5 & H2Oil 1 & $-1.03 \%$ & $0.53 \%$ \\
\hline & Cerion 1 & $-0.29 \%$ & - \\
\hline & NanoBonus & $-0.03 \%$ & $0.82 \%$ \\
\hline & & & \\
\hline Mode 6 & H2Oil 1 & $-0.41 \%$ & $0.67 \%$ \\
\hline & Cerion 1 & $-0.32 \%$ & - \\
\hline & NanoBonus & $-0.14 \%$ & $0.18 \%$ \\
\hline
\end{tabular}

\subsubsection{Emissions}

Carbon dioxide emissions reflected that of the fuel consumption results, that is H2Oil 1 showing reductions of $0.16 \%$ and $1.03 \%$ in modes 3 and 5, respectively. Also, Cerion 1 showed a reduction of $0.33 \%$ in mode 3 where the variations were only $0.25 \%$. The data and plots of the $\mathrm{CO}_{2}$ analysis can be found in Appendix 8.5.7. 
H2Oil 1 also was the only additive to show a statistical difference in $\mathrm{NO}_{\mathrm{x}}$ emissions. Again, mode 5 was affected with a 1.61\% reduction and mode 2 had a 1.33\% reduction from its baseline. The transient testing of the DDC showed no significant change in $\mathrm{NO}_{\mathrm{x}}$ emissions. The data and plots of the $\mathrm{NO}_{\mathrm{x}}$ analysis can be found in Appendix 8.5.9.

There were no significant differences in bsCO emissions during this testing. This may be due to the high variability between test to test. There were large changes but they could not be identified as significant due to this variability. For example, H2Oil 1 showed a $13 \%$ reduction in mode 4 but the resulting p-value was 0.265 , not near the significance level. This can be observed by the large bars in Figure 8-27 and Figure 8-28 of Appendix 8.5.10. The transient testing showed reductions in bsCO with H2Oil 1 and NanoBonus (both around 3\%), which was the same magnitude of the variations between test to test.

The bsPM results were inconclusive for most of the data due to the high variability in the measurements. Data for H2Oil 1 was invalid due to problems with the filter changing between modes. Mode 6 (low speed, full load) for NanoBonus, however, had consistent results showing an 8.64\% decrease in bsPM with a p-value of .006 . NanoBonus showed a 2.25\% reduction in bsPM for the transient testing, but this was not considered statistically significant. The data and plots of the PM analysis can be found in Appendix 8.5.11.

NanoBonus showed the greatest changes in bsHC of all the additives in each mode. The $16.70 \%$ reduction in mode 3 was the only considered statistically significant with a p-value of 0.049. Reductions were seen in each of the 6 modes for NanoBonus, which did not agree with the transient testing which showed a $2.90 \%$ increase in bsHC compared to the baseline, this increase was not statistically significant however. The data and plots of the HC analysis can be found in Appendix 8.5.12.

\subsubsection{In-Cylinder Pressure}

Due to the minimal number of tests for each additive, Student's t-test was abandoned for interpretation of in-cylinder pressure data. Instead, the averages for the 
available tests were plotted with 2 standard deviations as their range and illustrated with bars, which comes to a $95.5 \%$ confidence interval. It has been shown that repeat steadystate testing occurring over the course of a day has relatively low variation, and therefore not repeating modes could be practical [75]. The parameters analyzed include: heat released, maximum pressure, location of maximum pressure, pressure at start of combustion, temperature at start of combustion, location of start of combustion, location of $90 \%$ mass fraction burned, estimated end of combustion, length of the premix fraction, and length of the diffusion fraction. A few of the more important parameters will be mentioned in this section, and a summary for the rest can be found in Appendix 8.5.13.

The data comes from sampling that began after each mode had time to stabilize. The DAQ system was programmed to begin collecting data at the instant the PM sampling system was activated. The data presented here consists of the average from all the cycles within the collection period, which ranged from about 200 cycles for mode 2 to about 470 cycles for mode 4 , with the differences being the PM mode sampling length. It would be difficult to discern any differences between each test fuel by choosing "snap shots” of individual cycles, due to cycle-to-cycle variation.

The average maximum pressure in each mode appeared relatively unaffected by the additives, seen in Figure 5-12. Mode 5 is shown in Figure 5-13 to exemplify this for one mode. It can be clearly seen that the bars overlap for an additive and its respective baseline. It is interesting to note the large variation with Cerion 1 . This was attributed to the fact that the intercooler water flow had been adjusted at a much lower rate by mistake and was corrected after that test. The maximum pressure suffered from a higher intake air temperature. The difference between the average intake gas temperatures for the two Cerion 1 tests was nearly $40 \mathrm{~K}$. An affect can be seen between the two Cerion 1 tests in nearly every parameter analyzed. 


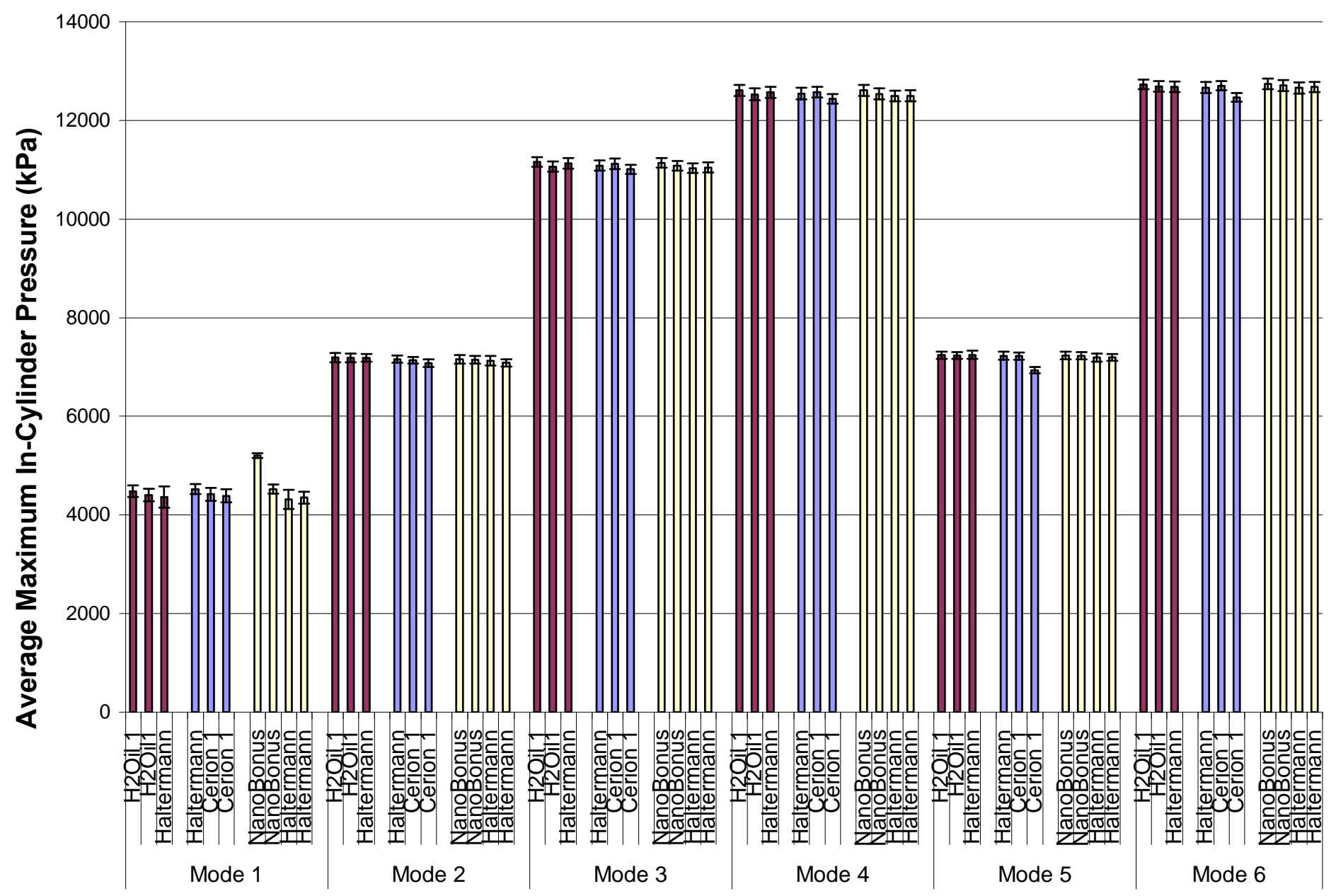

Figure 5-12 Average Maximum In-Cylinder Pressure 


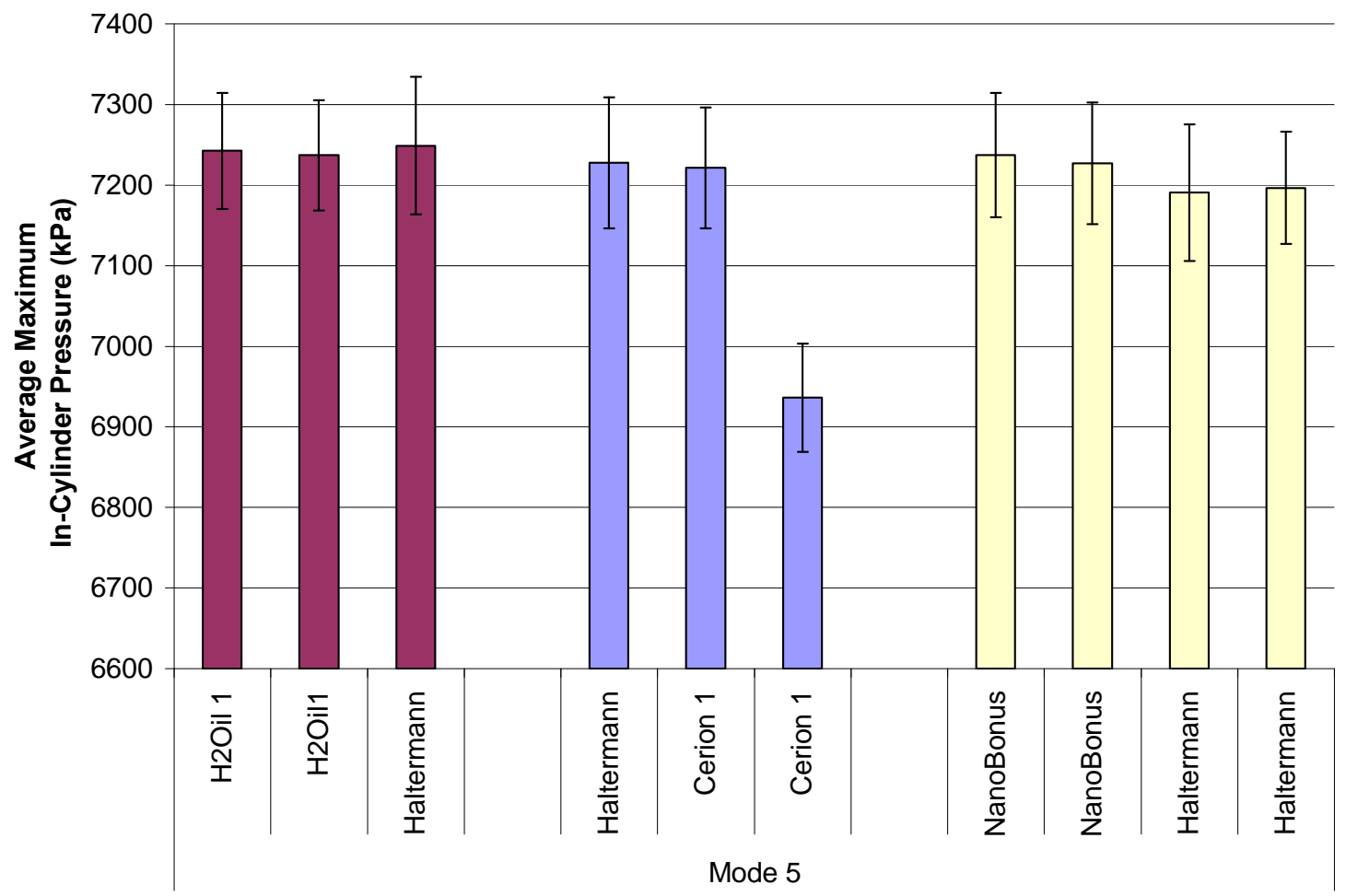

Figure 5-13 Average Maximum In-Cylinder Pressure of Mode 5

The start of combustion (SOC) can be an indication to the ignition delay and may provide insight into if the additive altered the combustion events. No difference was observed in the start of combustion for the additives as can be seen in Figure 5-14. Also, a plot of mode 3 is shown in Figure 5-15. It is interesting to note that the average start of combustion for the Cerion 1 test was advanced nearly 1 degree in mode 3 , due to the increased intake temperature. Note that the crank angle resolution was 0.25 degrees, and the cycle-to-cycle variation and test-to-test variation were within the crank angle resolution. The large variation in mode 5 for start of combustion was a result of several spikes in the data due to noise. This noise was limited for the majority of the testing by a low pass filter. It occurred for the baselines of H2Oil 1 and Cerion 1, and also for the Cerion 1 testing. 


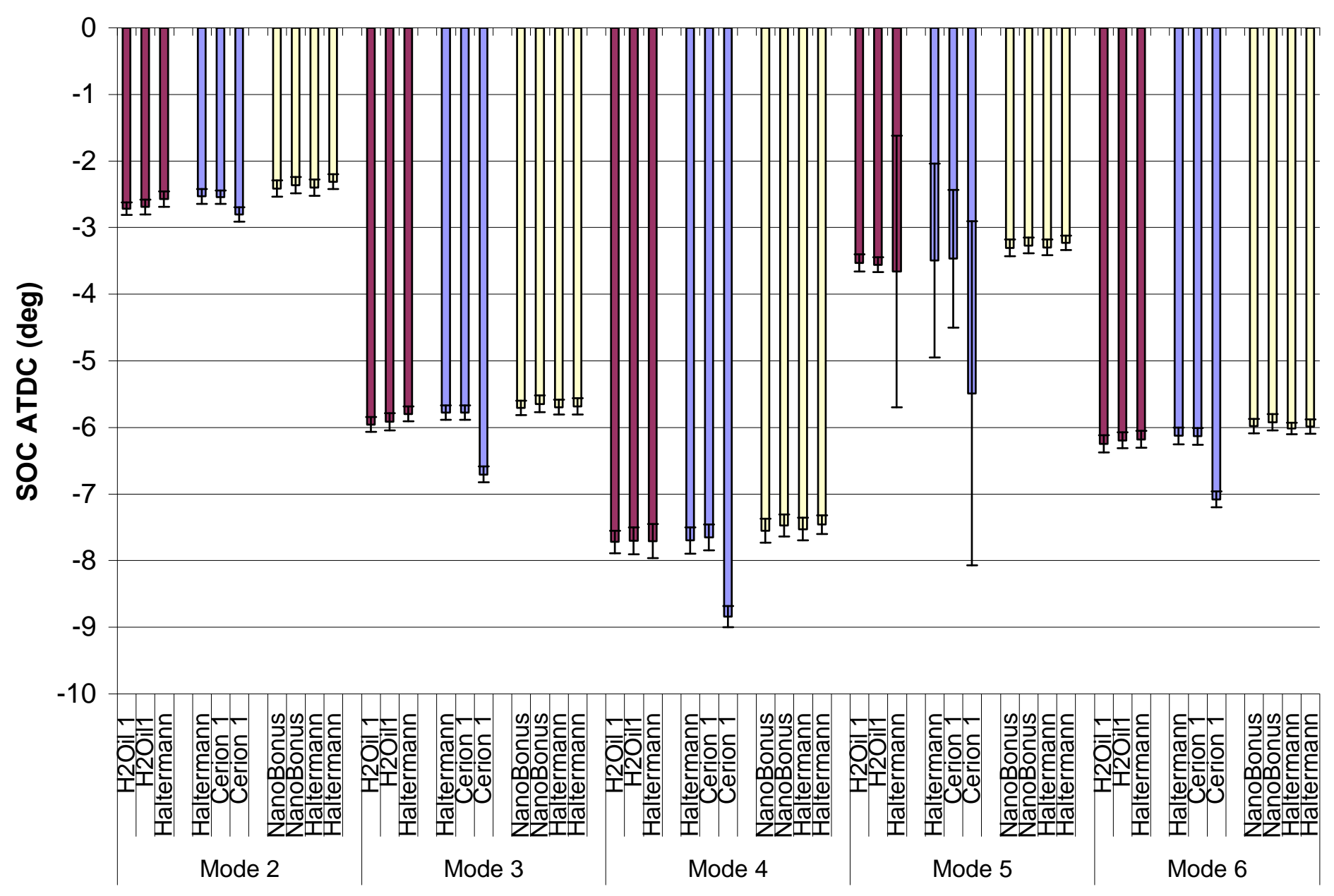

Figure 5-14 Location of Average Start of Combustion 


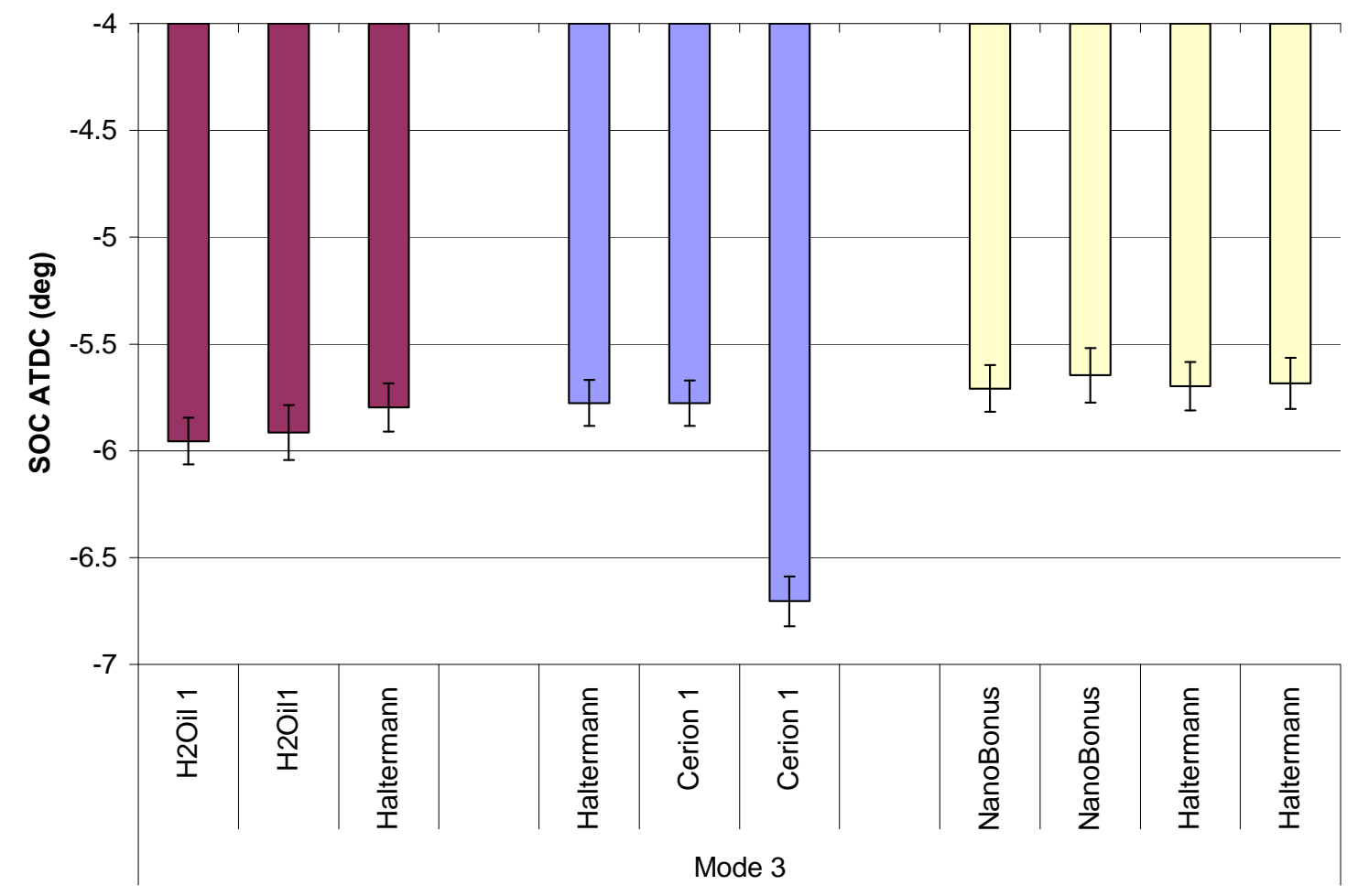

Figure 5-15 Average Start of Combustion for Mode 3

The fuel conversion efficiency was used to indicate whether any additives altered combustion efficiency. The efficiency provided how much energy was converted from the fuel into work from each combustion event [69]. As is seen in Figure 5-16, the additives had no noticeable effect on the conversion efficiency for any mode or additive for this engine and this fuel. Fuel borne catalysts intend to produce more complete combustion which would suggest greater fuel conversion efficiency. It is interesting to note the decrease in efficiency in every mode for the second Cerion 1 test, which is expected due to the higher intake temperature. 


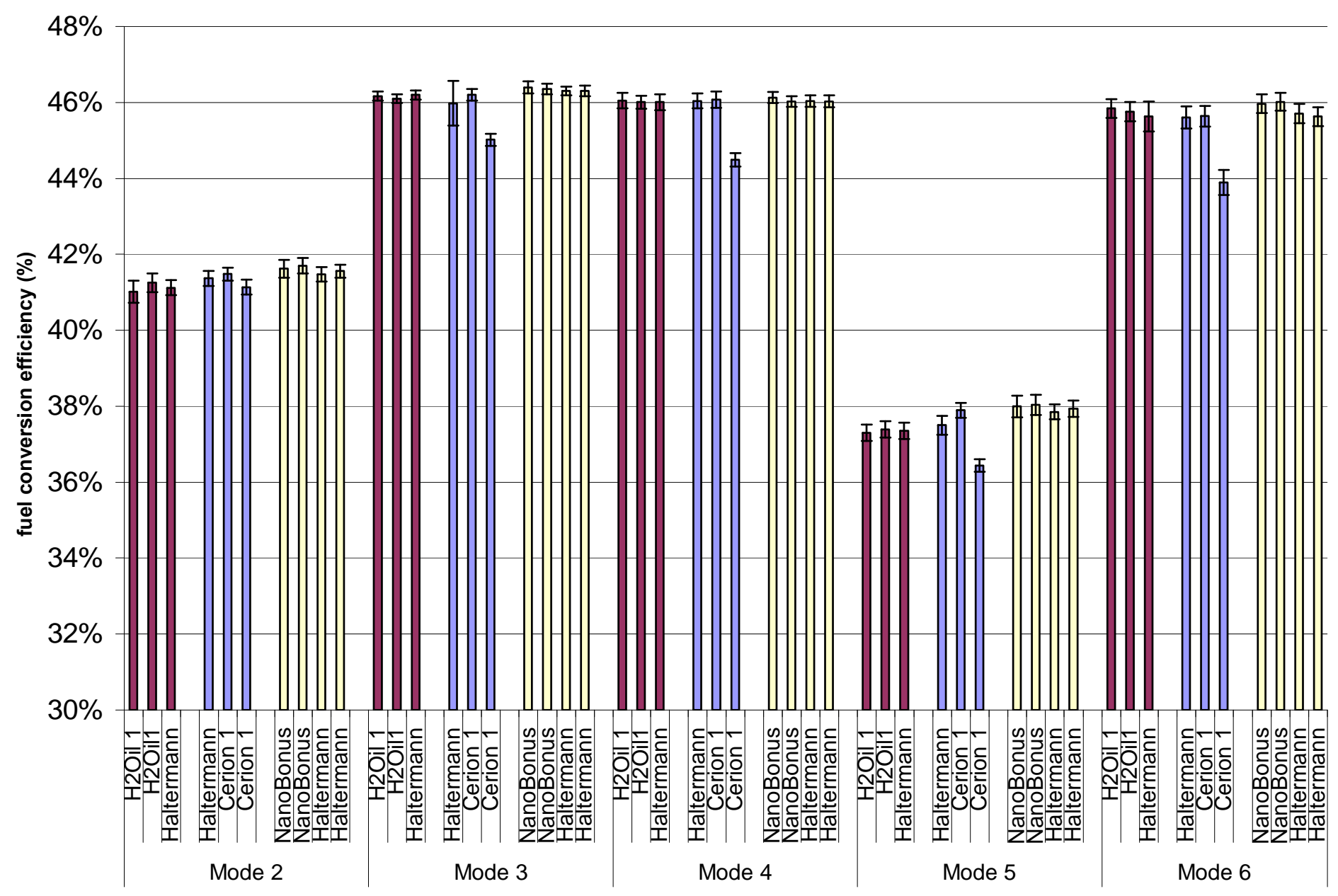

Figure 5-16 Fuel Conversion Efficiency 


\section{Conclusions and Recommendations}

\subsection{Conclusions}

Five fuel borne catalysts were tested on four heavy-duty diesel engines of different model years and technologies to determine their effects on fuel economy and emissions. Testing was completed in the CAFEE engine dynamometer laboratory using engines from the CAFEE inventory and from the DoD. The effectiveness of the additives was evaluated on transient and steady-state test cycles.

None of the additives showed greater than a $1.00 \%$ change in fuel economy over the transient testing. And the greatest change in the steady-state testing was a $1.03 \%$ reduction in fuel consumption obtained during a high speed low load mode. None of the additives proved to provide a consistent, clear-cut change in the fuel consumption or brake specific emissions for any of the engines, though significant changes were seen varying from engine to engine.

Transient testing of the 1999 Cummins ISM 370 ESP showed a 0.19\% reduction in bsfc using H2Oil 1 and no other significant changes with the other two additives tested. H2Oil 1 also proved to change $\mathrm{NO}_{\mathrm{x}}, \mathrm{CO}, \mathrm{HC}$, and $\mathrm{CO}_{2}$ emissions significantly by $-0.33 \%$, $+2.56 \%$, $+3.44 \%$, and $-0.20 \%$, respectively. Cerion 1 and NanoBonus both changed CO emissions by $4.34 \%$ and $-2.52 \%$, respectively, with NanoBonus also increasing $\mathrm{NO}_{\mathrm{x}}$ emissions by $0.40 \%$.

The 2004 Mack MP7-355E was tested on only the transient FTP with the Cerion 1 and Cerion 2 additives. Cerion 2 showed an increase of $0.52 \%$ in bsfc while Cerion 1 had no noticeable effect. Both Cerion 1 and Cerion 2 changed HC emissions by 3.44\% and $-2.23 \%$, respectively.

Transient testing of the rebuilt 1992 DDC Series 60 engine showed no significant changes in bsfc for any of the three additives tested. The steady-state testing mostly supported these findings with the only significant difference occurring in two of the six 
modes where reductions of $0.21 \%$ and $1.03 \%$ were seen with H2Oil 1 . The in-cylinder pressure data supported these findings to the extent that no significant differences were found in parameters, such as average maximum pressure, location of start of combustion, or the fuel conversion efficiency. NanoBonus may have proved to be effective in reducing bsPM emissions with 5.19\% reduction in the transient testing and an $8.64 \%$ reduction in the low speed, high load mode of the steady-state testing. The variability in test to test runs for the other steady state modes made it inconclusive of the effectiveness of NanoBonus in reducing PM.

The new 1998 GEP Optimizer engine was tested over a created transient test cycle representative of a fuel consumption course used for testing of military vehicles and a two mode steady state cycle. Cerion 1, NanoBonus, and H2Oil 2 were tested over these cycles. H2Oil 2 showed a $0.19 \%$ reduction in bsfc for transient testing and a $0.54 \%$ increase in the intermediate speed and 50\% load mode. NanoBonus again proved to reduce bsPM by $11.44 \%$ at the rated speed intermediate load mode.

\subsection{Recommendations}

Little evidence was provided by this study to conclude that any of the additives proved to alter the fuel economy or emissions for any of the engines. Several additions could have been made to this study to aid in distinguishing the effects, if any, the additives had on the baseline fuel.

The H2Oil additive technical information states that it could typically take 50 to 500 hours of engine operation before an effect may be reached, due to a chamber wall cleaning period. Therefore, it may be plausible to see an increase in emissions or decrease in performance while the additive cleanses the chamber walls. The engines used in this testing could be considered pristine and the opportunity for cleansing may not be available. Therefore, "dirtier" engines may show improvements in performance and emissions if the additives are allowed to run for several hours. Also, NanoBonus testing protocol requests at least 10 hours of testing where the first six hours are not used for 
data. These procedures were not followed in this testing due to limited resources and testing time.

All the additives were not run on each engine which left an "unfair” general evaluation of each additive. If all additives could be tested on each engine there may be a reoccurring effect for performance or emissions. All but two of the engines had different baseline fuels. The additives may have different effects relative to different baseline fuels, which would be easier to discern if all the baseline fuels were tested on each engine. Also, a fuel analysis with and without the additives could provide more insight if the additives are changing the chemical make-up of the baseline fuels.

Two different tunnels were used during testing. Though additives were not compared across engines, greater consistency could be found if all the testing could have been completed on the same tunnel with the same analyzers and testing set-up. This would have provided for a more equitable comparison of the absolute emissions values but it is believed that the same relative differences would have been measured regardless of which tunnel and sampling system was used. 


\section{References}

1. Energy Information Administration, "Weekly United States Spot Price FOB Weighted by Estimated Import Volume,” price per barrel 7/18/09 \$134.44, 12/26/08 \$31.84, Washington, DC, 2009.

2. Defense Energy Support Center, "Defense Energy Support Center Fact Book Fiscal Year 2008,” 31 $1^{\text {st }}$ ed., Fort Belvoir, VA, 2009.

3. Federal Register, Vol. 74, No. 59, Rules and Regulations, National Archives and Records Administration, Washington, DC, 30 March 2009.

4. Code of Federal Regulations, CFR Title 49 Part 531, Office of Federal Register National Archives and Records Administration, Washington, DC, 2009.

5. Code of Federal Regulations, CFR Title 40 Part 85, Office of Federal Register National Archives and Records Administration, Washington, DC, 2009.

6. United States Code, USC Title 42 Chapter 85, Office of the Law Revision Counsel of the U.S. House of Representatives, Washington, DC, 2006.

7. Bender, B., "Pentagon Study Says Oil Reliance Strains Military-Urges Development of Alternative Fuels,” The Boston Globe, Boston, MA, 1 May 2007.

8. Center for Naval Analyses Military Advisory Board, "Powering America's Defense: Energy and the Risks to National Security," Center for Naval Analyses, Alexandria, VA, 2009.

9. Pulkrabek, W., Engineering Fundamentals of the Internal Combustion Engine, $2^{\text {nd }}$ ed., Upper Saddle River, NJ, Prentice Hall, 2003.

10. Defense Energy Support Center, Detail Specification Document MIL-DTL83133F, Fort Belvoir, VA, April 2008.

11. Ribeiro, N., Pinto, A., Quintella, C., Rocha, G., Texeira, L., Guarieiro, L., Rangel, M., Veloso, M., Rezende, M., Cruz, R., Oliveira, A., Torres, E. and Andrade, J., "The Role of Additives for Diesel and Diesel Blended (Ethanol or Biodiesel) Fuels: A Review,” Energy \& Fuels, Vol. 21, pp. 2433-2445, 2006.

12. Speight, J., The Chemistry and Technology of Petroleum, $4^{\text {th }}$ ed., Boca Raton, FL, Taylor \& Francis, 2007. 
13. Goodger, E., Hydrocarbon Fuels, New York, NY, John Wiley \& Sons Inc., 1975.

14. Schmidt, P., Fuel Oil Manual, $3^{\text {rd }}$ ed., New York, NY, Industrial Press Inc., 1969.

15. Pedersen, K., Fredenslund, A. and Thomassen, P., Properties of Oils and Natural Gases, Houston, TX, Gulf Publishing Company, 1989.

16. Robinson, W., Odom, J. and Holtzclaw, H., General Chemistry with Qualitative Analysis, $10^{\text {th }}$ ed., Boston, MA, Houghton Mifflin Company, 1997.

17. Fanick, R., "Diesel Fuel Keeping Pace with Diesel Engine Technology," SAE Paper No. 2008-01-1808, SAE International, Warrendale, PA, 2008.

18. Karonis, D., Lois, E., Stournas, S. and Zannikos, F., "Correlations of Exhaust Emissions from a Diesel Engine with Diesel Fuel Properties.” Energy \& Fuels, Vol. 12, pp. 230-238, 1998.

19. Code of Federal Regulations, CFR Title 40 Part 86-89, Office of Federal Register National Archives and Records Administration, Washington, DC, 2006.

20. Mushrush, G. and Speight, J., Petroleum Products: Instability and Incompatibility, Washington DC, Taylor \& Francis, 1995.

21. Suppes, G., Goff, M., Burkhart, M., Bockwinkel, K., Mason, M., Botts, J. and Heppert, J., "Multifunctional Diesel Fuel Additives from Triglycerides," Energy \& Fuels, Vol. 15, pp. 151-157, 2001.

22. Ladommatos, N., Parsi, M. and Knowles, A., "The Effect of Fuel Cetane Improver on Diesel Pollutant Emissions,” Fuel, Vol. 75, pp. 8-14, 1996.

23. Hills, F. and Schleyerbach, C., "Diesel Fuel Properties and Engine Performance,” SAE Paper No. 770316, SAE International, Warrendale, PA, 1977.

24. Bertoli, C., Giacomo, N., Caprotti, R. and Smith, A., "Influence of Automotive Diesel Back End Volatility and New Fuel Additive Technology on Regulated Emissions," Journal of Automobile Engineering, Vol. 207, pp. 107-115, 1993.

25. Owen, K. and Coley, T., Automotive Fuels Reference Book, $2^{\text {nd }}$ ed., Warrendale, PA, SAE International, 1995. 
26. Kwon, Y., Mann, N., Rickeard, D., Haugland, R., Ulvund, K., Kvinge, F. and Wilson, G., "Fuel Effects on Diesel Emissions - a New Understanding," SAE Paper No. 2001-01-3522, SAE International, Warrendale, PA, 2001.

27. Frank, B., Tang, S., Lanni, T., Rideout, G., Beregszaszy, C. and Meyer, N., "A Study of the Effects of Fuel Type and Emission Control Systems on Regulated Gaseous Emissions From Heavy-Duty Diesel Engines,” SAE Paper No. 2004-01-1085, SAE International, Warrendale, PA, 2004.

28. Speight, J., The Desulfurization of Heavy Oils and Residua, New York, NY, Marcel Dekker Inc., 1981.

29. McCarthy, C., Slodowske, W., Sienicki, E. and Jass, R., "Diesel Fuel Property Effects on Exhaust Emissions from a Heavy Duty Diesel Engine that Meets 1994 Emissions Requirments,” SAE Paper No. 922267, SAE International, Warrendale, PA, 1992.

30. Ullman, T., Spreen, K. and Mason, R., “Effects of Cetane Number, Cetane Improver, Aromatics, and Oxygenates on 1994 Heavy-Duty Diesel Engine Emissions,” SAE Paper No. 941020, SAE International, Warrendale, PA, 1994.

31. Spreen, K., Ullman, T. and Mason, R., "Effects of Cetane Number, Aromatics, and Oxygenates on Emissions From a 1994 Heavy-Duty Diesel Engine With Exhaust Catalyst," SAE Paper No. 950250, SAE International, Warrendale, PA, 1995.

32. United States Environmental Protection Agency Office of Transportation and Air Quality-National Vehicle and Fuel Emissions Laboratory, "Fluorescent Indicator Adsorption Analysis of Petroleum Fuels Method," NVFEL Reference No. 124, Ann Arbor, MI, 2002.

33. Lapuerta, M., Armas, O. and Rodriguez-Fernandez, J., "Effect of Biodiesel Fuels on Diesel Engine Emissions," Progress in Energy and Combustion Science, Vol. 34, pp. 198-233, 2008.

34. Haycock, R. and Thatcher, R., "Fuel Additives and the Environment," Document 52 Revision, Technical Committee of Petroleum Additive Manufacturers in Europe (ATC), Europe, 2004.

35. United States Environmental Protection Agency, "The Effect of Cetane Number Increase Due to Additives on NOx Emissions from Heavy-Duty Highway Engines,” EPA420-R-03-002, Washington, DC, 2003. 
36. Liotta, F., "A Peroxide Based Cetane Improvement Additive with Favorable Fuel Blending Properties,” SAE Paper No. 932767, SAE International, Warrendale, PA, 1993.

37. Nandi, M., Jacobs, D., Liotta, F. and Kesling, H., "The Performance of a Peroxide-Based Cetane Improvement Additive in Different Diesel Fuels," SAE Paper No. 942019, SAE International, Warrendale, PA, 1994.

38. Schwab, S., Guinther, G., Henly, T. and Miller, K., "The Effects of 2Ethylhexyl Nitrate and Di-tertiary-butyl Peroxide on the Exhaust Emissions from a Heavy-Duty Diesel Engine,” SAE Paper No. 1999-01-1478, SAE International, Warrendale, PA, 1999.

39. Li, X., Chippior, W. and Gulder, O., "Effects of Cetane Enhancing Additives and Ignition Quality on Diesel Engine Emissions,” SAE Paper No. 972968, SAE International, Warrendale, PA, 1997.

40. Anastopoulos, G., Lois, E., Karonis, D., Zanikos, F. and Kalligeros, S., “A Preliminary Evaluation of Esters of Monocarboxylic Fatty Acid on the Lubrication Properties of Diesel Fuel,” Industrial \& Engineering Chemistry Research, Vol. 40, pp. 452-456, 2001.

41. Gairing, M., Marriott, J., Reders, K., Reglitzky, A. and Wolveridge, P., "The Effect of Modern Additive Technology on Diesel Fuel Performance," SAE Paper No. 950252, SAE International, Warrendale, PA, 1995.

42. Chapman, E., Bhide, S. and Boehman, A., "Emission Characteristics of a Navistar 7.3L Turbodiesel Fueled with Blends of Oxygenates and Diesel," SAE Paper No. 2000-01-2887, SAE International, Warrendale, PA, 2000.

43. Xing-cai, L., Jian-guang, Y., Wu-gao, Z. and Huang, Z., "Improving the Combustion and Emissions of Direct Injection Compression Ignition Engines Using Oxygenated Fuel Additives Combined with a Cetane Number Improver,” Energy \& Fuels, Vol. 19, pp. 1879-1888, 2005.

44. Cheng, A. and Dibble, R., "Emissions from a Cummins B5.9 Diesel Engine Fueled with Oxygenate-in-Diesel Blends," SAE Paper No. 2001-01-2505, SAE International, Warrendale, PA, 2001.

45. Yanfeng, G., Shenghua, L., Hejun, G., Tiegang, H. and Longbao, Z., “A New Diesel Oxygenate Additive and its Effects on Engine Combustion and Emissions,” Applied Thermal Engineering, Vol. 27, pp. 202-207, 2007.

46. Choi, C. and Reitz, R., "An Experimental Study on the Effects of Oxygenated Fuel Blends and Multiple Injection Strategies on DI Diesel Engine Emissions," Fuel, Vol. 78, pp. 1303-1317, 1999. 
47. Wu, F., Wang, J., Chen, W. and Shuai, S., "Effects of Different Biodiesels and their Blends with Oxygenated Additives on Emissions from a Diesel Engine," SAE Paper No. 2008-01-1812, SAE International, Warrendale, PA, 2008.

48. Senatore, A. and Cardone, M., "A Comparative Analysis of Combustion Process in D.I. Diesel Engine Fueled with Biodiesel and Diesel Fuel," SAE Paper No. 2000-01-0691, SAE International, Warrendale, PA, 2000.

49. McGill, R., Storey, J., Wagner, R., Irick, D., Aakko, P., Westerholm, M., Nylund, N. and Lappi, M., "Emission Performance of Selected Biodiesel Fuels,” SAE Paper No. 2003-01-1866, SAE International, Warrendale, PA, 2003.

50. Nabi, N., Shahadat, M., Rahman, S. and Beg, R., "Behavior of Diesel Combustion and Exhaust Emissions with Neat Diesel Fuel and DieselBiodiesel Blends," SAE Paper No. 2004-01-3034, SAE International, Warrendale, PA, 2004.

51. Xiaoming, L., Yunshan, G., Sijin W. and Xiukun, H., "An Experimental Investigation on Combustion and Emissions Characteristics of Turbocharged DI Engines Fueled with Blends of Biodiesel," SAE Paper No. 2005-01-2199, SAE International, Warrendale, PA, 2005.

52. McCormick, R., Tennant, C., Hayes, R., Black, S., Ireland, J., McDaniel, T., Williams, A., Frailey, M. and Sharp, C., "Regulated Emissions from Biodiesel Tested in Heavy-Duty Engines Meeting 2004 Emission Standards," SAE Paper No. 2005-01-2200, SAE International, Warrendale, PA, 2005.

53. Szybist, J., Simmons, J., Druckenmiller, M., Al-Qurashi, K., Boehman, A. and Scaroni, A., "Potential Methods for $\mathrm{NO}_{\mathrm{x}}$ Reduction from Biodiesel," SAE Paper No. 2003-01-3205, SAE International, Warrendale, PA, 2003.

54. Hansen, A., Zhang, Q. and Lyne, P., "Ethanol-Diesel Fuel Blends-a Review,” Bioresource Technology, Vol. 96, pp. 277-285, 2005.

55. Jackson, M., Corkwell, K. and DeGroote, C., "Study of Diesel and Ethanol Blends Stability,” SAE Paper No. 2003-01-3191, SAE International, Warrendale, PA, 2003.

56. McCormick, R. and Parish R., “Advanced Petroleum Based Fuels Program and Renewable Diesel Program Milestone Report: Technical Barriers to the Use of Ethanol in Diesel Fuel," National Renewable Energy Laboratory, Golden, CO, Report NREL/MP-540-32674, 2001. 
57. Ahmed, I., "Oxygenated Diesel: Emissions and Performance Characteristics of Ethanol-Diesel Blends in CI Engines," SAE Paper No. 2001-01-2475, SAE International, Warrendale, PA, 2001.

58. Reddy, V., "Evaluation of Current and Early Production Electronically Controlled Heavy-Duty Diesel Engine Emissions Based on Fuel Property Differences," M.S. Thesis, Department of Mechanical and Aerospace Engineering, West Virginia University, Morgantown, WV, 2006.

59. Tincher, R., "Evaluation of Heavy Duty Diesel Engines Regulated Emissions Based on Variation of Fuel Properties by Use of Additives,” M.S. Thesis, Department of Mechanical and Aerospace Engineering, West Virginia University, Morgantown, WV, 2007.

60. Ullman, T., Webb, C., Jackson, C., and Doorlag, M., "Nonroad Engine Activity Analysis and Transient Cycle Generation,” SAE Paper No. 1999-012800, SAE International, Warrendale, PA, 1999.

61. Krishnamurthy, M., and Gautam, M., "Development of a Heavy-Duty Engine Test Cycle Representitive of On-Highway Not-To-Exceed Operation,” Proceedings of the Institution of Mechanical Engineers, Part D Journal of Automobile Engineering, Vol. 220, pp. 837-848, 2006.

62. Clark, N., Gautam, M., Wayne, W., Thompson, G., Lyons, D., Zhen, F., Bedick, C., Atkinson, R. and McKain, D., "Creation of the 'Heavy HeavyDuty Diesel Engine Test Schedule' for Representative Measurement of Heavy-Duty Engine Emissions,” CRC Report No. ACES-1, Coordinating Research Council, Inc., Alpharetta, GA, 2007.

63. “Horiba FIA-236 Instruction Manual No. 091652,” Horiba Instruments Incorporated, Irvine, CA, March 1997.

64. "California Analytical Instruments Model 600 HFID Operators Manual," California Analytical Instruments, Orange, CA, June 2005.

65. "Horiba AIA-210LE Instruction Manual No. 091863,” Horiba Instruments Incorporated, Irvine, CA, April 1992.

66. “Horiba AIA-210/220 Instruction Manual No. 091215,” Horiba Instruments Incorporated, Irvine, CA, March 1995.

67. “Eco Physics CLD-8xx User Manual,” Eco Physics Incorporated, Ann Arbor, MI.

68. "Rosemount Analytical Model 955 Instruction Manual,” Rosemount Analytical Incorporated, La Habra, CA, February 1994. 
69. Nuszkowski, J., "The Effects of Fuel Additives on Diesel Engine Emissions During Steady State and Transient Operation,” Ph.D. Dissertation, Department of Mechanical and Aerospace Engineering, West Virginia University, Morgantown, WV, 2008.

70. Cerion Energy Inc., One Blossom Road, Rochester, NY, 877-845-5630, 2009.

71. H2Oil Corporation, 2509 Technology Drive, Hayward, CA, 510-785-8833, 2009.

72. Clark, N., Jarrett, R. and Atkinson, C., "Field Measurements of Particulate Matter Emissions, Carbon Monoxide, and Exhaust Opacity from Heavy Duty Diesel Vehicles”, Journal of the Air \& Waste Management Association, Vol. 49, pp. 76-84, 1999.

73. Jarrett, R., "Evaluation of Opacity, Particulate Matter, and Carbon Monoxide From Heavy-Duty Diesel Transient Chassis Tests,” M.S. Thesis, Department of Mechanical and Aerospace Engineering, West Virginia University, Morgantown, WV, 2000.

74. "Vehicle Fuel Consumption,” TOP 2-2-603. U.S. Army Test and Evaluation Command, Aberdeen Proving Ground, MD, February 1986.

75. Nuszkowski, J., and Thompson, G., “Application and Repeatability of Transient Heat Release Analysis for Heavy Duty Diesel Engines," SAE Paper No. 2009-01-1125, SAE International, Warrendale, PA, 1999. 


\section{Appendices}

\subsection{Set Points for Steady-State Testing of 1992 DDC}

Table 8-1 Speed and Load Points for 13 Mode Steady-State Testing

\begin{tabular}{|c|c|c|c|}
\hline Mode & $\begin{array}{c}\text { Set Speed } \\
(\mathrm{rpm})\end{array}$ & $\begin{array}{c}\text { Set Torque } \\
(\mathrm{ft}-\mathrm{lb})\end{array}$ & $\begin{array}{c}\text { Duration } \\
(\mathrm{sec})\end{array}$ \\
\hline 1 & 700 & 0 & 240 \\
\hline 2 & 1196 & 350 & 120 \\
\hline 3 & 1420 & 1003 & 120 \\
\hline 4 & 1644 & 1173 & 120 \\
\hline 5 & 1644 & 293 & 120 \\
\hline 6 & 1196 & 1398 & 120 \\
\hline 7 & 1420 & 669 & 120 \\
\hline 8 & 1196 & 669 & 120 \\
\hline 9 & 1196 & 1049 & 120 \\
\hline 10 & 1420 & 1337 & 120 \\
\hline 11 & 1420 & 334 & 120 \\
\hline 12 & 1644 & 880 & 120 \\
\hline 13 & 1644 & 587 & 120 \\
\hline
\end{tabular}

Table 8-2 Set Points for 6 Mode Steady-State Testing

\begin{tabular}{|c|c|c|c|}
\hline Mode & $\begin{array}{c}\text { Set Speed } \\
(\mathrm{rpm})\end{array}$ & $\begin{array}{c}\text { Set Torque } \\
(\mathrm{ft}-\mathrm{lb})\end{array}$ & $\begin{array}{c}\text { Duration } \\
(\mathrm{sec})\end{array}$ \\
\hline 1 & 700 & 0 & 240 \\
\hline 2 & 1196 & 350 & 120 \\
\hline 3 & 1420 & 1003 & 120 \\
\hline 4 & 1644 & 1173 & 120 \\
\hline 5 & 1644 & 293 & 120 \\
\hline 6 & 1196 & 1398 & 120 \\
\hline
\end{tabular}




\subsection{Set Points for Steady-State Testing of AM General}

\section{Table 8-3 Set Points for Steady-State Testing of 1998 AM General Engine}

\begin{tabular}{|c|c|c|c|}
\hline Mode & $\begin{array}{c}\text { Set Speed } \\
(\mathrm{rpm})\end{array}$ & $\begin{array}{c}\text { Set Torque } \\
(\mathrm{ft}-\mathrm{lb})\end{array}$ & $\begin{array}{c}\text { Duration } \\
(\mathrm{sec})\end{array}$ \\
\hline A & 1826 & 176 & 480 \\
\hline B & 3471 & 137 & 180 \\
\hline C & 700 & 0 & 540 \\
\hline
\end{tabular}

\subsection{AM General Test Cycle Creation Procedure}

Torque and speed data was supplied for four different types of operation:
o No Load
o Paved Road (Harford)
o Secondary Road (Munson)
o Cross Country (Churchville)

The number of test runs for each type of operation differed as such:

o No Load data for 13 different engine speeds.

o Paved road data for 5 different runs with the target speed as posted by the speed limits.

o Secondary Road data for multiple runs at 6 different target speeds: 5, 10, 15, 20, 25, $30 \mathrm{mph}$.

o Cross Country data for multiple runs at 7 different target speeds: 5, 10, 15, 20, 25, 30, $35 \mathrm{mph}$.

To determine runs representative of the course, statistics were compared between the runs for the same speed at each course. These statistics include: run time, average front end torque, average rear torque, average front shaft speed, average rear shaft speed, average fueling rate as given, total fuel consumed as given, average vehicle speed, average engine speed, and total work done by the drives.

Any run statistic that was an outlier from the average of all the runs was considered nonrepresentative of the course and was not used in building the test cycle. Of the remaining runs, one was arbitrarily chosen to be representative of the course.

TOP 2-2-603 titled U.S. Army Test and Evaluation Command Test Operations Procedure "Vehicle Fuel Consumption" was considered in building the test cycle [74]. The Tactical Support Schedule found in Table 2 of Appendix A of this document, Recommended 
Operating Schedules, was used in building the test cycle. The tactical support schedule is for specifying the duty cycle for the role normally filled by wheeled vehicles with a high degree of off-road capability. The support schedule is as follows:

o Engine idling - $10 \%$ of test time

o Paved road (15 to $20 \mathrm{mph})-30 \%$ of test time

o Secondary road (15 to $20 \mathrm{mph}$ ) $-30 \%$ of test time

o Cross-country (5 to $10 \mathrm{mph}$ )- $30 \%$ of test time

A portion of the test cycle representative of the paved road, secondary road, and crosscountry road was constructed as follows:

- Speed and torque data for the entire run (population) that was selected as representative of the course was observed.

- The raw data was filtered and interpolated to be put on the same time scale at a frequency of $2 \mathrm{~Hz}$.

- Several "microtrips", segments of data that are considered representative of the specific run, was chosen using engineering judgment.

- The population and microtrip data was separated into 25 different bins categorized as \%speed and \%load. Where:

$\%$ SPEED $=\left(\mathrm{N}_{\text {Actual }}-\mathrm{N}_{\text {Curb Idle }}\right) /\left(\mathrm{N}_{\text {Rated }}-\mathrm{N}_{\text {Curb Idle }}\right)$
$\% \mathrm{LOAD}=\mathrm{T}_{\text {Actual }} / \mathrm{T}_{\text {Max }}$

where:

$\mathrm{N}_{\text {Actual }}$ - Engine speed from data in rpm

$\mathrm{N}_{\text {Curb Idle }}-$ Curb Idle speed from manufacturers specifications $=700 \mathrm{rpm}$

$\mathrm{N}_{\text {Rated }}$ - Rated engine speed from manufacturers specifications $=3400 \mathrm{rpm}$

$\mathrm{T}_{\text {actual }}$ - Engine torque from data in $\mathrm{ft}-\mathrm{lb}$

$\mathrm{T}_{\mathrm{Max}}-$ Maximum engine torque from manufacturers specifications $=380 \mathrm{ft}-\mathrm{lb}$

The 25 bins are:

$0-20 \%$ Load and 0-20\% Speed

$0-20 \%$ Load and $20-40 \%$ Speed

$0-20 \%$ Load and $40-60 \%$ Speed

$0-20 \%$ Load and $60-80 \%$ Speed

$0-20 \%$ Load and $80-100 \%$ Speed

20-40\% Load and 0-20\% Speed

80-100\% Load and 80-100\% Speed

For the population, the value in the bins represents the percentage of time at which the vehicle operated at that specific load and speed setting over the course of the trip.

For the microtrips selected, the value in the bins represents the number of data points the vehicle operated at that specific load and speed setting over the course of the trip. The value of the bins of the population data are then multiplied by the number of test points 
for the combined microtrips. This number represents the number of datapoints expected to be seen in each bin for the combined microtrips.

A chi-square statistic was then computed to determine if the selected microtrips were representative of the population data. If the created cycle passed the chi-square test then that data was analyzed further to determine if the speed and load points could be met. The maximum positive and negative rates of change of speed, torque, and power were computed for the population data and created cycle. If the created cycle had any points where the rates of change were greater than the population data, those points were smoothed out. At least 20 seconds of idle was placed before and after each created section for testing purposes.

This procedure was followed for the paved road, secondary road, and cross-country road sections. Each section was the same amount of time to comply with the TOP 2-2-603 as mentioned earlier. The idling period was then added to the existing cycle to contribute the required $10 \%$ of test time.

The following figures show the speed and load set points of the 1523 second test cycle for testing of the AM General engine.

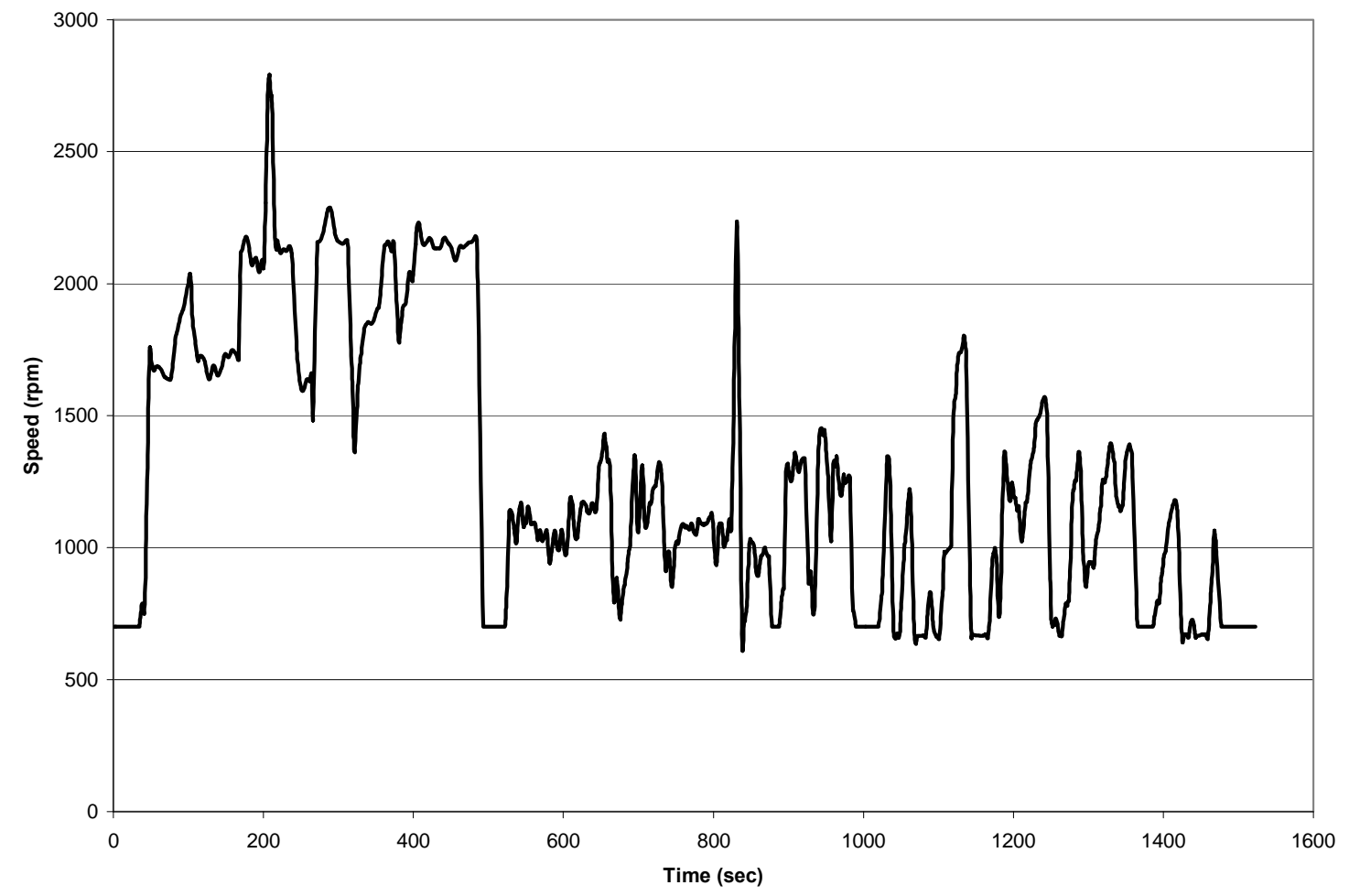

Figure 8-1 Time Versus Speed Set Points for AM General Engine Created Cycle 


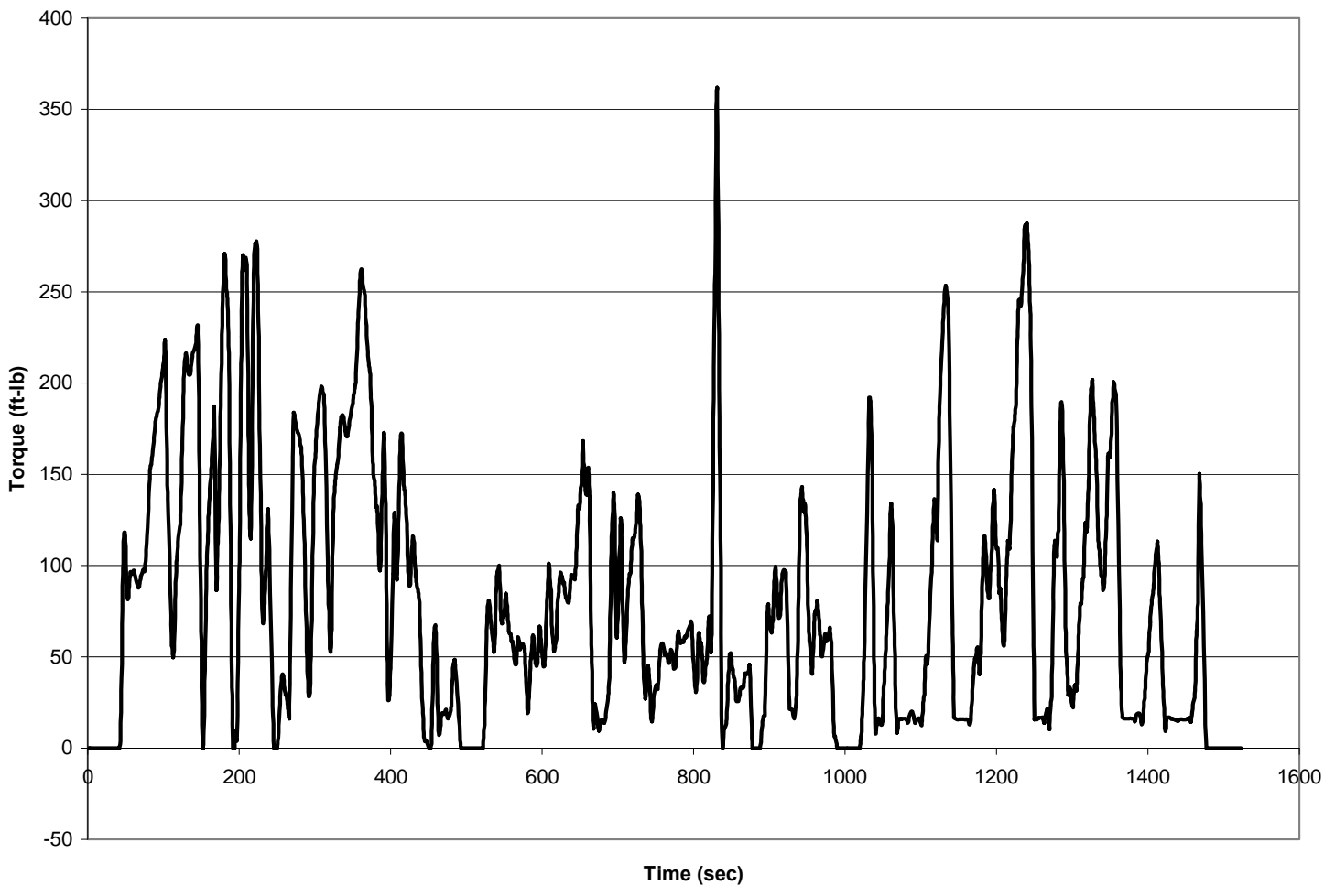

Figure 8-2 Time Versus Speed Set Points for AM General Engine Created Cycle 


\subsection{Transient Test Results}

\subsubsection{Transient Testing Averages and Variation Results}

Table 8-4 Transient BSFC Variation Results

\begin{tabular}{|c|c|c|c|}
\hline Engine & Additive & $\begin{array}{c}\text { Difference } \\
\text { from } \\
\text { Baseline }\end{array}$ & $\begin{array}{l}\text { Combined } \\
\text { Variations }\end{array}$ \\
\hline \multirow[t]{3}{*}{1999 Cummins } & Cerion 1 & $0.14 \%$ & $0.57 \%$ \\
\hline & H2Oil 1 & $-0.19 \%$ & $0.25 \%$ \\
\hline & NanoBonus & $-0.12 \%$ & $0.33 \%$ \\
\hline \multirow[t]{2}{*}{2004 Mack } & Cerion 1 & $0.11 \%$ & $0.36 \%$ \\
\hline & Cerion 2 & $0.52 \%$ & $0.77 \%$ \\
\hline \multirow[t]{3}{*}{1992 DDC } & H2Oil 1 & $0.07 \%$ & $0.33 \%$ \\
\hline & Cerion 1 & $0.23 \%$ & $0.39 \%$ \\
\hline & NanoBonus & $0.20 \%$ & $0.53 \%$ \\
\hline \multirow{4}{*}{$\begin{array}{l}1999 \text { AM } \\
\text { General }\end{array}$} & & & \\
\hline & NanoBonus & $0.51 \%$ & $1.03 \%$ \\
\hline & H2Oil 2 & $-0.56 \%$ & $0.39 \%$ \\
\hline & Cerion 1 & $0.13 \%$ & $0.74 \%$ \\
\hline
\end{tabular}


Table 8-5 Transient $\mathrm{CO}_{2}$ Variation Results

\begin{tabular}{|c|c|c|c|}
\hline Engine & Additive & $\begin{array}{c}\text { Difference } \\
\text { from } \\
\text { Baseline }\end{array}$ & $\begin{array}{l}\text { Combined } \\
\text { Variations }\end{array}$ \\
\hline \multirow[t]{3}{*}{1999 Cummins } & Cerion 1 & $0.12 \%$ & $0.57 \%$ \\
\hline & H2Oil 1 & $-0.20 \%$ & $0.26 \%$ \\
\hline & NanoBonus & $-0.12 \%$ & $0.34 \%$ \\
\hline \multirow[t]{2}{*}{2004 Mack } & Cerion 1 & $0.09 \%$ & $0.33 \%$ \\
\hline & Cerion 2 & $0.52 \%$ & $0.75 \%$ \\
\hline \multirow[t]{3}{*}{1992 DDC } & H2Oil 1 & $0.11 \%$ & $0.39 \%$ \\
\hline & Cerion 1 & $0.23 \%$ & $0.39 \%$ \\
\hline & NanoBonus & $0.24 \%$ & $0.51 \%$ \\
\hline \multirow[t]{3}{*}{$\begin{array}{l}1998 \text { AM } \\
\text { General }\end{array}$} & NanoBonus & $0.51 \%$ & $1.02 \%$ \\
\hline & H2Oil 2 & $-0.55 \%$ & $0.39 \%$ \\
\hline & Cerion 1 & $0.13 \%$ & $0.76 \%$ \\
\hline
\end{tabular}

Table 8-6 Transient NOx Variation Results

\begin{tabular}{|c|c|c|c|}
\hline Engine & Additive & $\begin{array}{c}\text { Difference } \\
\text { from } \\
\text { Baseline }\end{array}$ & $\begin{array}{l}\text { Combined } \\
\text { Variations }\end{array}$ \\
\hline \multirow[t]{3}{*}{1999 Cummins } & Cerion 1 & $-0.74 \%$ & $1.96 \%$ \\
\hline & H2Oil 1 & $-0.33 \%$ & $0.72 \%$ \\
\hline & NanoBonus & $0.40 \%$ & $0.95 \%$ \\
\hline \multirow[t]{2}{*}{2004 Mack } & Cerion 1 & $0.87 \%$ & $5.36 \%$ \\
\hline & Cerion 2 & $0.19 \%$ & $5.46 \%$ \\
\hline \multirow[t]{3}{*}{1992 DDC } & H2Oil 1 & $0.76 \%$ & $1.77 \%$ \\
\hline & Cerion 1 & $0.09 \%$ & $0.87 \%$ \\
\hline & NanoBonus & $-0.32 \%$ & $1.25 \%$ \\
\hline \multirow{4}{*}{$\begin{array}{l}2008 \text { AM } \\
\text { General }\end{array}$} & & & \\
\hline & NanoBonus & $0.96 \%$ & $5.98 \%$ \\
\hline & H2Oil 2 & $-0.27 \%$ & $2.18 \%$ \\
\hline & Cerion 1 & $3.46 \%$ & $4.25 \%$ \\
\hline
\end{tabular}


Table 8-7 Transient CO Variation Results

\begin{tabular}{|c|c|c|c|}
\hline Engine & Additive & $\begin{array}{c}\text { Difference } \\
\text { from } \\
\text { Baseline }\end{array}$ & $\begin{array}{l}\text { Combined } \\
\text { Variations }\end{array}$ \\
\hline \multirow[t]{3}{*}{1999 Cummins } & Cerion 1 & $4.34 \%$ & $5.28 \%$ \\
\hline & H2Oil 1 & $2.56 \%$ & $2.46 \%$ \\
\hline & NanoBonus & $-2.52 \%$ & $4.18 \%$ \\
\hline \multirow[t]{2}{*}{2004 Mack } & Cerion 1 & $1.69 \%$ & $4.96 \%$ \\
\hline & Cerion 2 & $1.27 \%$ & $11.30 \%$ \\
\hline \multirow[t]{3}{*}{1992 DDC } & H2Oil 1 & $-3.65 \%$ & $5.40 \%$ \\
\hline & Cerion 1 & $0.43 \%$ & $2.62 \%$ \\
\hline & NanoBonus & $-3.31 \%$ & $3.85 \%$ \\
\hline \multirow[t]{3}{*}{$\begin{array}{l}1998 \text { AM } \\
\text { General }\end{array}$} & NanoBonus & $1.52 \%$ & $6.89 \%$ \\
\hline & H2Oil 2 & $-2.79 \%$ & $3.52 \%$ \\
\hline & Cerion 1 & $-0.28 \%$ & $6.17 \%$ \\
\hline
\end{tabular}

Table 8-8 Transient PM Variation Results

\begin{tabular}{|c|c|c|c|}
\hline Engine & Additive & $\begin{array}{c}\text { Difference } \\
\text { from } \\
\text { Baseline }\end{array}$ & $\begin{array}{l}\text { Combined } \\
\text { Variations }\end{array}$ \\
\hline \multirow[t]{3}{*}{1999 Cummins } & Cerion 1 & $2.62 \%$ & $27.98 \%$ \\
\hline & H2Oil 1 & $5.77 \%$ & $9.93 \%$ \\
\hline & NanoBonus & $-5.19 \%$ & $19.51 \%$ \\
\hline \multirow[t]{2}{*}{2004 Mack } & Cerion 1 & $0.48 \%$ & $11.18 \%$ \\
\hline & Cerion 2 & $1.89 \%$ & $22.95 \%$ \\
\hline \multirow[t]{3}{*}{1992 DDC } & H2Oil 1 & $2.62 \%$ & $6.44 \%$ \\
\hline & Cerion 1 & $5.77 \%$ & $3.42 \%$ \\
\hline & NanoBonus & $-5.19 \%$ & $3.40 \%$ \\
\hline \multirow[t]{3}{*}{$\begin{array}{l}1998 \text { AM } \\
\text { General }\end{array}$} & NanoBonus & $-2.25 \%$ & $16.60 \%$ \\
\hline & H2Oil 2 & $-0.31 \%$ & $14.54 \%$ \\
\hline & Cerion 1 & $7.47 \%$ & $9.57 \%$ \\
\hline
\end{tabular}


Table 8-9 Transient HC Variation Results

\begin{tabular}{|c|c|c|c|}
\hline Engine & Additive & $\begin{array}{c}\text { Difference } \\
\text { from } \\
\text { Baseline }\end{array}$ & $\begin{array}{l}\text { Combined } \\
\text { Variations }\end{array}$ \\
\hline \multirow[t]{3}{*}{1999 Cummins } & Cerion 1 & $2.44 \%$ & $1.61 \%$ \\
\hline & H2Oil 1 & $3.44 \%$ & $5.73 \%$ \\
\hline & NanoBonus & $-0.87 \%$ & $6.70 \%$ \\
\hline \multirow[t]{2}{*}{2004 Mack } & Cerion 1 & $3.44 \%$ & $9.87 \%$ \\
\hline & Cerion 2 & $-2.23 \%$ & $5.32 \%$ \\
\hline \multirow[t]{3}{*}{1992 DDC } & H2Oil 1 & $5.23 \%$ & $6.17 \%$ \\
\hline & Cerion 1 & $-6.34 \%$ & $14.97 \%$ \\
\hline & NanoBonus & $2.90 \%$ & $6.50 \%$ \\
\hline \multirow{4}{*}{$\begin{array}{l}1998 \text { AM } \\
\text { General }\end{array}$} & & & \\
\hline & NanoBonus & $5.03 \%$ & $13.94 \%$ \\
\hline & H2Oil 2 & $-7.80 \%$ & $19.52 \%$ \\
\hline & Cerion 1 & $-4.87 \%$ & $12.71 \%$ \\
\hline
\end{tabular}

\subsubsection{Trends Between PM and CO}

Table 8-10 Percent Change in bsPM and bsCO for Transient Testing

\begin{tabular}{|c|c|c|c|}
\hline Engine & Additive & $\begin{array}{c}\% \Delta \text { from } \\
\text { baseline for } \\
\text { bsPM }\end{array}$ & $\begin{array}{c}\% \Delta \text { from } \\
\text { baseline for } \\
\text { bs CO }\end{array}$ \\
\hline \multirow[t]{3}{*}{ Cummins } & Cerion 1 & $2.62 \%$ & $4.34 \%$ \\
\hline & H2Oil 1 & $5.77 \%$ & $2.56 \%$ \\
\hline & NanoBonus & $-5.19 \%$ & $-2.52 \%$ \\
\hline \multirow[t]{2}{*}{ Mack } & Cerion 1 & $0.48 \%$ & $1.69 \%$ \\
\hline & Cerion 2 & $1.89 \%$ & $1.27 \%$ \\
\hline \multirow[t]{3}{*}{ DDC } & H2Oil 1 & $2.62 \%$ & $-3.65 \%$ \\
\hline & Cerion 1 & $5.77 \%$ & $0.43 \%$ \\
\hline & NanoBonus & $-5.19 \%$ & $-3.31 \%$ \\
\hline \multirow[t]{3}{*}{$\begin{array}{l}\text { AM } \\
\text { General }\end{array}$} & NanoBonus & $-2.25 \%$ & $1.52 \%$ \\
\hline & H2Oil 2 & $-0.31 \%$ & $-2.79 \%$ \\
\hline & Cerion 1 & $7.47 \%$ & $-0.28 \%$ \\
\hline
\end{tabular}




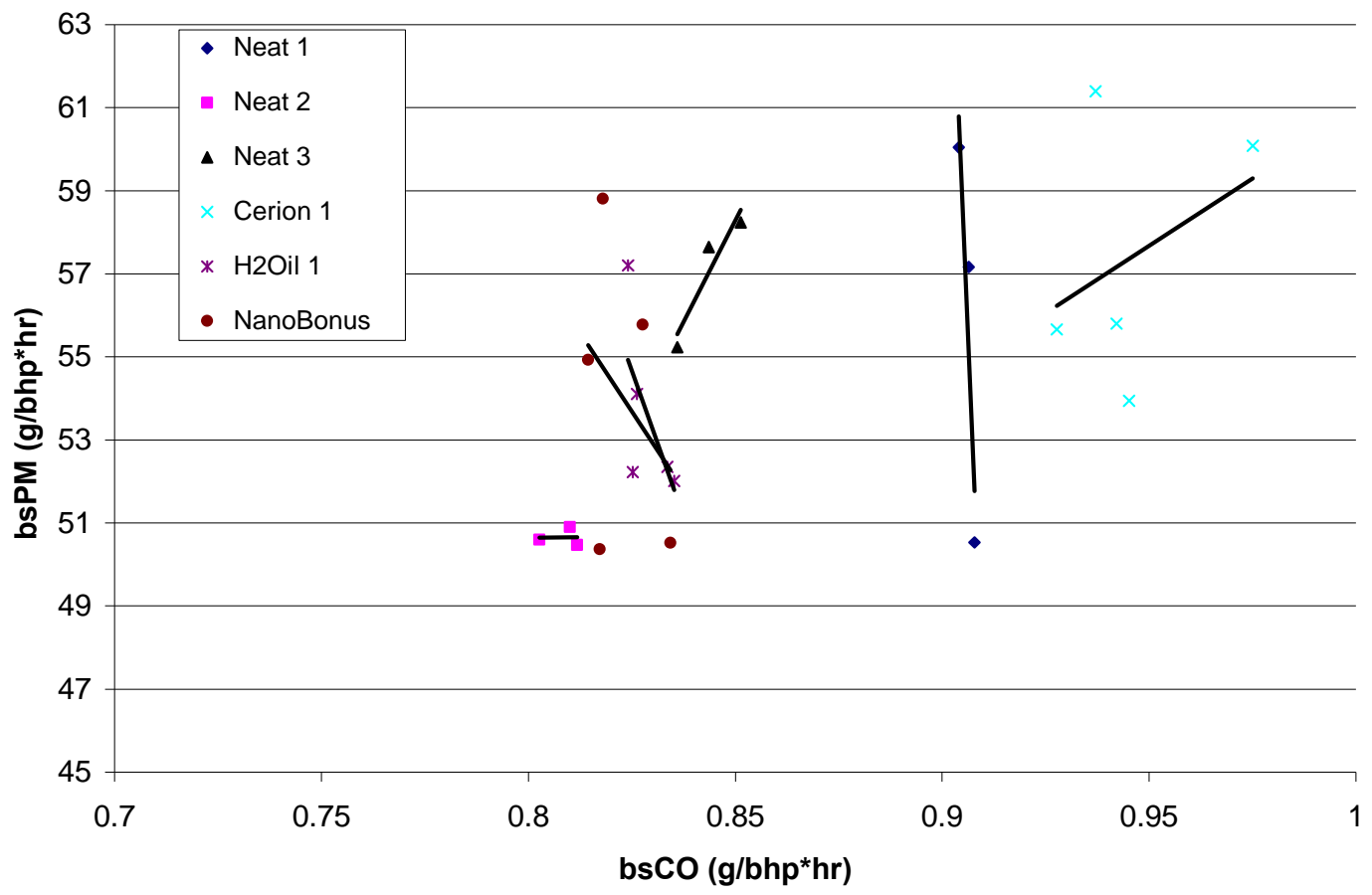

Figure 8-3 PM-CO Trend for Cummins Transient Testing 


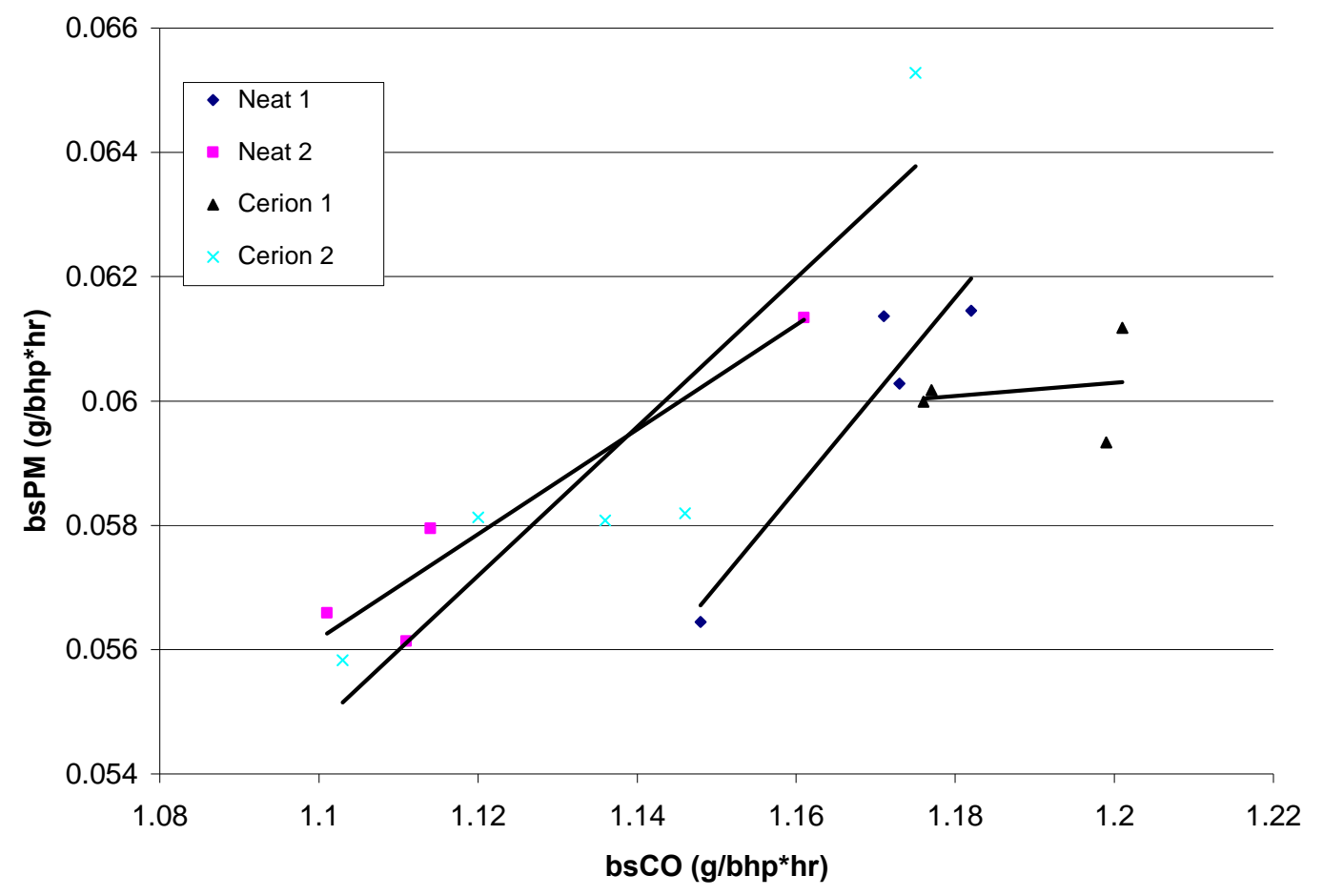

Figure 8-4 PM-CO Trend for Mack Transient Testing 


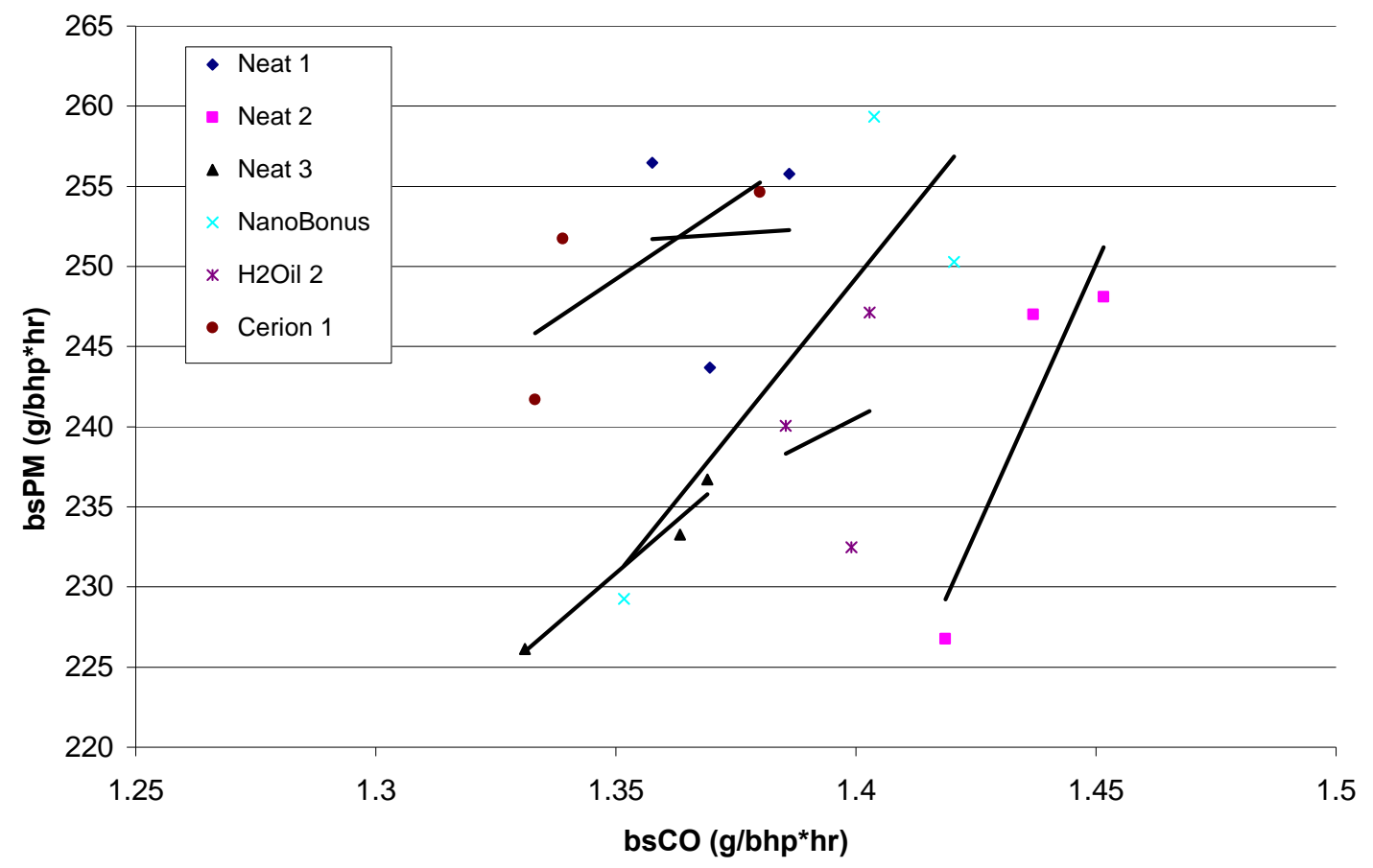

Figure 8-5 PM-CO Trend for AM General Transient Testing 


\subsection{Steady-State Test Results}

\subsubsection{AM General BSFC Results}

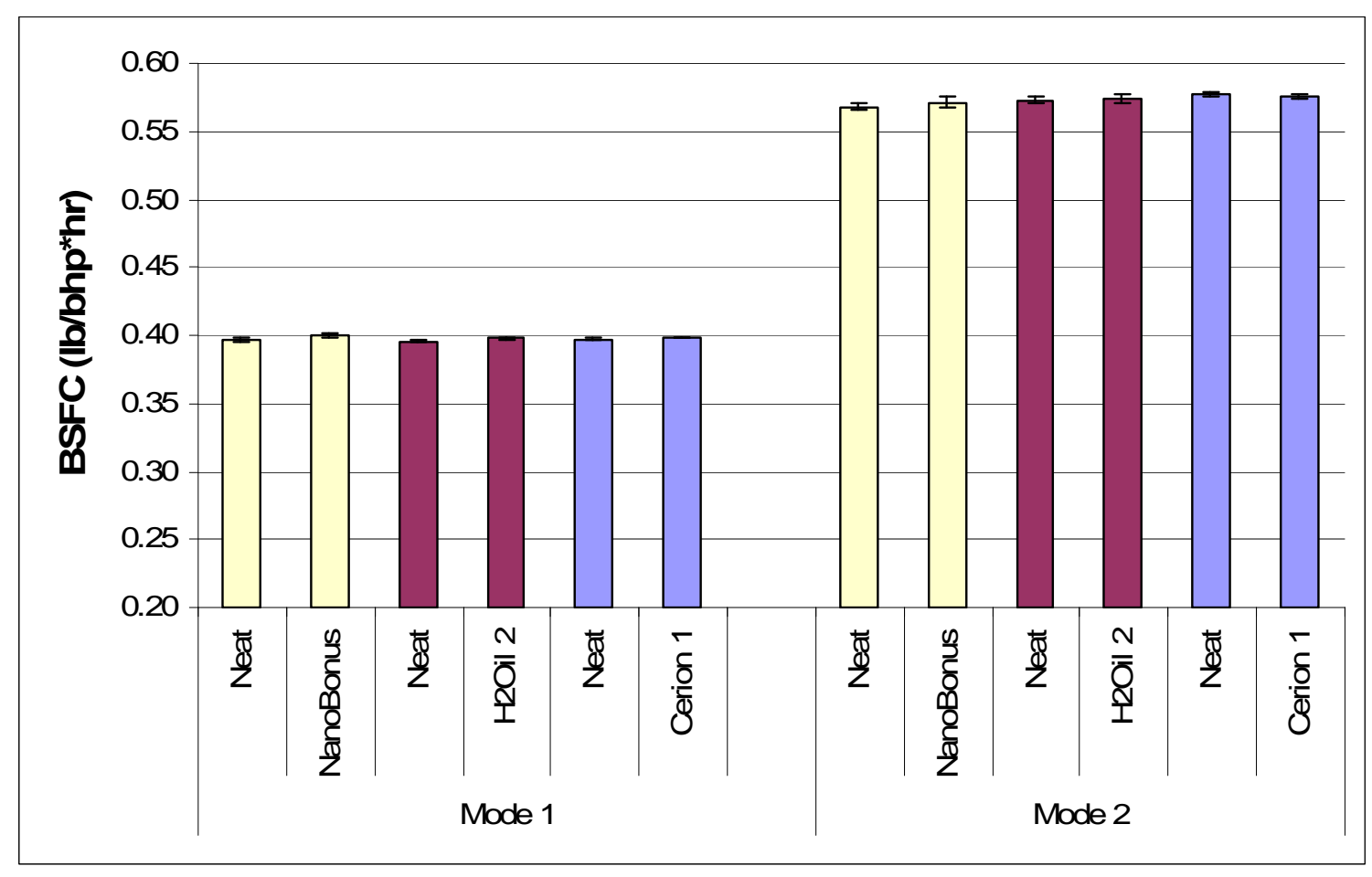

Figure 8-6 Average BSFC Steady-State Test Results for AM General 


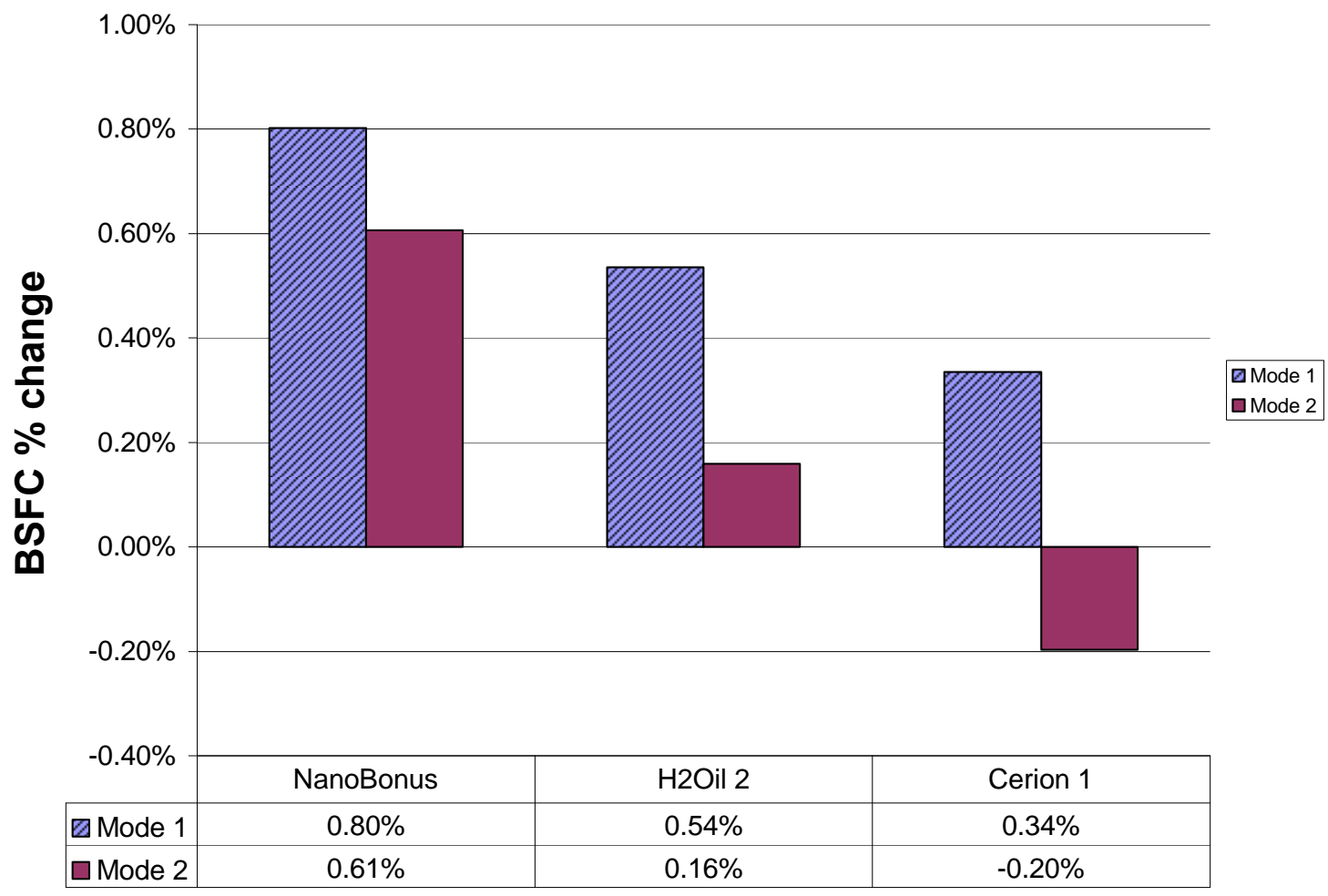

Figure 8-7 Percent Change in BSFC from Baseline

Table 8-11 AM General Steady-State BSFC p-values

\begin{tabular}{|l|r|r|}
\hline Additive & \multicolumn{1}{|c|}{ Mode 1 } & \multicolumn{1}{c|}{ Mode 2 } \\
\hline NanoBonus & $\mathbf{0 . 0 3 9}$ & 0.289 \\
\hline H2Oil 2 & $\mathbf{0 . 0 2 1}$ & 0.659 \\
\hline Cerion 1 & $\mathbf{0 . 0 4 4}$ & 0.380 \\
\hline
\end{tabular}

Table 8-12 AM General Steady-State BSFC Variation Results

\begin{tabular}{|c|c|c|c|}
\hline & & $\begin{array}{c}\text { Difference } \\
\text { from } \\
\text { Baseline }\end{array}$ & $\begin{array}{c}\text { Combined } \\
\text { Variations }\end{array}$ \\
\hline Mode 1 & NanoBonus & $\mathbf{0 . 8 0 \%}$ & $1.26 \%$ \\
\hline & H2Oil 2 & $\mathbf{0 . 5 4 \%}$ & $0.86 \%$ \\
\hline & Cerion 1 & $\mathbf{0 . 3 4 \%}$ & $0.55 \%$ \\
\hline & & & \\
\hline Mode 2 & NanoBonus & $0.61 \%$ & $2.23 \%$ \\
\hline & H2Oil 2 & $0.16 \%$ & $1.84 \%$ \\
\hline & Cerion 1 & $-0.20 \%$ & $1.17 \%$ \\
\hline
\end{tabular}




\subsubsection{AM General $\mathrm{CO}_{2}$ Results}

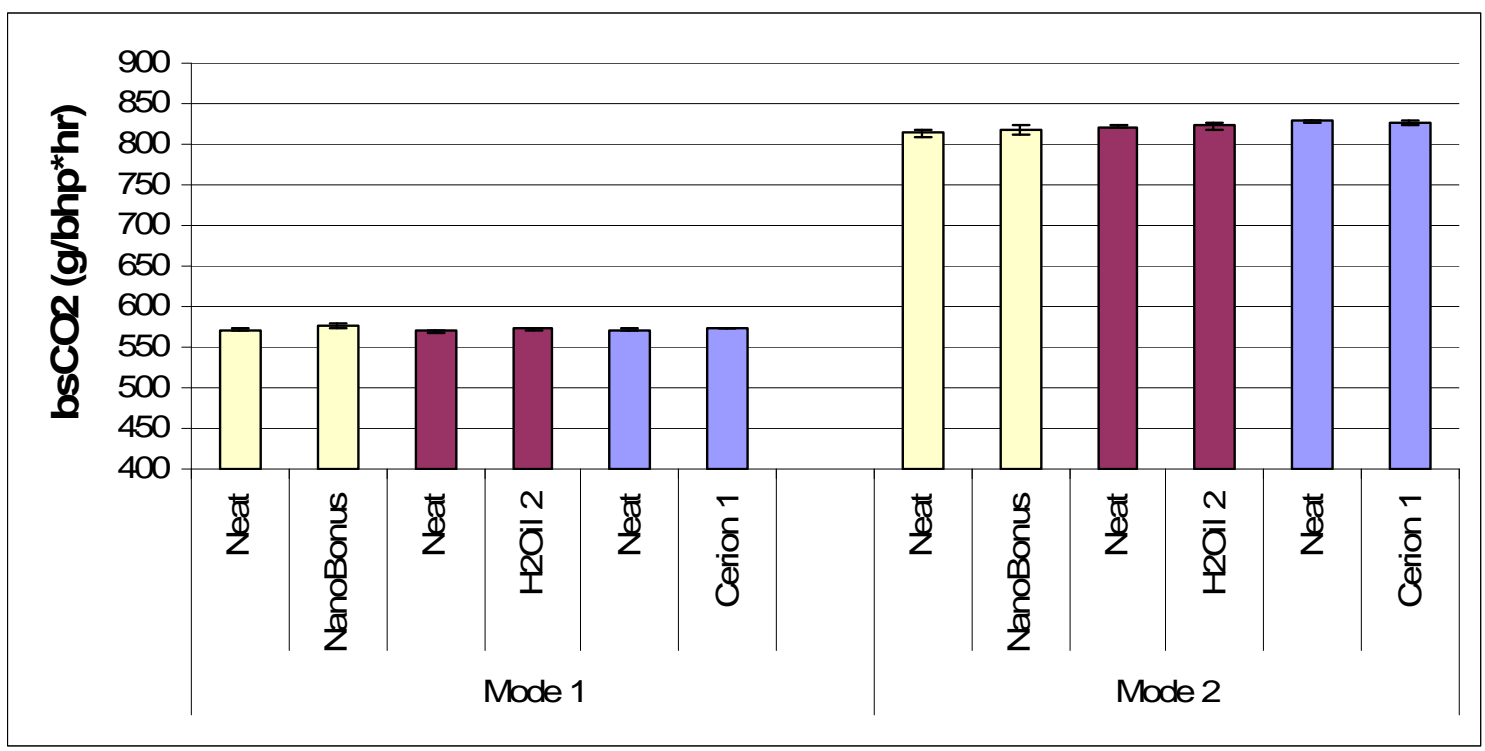

Figure 8-8 Average $\mathrm{BSCO}_{2}$ Steady-State Test Results for AM General

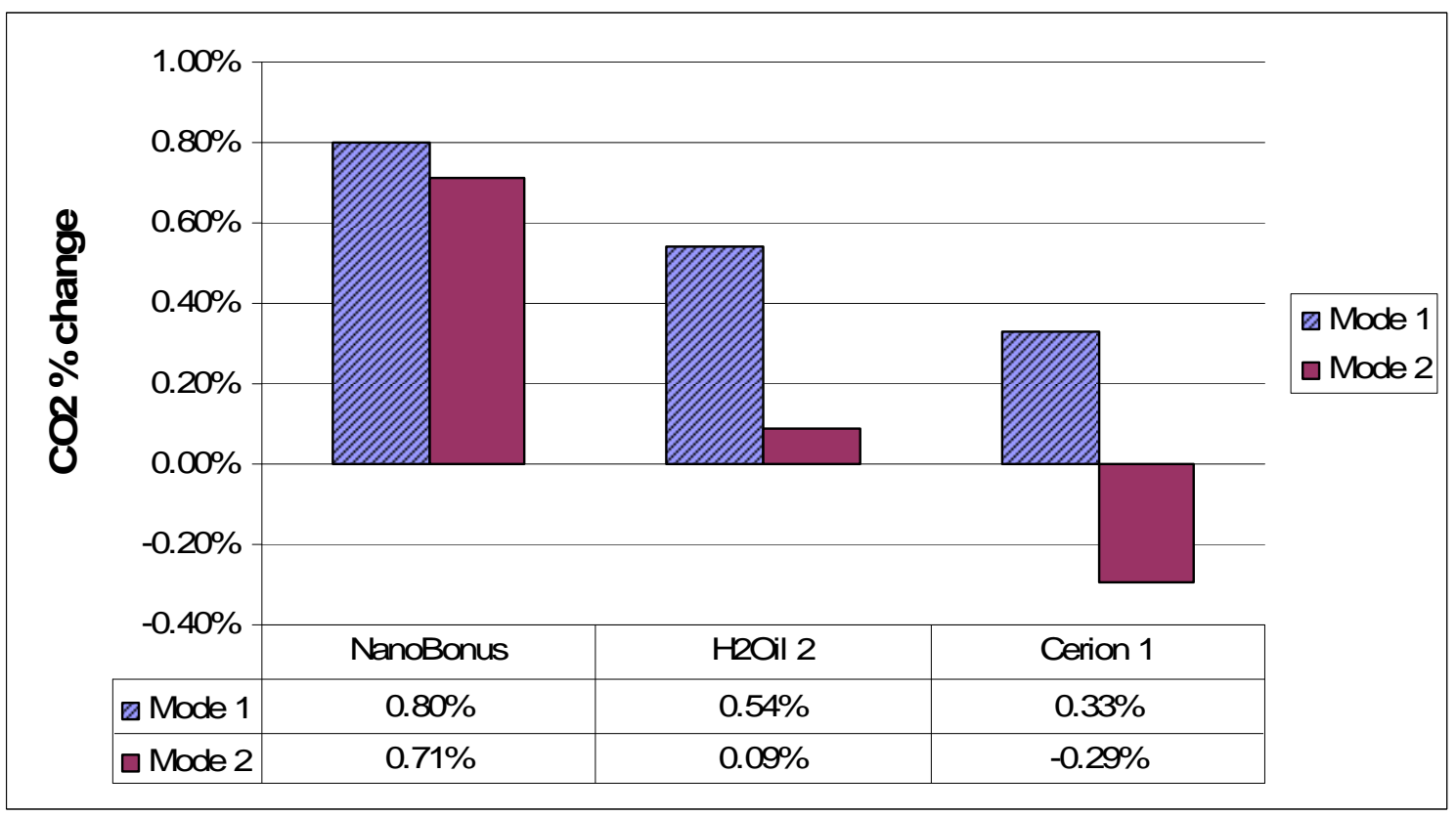

Figure 8-9 Percent Change in $\mathrm{BSCO}_{2}$ from Baseline for $\mathrm{AM}$ General 
Table 8-13 AM General Steady-State $\mathrm{CO}_{2}$ p-values

\begin{tabular}{|l|r|r|}
\hline Additive & Mode 1 & Mode 2 \\
\hline NanoBonus & $\mathbf{0 . 0 4 0}$ & 0.206 \\
\hline H2Oil 2 & $\mathbf{0 . 0 2 0}$ & 0.819 \\
\hline Cerion 1 & $\mathbf{0 . 0 4 5}$ & 0.213 \\
\hline
\end{tabular}

Table 8-14 AM General Steady-State $\mathrm{CO}_{2}$ Variation Results

\begin{tabular}{|l|c|r|r|}
\hline & & $\begin{array}{c}\text { Difference } \\
\text { from } \\
\text { Baseline }\end{array}$ & $\begin{array}{c}\text { Combined } \\
\text { Variations }\end{array}$ \\
\hline Mode 1 & NanoBonus & $\mathbf{0 . 8 0 \%}$ & $1.26 \%$ \\
\hline & H2Oil 2 & $\mathbf{0 . 5 4 \%}$ & $0.84 \%$ \\
\hline & Cerion 1 & $\mathbf{0 . 3 3 \%}$ & $0.54 \%$ \\
\hline & & & \\
\hline Mode 2 & NanoBonus & $0.71 \%$ & $2.16 \%$ \\
\hline & H2Oil 2 & $0.09 \%$ & $1.86 \%$ \\
\hline & Cerion 1 & $-0.29 \%$ & $1.16 \%$ \\
\hline
\end{tabular}

\subsubsection{AM General $\mathrm{NO}_{\mathrm{x}}$ Results}

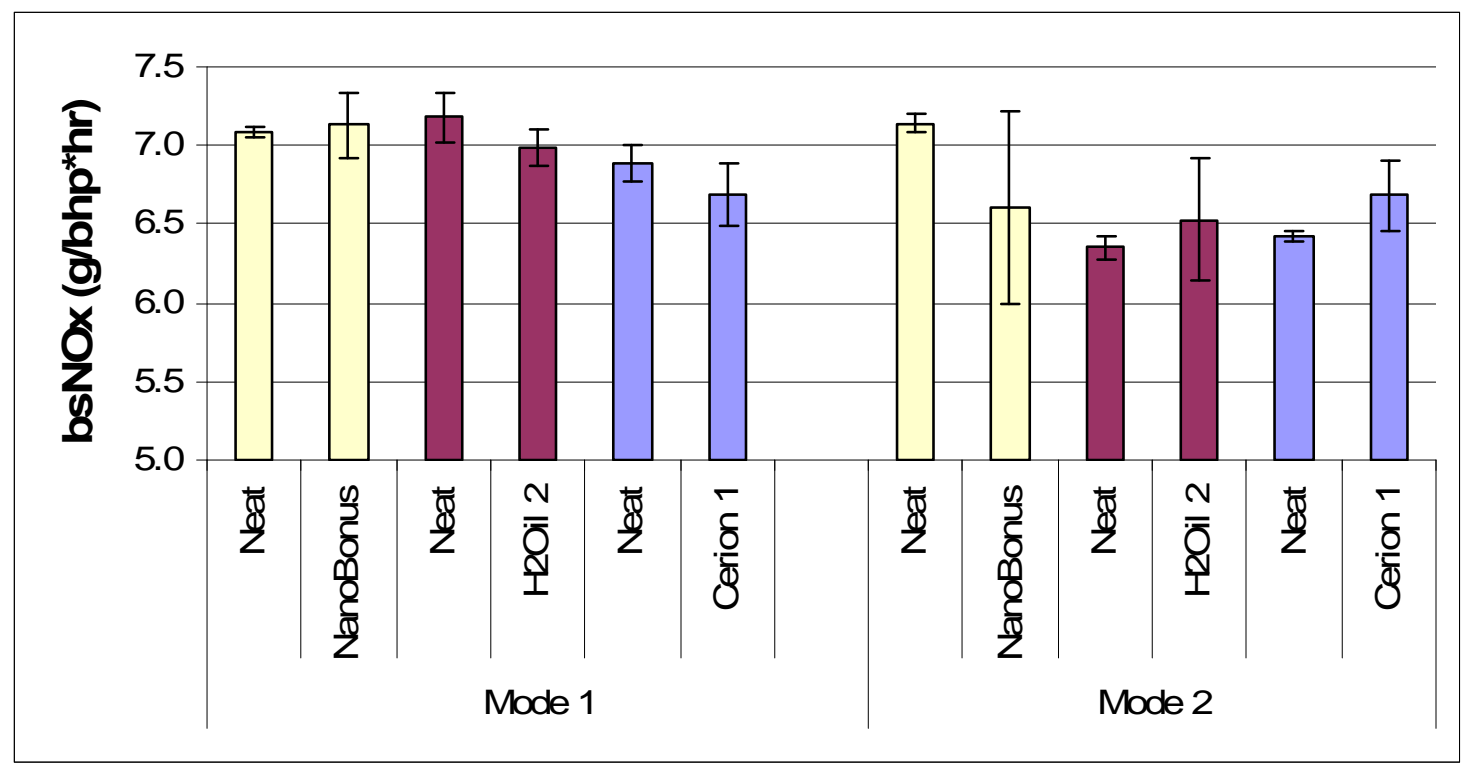

Figure 8-10 Average $\mathrm{BSNO}_{\mathrm{x}}$ Steady-State Test Results for AM General 


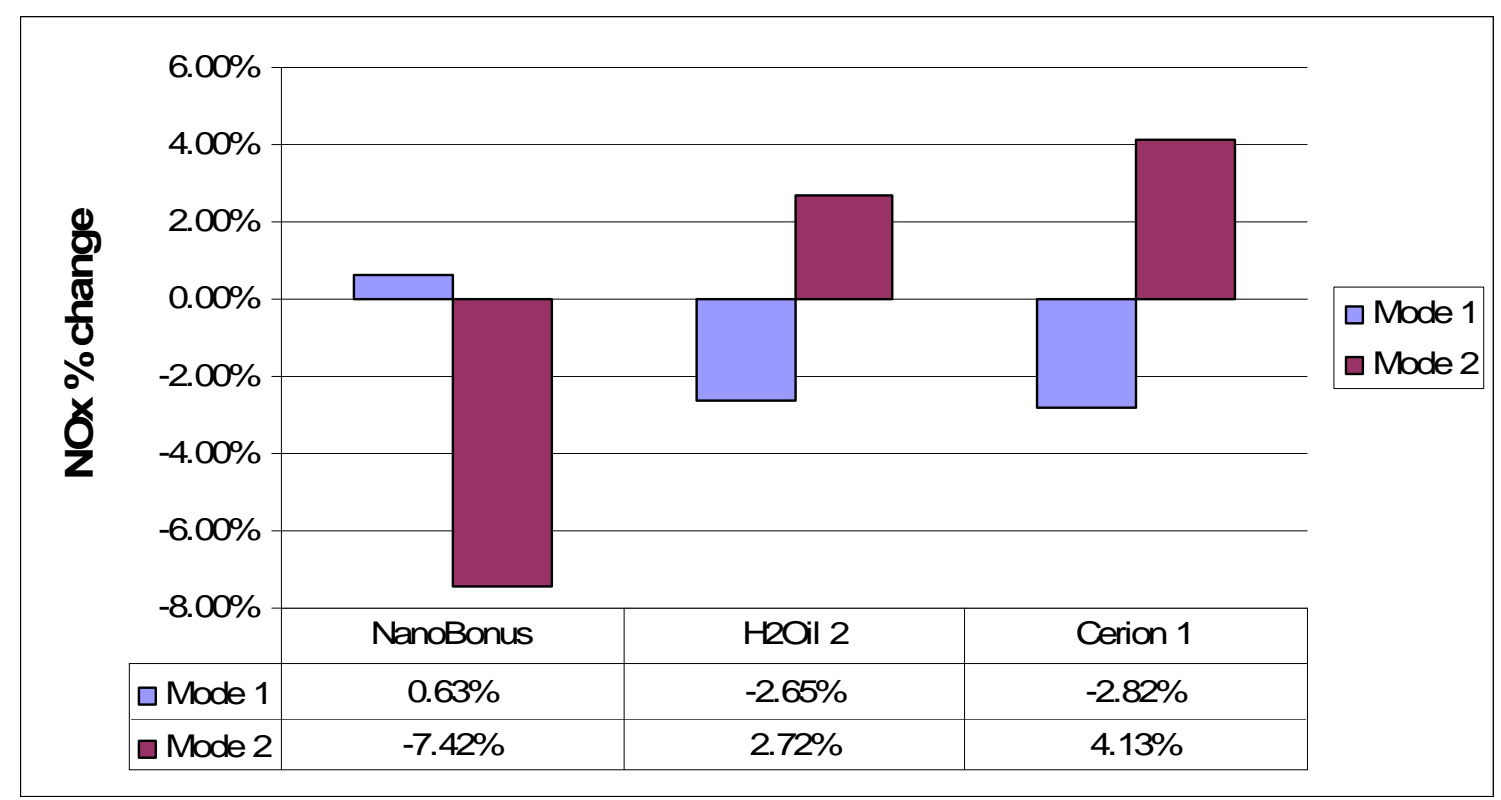

Figure 8-11 Percent Change in $\mathrm{BSNO}_{\mathrm{x}}$ from Baseline for AM General

Table 8-15 AM General Steady-State NO $_{x}$ p-values

\begin{tabular}{|l|r|r|}
\hline Additive & \multicolumn{1}{|c|}{ Mode 1 } & \multicolumn{1}{c|}{ Mode 2 } \\
\hline NanoBonus & 0.728 & 0.208 \\
\hline H2Oil 2 & 0.123 & 0.490 \\
\hline Cerion 1 & 0.159 & 0.058 \\
\hline
\end{tabular}

Table 8-16 AM General Steady-State $\mathrm{NO}_{\mathrm{x}}$ Variation Results

\begin{tabular}{|l|c|r|r|}
\hline & & $\begin{array}{c}\text { Difference } \\
\text { from } \\
\text { Baseline }\end{array}$ & $\begin{array}{r}\text { Combined } \\
\text { Variations }\end{array}$ \\
\hline Mode 1 & NanoBonus & $0.63 \%$ & $6.32 \%$ \\
\hline & H2Oil 2 & $-2.65 \%$ & $8.28 \%$ \\
\hline & Cerion 1 & $-2.82 \%$ & $9.13 \%$ \\
\hline & & & \\
\hline Mode 2 & NanoBonus & $-7.42 \%$ & $16.44 \%$ \\
\hline & H2Oil 2 & $2.72 \%$ & $13.14 \%$ \\
\hline & Cerion 1 & $4.13 \%$ & $7.35 \%$ \\
\hline
\end{tabular}




\subsubsection{AM General CO Results}

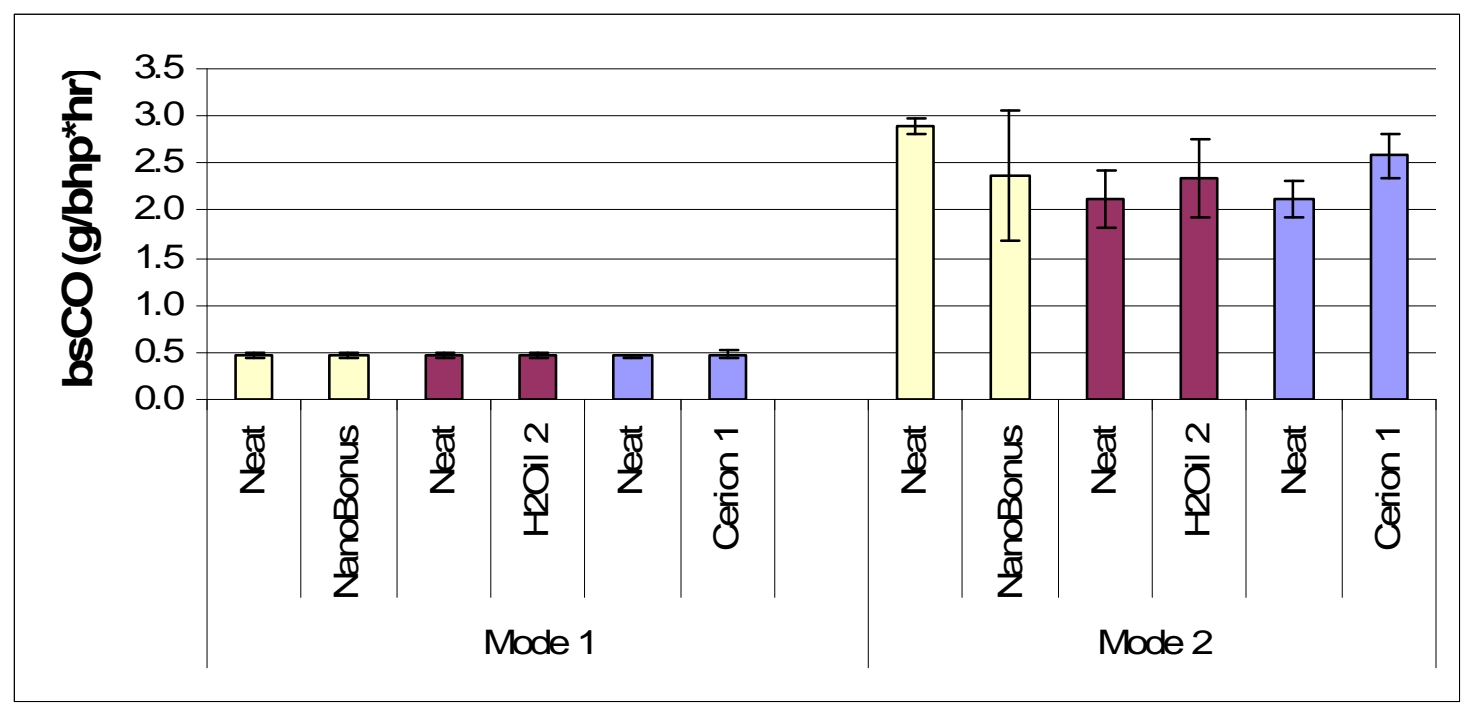

Figure 8-12 Average BSCO Steady-State Test Results for AM General

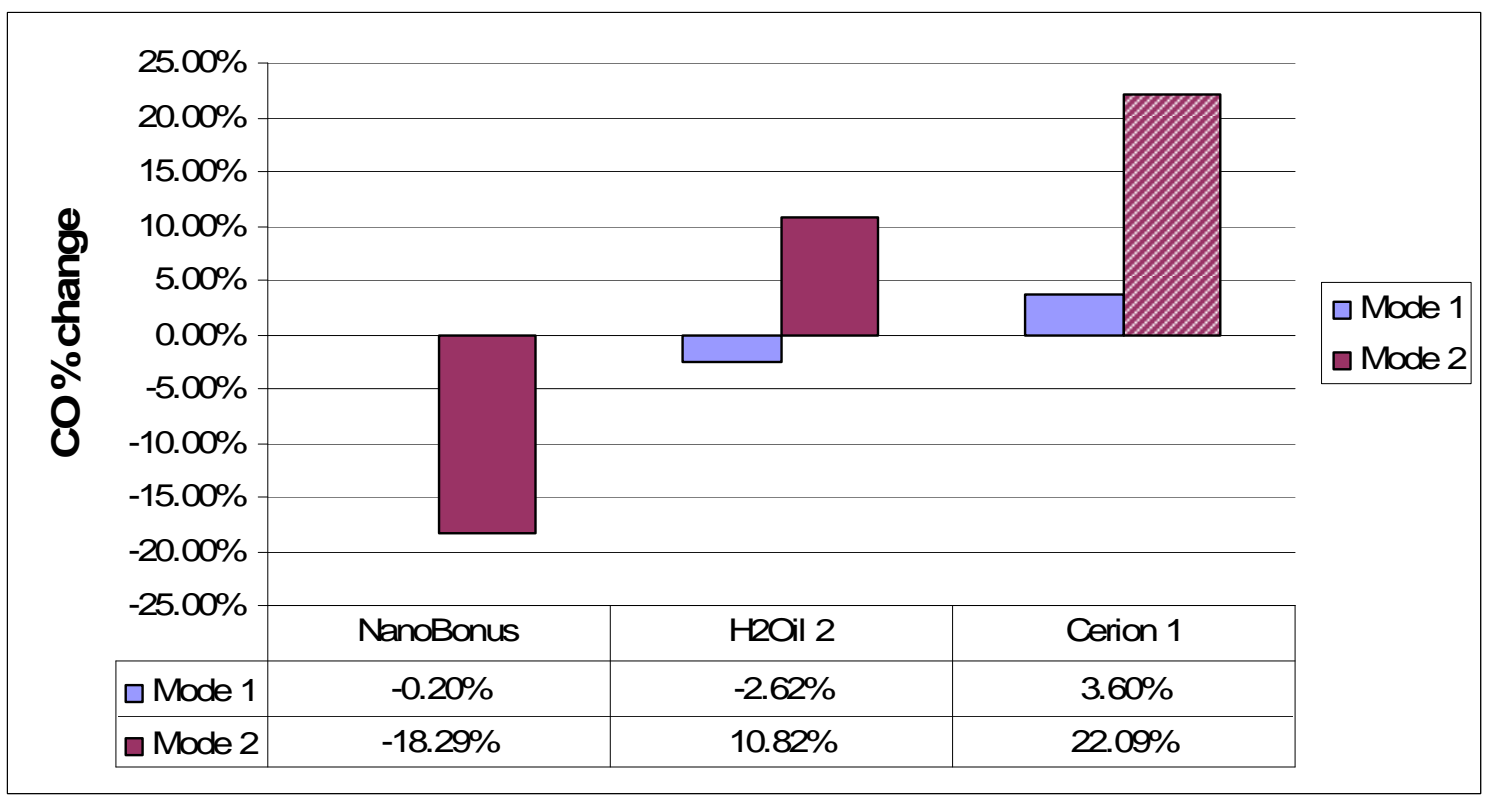

Figure 8-13 Percent Change in BSCO from Baseline for AM General 
Table 8-17 AM General Steady-State CO p-values

\begin{tabular}{|l|r|r|}
\hline Additive & Mode 1 & \multicolumn{1}{|l|}{ Mode 2 } \\
\hline NanoBonus & 0.965 & 0.254 \\
\hline H2Oil 2 & 0.578 & 0.459 \\
\hline Cerion 1 & 0.482 & $\mathbf{0 . 0 3 2}$ \\
\hline
\end{tabular}

Table 8-18 AM General Steady-State CO Variation Results

\begin{tabular}{|l|c|r|r|}
\hline & & $\begin{array}{c}\text { Difference } \\
\text { from } \\
\text { Baseline }\end{array}$ & $\begin{array}{c}\text { Combined } \\
\text { Variations }\end{array}$ \\
\hline Mode 1 & NanoBonus & $-0.20 \%$ & $18.66 \%$ \\
\hline & H2Oil 2 & $-2.62 \%$ & $21.85 \%$ \\
\hline & Cerion 1 & $3.60 \%$ & $24.69 \%$ \\
\hline & & & \\
\hline Mode 2 & NanoBonus & $-18.29 \%$ & $46.49 \%$ \\
\hline & H2Oil 2 & $10.82 \%$ & $56.01 \%$ \\
\hline & Cerion 1 & $\mathbf{2 2 . 0 9 \%}$ & $33.78 \%$ \\
\hline
\end{tabular}

\subsubsection{AM General PM Results}

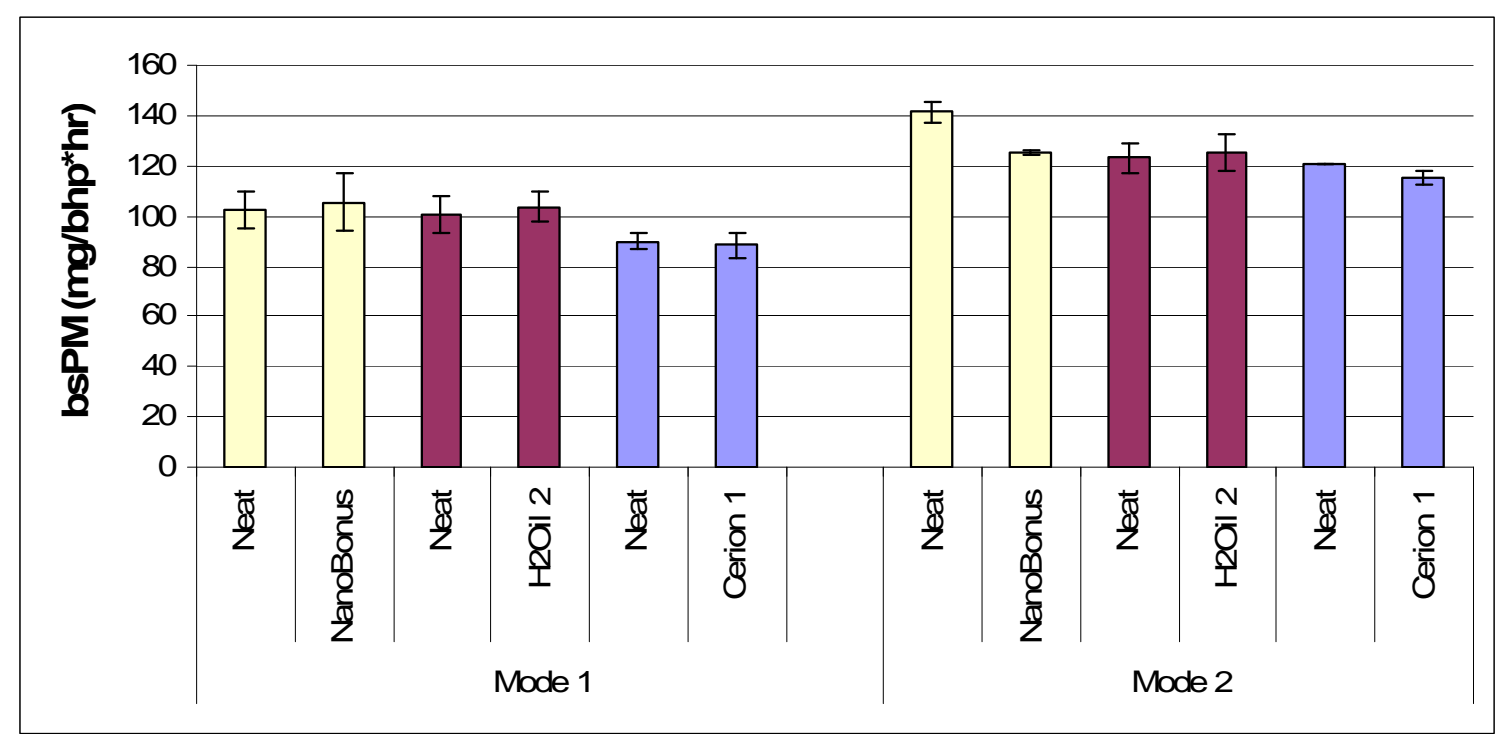

Figure 8-14 Average BSPM Steady-State Test Results for AM General 


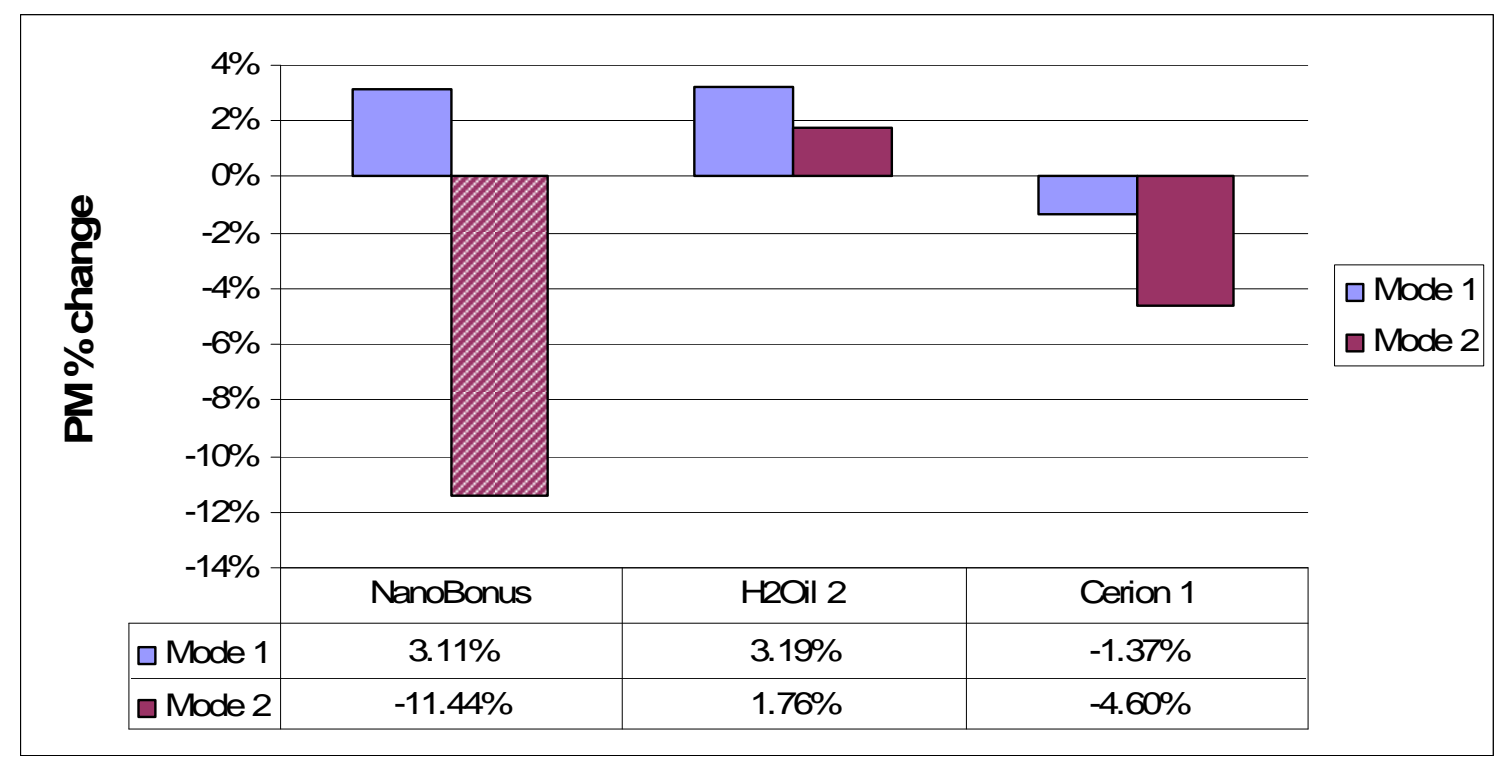

Figure 8-15 Percent Change in BSPM from Baseline for AM General

Table 8-19 AM General Steady-State PM p-values

\begin{tabular}{|l|r|r|}
\hline Additive & \multicolumn{1}{|c|}{ Mode 1 } & \multicolumn{1}{c|}{ Mode 2 } \\
\hline NanoBonus & 0.756 & $\mathbf{0 . 0 3 4}$ \\
\hline H2Oil 2 & 0.552 & 0.708 \\
\hline Cerion 1 & 0.753 & 0.028 \\
\hline
\end{tabular}

Table 8-20 AM General Steady-State PM Variation Results

\begin{tabular}{|l|l|c|c|}
\hline & & $\begin{array}{c}\text { Difference } \\
\text { from } \\
\text { Baseline }\end{array}$ & $\begin{array}{c}\text { Combined } \\
\text { Variations }\end{array}$ \\
\hline Mode 1 & NanoBonus & $3.11 \%$ & $29.29 \%$ \\
\hline & H2Oil 2 & $3.19 \%$ & $25.00 \%$ \\
\hline & Cerion 1 & $-6.96 \%$ & $41.25 \%$ \\
\hline & & & \\
\hline Mode 2 & NanoBonus & $-11.44 \%$ & $5.52 \%$ \\
\hline & H2Oil 2 & $1.76 \%$ & $18.84 \%$ \\
\hline & Cerion 1 & $12.60 \%$ & $3.42 \%$ \\
\hline
\end{tabular}




\subsubsection{AM General HC Results}

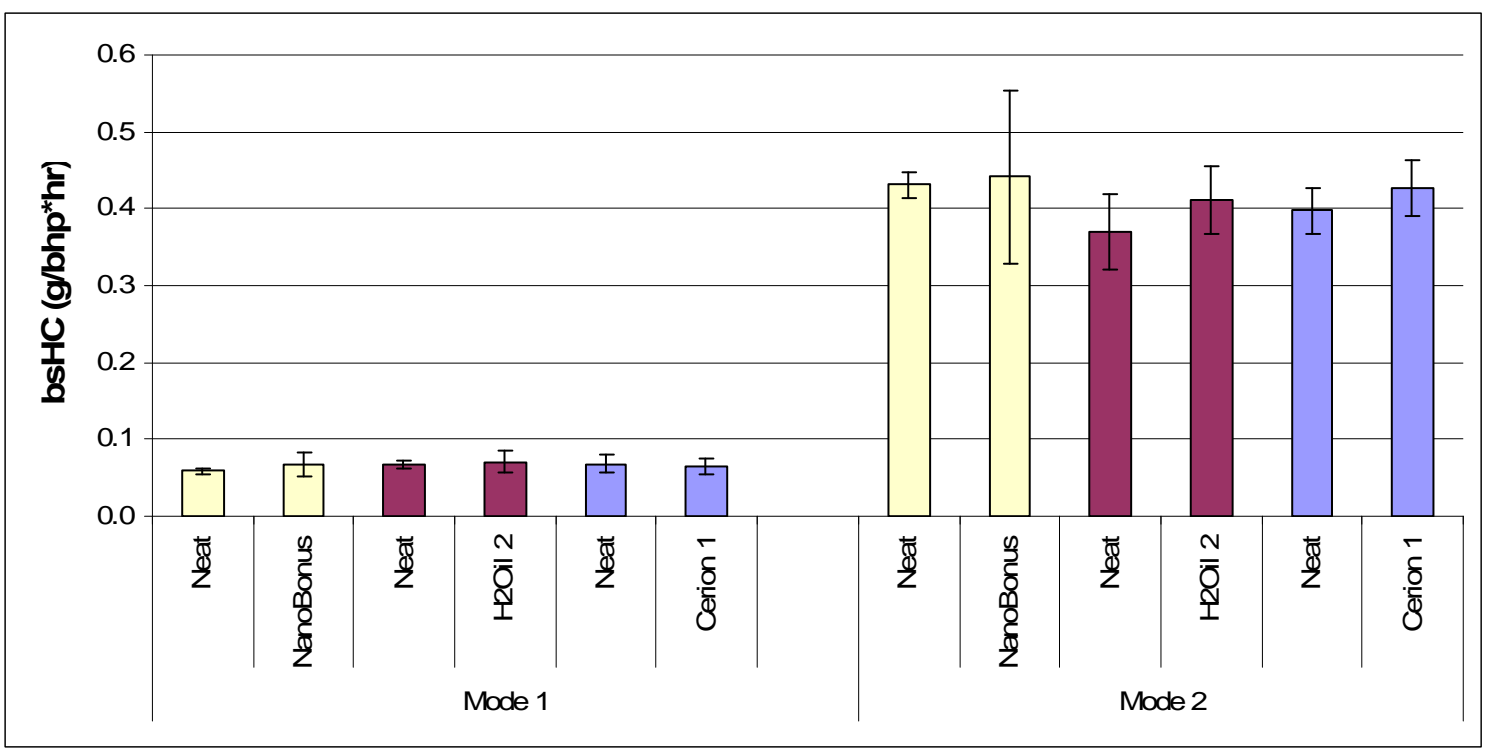

Figure 8-16 Average BSHC Steady-State Test Results for AM General

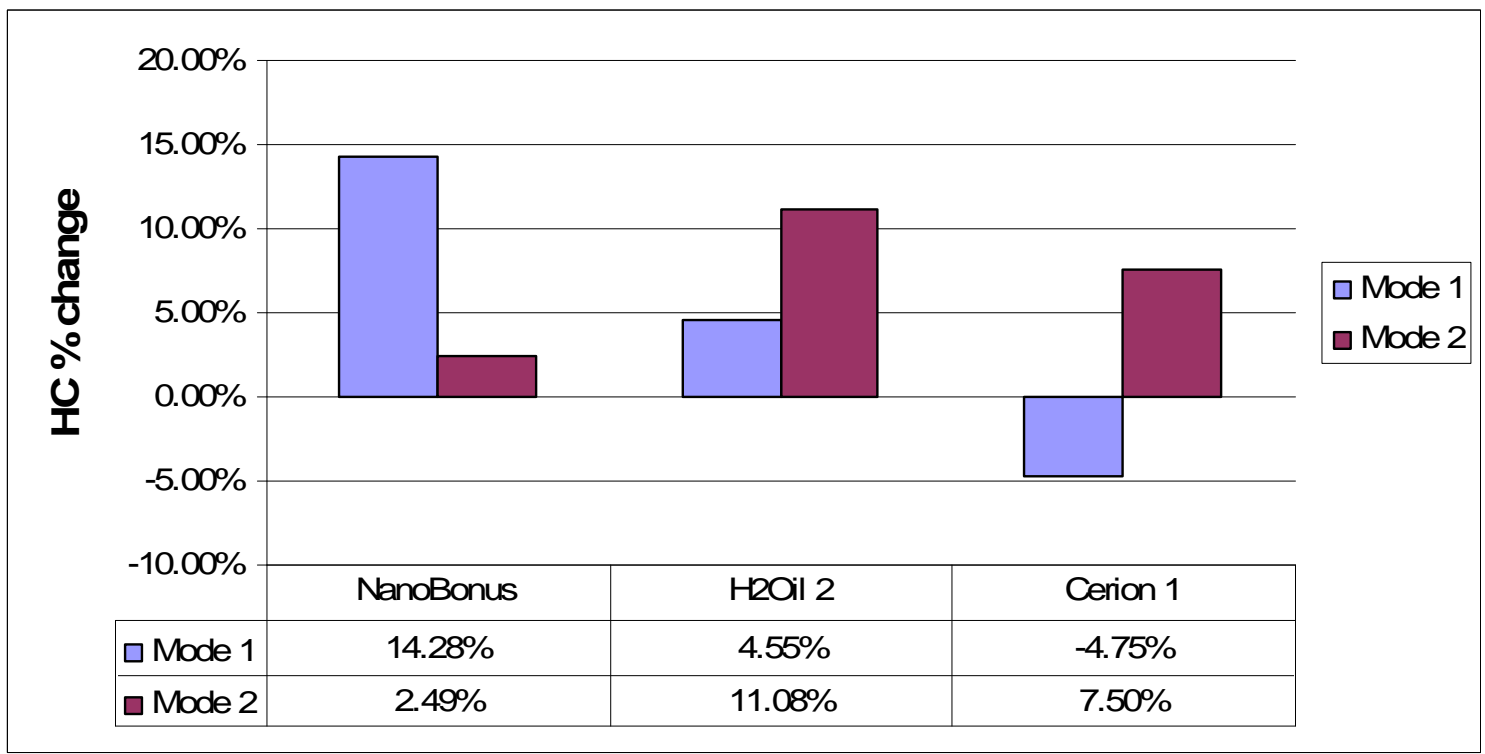

Figure 8-17 Percent Change in BSHC from Baseline for AM General 
Table 8-21 AM General Steady-State HC p-values

\begin{tabular}{|l|r|r|}
\hline Additive & \multicolumn{1}{|c|}{ Mode 1 } & \multicolumn{1}{|l|}{ Mode 2 } \\
\hline NanoBonus & 0.143 & 0.878 \\
\hline H2Oil 2 & 0.743 & 0.299 \\
\hline Cerion 1 & 0.714 & 0.277 \\
\hline
\end{tabular}

Table 8-22 AM General Steady-State HC Variation Results

\begin{tabular}{|l|c|r|r|}
\hline & & $\begin{array}{c}\text { Difference } \\
\text { from } \\
\text { Baseline }\end{array}$ & $\begin{array}{c}\text { Combined } \\
\text { Variations }\end{array}$ \\
\hline Mode 1 & NanoBonus & $14.28 \%$ & $14.59 \%$ \\
\hline & H2Oil 2 & $4.55 \%$ & $46.57 \%$ \\
\hline & Cerion 1 & $-4.75 \%$ & $52.40 \%$ \\
\hline & & & $46.76 \%$ \\
\hline Mode 2 & NanoBonus & $2.49 \%$ & $46.65 \%$ \\
\hline & H2Oil 2 & $11.08 \%$ & $31.44 \%$ \\
\hline & Cerion 1 & $7.50 \%$ & \\
\hline
\end{tabular}

\subsubsection{DDC BSFC Results}

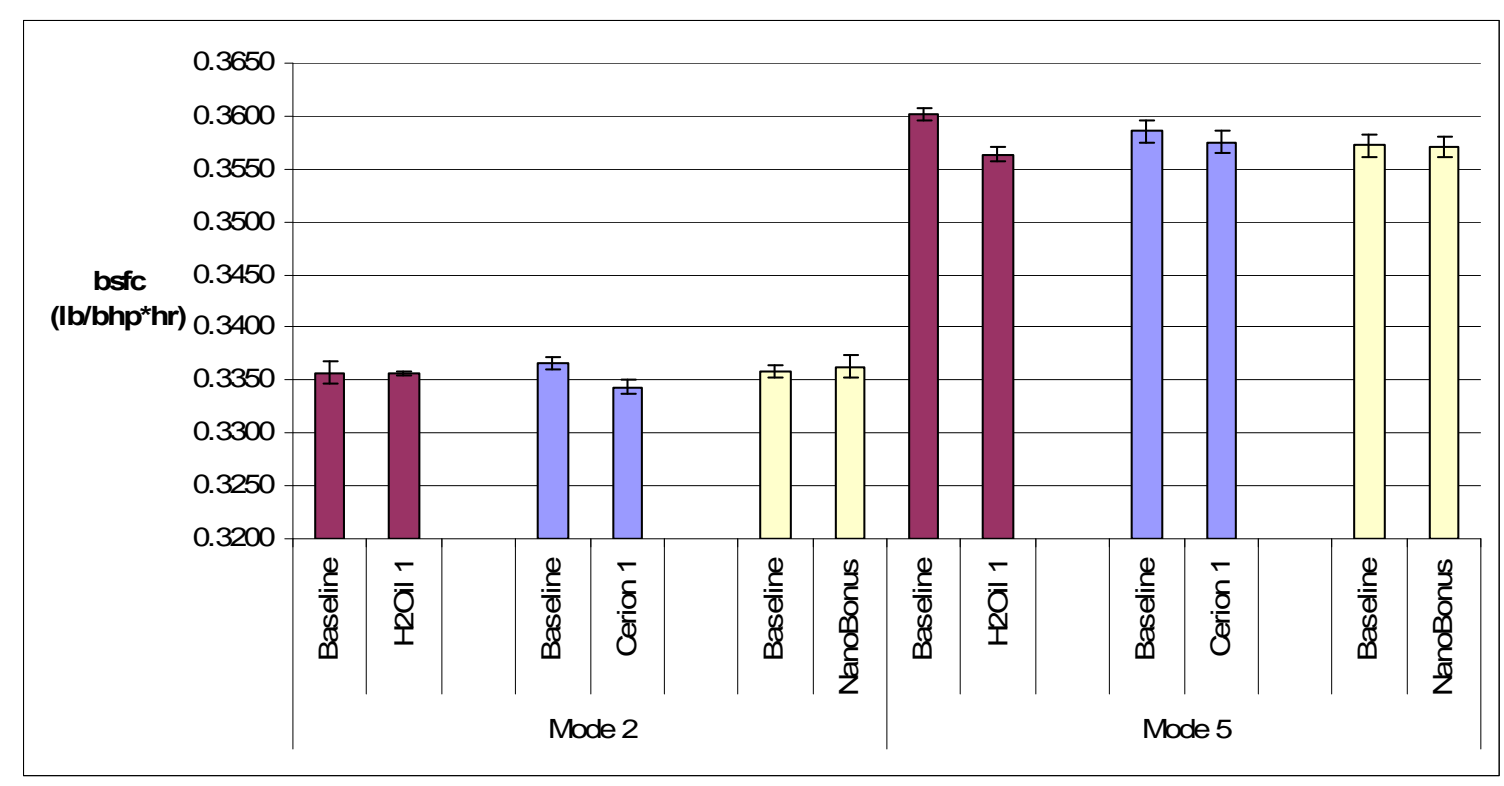

Figure 8-18 BSFC for Modes 2 and 5 of DDC Steady State Testing 


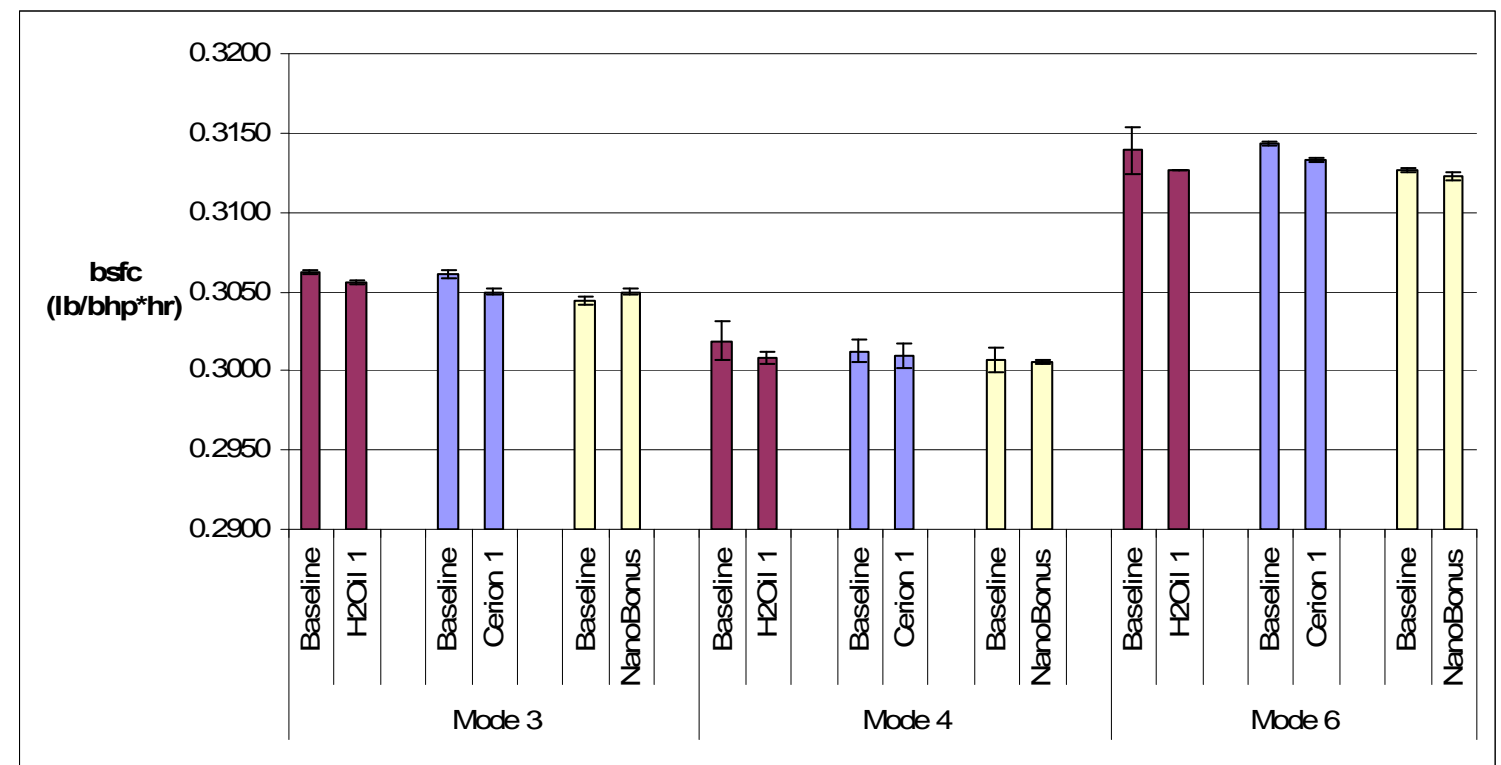

Figure 8-19 BSFC for Modes 3, 4, and 5 of DDC Steady State Testing

\subsubsection{DDC $\mathrm{CO}_{2}$ Results}

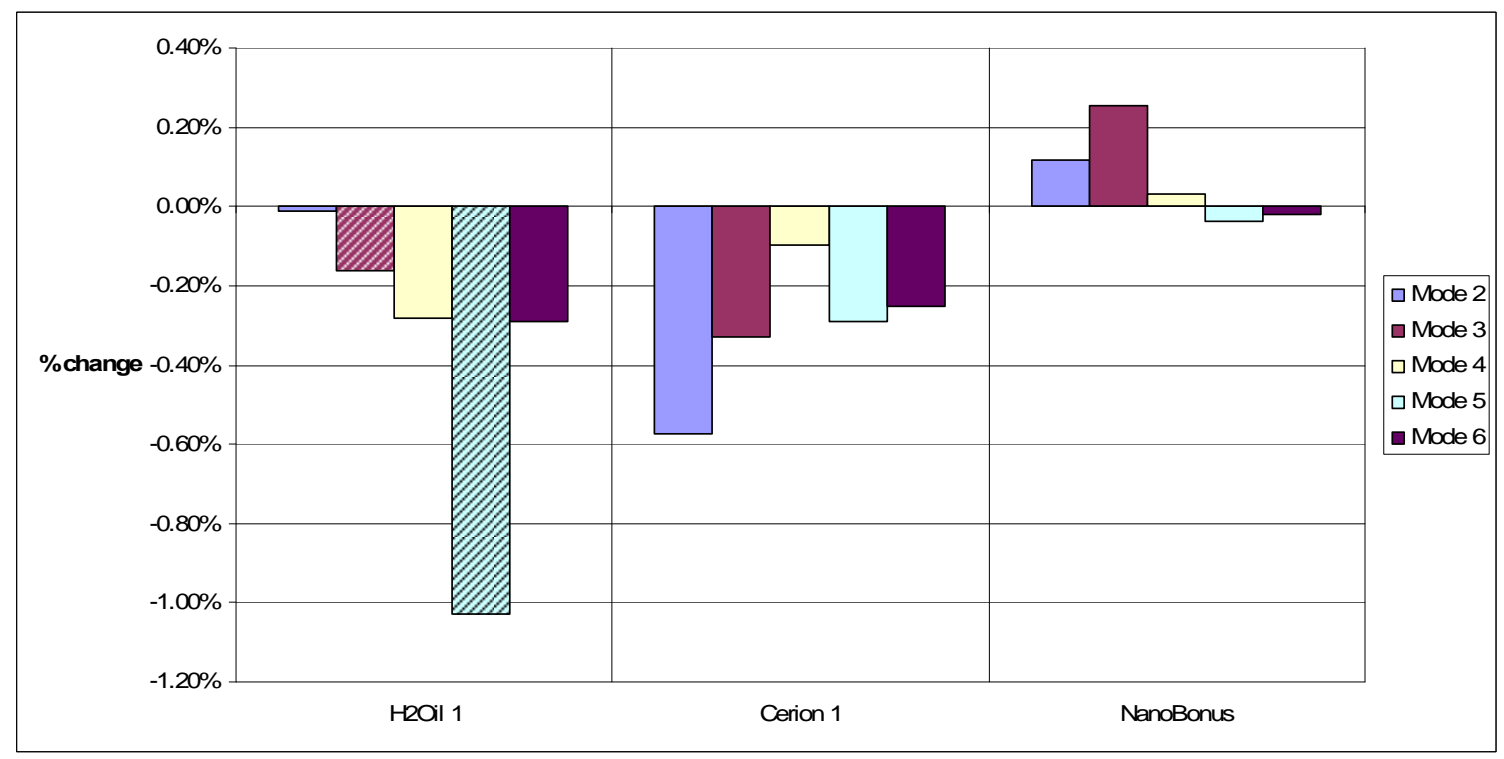

Figure 8-20 Percent Change in $\mathrm{BSCO}_{2}$ for DDC Steady State Testing 
Table 8-23 p-Values for $\mathrm{CO}_{2}$ for DDC Steady State Testing

\begin{tabular}{|l|c|c|c|c|}
\hline Additive & Mode 2 & Mode 3 & Mode 4 & Mode 5 \\
\hline H2Oil 1 & 0.962 & $\mathbf{0 . 0 0 5}$ & 0.399 & $\mathbf{0 . 0 2 0}$ \\
Cerion 1 & - & - & - & - \\
NanoBonus & 0.707 & 0.108 & 0.848 & 0.421 \\
\hline
\end{tabular}

Table 8-24 $\mathrm{BSCO}_{2}$ Variation Results of DDC for Steady State Testing

\begin{tabular}{|l|l|c|c|}
\hline & & $\begin{array}{c}\text { Difference } \\
\text { from Baseline }\end{array}$ & $\begin{array}{c}\text { Combined } \\
\text { Variations }\end{array}$ \\
\hline Mode 2 & H2Oil 1 & $-0.01 \%$ & $0.64 \%$ \\
\hline & Cerion 1 & $-0.57 \%$ & - \\
\hline & NanoBonus & $0.11 \%$ & $0.72 \%$ \\
\hline Mode 3 & H2Oil 1 & $-0.16 \%$ & $0.03 \%$ \\
\hline & Cerion 1 & $-0.33 \%$ & - \\
\hline & NanoBonus & $0.25 \%$ & $0.25 \%$ \\
\hline & & & \\
\hline & H2Oil 1 & $-0.28 \%$ & $0.67 \%$ \\
\hline & Cerion 1 & $-0.10 \%$ & - \\
\hline & NanoBonus & $0.03 \%$ & $0.34 \%$ \\
\hline & & & $0.41 \%$ \\
\hline & H2Oil 1 & $-1.03 \%$ & - \\
\hline & Cerion 1 & $-0.29 \%$ & $0.82 \%$ \\
\hline & NanoBonus & $-0.04 \%$ & \\
\hline & & & - \\
\hline & H2Oil 1 & $-0.29 \%$ & $0.48 \%$ \\
\hline & Cerion 1 & $-0.25 \%$ & \\
\hline & NanoBonus & $-0.02 \%$ & $0.03 \%$ \\
\hline
\end{tabular}




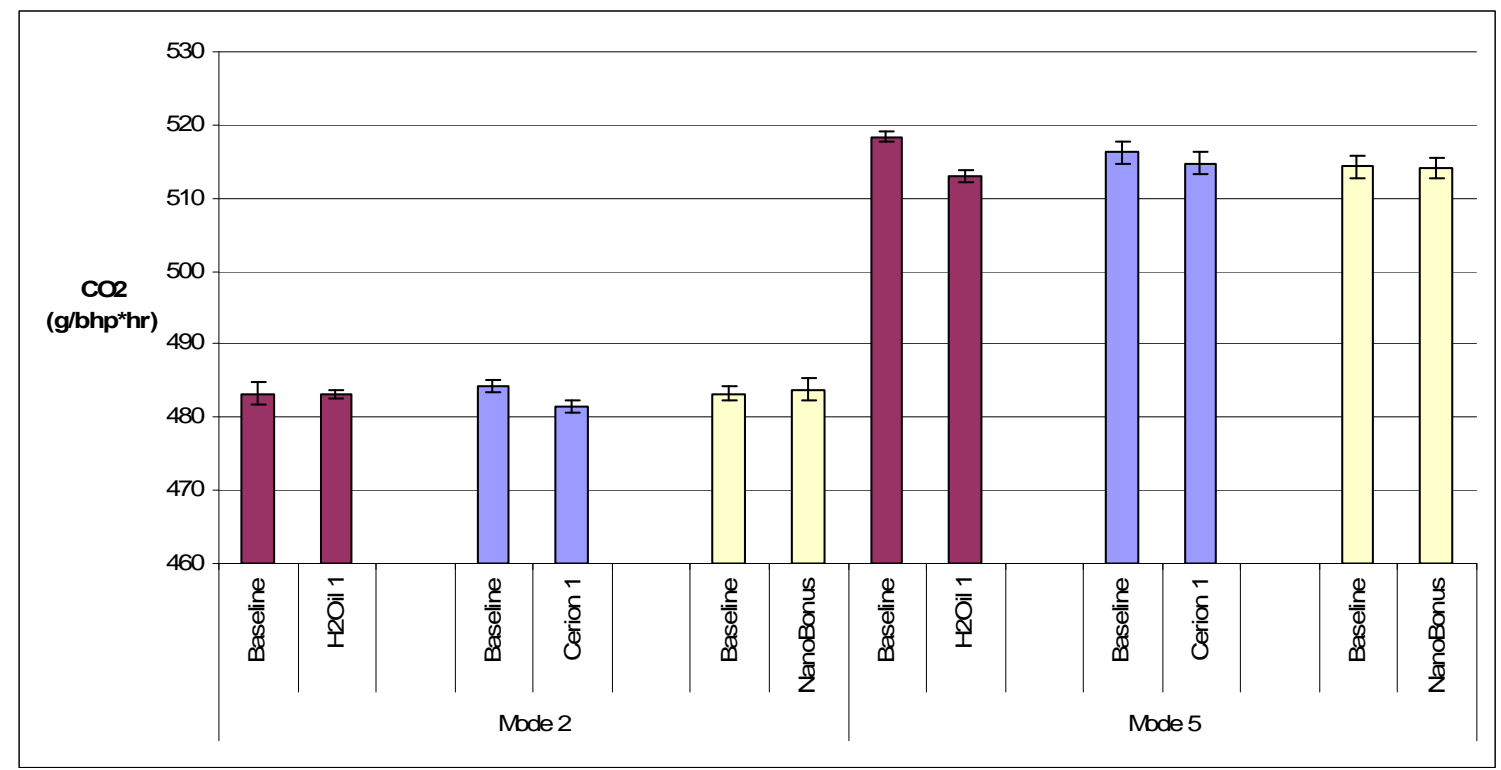

Figure 8-21 $\mathrm{BSCO}_{2}$ for Modes 2 and 5 of DDC Steady State Testing

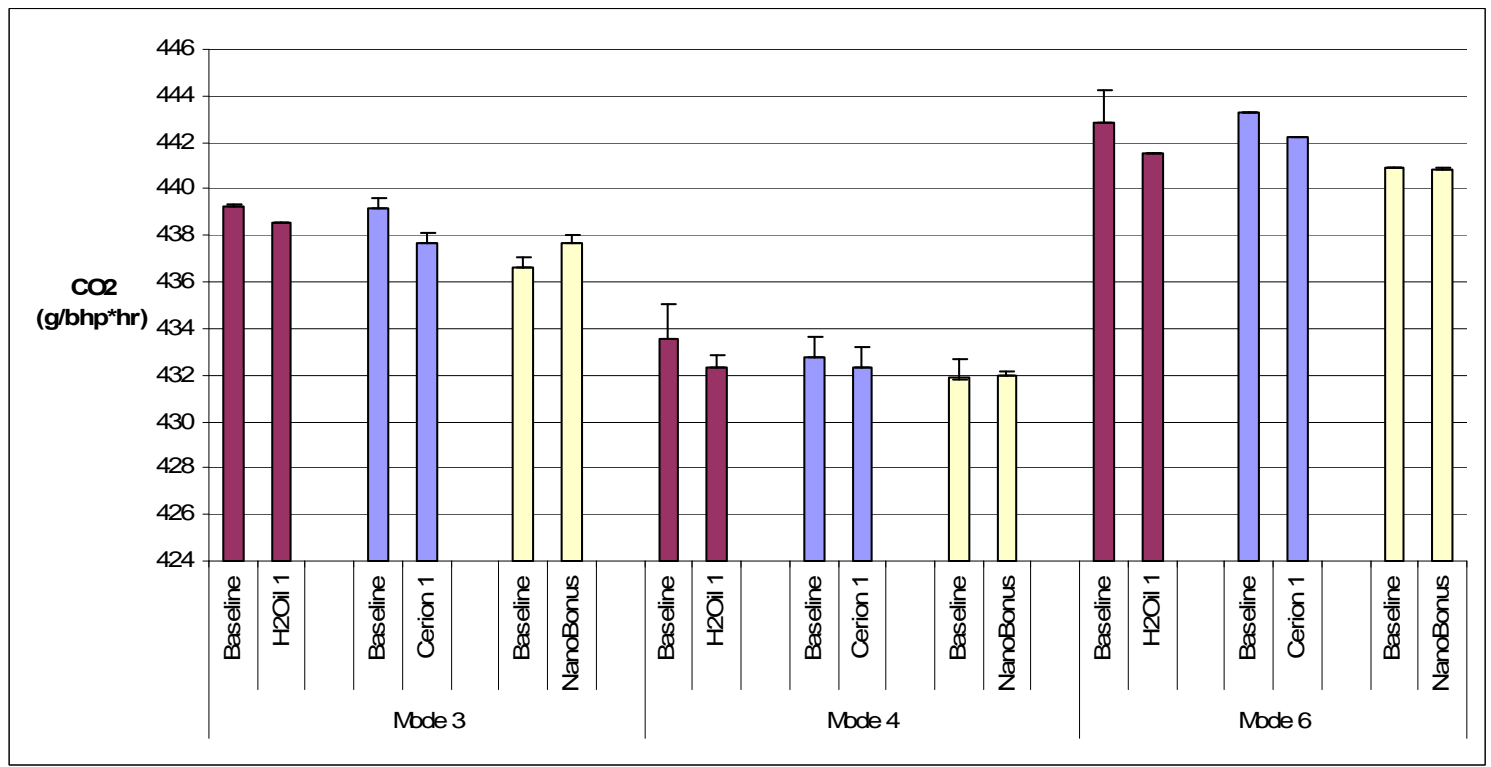

Figure 8-22 $\mathrm{BSCO}_{2}$ for Modes 3, 4, and 5 of DDC Steady State Testing 


\subsubsection{DDC NOx Results}

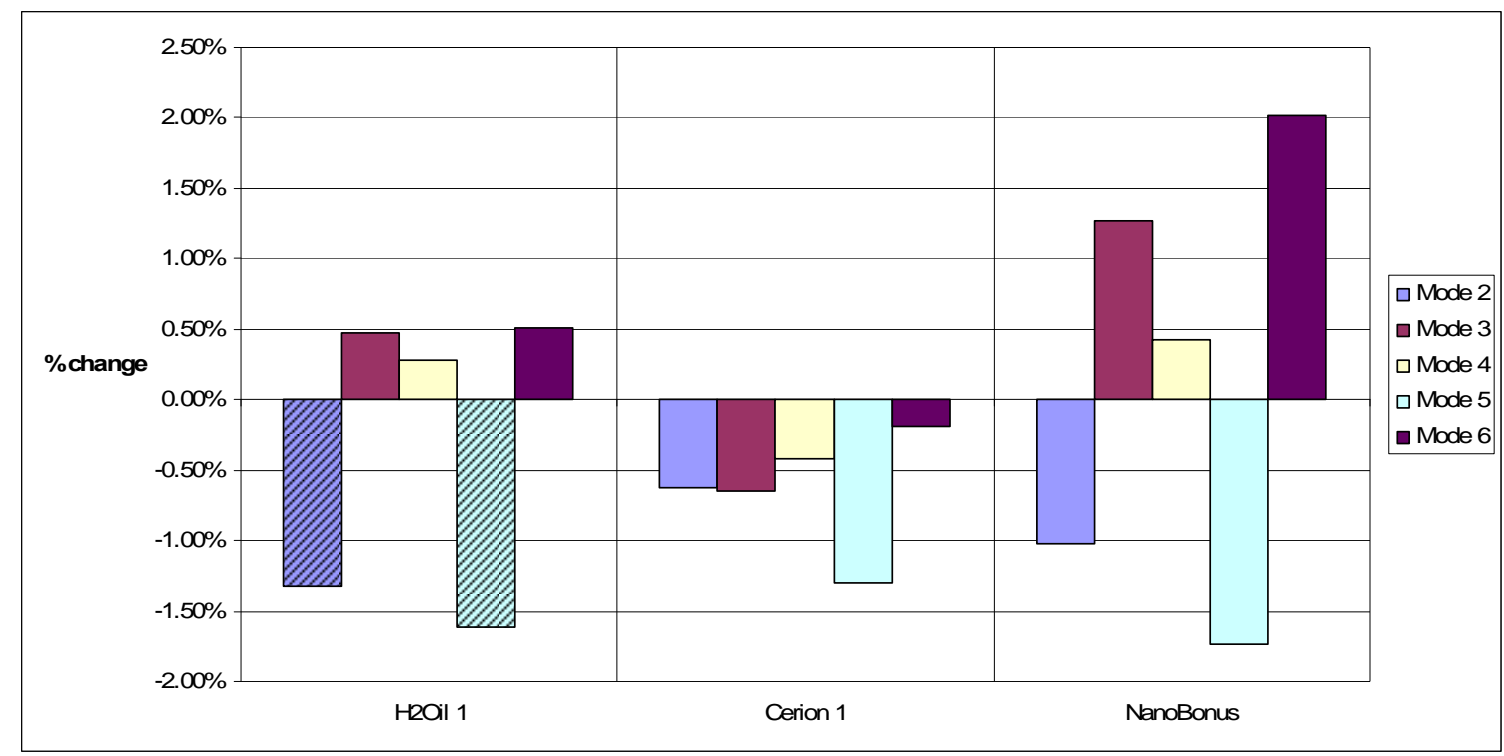

Figure 8-23 Percent Change in BSNOx for DDC Steady State Testing

Table 8-25 p-values for NOx for DDC Steady State Testing

\begin{tabular}{|l|c|c|c|c|c|}
\hline Additive & Mode 2 & Mode 3 & Mode 4 & Mode 5 & Mode 6 \\
\hline H2Oil 1 & $\mathbf{0 . 0 1 2}$ & 0.553 & 0.733 & $\mathbf{0 . 0 7 8}$ & 0.684 \\
Cerion 1 & - & - & - & - & - \\
NanoBonus & 0.236 & 0.340 & 0.875 & 0.190 & 0.151 \\
\hline
\end{tabular}


Table 8-26 BSNOx Variation Results of DDC for Steady State Testing

\begin{tabular}{|l|l|c|c|}
\hline & & $\begin{array}{c}\text { Difference from } \\
\text { Baseline }\end{array}$ & $\begin{array}{c}\text { Combined } \\
\text { Variations }\end{array}$ \\
\hline Mode 2 & H2Oil 1 & $-1.33 \%$ & $0.31 \%$ \\
\hline & Cerion 1 & $-0.62 \%$ & \\
\hline & NanoBonus & $-1.02 \%$ & $1.72 \%$ \\
\hline Mode 3 & H2Oil 1 & $0.47 \%$ & $1.84 \%$ \\
\hline & Cerion 1 & $-0.64 \%$ & \\
\hline & NanoBonus & $1.27 \%$ & $2.69 \%$ \\
\hline & & & \\
\hline Mode 4 & H2Oil 1 & $0.28 \%$ & $1.79 \%$ \\
\hline & Cerion 1 & $-0.42 \%$ & \\
\hline & NanoBonus & $0.00 \%$ & $5.47 \%$ \\
\hline & & & \\
\hline Mode 5 & H2Oil 1 & $-1.61 \%$ & $1.33 \%$ \\
\hline & Cerion 1 & $-1.30 \%$ & \\
\hline & NanoBonus & $-1.74 \%$ & $2.40 \%$ \\
\hline & & & \\
\hline Mode 6 & H2Oil 1 & $0.51 \%$ & $2.98 \%$ \\
\hline & Cerion 1 & $-0.19 \%$ & \\
\hline & NanoBonus & $2.02 \%$ & $1.75 \%$ \\
\hline
\end{tabular}

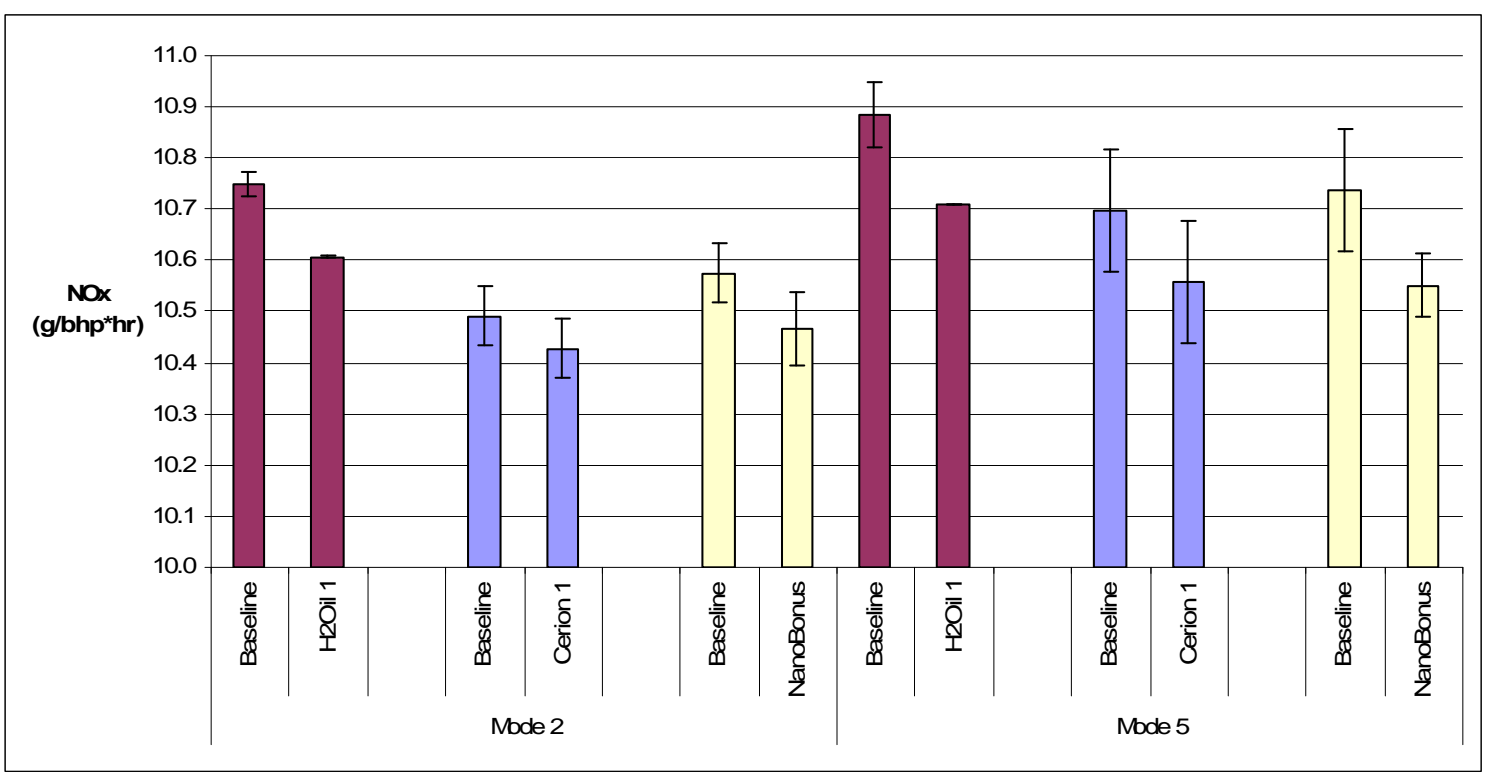

Figure 8-24 BSNOx for Modes 2 and 5 of DDC Steady State Testing 


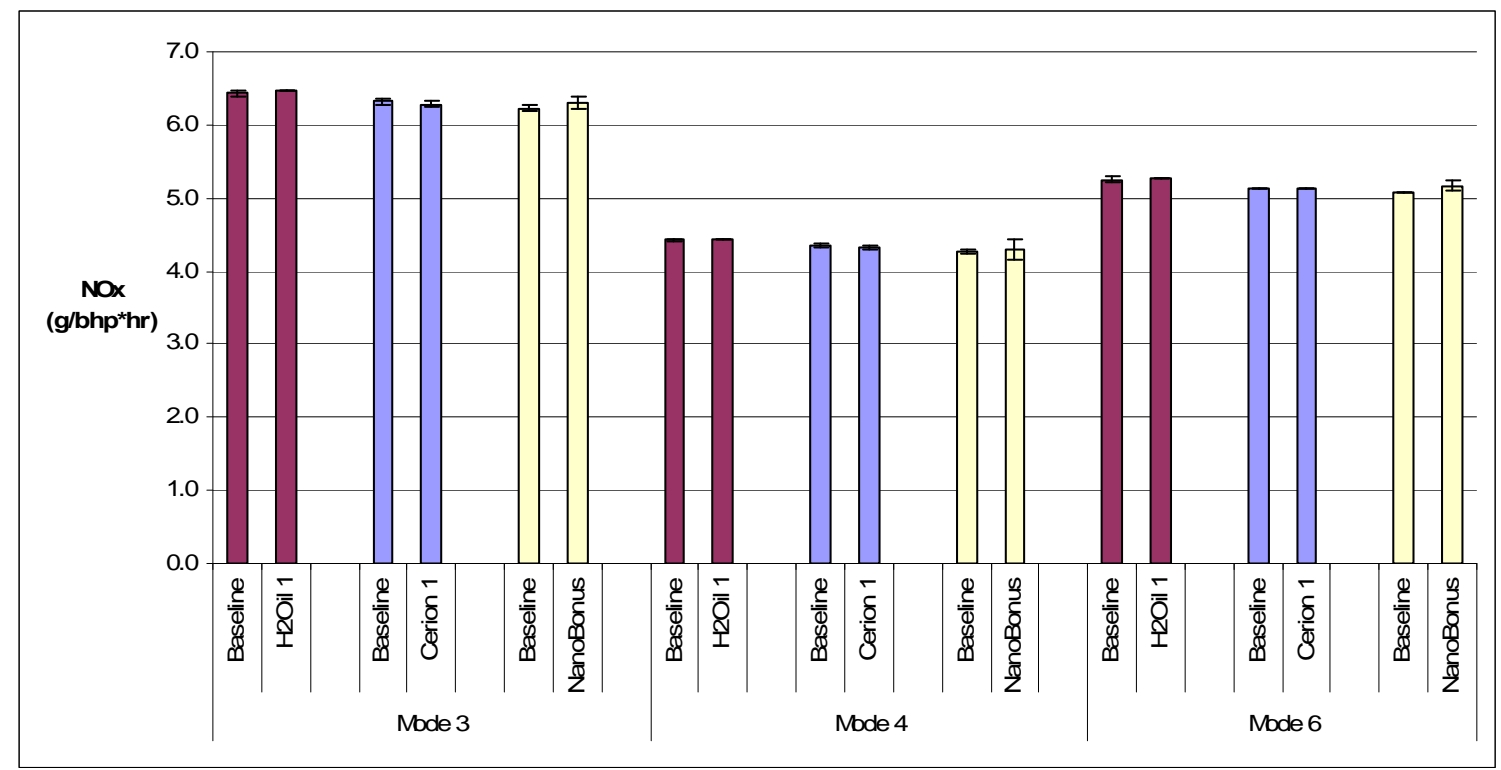

Figure 8-25 BSNOx for Modes 3, 4, and 5 of DDC Steady State Testing

\subsubsection{DDC CO Results}

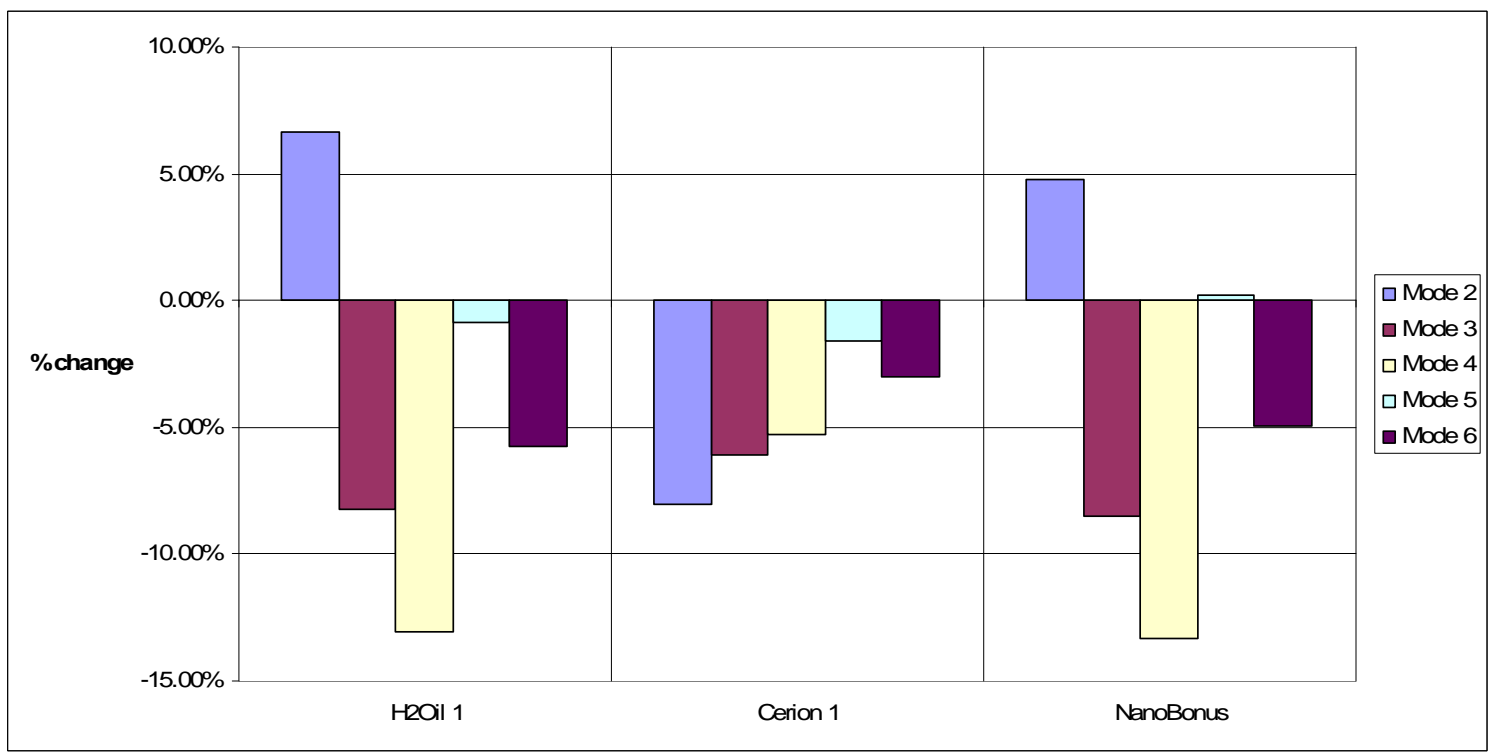

Figure 8-26 Percent Change in BSCO of DDC For Steady State Testing 
Table 8-27 p-values for CO for DDC Steady State Testing

\begin{tabular}{|l|c|c|c|c|c}
\hline Additive & Mode 2 & Mode 3 & Mode 4 & Mode 5 & Mode 6 \\
\hline H2Oil 1 & 0.381 & 0.165 & 0.265 & 0.876 & 0.340 \\
Cerion 1 & - & - & - & - & - \\
NanoBonus & 0.466 & 0.130 & 0.198 & 0.951 & 0.183 \\
\hline
\end{tabular}

Table 8-28 BSCO Variation Results of DDC for Steady State Testing

\begin{tabular}{|l|l|c|c|}
\hline & & $\begin{array}{c}\text { Difference } \\
\text { from Baseline }\end{array}$ & $\begin{array}{c}\text { Combined } \\
\text { Variations }\end{array}$ \\
\hline Mode 2 & H2Oil 1 & $6.62 \%$ & $14.60 \%$ \\
\hline & Cerion 1 & $-8.00 \%$ & \\
\hline & NanoBonus & $4.79 \%$ & $11.16 \%$ \\
\hline Mode 3 & H2Oil 1 & $-8.22 \%$ & $10.96 \%$ \\
\hline & Cerion 1 & $-6.11 \%$ & \\
\hline & NanoBonus & $-8.52 \%$ & $9.34 \%$ \\
\hline & & & \\
\hline & H2Oil 1 & $-13.09 \%$ & $16.53 \%$ \\
\hline & Cerion 1 & $-5.31 \%$ & \\
\hline & NanoBonus & $-13.34 \%$ & $16.59 \%$ \\
\hline Mode 5 4 & H2Oil 1 & $-0.85 \%$ & $13.18 \%$ \\
\hline & Cerion 1 & $-1.57 \%$ & \\
\hline & NanoBonus & $0.21 \%$ & $7.74 \%$ \\
\hline & & & \\
\hline Mode 6 & H2Oil 1 & $-5.75 \%$ & \\
\hline & Cerion 1 & $-3.01 \%$ & \\
\hline & NanoBonus & $-4.98 \%$ & $6.47 \%$ \\
\hline
\end{tabular}




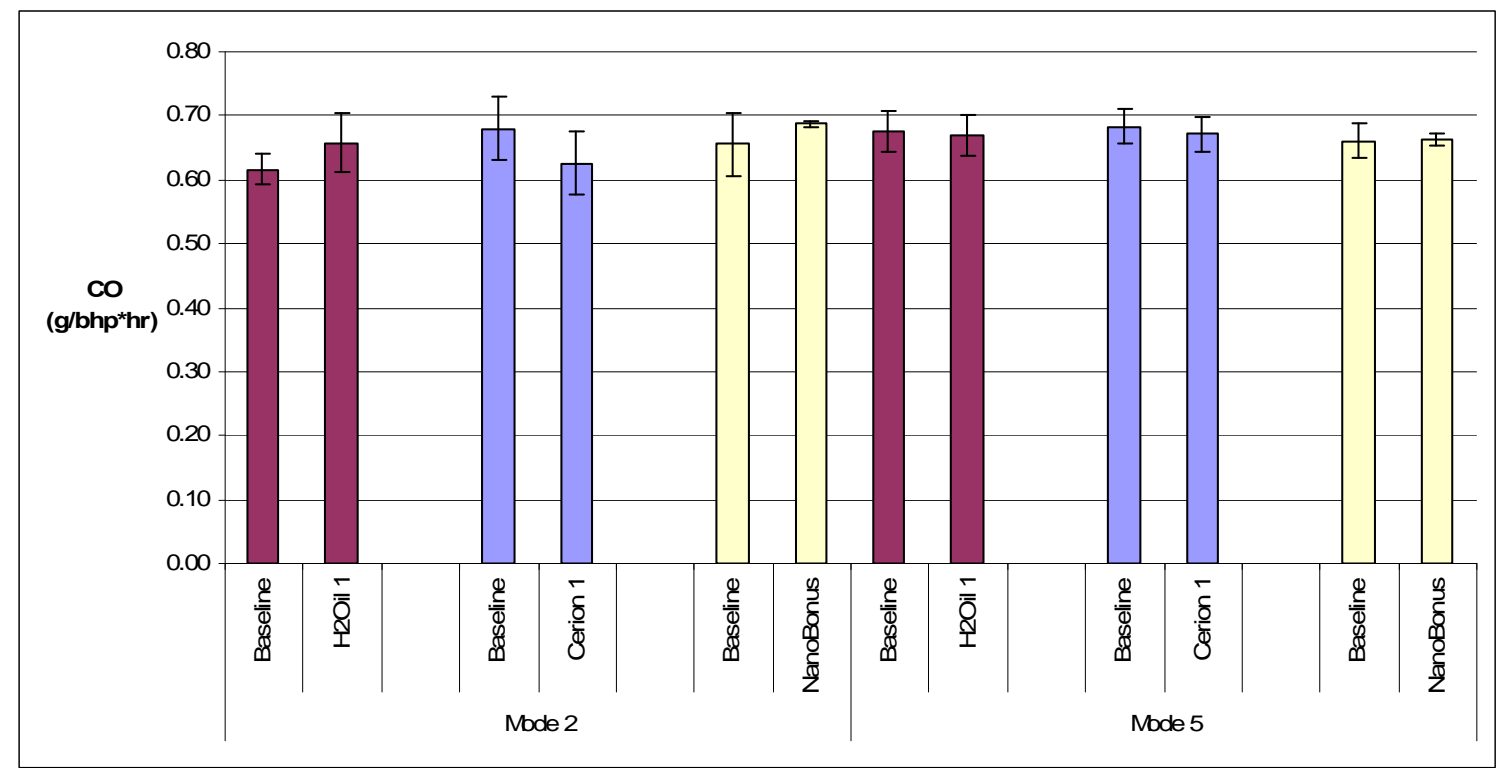

Figure 8-27 BSCO for Modes 2 and 5 of DDC Steady State Testing

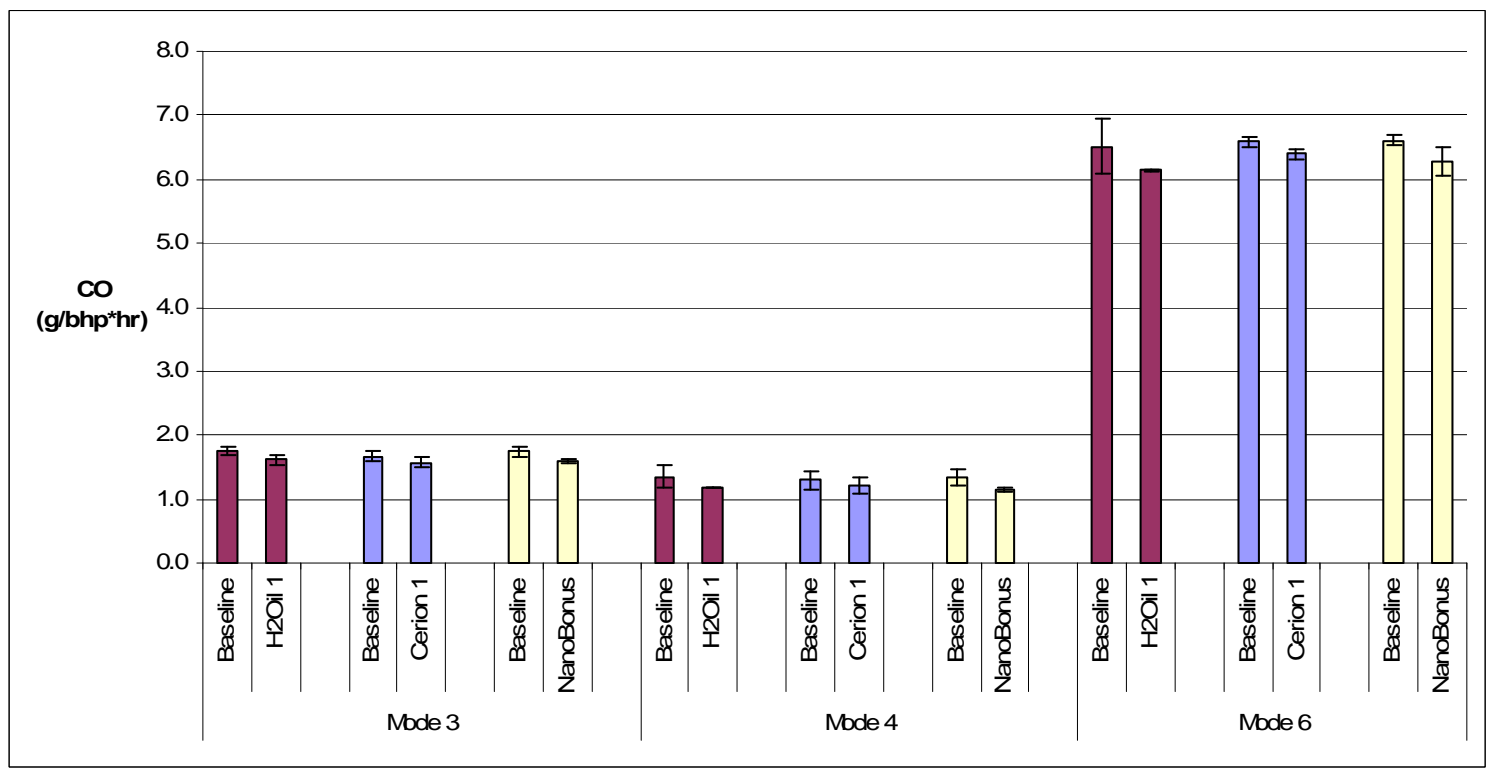

Figure 8-28 BSCO for Modes 3, 4, and 5 of DDC Steady State Testing 


\subsubsection{DDC PM Results}

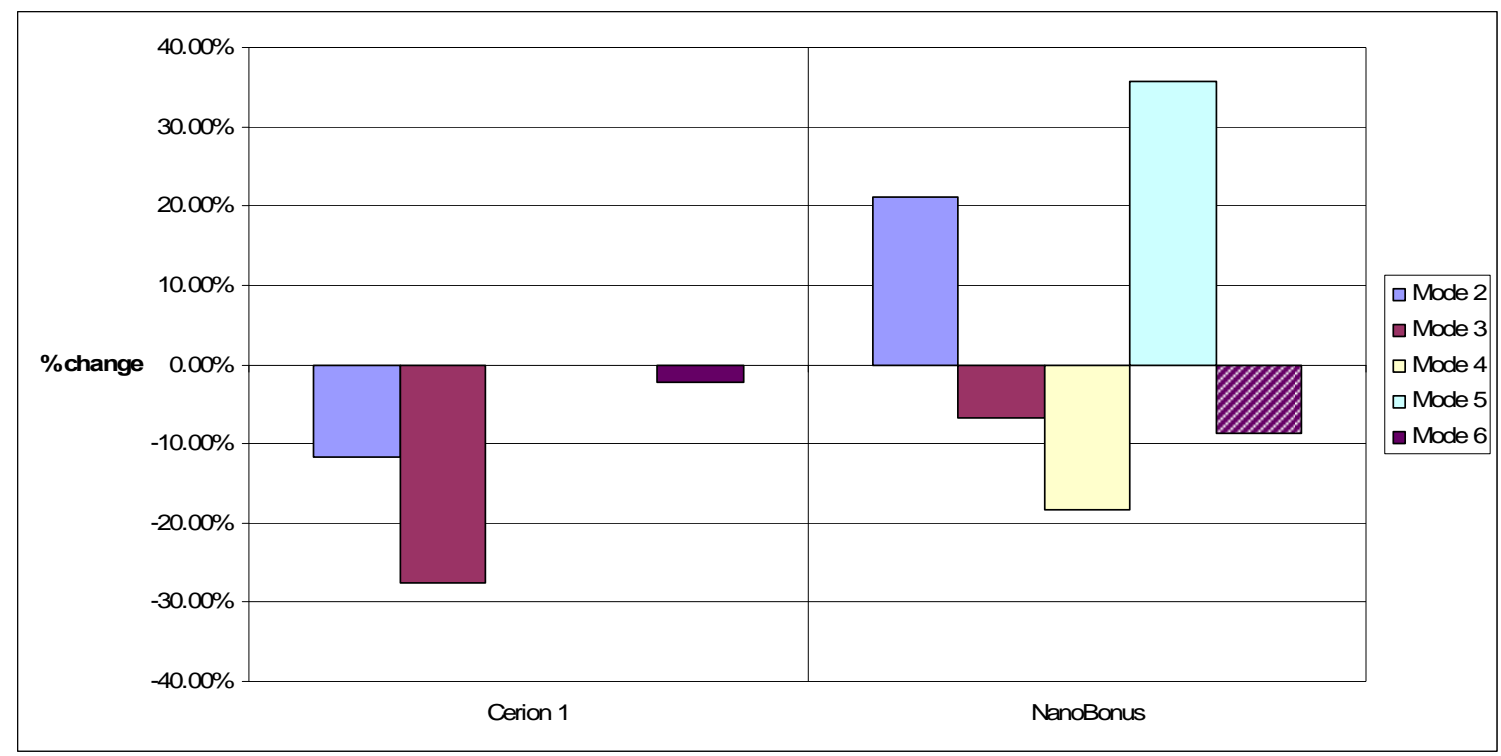

Figure 8-29 Percent Change in BSPM of DDC for Steady State Testing

Table 8-29 p-values for PM for DDC Steady State Testing

\begin{tabular}{|l|c|c|c|c|c}
\hline Additive & Mode 2 & Mode 3 & Mode 4 & Mode 5 & Mode 6 \\
\hline H2Oil 1 & - & - & - & - & - \\
Cerion 1 & - & - & - & - & - \\
NanoBonus & 0.147 & 0.464 & 0.117 & 0.225 & $\mathbf{0 . 0 0 5}$ \\
\hline
\end{tabular}


Table 8-30 BSPM Variation Results of DDC for Steady State Testing

\begin{tabular}{|c|c|c|c|}
\hline & & $\begin{array}{c}\text { Difference from } \\
\text { Baseline }\end{array}$ & $\begin{array}{l}\text { Combined } \\
\text { Variations }\end{array}$ \\
\hline \multirow[t]{3}{*}{ Mode 2} & H2Oil 1 & - & - \\
\hline & Cerion 1 & $-11.65 \%$ & - \\
\hline & NanoBonus & $21.13 \%$ & $21.24 \%$ \\
\hline \multirow[t]{3}{*}{ Mode 3} & H2Oil 1 & - & - \\
\hline & Cerion 1 & $-27.53 \%$ & - \\
\hline & NanoBonus & $-6.77 \%$ & $15.74 \%$ \\
\hline \multirow[t]{3}{*}{ Mode 4} & H2Oil 1 & - & - \\
\hline & Cerion 1 & $210.17 \%$ & - \\
\hline & NanoBonus & $-18.34 \%$ & $14.68 \%$ \\
\hline \multirow[t]{3}{*}{ Mode 5} & H2Oil 1 & - & - \\
\hline & Cerion 1 & $-75.39 \%$ & - \\
\hline & NanoBonus & $35.63 \%$ & $28.74 \%$ \\
\hline \multirow[t]{3}{*}{ Mode 6} & H2Oil 1 & - & - \\
\hline & Cerion 1 & $-2.32 \%$ & - \\
\hline & NanoBonus & $-8.64 \%$ & $1.46 \%$ \\
\hline
\end{tabular}

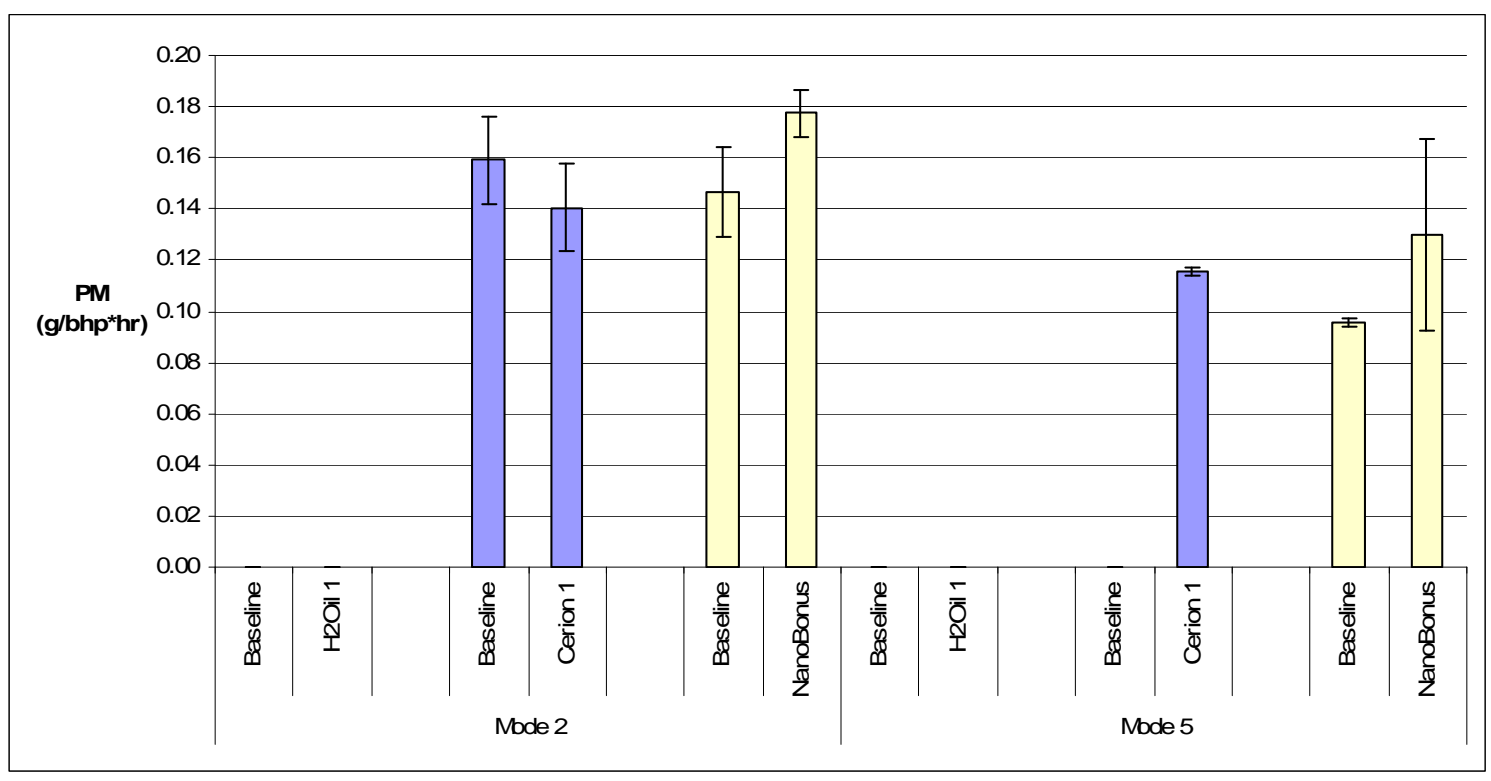

Figure 8-30 BSPM for Modes 2 and 5 of DDC Steady State Testing 


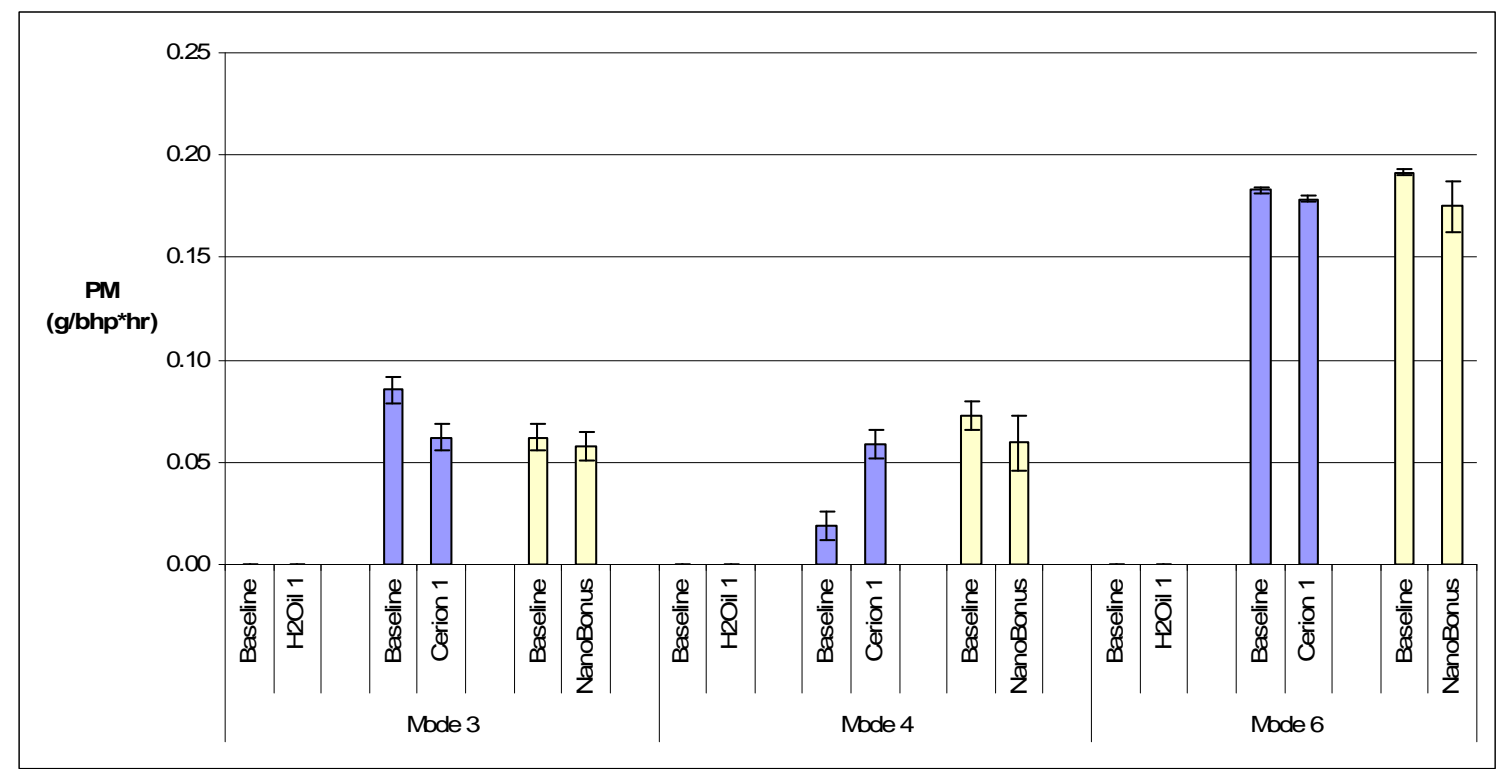

Figure 8-31 BSPM for Modes 3, 4, and 5 of DDC Steady State Testing

\subsubsection{DDC HC Results}

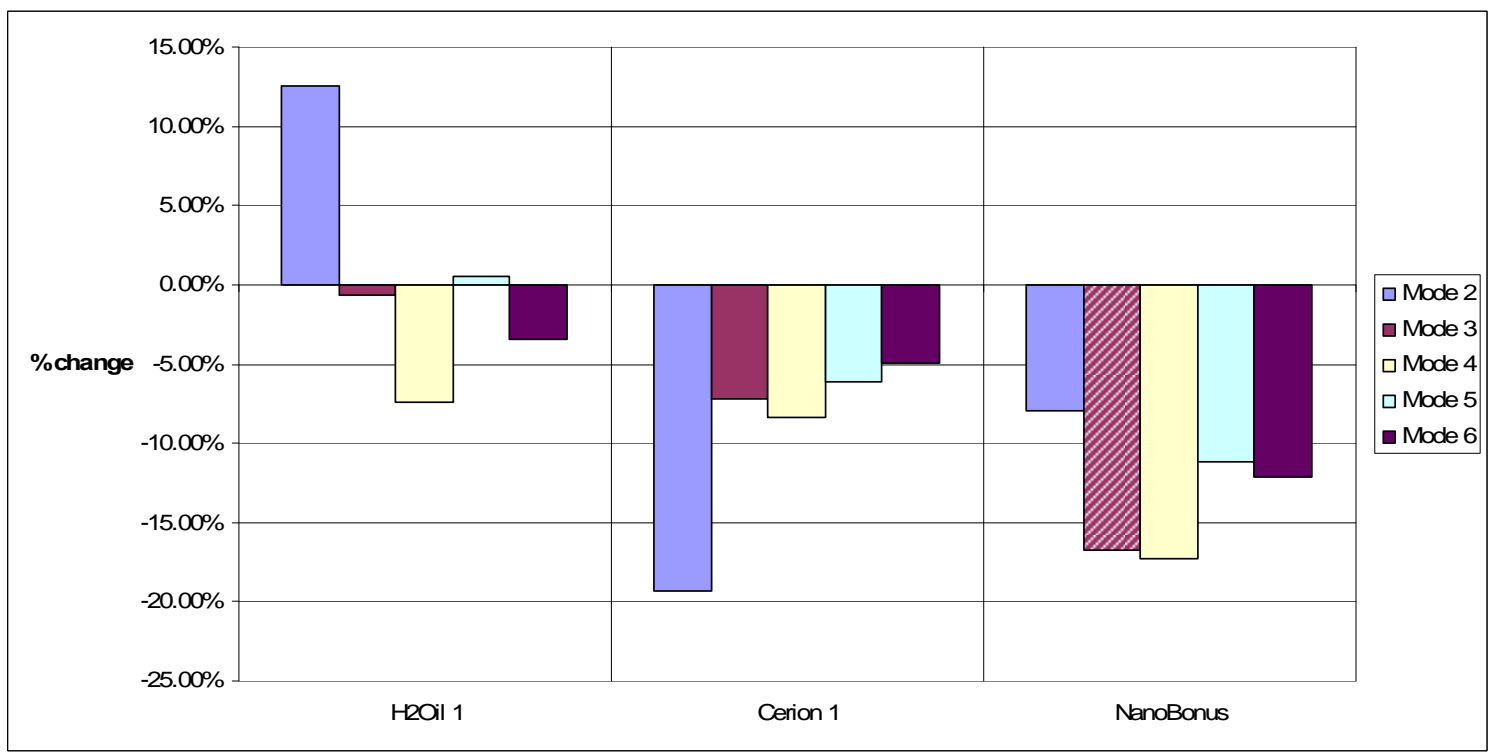

Figure 8-32 Percent Change in BSHC of DDC for Steady State Testing 
Table 8-31 p-values for PM for DDC Steady State Testing

\begin{tabular}{|l|c|c|c|c|c}
\hline Additive & Mode 2 & Mode 3 & Mode 4 & Mode 5 & Mode 6 \\
\hline H2Oil 1 & 0.667 & 0.213 & 0.283 & 0.489 & 0.261 \\
Cerion 1 & - & - & - & - & - \\
NanoBonus & 0.375 & $\mathbf{0 . 0 4 9}$ & 0.154 & 0.252 & 0.170 \\
\hline
\end{tabular}

Table 8-32 BSHC Variation Results of DDC for Steady State Testing

\begin{tabular}{|c|c|c|c|}
\hline & & $\begin{array}{c}\text { Difference } \\
\text { from Baseline }\end{array}$ & $\begin{array}{l}\text { Combined } \\
\text { Variations }\end{array}$ \\
\hline \multirow[t]{3}{*}{ Mode 2} & H2Oil 1 & $8.68 \%$ & $27.26 \%$ \\
\hline & Cerion 1 & $-19.32 \%$ & - \\
\hline & NanoBonus & $-7.95 \%$ & $19.57 \%$ \\
\hline \multirow[t]{3}{*}{ Mode 3} & H2Oil 1 & $6.03 \%$ & $5.84 \%$ \\
\hline & Cerion 1 & $-7.22 \%$ & - \\
\hline & NanoBonus & $-16.70 \%$ & $9.53 \%$ \\
\hline \multirow[t]{3}{*}{ Mode 4} & H2Oil 1 & $-9.30 \%$ & $5.60 \%$ \\
\hline & Cerion 1 & $-8.36 \%$ & - \\
\hline & NanoBonus & $-17.24 \%$ & $22.13 \%$ \\
\hline \multirow[t]{3}{*}{ Mode 5} & H2Oil 1 & $-4.51 \%$ & $8.86 \%$ \\
\hline & Cerion 1 & $-6.11 \%$ & - \\
\hline & NanoBonus & $-11.14 \%$ & $14.82 \%$ \\
\hline \multirow[t]{3}{*}{ Mode 6} & H2Oil 1 & $9.38 \%$ & $9.58 \%$ \\
\hline & Cerion 1 & $-4.91 \%$ & - \\
\hline & NanoBonus & $-12.13 \%$ & $13.81 \%$ \\
\hline
\end{tabular}




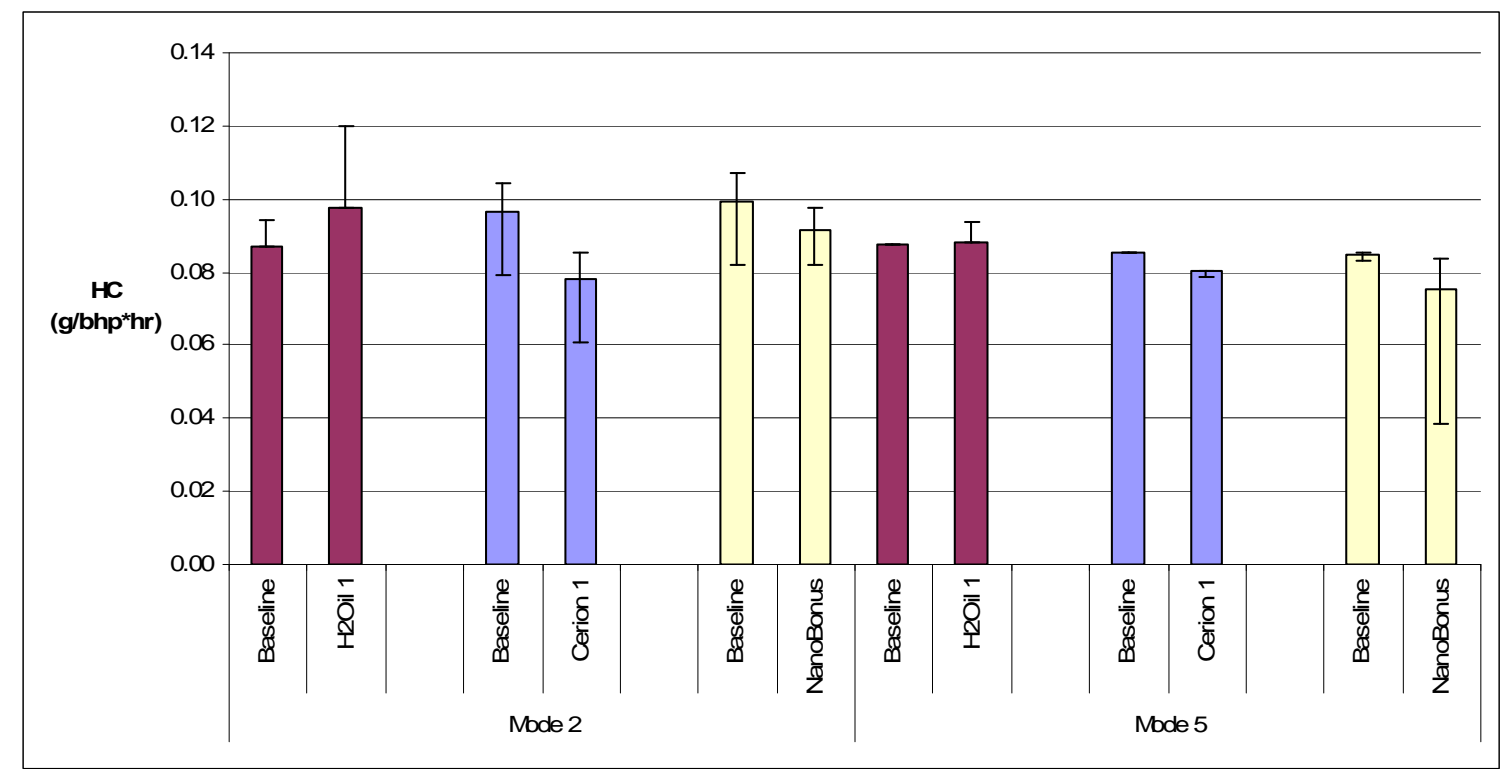

Figure 8-33 BSHC for Modes 2 and 5 of DDC Steady State Testing

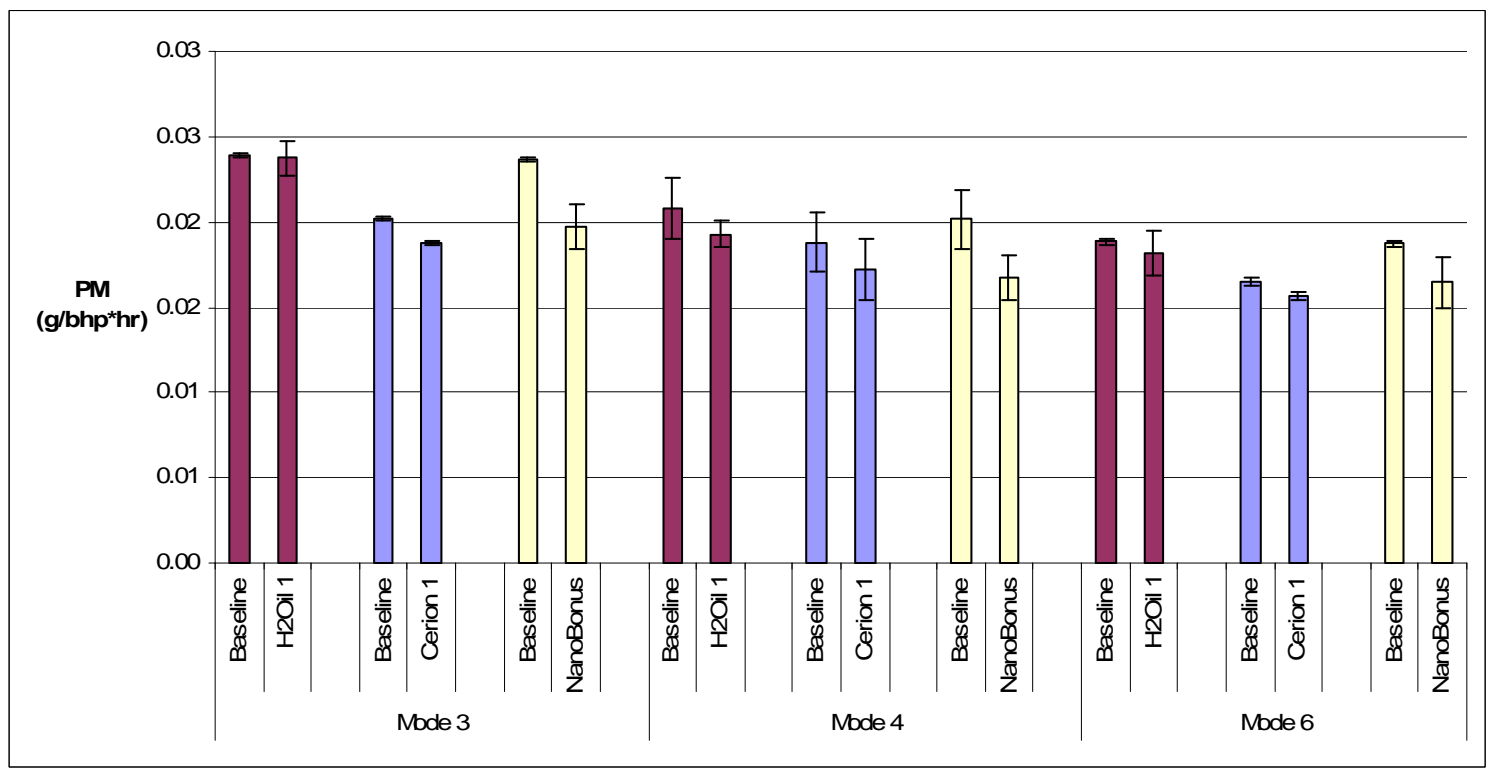

Figure 8-34 BSHC for Modes 3, 4, and 5 of DDC Steady State Testing

\subsubsection{In-Cylinder Analysis}




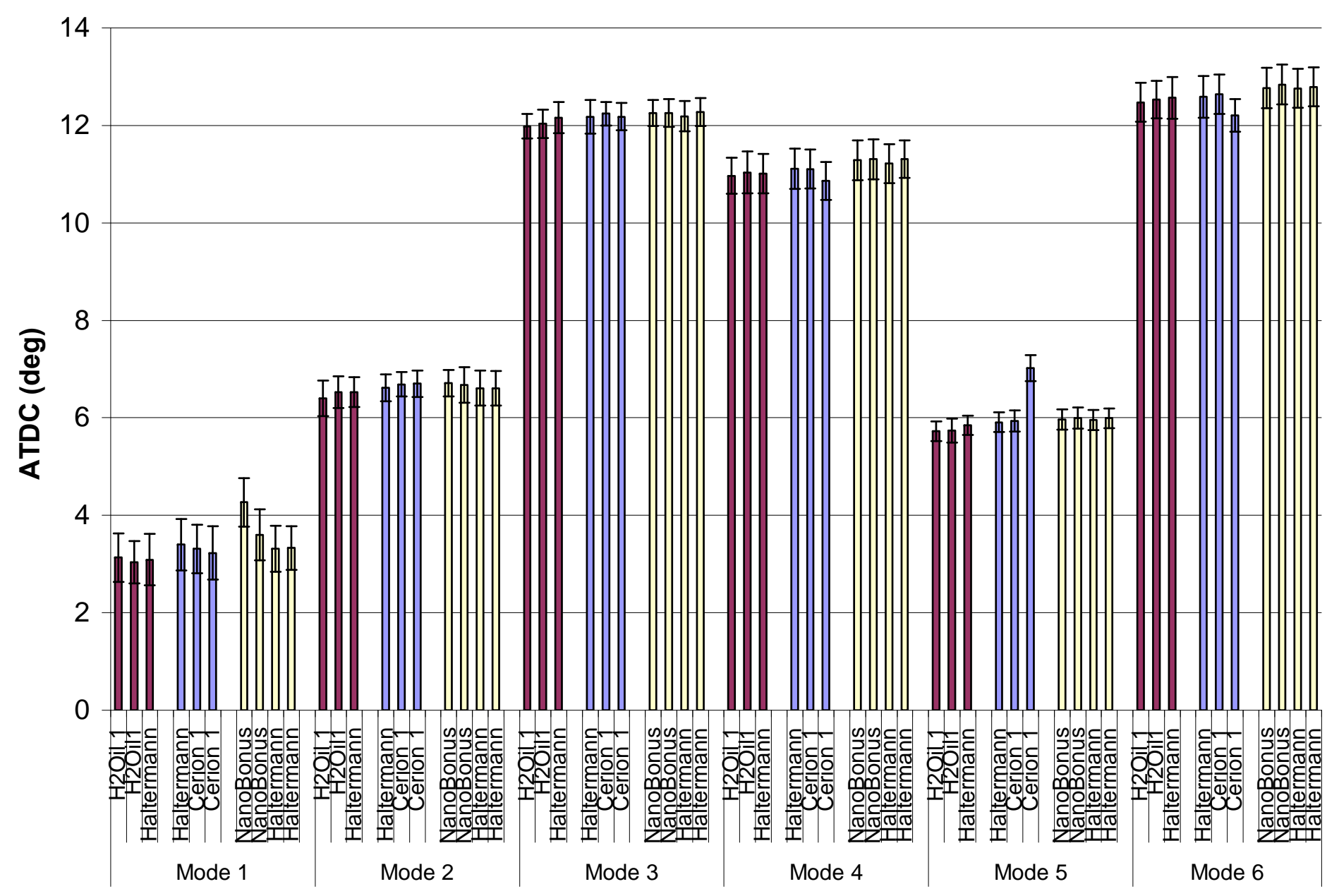

Figure 8-35 Location of Maximum Pressure 


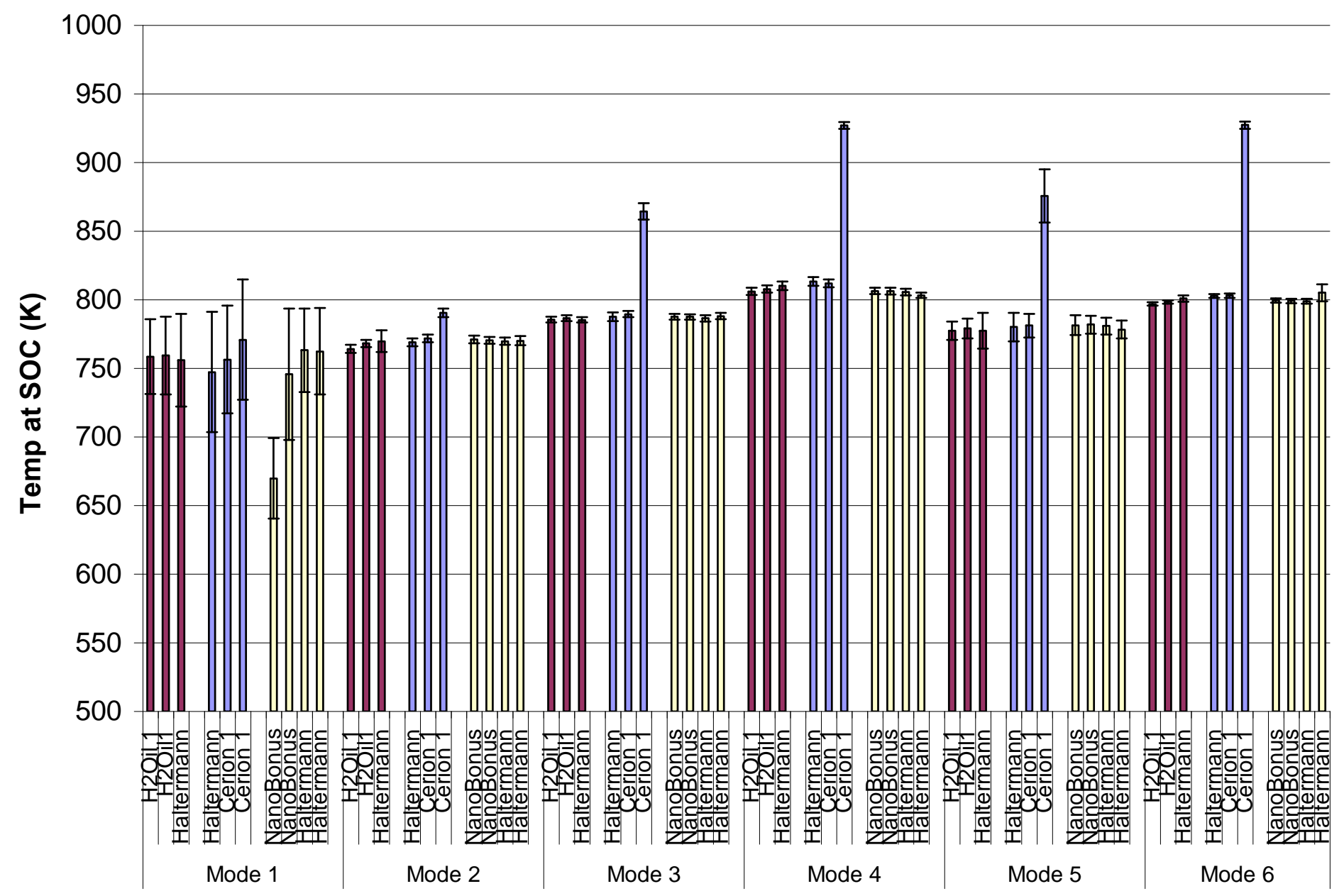

Figure 8-36 Temperature at Start of Combustion 


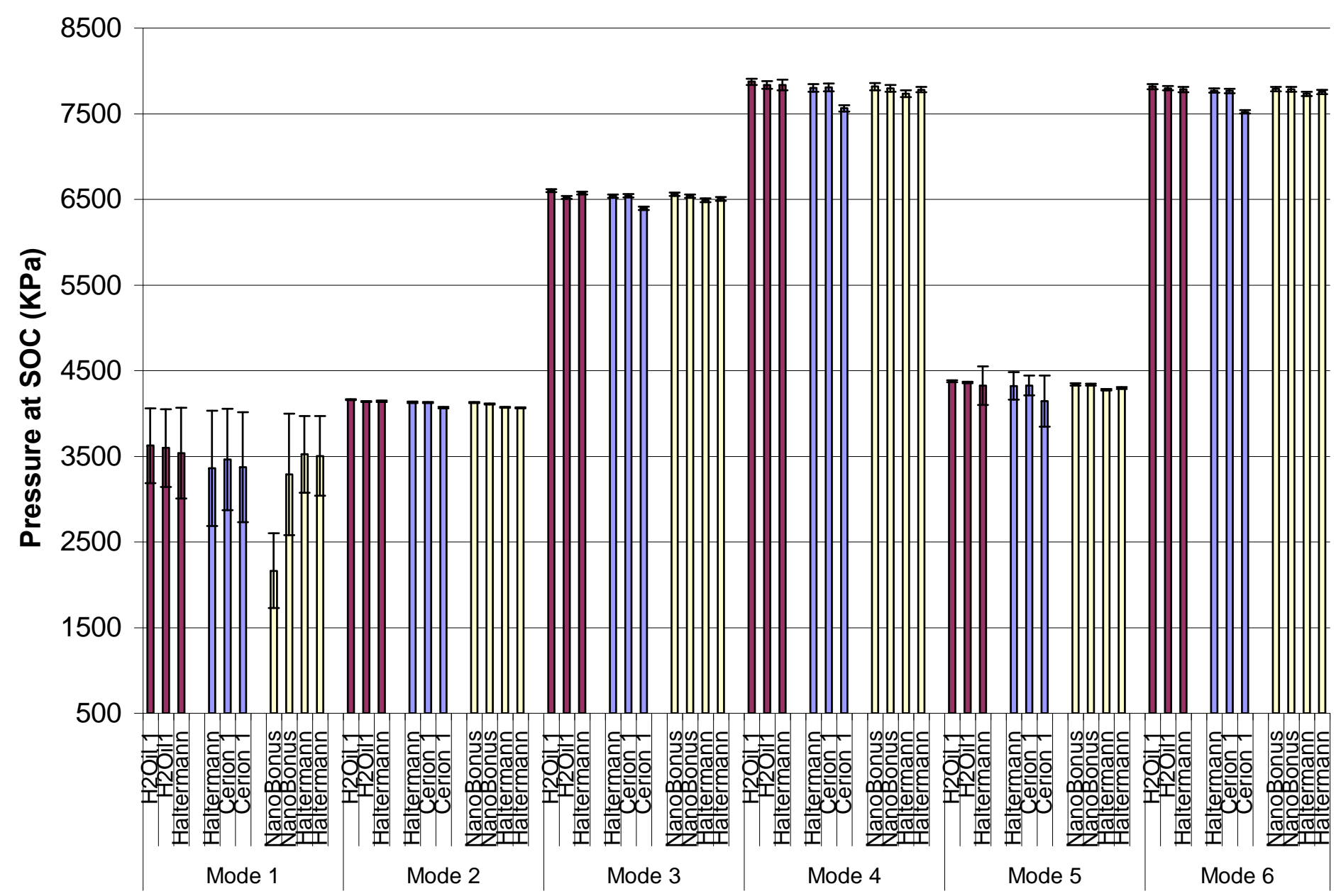

Figure 8-37 Pressure at Start of Combustion 


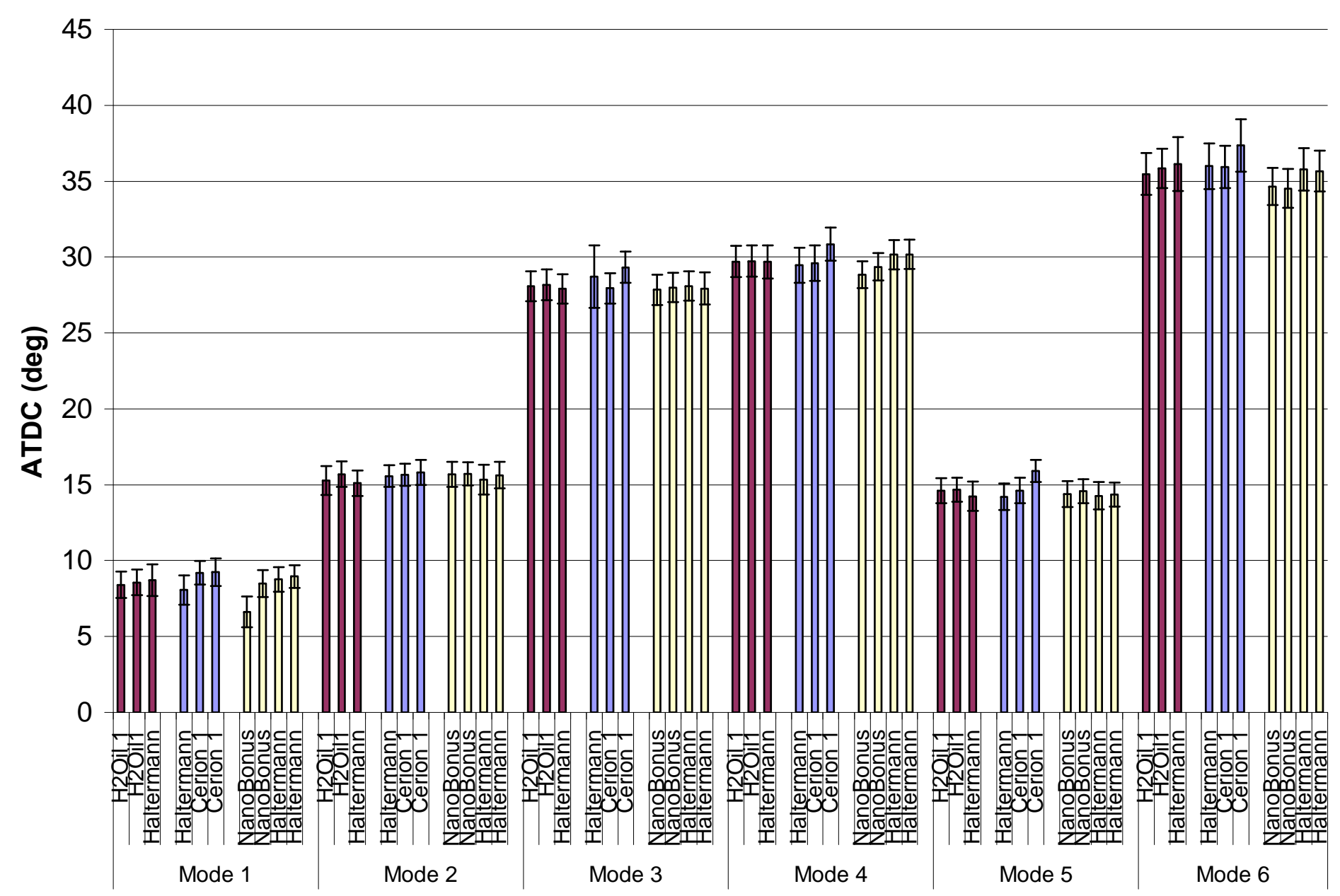

Figure 8-38 Location of 90\% Mass Fraction Burned 


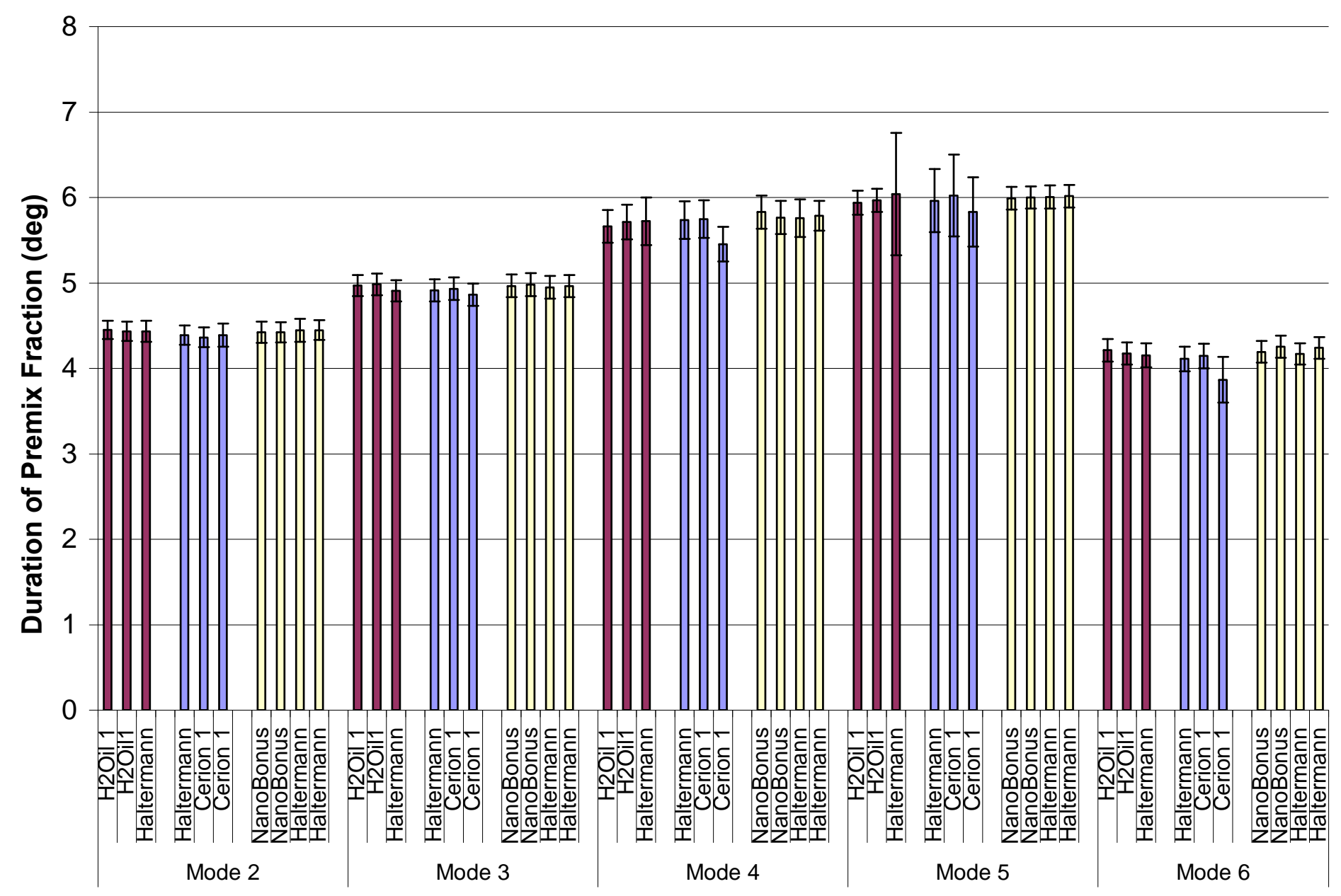

Figure 8-39 Duration of Premix Fraction 


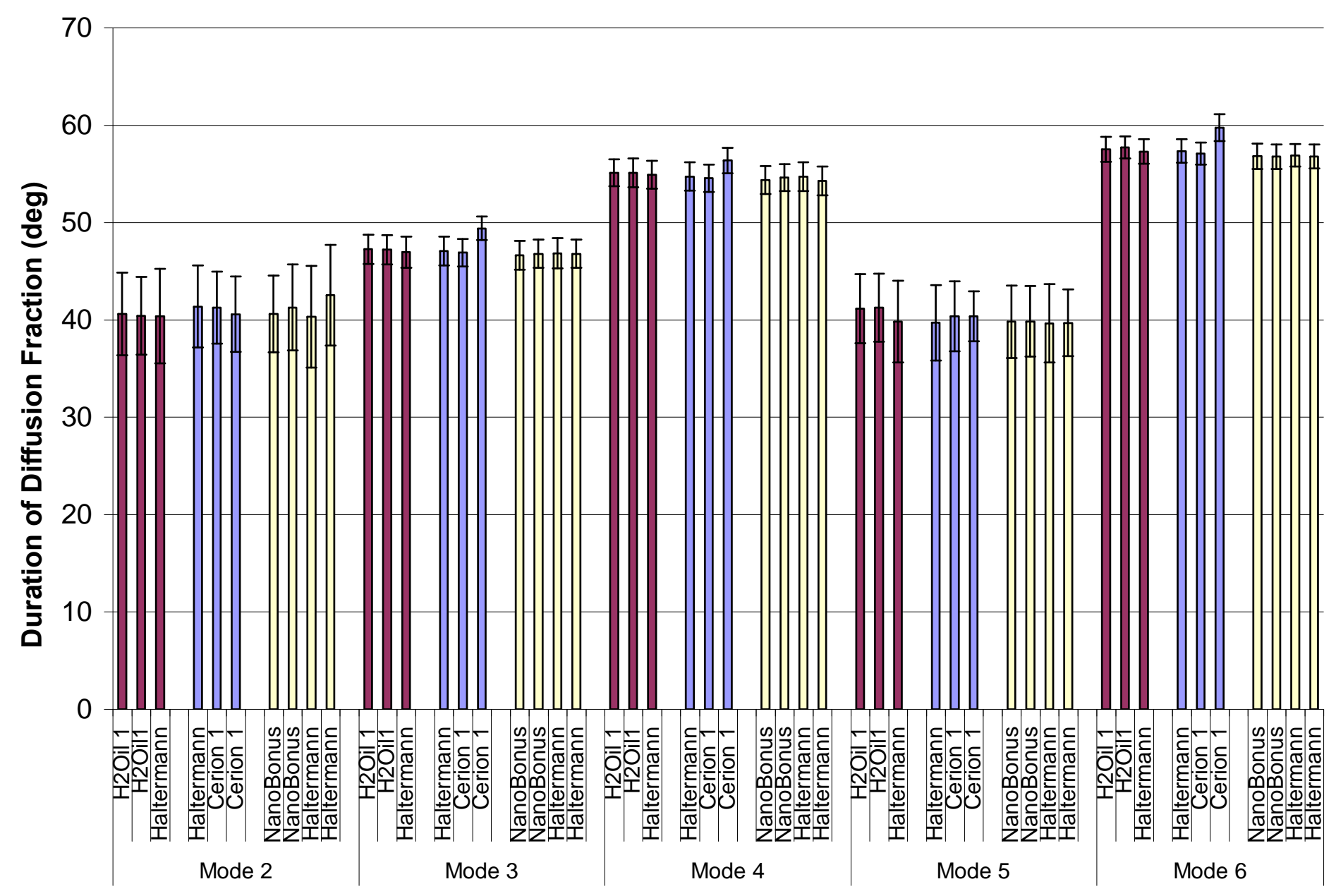

Figure 8-40 Duration of Diffusion Fraction 


\subsection{Data Summary of all Tests}

\subsubsection{Averages of Transent Tests}

Table 8-33 Averages and Standard Deviations for all Transient Tests

\begin{tabular}{|c|c|c|c|c|c|c|c|c|c|c|c|c|c|}
\hline & & \multicolumn{2}{|c|}{$\begin{array}{c}\text { BSFC } \\
\text { (lb/bhp*hr) }\end{array}$} & \multicolumn{2}{|c|}{$\mathrm{CO}_{2}$ (g/bhp*hr) } & \multicolumn{2}{|c|}{ NOx (g/bhp*hr) } & \multicolumn{2}{|c|}{ CO (g/bhp*hr) } & \multicolumn{2}{|c|}{ PM (g/bhp*hr) } & \multicolumn{2}{|c|}{$\mathrm{HC}\left(\mathrm{g} / \mathrm{bhp} \mathrm{p}^{\star} \mathrm{hr}\right)$} \\
\hline & & Avg & $\begin{array}{l}\text { Std } \\
\text { Dev }\end{array}$ & Avg & $\begin{array}{l}\text { Std } \\
\text { Dev }\end{array}$ & Avg & Std Dev & Avg & $\begin{array}{l}\text { Std } \\
\text { Dev }\end{array}$ & Avg & $\begin{array}{l}\text { Std } \\
\text { Dev }\end{array}$ & Avg & Std Dev \\
\hline \multirow[t]{6}{*}{ Cummins } & Neat & 0.3866 & 0.0004 & 556.2 & 0.5793 & 4.147 & 0.021 & 0.906 & 0.002 & 55.9118 & 4.8742 & 0.2285 & 0.0007 \\
\hline & Cerion 1 & 0.3871 & 0.0006 & 556.9 & 0.9053 & 4.117 & 0.016 & 0.945 & 0.018 & 57.3753 & 3.1910 & 0.2340 & 0.0012 \\
\hline & Neat & 0.3886 & 0.0003 & 559.2 & 0.4242 & 4.100 & 0.010 & 0.808 & 0.005 & 50.6583 & 0.2234 & 0.2299 & 0.0016 \\
\hline & H2Oil 1 & 0.3879 & 0.0002 & 558.1 & 0.2433 & 4.087 & 0.005 & 0.829 & 0.005 & 53.5802 & 2.1907 & 0.2378 & 0.0044 \\
\hline & Neat & 0.3899 & 0.0003 & 561.0 & 0.4697 & 4.118 & 0.013 & 0.844 & 0.008 & 57.0387 & 1.5896 & 0.2310 & 0.0022 \\
\hline & NanoBonus & 0.3894 & 0.0003 & 560.3 & 0.3839 & 4.134 & 0.006 & 0.822 & 0.008 & 54.0803 & 3.6188 & 0.2290 & 0.0044 \\
\hline \multirow[t]{4}{*}{ Mack } & Neat & 0.3645 & 0.0003 & 523.6 & 0.4597 & 1.722 & 0.022 & 1.169 & 0.014 & 59.8825 & 2.3558 & 0.1810 & 0.0058 \\
\hline & Cerion 1 & 0.3649 & 0.0003 & 524.1 & 0.3234 & 1.737 & 0.020 & 1.188 & 0.014 & 60.1675 & 0.7655 & 0.1872 & 0.0023 \\
\hline & Neat & 0.3632 & 0.0005 & 521.8 & 0.7399 & 1.698 & 0.026 & 1.122 & 0.027 & 58.0050 & 2.3527 & 0.1897 & 0.0031 \\
\hline & Cerion 2 & 0.3651 & 0.0006 & 524.5 & 0.8736 & 1.701 & 0.014 & 1.136 & 0.027 & 59.1020 & 3.5950 & 0.1854 & 0.0015 \\
\hline \multirow[t]{6}{*}{ DDC } & Neat & 0.3610 & 0.0003 & 515.8 & 0.2893 & 4.706 & 0.031 & 3.206 & 0.027 & 55.9118 & 0.0011 & 0.0925 & 0.0011 \\
\hline & H2Oil 1 & 0.3612 & 0.0004 & 516.3 & 0.7082 & 4.742 & 0.014 & 3.089 & 0.063 & 57.3753 & 0.0072 & 0.0973 & 0.0021 \\
\hline & Neat & 0.3610 & 0.0002 & 516.0 & 0.3270 & 4.603 & 0.012 & 3.089 & 0.009 & 50.6583 & 0.0006 & 0.0931 & 0.0051 \\
\hline & Cerion 1 & 0.3619 & 0.0005 & 517.2 & 0.7305 & 4.608 & 0.009 & 3.102 & 0.033 & 53.5802 & 0.0036 & 0.0872 & 0.0026 \\
\hline & Neat & 0.3604 & 0.0006 & 514.9 & 0.8192 & 4.641 & 0.021 & 3.227 & 0.028 & 57.0387 & 0.0022 & 0.0849 & 0.0024 \\
\hline & NanoBonus & 0.3611 & 0.0004 & 516.1 & 0.5138 & 4.626 & 0.010 & 3.120 & 0.035 & 54.0803 & 0.0021 & 0.0874 & 0.0006 \\
\hline & & & & & & & & & & & & & \\
\hline
\end{tabular}


Table 8-34 Continuation of Averages and Standard Deviations for all Transient Tests

\begin{tabular}{|c|c|c|c|c|c|c|c|c|c|c|c|c|c|}
\hline \multirow[b]{2}{*}{$\begin{array}{l}\text { AM } \\
\text { General }\end{array}$} & \multirow[b]{2}{*}{ Neat } & \multicolumn{2}{|c|}{ BSFC (Ib/bhp*hr) } & \multicolumn{2}{|c|}{$\mathrm{CO}_{2}(\mathrm{~g} / \mathrm{bhp} \star \mathrm{hr})$} & \multicolumn{2}{|c|}{ NOx (g/bhp*hr) } & \multicolumn{2}{|c|}{ CO (g/bhp*hr) } & \multicolumn{2}{|c|}{ PM (g/bhp*hr) } & \multicolumn{2}{|c|}{$\mathrm{HC}$ (g/bhp*hr) } \\
\hline & & 0.4820 & 0.0012 & 693.3 & 1.6959 & 9.126 & 0.269 & 1.371 & 0.014 & 251.9767 & 7.1936 & 0.1208 & 0.0029 \\
\hline & $\begin{array}{l}\text { Nano- } \\
\text { Bonus }\end{array}$ & 0.4844 & 0.0015 & 696.8 & 2.0384 & 9.214 & 0.040 & 1.392 & 0.036 & 246.2992 & 15.4484 & 0.1268 & 0.0064 \\
\hline & Neat & 0.4876 & 0.0008 & 701.3 & 1.1272 & 9.326 & 0.051 & 1.436 & 0.017 & 240.6269 & 12.0277 & 0.1296 & 0.0053 \\
\hline & H2Oil 2 & 0.4848 & 0.0002 & 697.4 & 0.3468 & 9.301 & 0.058 & 1.396 & 0.009 & 239.8808 & 7.3221 & 0.1195 & 0.0078 \\
\hline & Neat & 0.4846 & 0.0011 & 697.1 & 1.5256 & 9.114 & 0.098 & 1.354 & 0.021 & 232.0333 & 5.4051 & 0.1063 & 0.0030 \\
\hline & Cerion 1 & 0.4852 & 0.0008 & 698.0 & 1.1141 & 9.429 & 0.106 & 1.351 & 0.026 & 249.3596 & 6.7971 & 0.1011 & 0.0043 \\
\hline
\end{tabular}




\subsubsection{Mack Transient Testing Summaries}

Table 8-35 Summary of Guttman testing for Mack

\begin{tabular}{|c|c|c|c|c|c|c|c|c|c|c|c|c|}
\hline Fuel: & Guttman & & & Work & Fuel Rec. & bsFC & bsTHC & $\mathrm{bsCO}$ & $\mathrm{bsCO}_{2}$ & bsNOx & bsNOx2 & bsTPM \\
\hline Date & Time & Test No. & Start Type & bhp-hr & $\mathrm{lb}$ & lb/bhp-hr & g/bhp-hr & g/bhp-hr & g/bhp-hr & g/bhp-hr & g/bhp-hr & g/bhp-hr \\
\hline $2 / 14 / 09$ & $13: 14$ & E02556-01 & Warm & 25.15 & 9.265 & 0.3683 & 0.0840 & 1.308 & 529.3 & 2.439 & 1.846 & 0.0685 \\
\hline 2/14/09 & $14: 02$ & E02556-02 & Warm & 25.15 & 9.155 & 0.3640 & 0.0846 & 1.286 & 523.2 & 2.371 & 1.775 & 0.0634 \\
\hline 2/14/09 & $14: 42$ & E02556-03 & Hot & 25.13 & 9.117 & 0.3627 & 0.1940 & 1.195 & 521.0 & 2.390 & 1.815 & 0.0593 \\
\hline 2/14/09 & $15: 22$ & E02556-04 & Hot & 25.14 & 9.119 & 0.3627 & 0.1947 & 1.184 & 521.0 & 2.390 & 1.793 & 0.0591 \\
\hline $2 / 14 / 09$ & $16: 02$ & E02556-05 & Hot & 25.15 & 9.092 & 0.3615 & 0.1829 & 1.217 & 519.3 & 2.329 & 1.755 & 0.0612 \\
\hline Comments: & Not Used & & & & & & & & & & & \\
\hline
\end{tabular}

Table 8-36 Summary of Cerion 1 Testing for Mack

\begin{tabular}{|c|c|c|c|c|c|c|c|c|c|c|c|c|}
\hline Fuel: & Cerion 1 & & & Work & Fuel Rec. & bsFC & bsTHC & $\mathrm{bsCO}$ & $\mathrm{bsCO}_{2}$ & bsNOx & bsNOx2 & bsTPM \\
\hline Date & Time & Test No. & Start Type & bhp-hr & $\mathrm{lb}$ & lb/bhp-hr & g/bhp-hr & g/bhp-hr & g/bhp-hr & g/bhp-hr & g/bhp-hr & g/bhp-hr \\
\hline $2 / 15 / 09$ & $11: 55$ & E02558-01 & Warm & 25.17 & 9.187 & 0.3650 & 0.1513 & 1.209 & 524.4 & 2.322 & 1.744 & 0.0596 \\
\hline $2 / 15 / 09$ & $12: 33$ & E02558-02 & Hot & 25.16 & 9.186 & 0.3651 & 0.1900 & 1.199 & 524.4 & 2.330 & 1.756 & 0.0593 \\
\hline $2 / 15 / 09$ & $13: 10$ & E02558-03 & Hot & 25.16 & 9.172 & 0.3646 & 0.1866 & 1.176 & 523.7 & 2.320 & 1.748 & 0.0600 \\
\hline $2 / 15 / 09$ & $13: 50$ & E02558-04 & Hot & 25.16 & 9.187 & 0.3651 & 0.1877 & 1.201 & 524.4 & 2.280 & 1.711 & 0.0612 \\
\hline $2 / 15 / 09$ & $14: 30$ & E02558-05 & Hot & 25.16 & 9.177 & 0.3647 & 0.1846 & 1.177 & 523.9 & 2.301 & 1.732 & 0.0602 \\
\hline Comments: & & & & & & & & & & & & \\
\hline
\end{tabular}


Table 8-37 Summary of Baseline of Cerion 1 Testing for Mack

\begin{tabular}{|c|c|c|c|c|c|c|c|c|c|c|c|c|}
\hline Fuel: & Guttman & & & Work & Fuel Rec. & bsFC & bsTHC & $\mathrm{bsCO}$ & $\mathrm{bsCO}_{2}$ & bsNOx & bsNOx2 & bsTPM \\
\hline Date & Time & Test No. & Start Type & bhp-hr & $\mathrm{lb}$ & lb/bhp-hr & g/bhp-hr & g/bhp-hr & g/bhp-hr & g/bhp-hr & g/bhp-hr & g/bhp-hr \\
\hline $2 / 15 / 09$ & $16: 26$ & E02560-01 & Warm & 25.17 & 9.174 & 0.3645 & 0.1807 & 1.200 & 523.5 & 2.292 & 1.729 & 0.0599 \\
\hline $2 / 15 / 09$ & $17: 07$ & E02560-02 & Hot & 25.17 & 9.175 & 0.3645 & 0.1893 & 1.148 & 523.7 & 2.325 & 1.754 & 0.0564 \\
\hline $2 / 15 / 09$ & $17: 47$ & E02560-03 & Hot & 25.17 & 9.181 & 0.3648 & 0.1804 & 1.173 & 524.1 & 2.278 & 1.705 & 0.0603 \\
\hline $2 / 15 / 09$ & $18: 27$ & E02560-04 & Hot & 25.16 & 9.172 & 0.3646 & 0.1783 & 1.182 & 523.8 & 2.278 & 1.711 & 0.0615 \\
\hline $2 / 15 / 09$ & 19:07 & E02560-05 & Hot & 25.17 & 9.161 & 0.3640 & 0.1760 & 1.171 & 523.0 & 2.285 & 1.717 & 0.0614 \\
\hline Comments: & \multicolumn{2}{|c|}{ Baseline for Cerion 1} & & & & & & & & & & \\
\hline
\end{tabular}

Table 8-38 Summary of Cerion 2 Testing for Mack

\begin{tabular}{|c|c|c|c|c|c|c|c|c|c|c|c|c|}
\hline Fuel: & Cerion 2 & & & Work & Fuel Rec. & bsFC & bsTHC & bsCO & $\mathrm{bsCO}_{2}$ & bsNOx & bsNOx2 & bsTPM \\
\hline Date & Time & Test No. & Start Type & bhp-hr & lb & lb/bhp-hr & g/bhp-hr & g/bhp-hr & g/bhp-hr & g/bhp-hr & g/bhp-hr & g/bhp-hr \\
\hline 2/16/09 & $20: 39$ & E02562-01 & Warm & 25.16 & 9.225 & 0.3667 & 0.1833 & 1.121 & 526.9 & 2.316 & 1.748 & 0.0548 \\
\hline 2/16/09 & $21: 20$ & E02562-02 & Hot & 25.16 & 9.212 & 0.3661 & 0.1865 & 1.175 & 526.0 & 2.269 & 1.702 & 0.0653 \\
\hline $2 / 16 / 09$ & $22: 00$ & E02562-03 & Hot & 25.16 & 9.188 & 0.3651 & 0.1833 & 1.146 & 524.6 & 2.242 & 1.688 & 0.0582 \\
\hline 2/16/09 & $22: 40$ & E02562-04 & Hot & 25.16 & 9.172 & 0.3645 & 0.1866 & 1.120 & 523.7 & 2.236 & 1.686 & 0.0581 \\
\hline 2/16/09 & $23: 20$ & E02562-05 & Hot & 25.16 & 9.177 & 0.3647 & 0.1864 & 1.136 & 524.0 & 2.274 & 1.717 & 0.0581 \\
\hline $2 / 17 / 09$ & 0:02 & E02562-06 & Hot & 25.17 & 9.182 & 0.3649 & 0.1843 & 1.103 & 524.3 & 2.294 & 1.711 & 0.0558 \\
\hline Comments: & & & & & & & & & & & & \\
\hline
\end{tabular}


Table 8-39 Summary of Baseline for Cerion 2 Testing for Mack

\begin{tabular}{|c|c|c|c|c|c|c|c|c|c|c|c|c|}
\hline Fuel & Guttman & & & Work & Fuel Rec. & bsFC & bsTHC & bsCO & $\mathrm{bsCO}_{2}$ & bsNOx & bsNOx2 & bsTPM \\
\hline Date & Time & Test No. & Start Type & bhp-hr & $\mathrm{lb}$ & lb/bhp-hr & g/bhp-hr & g/bhp-hr & g/bhp-hr & g/bhp-hr & g/bhp-hr & g/bhp-hr \\
\hline $2 / 17 / 09$ & $2: 13$ & E02564-01 & Warm & 25.17 & 9.165 & 0.3641 & 0.2022 & 1.132 & 523.1 & 2.274 & 1.725 & 0.0583 \\
\hline $2 / 17 / 09$ & $2: 54$ & E02564-02 & Hot & 25.17 & 9.147 & 0.3634 & 0.1891 & 1.101 & 522.2 & 2.279 & 1.703 & 0.0566 \\
\hline $2 / 17 / 09$ & $3: 34$ & E02564-03 & Hot & 25.17 & 9.135 & 0.3629 & 0.1872 & 1.111 & 521.5 & 2.290 & 1.725 & 0.0561 \\
\hline $2 / 17 / 09$ & $4: 14$ & E02564-04 & Hot & 25.17 & 9.155 & 0.3638 & 0.1941 & 1.161 & 522.6 & 2.218 & 1.662 & 0.0613 \\
\hline $2 / 17 / 09$ & $4: 54$ & E02564-05 & Hot & 25.17 & 9.125 & 0.3626 & 0.1882 & 1.114 & 520.9 & 2.288 & 1.700 & 0.0580 \\
\hline
\end{tabular}

Comments: Baseline for Cerion 2

\subsubsection{DDC Testing Summaries}

Table 8-40 Summary of Baseline Testing for DDC Transient

\begin{tabular}{|c|c|c|c|c|c|c|c|c|c|c|c|c|c|c|}
\hline Fuel: & Halterm & & & Work & Fuel Cons & bsFC & bsTHC & bsTHC2 & bsCO & $\mathrm{bsCO}_{2}$ & bsNOx & bsNOx2 & bsTPM & bsFC \\
\hline Date & Time & Test No. & Start Type & bhp-hr & $\mathrm{lb}$ & lb/bhp-hr & g/bhp-hr & g/bhp-hr & g/bhp-hr & g/bhp-hr & g/bhp-hr & g/bhp-hr & g/bhp-hr & lb/bhp-hr \\
\hline $3 / 24 / 09$ & $11: 14$ & E02597-01 & Warm & 24.63 & 9.234 & 0.3748 & 0.1127 & 0.1488 & 3.312 & 521.2 & 4.812 & 4.752 & 0.2594 & 0.3650 \\
\hline $3 / 24 / 09$ & $11: 54$ & E02597-02 & Hot & 24.64 & 9.214 & 0.3740 & 0.0921 & 0.1186 & 3.189 & 519.7 & 4.807 & 4.748 & 0.2370 & 0.3637 \\
\hline $3 / 24 / 09$ & $12: 34$ & E02597-03 & Hot & 24.63 & 9.215 & 0.3741 & 0.0864 & 0.1125 & 3.251 & 520.0 & 4.779 & 4.828 & 0.2388 & 0.3640 \\
\hline $3 / 24 / 09$ & $13: 14$ & E02597-04 & Hot & 24.63 & 9.174 & 0.3725 & 0.0874 & 0.1134 & 3.236 & 517.7 & 4.769 & 4.799 & 0.2413 & 0.3623 \\
\hline 3/24/09 & $13: 54$ & E02597-05 & Hot & 24.62 & 9.173 & 0.3726 & 0.0853 & 0.1077 & 3.246 & 517.1 & 4.807 & 4.805 & 0.2898 & 0.3619 \\
\hline
\end{tabular}

Comments: Not Used 
Table 8-41 Summary of Baseline for H2Oil 1 Testing for DDC Transient

\begin{tabular}{|c|c|c|c|c|c|c|c|c|c|c|c|c|c|c|}
\hline Fuel: & Halterma & & & Work & Fuel Cons & bsFC & bsTHC & bsTHC2 & $\mathrm{bsCO}$ & $\mathrm{bsCO}_{2}$ & bsNOx & bsNOx2 & bsTPM & bsFC \\
\hline Date & Time & Test No. & Start Type & bhp-hr & $\mathrm{lb}$ & lb/bhp-hr & g/bhp-hr & g/bhp-hr & g/bhp-hr & g/bhp-hr & g/bhp-hr & g/bhp-hr & g/bhp-hr & lb/bhp-hr \\
\hline $3 / 25 / 09$ & $14: 54$ & E02601-01 & Warm & 24.58 & 9.196 & 0.3742 & 0.0810 & 0.1042 & 3.402 & 520.6 & 4.653 & 4.670 & 0.2390 & 0.3645 \\
\hline $3 / 25 / 09$ & $15: 34$ & E02601-02 & Invalid & 24.59 & 9.157 & 0.3723 & 0.0747 & 0.0970 & 3.310 & 517.3 & 4.652 & 4.656 & 0.2385 & 0.3622 \\
\hline $3 / 25 / 09$ & 16:14 & E02601-03 & Hot & 24.62 & 8.946 & 0.3634 & 0.0721 & 0.0937 & 3.237 & 516.1 & 4.742 & 4.751 & 0.2368 & 0.3612 \\
\hline $3 / 25 / 09$ & $16: 55$ & E02601-04 & Hot & 24.64 & 8.721 & 0.3539 & 0.0710 & 0.0917 & 3.193 & 515.8 & 4.686 & 4.710 & 0.2387 & 0.3610 \\
\hline $3 / 25 / 09$ & $17: 35$ & E02601-05 & $\mathrm{Hot}$ & 24.64 & 9.239 & 0.3750 & 0.0708 & 0.0920 & 3.189 & 515.5 & 4.690 & 4.715 & 0.2369 & 0.3607 \\
\hline Comments & Baseline & H2Oil 1 & & & & & & & & & & & & \\
\hline
\end{tabular}

Table 8-42 Summary for H2Oil 1 for DDC Transient

\begin{tabular}{|c|c|c|c|c|c|c|c|c|c|c|c|c|c|c|}
\hline Fuel: & H2Oil 1 & & & Work & Fuel Cons & bsFC & bsTHC & bsTHC2 & bsCO & bsCO 2 & bsNOx & bsNOx2 & bsTPM & bsFC \\
\hline Date & Time & Test No. & Start Type & bhp-hr & lb & lb/bhp-hr & g/bhp-hr & g/bhp-hr & g/bhp-hr & g/bhp-hr & g/bhp-hr & g/bhp-hr & g/bhp-hr & lb/bhp-hr \\
\hline $3 / 25 / 09$ & $7: 30$ & E02599-01 & Warm & 24.61 & 9.182 & 0.3731 & 0.0971 & 0.1262 & 3.320 & 526.0 & 4.811 & 4.829 & 0.2511 & 0.3682 \\
\hline $3 / 25 / 09$ & $9: 16$ & E02599-02 & Warm & 24.61 & 9.221 & 0.3747 & 0.0779 & 0.1010 & 3.191 & 521.3 & 4.773 & 4.818 & 0.2291 & 0.3648 \\
\hline $3 / 25 / 09$ & $9: 56$ & E02599-03 & Hot & 24.65 & 9.136 & 0.3707 & 0.0736 & 0.0979 & 3.021 & 517.1 & 4.746 & 4.789 & 0.2228 & 0.3616 \\
\hline $3 / 25 / 09$ & $10: 37$ & E02599-04 & Hot & 24.64 & 9.142 & 0.3710 & 0.0741 & 0.0990 & 3.103 & 516.3 & 4.754 & 4.809 & 0.2361 & 0.3612 \\
\hline $3 / 25 / 09$ & $11: 17$ & E02599-05 & Hot & 24.64 & 9.153 & 0.3714 & 0.0713 & 0.0950 & 3.144 & 515.6 & 4.726 & 4.784 & 0.2342 & 0.3609 \\
\hline Comments: & & & & & & & & & & & & & &
\end{tabular}


Table 8-43 Summary of Baseline of Cerion 1 for DDC Transient

\begin{tabular}{|c|c|c|c|c|c|c|c|c|c|c|c|c|c|c|}
\hline Fuel: & Halterma & & & Work & Fuel Cons & bsFC & bsTHC & bsTHC2 & bsCO & $\mathrm{bsCO}_{2}$ & bsNOx & bsNOx2 & bsTPM & bsFC \\
\hline Date & Time & Test No. & Start Type & bhp-hr & $\mathrm{lb}$ & lb/bhp-hr & g/bhp-hr & g/bhp-hr & g/bhp-hr & g/bhp-hr & g/bhp-hr & g/bhp-hr & g/bhp-hr & lb/bhp-hr \\
\hline $3 / 27 / 09$ & 19:31 & E02603-01 & Warm & 24.64 & 8.252 & 0.3349 & 0.0568 & 0.0897 & 3.242 & 515.0 & 4.614 & 4.650 & 0.0000 & 0.3604 \\
\hline $3 / 27 / 09$ & $20: 11$ & E02603-02 & Hot & 24.63 & 9.149 & 0.3715 & 0.0695 & 0.0905 & 3.093 & 515.9 & 4.593 & 4.609 & 0.2325 & 0.3609 \\
\hline $3 / 27 / 09$ & $20: 51$ & E02603-03 & Hot & 24.62 & 9.146 & 0.3715 & 0.0696 & 0.0898 & 3.079 & 516.4 & 4.617 & 4.665 & 0.2322 & 0.3613 \\
\hline $3 / 27 / 09$ & $21: 31$ & E02603-04 & Hot & 24.62 & 9.167 & 0.3723 & 0.0759 & 0.0990 & 3.095 & 515.8 & 4.600 & 4.691 & 0.2314 & 0.3609 \\
\hline Comments & Baseline & Cerion 1 & & & & & & & & & & & & \\
\hline
\end{tabular}

Table 8-44 Summary of Cerion 1 for DDC Transient

\begin{tabular}{|c|c|c|c|c|c|c|c|c|c|c|c|c|c|c|}
\hline Fuel: & Cerion 1 & & & Work & Fuel Cons & bsFC & bsTHC & bsTHC2 & $\mathrm{bsCO}$ & $\mathrm{bsCO}_{2}$ & bsNOx & bsNOx2 & bsTPM & bsFC \\
\hline Date & Time & Test No. & Start Type & bhp-hr & $\mathrm{lb}$ & lb/bhp-hr & g/bhp-hr & g/bhp-hr & g/bhp-hr & g/bhp-hr & g/bhp-hr & g/bhp-hr & g/bhp-hr & lb/bhp-hr \\
\hline $3 / 28 / 09$ & $0: 34$ & E02605-01 & Warm & 24.61 & 8.962 & 0.3642 & 0.0764 & 0.0975 & 3.144 & 518.3 & 4.588 & 4.678 & 0.2281 & 0.3627 \\
\hline $3 / 28 / 09$ & $1: 15$ & E02605-02 & Hot & 24.63 & 8.833 & 0.3586 & 0.0677 & 0.0871 & 3.103 & 516.4 & 4.598 & 4.672 & 0.2317 & 0.3613 \\
\hline $3 / 28 / 09$ & $1: 55$ & E02605-03 & Hot & 24.64 & 9.150 & 0.3713 & 0.0660 & 0.0847 & 3.069 & 517.5 & 4.614 & 4.703 & 0.2249 & 0.3620 \\
\hline $3 / 28 / 09$ & $2: 35$ & E02605-04 & Hot & 24.64 & 9.168 & 0.3721 & 0.0707 & 0.0898 & 3.135 & 517.8 & 4.611 & 4.703 & 0.2301 & 0.3623 \\
\hline Comments: & & & & & & & & & & & & & & \\
\hline
\end{tabular}


Table 8-45 Summary of Baseline of NanoBonus for DDC Transient

\begin{tabular}{|c|c|c|c|c|c|c|c|c|c|c|c|c|c|c|}
\hline Fuel: & \multicolumn{3}{|c|}{ Haltermann } & \multirow{2}{*}{$\begin{array}{c}\text { Work } \\
\text { bhp-hr }\end{array}$} & \multirow{2}{*}{$\begin{array}{c}\text { Fuel Cons } \\
\text { lb }\end{array}$} & \multirow{2}{*}{$\begin{array}{c}\text { bsFC } \\
\text { lb/bhp-hr }\end{array}$} & \multirow{2}{*}{$\begin{array}{l}\text { bsTHC } \\
\text { g/bhp-hr }\end{array}$} & \multirow{2}{*}{$\begin{array}{l}\text { bsTHC2 } \\
\text { g/bhp-hr }\end{array}$} & \multirow{2}{*}{$\begin{array}{c}\text { bsCO } \\
\text { g/bhp-hr }\end{array}$} & \multirow{2}{*}{$\begin{array}{c}\mathrm{bsCO}_{2} \\
\text { g/bhp-hr }\end{array}$} & \multirow{2}{*}{$\begin{array}{l}\text { bsNOx } \\
\text { g/bhp-hr }\end{array}$} & \multirow{2}{*}{$\begin{array}{l}\text { bsNOx2 } \\
\text { g/bhp-hr }\end{array}$} & \multirow{2}{*}{$\begin{array}{l}\text { bsTPM } \\
\text { g/bhp-hr }\end{array}$} & \multirow{2}{*}{$\begin{array}{c}\text { bsFC } \\
\text { lb/bhp-hr }\end{array}$} \\
\hline Date & Time & Test No. & Start Type & & & & & & & & & & & \\
\hline $3 / 28 / 09$ & 21:03 & E02609-01 & Warm & 24.61 & 9.207 & 0.3741 & 0.0778 & 0.0887 & 3.344 & 517.9 & 4.675 & 4.726 & 0.2369 & 0.3626 \\
\hline $3 / 28 / 09$ & $21: 43$ & E02609-02 & Hot & 24.58 & 9.064 & 0.3687 & 0.0753 & 0.0876 & 3.252 & 515.7 & 4.665 & 4.688 & 0.2410 & 0.3610 \\
\hline $3 / 28 / 09$ & $22: 23$ & E02609-03 & Hot & 24.58 & 9.150 & 0.3723 & 0.0729 & 0.0842 & 3.197 & 514.7 & 4.633 & 4.703 & 0.2366 & 0.3602 \\
\hline 3/28/09 & 23:03 & E02609-04 & Hot & 24.58 & 9.148 & 0.3722 & 0.0740 & 0.0830 & 3.231 & 514.1 & 4.626 & 4.701 & 0.2397 & 0.3599 \\
\hline
\end{tabular}

Comments: Baseline NanoBonus

Table 8-46 Summary of NanoBonus for DDC Transient

\begin{tabular}{|c|c|c|c|c|c|c|c|c|c|c|c|c|c|c|}
\hline Fuel: & Nano & onus & & Work & Fuel Cons & bsFC & bsTHC & bsTHC2 & bsCO & $\mathrm{bsCO}_{2}$ & bsNOx & bsNOx2 & bsTPM & bsFC \\
\hline Date & Time & Test No. & Start Type & bhp-hr & $\mathrm{lb}$ & lb/bhp-hr & g/bhp-hr & g/bhp-hr & g/bhp-hr & g/bhp-hr & g/bhp-hr & g/bhp-hr & g/bhp-hr & lb/bhp-hr \\
\hline 3/28/09 & 5:09 & E02607-01 & Warm & 24.66 & 9.160 & 0.3714 & 0.0652 & 0.0819 & 3.364 & 519.8 & 4.775 & 4.872 & 0.2404 & 0.3639 \\
\hline $3 / 28 / 09$ & $5: 49$ & E02607-02 & Hot & 24.64 & 9.147 & 0.3712 & 0.0685 & 0.0869 & 3.149 & 516.0 & 4.615 & 4.680 & 0.2320 & 0.3611 \\
\hline 3/28/09 & $6: 29$ & E02607-03 & Hot & 24.63 & 9.130 & 0.3707 & 0.0677 & 0.0880 & 3.130 & 516.7 & 4.630 & 4.694 & 0.2321 & 0.3615 \\
\hline 3/28/09 & 7:09 & E02607-04 & Hot & 24.63 & 9.131 & 0.3708 & 0.0689 & 0.0873 & 3.081 & 515.6 & 4.634 & 4.723 & 0.2284 & 0.3607 \\
\hline
\end{tabular}

Comments: 
Table 8-47 Summary of Baseline for H2Oil 1 for DDC Steady State

\begin{tabular}{|c|c|c|c|c|c|c|c|c|c|}
\hline \multicolumn{3}{|c|}{ Haltermann } & Mode: & 1 & 2 & 3 & 4 & 5 & 6 \\
\hline Date & Test \# & Work & bhp-hr & 0 & 1.671 & 5.677 & 7.667 & 1.91 & 6.66 \\
\hline $3 / 24 / 2009$ & E02598-01 & Fuel-Meter & $\mathrm{lb}$ & 0.13091 & 0.23098 & 1.82498 & 2.44669 & 0.68349 & 2.1815 \\
\hline Time & & Fuel-Tunnel & $\mathrm{lb}$ & 0.08508 & 0.55967 & 1.73917 & 2.32108 & 0.68856 & 2.09766 \\
\hline $14: 34: 48$ & & Fuel-Scale & lb & 0.09981 & 0.19872 & 1.82475 & 2.41981 & 0.67671 & 2.17041 \\
\hline & & bsFC & lb/bhp-hr & - & 0.3349 & 0.3064 & 0.3027 & 0.3605 & 0.3150 \\
\hline & & bsHC & g/bhp-hr & 11.4905 & 0.0939 & 0.0238 & 0.0235 & 0.1000 & 0.0183 \\
\hline & & bsHC2 & g/bhp-hr & 8.7730 & 0.0875 & 0.0222 & 0.0225 & 0.0948 & 0.0170 \\
\hline & & bsLoCO & g/bhp-hr & 110.679 & 0.6484 & 1.8533 & 1.5094 & 0.725 & 6.064 \\
\hline & & bsHiCO & g/bhp-hr & 103.9031 & 0.6326 & 1.7977 & 1.4678 & 0.6989 & 6.8184 \\
\hline & & $\mathrm{bsCO}_{2}$ & g/bhp-hr & 14532.39 & 482.1 & 439.32 & 434.61 & 518.88 & 443.86 \\
\hline & & bsNOx & g/bhp-hr & 369.453 & 10.765 & 6.399 & 4.417 & 10.928 & 5.223 \\
\hline & & bsNOx2 & g/bhp-hr & 345.448 & 10.892 & 7.018 & 6.769 & 11.092 & 5.742 \\
\hline & & bsNO_2 & g/bhp-hr & 305.462 & 10.230 & 6.800 & 6.580 & 10.664 & 5.526 \\
\hline & & bSIPM & g/bhp-hr & 2.2802 & 0.7541 & 0.2342 & 0.3106 & 0.6742 & 0.8604 \\
\hline & Comments: & Emisisons & for & H2Oil 1 & & & & & \\
\hline
\end{tabular}

Bad PM 
Table 8-48 Summary of Baseline for H2Oil 1 for DDC Steady State

\begin{tabular}{|c|c|c|c|c|c|c|c|c|c|c|}
\hline \multicolumn{4}{|c|}{ Haltermann } & \multirow{2}{*}{$\begin{array}{l}\text { Mode: } \\
\text { bhp-hr }\end{array}$} & \multirow{2}{*}{$\begin{array}{l}\mathbf{1}^{*} \\
0 \\
\end{array}$} & \multirow{2}{*}{$\begin{array}{r}2 \\
1.663 \\
\end{array}$} & \multirow{2}{*}{$\begin{array}{r}3 \\
5.674 \\
\end{array}$} & \multirow{2}{*}{$\begin{array}{r}4 \\
7.681 \\
\end{array}$} & \multirow{2}{*}{$\begin{array}{r}5 \\
1.901 \\
\end{array}$} & \multirow{2}{*}{$\begin{array}{r}6 \\
6.658 \\
\end{array}$} \\
\hline Date & Time & Test \# & Work & & & & & & & \\
\hline 3/24/2009 & 15:35:40 & E02598-02 & Fuel-Meter & $\mathrm{lb}$ & 0.14481 & 0.03095 & 1.8145 & 2.4485 & 0.69173 & 2.17468 \\
\hline & & & Fuel-Tunnel & $\mathrm{lb}$ & 0.08914 & 0.55962 & 1.73728 & 2.31187 & 0.68373 & 2.08301 \\
\hline & & & Fuel-Scale & $\mathrm{lb}$ & 0.1079 & -0.02223 & 1.81429 & 2.43001 & 0.68037 & 2.1537 \\
\hline & & & bsFC & lb/bhp-hr & - & 0.3365 & 0.3062 & 0.3010 & 0.3597 & 0.3129 \\
\hline & & & $\mathrm{bsHC}$ & g/bhp-hr & 14.8195 & 0.1011 & 0.0247 & 0.0213 & 0.0961 & 0.0178 \\
\hline & & & bsHC2 & g/bhp-hr & 11.2323 & 0.0926 & 0.0226 & 0.0200 & 0.0892 & 0.0162 \\
\hline & & & bsLoCO & g/bhp-hr & 108.1477 & 0.6159 & 1.7701 & 1.2747 & 0.6756 & 5.961 \\
\hline & & & bsHicO & g/bhp-hr & 100.9111 & 0.6008 & 1.7145 & 1.2368 & 0.6528 & 6.2146 \\
\hline & & & $\mathrm{bsCO}_{2}$ & g/bhp-hr & 15227.02 & 484.38 & 439.22 & 432.44 & 517.93 & 441.78 \\
\hline & & & bsNOx & g/bhp-hr & 377.981 & 10.733 & 6.467 & 4.437 & 10.840 & 5.287 \\
\hline & & & bsNOx2 & g/bhp-hr & 352.248 & 10.843 & 6.991 & 6.773 & 11.021 & 5.809 \\
\hline & & & bsNO_2 & g/bhp-hr & 316.130 & 10.212 & 6.780 & 6.561 & 10.552 & 5.575 \\
\hline & & & bs DPM & g/bhp-hr & 3.2663 & 0.7960 & 0.1870 & 0.2433 & 0.7493 & 0.6383 \\
\hline & & Comments & Emissions & for H2Oil 1 & & & & & & \\
\hline
\end{tabular}


Table 8-49 Summary of H2Oil 1 for DDC Steady State

\begin{tabular}{|c|c|c|c|c|c|c|c|c|c|c|}
\hline \multicolumn{4}{|c|}{ H2Oil 1} & Mode: & $1^{*}$ & 2 & 3 & 4 & 5 & 6 \\
\hline Date & Time & Test \# & Work & bhp-hr & 0 & 1.671 & 5.687 & 7.688 & 1.933 & 6.662 \\
\hline $3 / 25 / 2009$ & $12: 07: 10$ & E02600-01 & Fuel-Meter & $\mathrm{lb}$ & 0.13045 & 0.33375 & 1.74304 & 2.43963 & 0.68582 & 2.16652 \\
\hline & & & Fuel-Tunnel & $\mathrm{lb}$ & 0.08603 & 0.56118 & 1.7376 & 2.31453 & 0.68991 & 2.08282 \\
\hline & & & Fuel-Scale & $\mathrm{lb}$ & 0 & 0 & 0 & 0 & 0 & 0 \\
\hline & & & bsFC & lb/bhp-hr & - & 0.3358 & 0.3055 & 0.3011 & 0.3569 & 0.3126 \\
\hline & & & bsHC & g/bhp-hr & 6.2517 & 0.0770 & 0.0217 & 0.0190 & 0.0876 & 0.0181 \\
\hline & & & bsHC2 & g/bhp-hr & 8.5530 & 0.0824 & 0.0230 & 0.0198 & 0.0920 & 0.0191 \\
\hline & & & bsLoCO & g/bhp-hr & 110.3597 & 0.6298 & 1.6077 & 1.2068 & 0.711 & 5.9173 \\
\hline & & & bsHiCO & g/bhp-hr & 106.4601 & 0.6245 & 1.5591 & 1.1707 & 0.6929 & 6.1327 \\
\hline & & & $\mathrm{bsCO}_{2}$ & g/bhp-hr & 14711 & 483.59 & 438.54 & 432.68 & 513.66 & 441.56 \\
\hline & & & bsNOx & g/bhp-hr & 359.421 & 10.607 & 6.489 & 4.470 & 10.681 & 5.330 \\
\hline & & & bsNOX2 & g/bhp-hr & 318.557 & 10.771 & 7.061 & 6.815 & 10.878 & 5.831 \\
\hline & & & bsNO_2 & g/bhp-hr & 278.487 & 10.116 & 6.852 & 6.635 & 10.455 & 5.634 \\
\hline & & & PM & g/bhp-hr & 0.0000 & 0.0000 & 0.0000 & 0.0000 & 0.0000 & 0.0000 \\
\hline
\end{tabular}

Bad PM 
Table 8-50 Summary of H2Oil 1 for DDC Steady State

\begin{tabular}{|c|c|c|c|c|c|c|c|c|c|c|}
\hline \multicolumn{4}{|c|}{ H2Oil 1} & \multirow{2}{*}{$\begin{array}{l}\text { Mode: } \\
\text { bhp-hr }\end{array}$} & \multirow{2}{*}{ 1* $^{*}$} & \multirow{2}{*}{$\begin{array}{r}2 \\
1.668 \\
\end{array}$} & \multirow{2}{*}{$\begin{array}{r}3 \\
5.67 \\
\end{array}$} & \multirow{2}{*}{$\begin{array}{r}4 \\
7.687 \\
\end{array}$} & \multirow{2}{*}{$\begin{array}{r}\mathbf{5} \\
1.918 \\
\end{array}$} & \multirow{2}{*}{$\begin{array}{r}6 \\
6.659 \\
\end{array}$} \\
\hline Date & Time & Test \# & Work & & & & & & & \\
\hline 3/25/2009 & $13: 06: 58$ & E02600-02 & Fuel-Meter & $\mathrm{lb}$ & 0.15436 & 0.01333 & 1.86173 & 2.46951 & 0.71519 & 2.16572 \\
\hline & & & Fuel-Tunnel & $\mathrm{lb}$ & 0.08559 & 0.55966 & 1.7333 & 2.3104 & 0.68253 & 2.08175 \\
\hline & & & Fuel-Scale & $\mathrm{lb}$ & 0 & 0 & 0 & 0 & 0 & 0 \\
\hline & & & bsFC & lb/bhp-hr & - & 0.3355 & 0.3057 & 0.3006 & 0.3559 & 0.3126 \\
\hline & & & bsHC & g/bhp-hr & 7.7521 & 0.1115 & 0.0240 & 0.0184 & 0.0823 & 0.0169 \\
\hline & & & bsHC2 & g/bhp-hr & 8.5302 & 0.1133 & 0.0245 & 0.0187 & 0.0838 & 0.0173 \\
\hline & & & bsLoCO & g/bhp-hr & 103.1785 & 0.7015 & 1.7194 & 1.2184 & 0.6687 & 5.8871 \\
\hline & & & bsHiCO & g/bhp-hr & 97.7414 & 0.6906 & 1.6645 & 1.18 & 0.6473 & 6.1504 \\
\hline & & & $\mathrm{bsCO}_{2}$ & g/bhp-hr & 14643.2 & 482.76 & 438.57 & 431.93 & 512.48 & 441.52 \\
\hline & & & bsNOx & g/bhp-hr & 364.140 & 10.606 & 6.437 & 4.409 & 10.737 & 5.234 \\
\hline & & & bsNOx2 & g/bhp-hr & 319.635 & 10.717 & 7.002 & 6.778 & 10.903 & 5.800 \\
\hline & & & bsNO_2 & g/bhp-hr & 287.277 & 10.107 & 6.813 & 6.588 & 10.465 & 5.586 \\
\hline & & & hCIPM & g/bhp-hr & 0.0000 & 0.0000 & 0.0000 & 0.0000 & 0.0000 & 0.0000 \\
\hline
\end{tabular}


Table 8-51 Summary of Baseline of DDC Steady State

\begin{tabular}{|l|l|l|l|l|r|r|r|r|r|r|}
\hline \multicolumn{4}{|c}{ Haltermann } & Mode: & \multicolumn{1}{|c|}{$\mathbf{*}^{*}$} & $\mathbf{2}$ & $\mathbf{3}$ & $\mathbf{4}$ & $\mathbf{5}$ & $\mathbf{6}$ \\
\hline Date & Time & Test \# & Work & bhp-hr & 0 & 1.675 & 5.681 & 7.676 & 1.931 & 6.657 \\
\hline $3 / 25 / 2009$ & $18: 14: 46$ & E02602-01 & Fuel-Meter & lb & 0.11272 & 0.41112 & 1.61228 & 2.43874 & 0.67978 & 2.16607 \\
\hline & & & Fuel-Tunnel & lb & 0.08646 & 0.5605 & 1.73521 & 2.31319 & 0.68559 & 2.08488 \\
\hline & & & Fuel-Scale & lb & 0 & 0 & 0 & 0 & 0 & 0 \\
\hline & & & bsFC & lb/bhp-hr & - & 0.3346 & 0.3054 & 0.3014 & 0.3550 & 0.3132 \\
\hline & & & bsHC & g/bhp-hr & 8.9159 & 0.0838 & 0.0231 & 0.0203 & 0.0849 & 0.0182 \\
\hline & & & bsHC2 & g/bhp-hr & 10.2605 & 0.0870 & 0.0239 & 0.0208 & 0.0875 & 0.0188 \\
\hline & & & bsLoCO & g/bhp-hr & 118.1307 & 0.6546 & 1.6822 & 1.292 & 0.6927 & 6.0298 \\
\hline & & & bsHiCO & g/bhp-hr & 108.6951 & 0.6295 & 1.6313 & 1.2547 & 0.6695 & 6.4365 \\
\hline & & & bsCO 2 & g/bhp-hr & 14773.5 & 481.75 & 438.25 & 432.95 & 511.25 & 441.87 \\
\hline & & & bsNOx & g/bhp-hr & 357.842 & 10.598 & 6.515 & 4.473 & 10.731 & 5.307 \\
\hline & & & bsNOx2 & g/bhp-hr & 318.220 & 10.813 & 7.048 & 6.824 & 10.962 & 5.806 \\
\hline & & & bsNO_2 & g/bhp-hr & 278.589 & 10.209 & 6.867 & 6.658 & 10.582 & 5.620 \\
\hline & & & bsTPM & g/bhp-hr & 0.66013 & 0.13262 & 0.06929 & 0.07145 & 0.11477 & 0.18583 \\
\hline
\end{tabular}

Bad PM 
Table 8-52 Summary of Baseline of Cerion 1 of DDC Steady State

\begin{tabular}{|c|c|c|c|c|c|c|c|c|c|c|}
\hline \multicolumn{4}{|c|}{ Haltermann } & \multirow{2}{*}{$\begin{array}{l}\text { Mode: } \\
\text { bhp-hr }\end{array}$} & \multirow{2}{*}{$1^{*}$} & \multirow{2}{*}{$\begin{array}{r}\mathbf{2} \\
1.669 \\
\end{array}$} & \multirow{2}{*}{$\begin{array}{r}\mathbf{3} \\
5.672 \\
\end{array}$} & \multirow{2}{*}{$\begin{array}{r}4 \\
7.687 \\
\end{array}$} & \multirow{2}{*}{$\begin{array}{r}\mathbf{5} \\
1.917 \\
\end{array}$} & \multirow{2}{*}{$\begin{array}{r}6 \\
6.665 \\
\end{array}$} \\
\hline Date & Time & Test \# & Work & & & & & & & \\
\hline \multirow[t]{13}{*}{$3 / 27 / 2009$} & $22: 55: 22$ & E02604-01 & Fuel-Meter & $\mathrm{lb}$ & 0.127 & 0.30947 & 1.70219 & 2.4369 & 0.68153 & 2.16237 \\
\hline & & & Fuel-Tunnel & $\mathrm{lb}$ & 0.0878 & 0.56172 & 1.73607 & 2.3158 & 0.68734 & 2.0951 \\
\hline & & & Fuel-Scale & $\mathrm{lb}$ & 0 & 0 & 0 & 0 & 0 & 0 \\
\hline & & & bsFC & lb/bhp-hr & - & 0.3366 & 0.3061 & 0.3013 & 0.3585 & 0.3143 \\
\hline & & & bsHC & g/bhp-hr & 12.0542 & 0.1001 & 0.0211 & 0.0193 & 0.0881 & 0.0172 \\
\hline & & & bsHC2 & g/bhp-hr & 10.5674 & 0.0966 & 0.0202 & 0.0188 & 0.0853 & 0.0165 \\
\hline & & & bsLoCO & g/bhp-hr & 121.5775 & 0.7192 & 1.7264 & 1.3315 & 0.7164 & 6.0436 \\
\hline & & & bsHicO & g/bhp-hr & 109.0602 & 0.6803 & 1.6722 & 1.2912 & 0.6826 & 6.5929 \\
\hline & & & $\mathrm{bsCO}_{2}$ & g/bhp-hr & 14992.44 & 484.29 & 439.13 & 432.78 & 516.22 & 443.31 \\
\hline & & & bsNOx & g/bhp-hr & 366.158 & 10.492 & 6.319 & 4.339 & 10.699 & 5.137 \\
\hline & & & bsNOx2 & g/bhp-hr & 336.473 & 10.603 & 6.932 & 6.714 & 10.845 & 5.693 \\
\hline & & & bsNO_2 & g/bhp-hr & 301.200 & 9.969 & 6.731 & 6.543 & 10.460 & 5.498 \\
\hline & & & bsTPM & g/bhp-hr & -0.1786 & 0.1591 & 0.0856 & 0.0190 & 0.4695 & 0.1830 \\
\hline
\end{tabular}


Table 8-53 Summary of Cerion 1 for DDC Steady State

\begin{tabular}{|l|l|l|l|l|r|r|r|r|r|r|}
\hline \multicolumn{4}{|c}{ Cerion 1 } & Mode: & \multicolumn{1}{|l}{$\mathbf{1}^{*}$} & $\mathbf{2}$ & $\mathbf{3}$ & $\mathbf{4}$ & $\mathbf{5}$ & $\mathbf{6}$ \\
\hline Date & Time & Test \# & Work & bhp-hr & 0 & 1.673 & 5.676 & 7.679 & 1.927 & 6.658 \\
\hline $3 / 28 / 2009$ & $3: 15: 34$ & E02606-01 & Fuel-Meter & lb & 0.13002 & 0.43114 & 1.59676 & 2.43205 & 0.67818 & 2.16372 \\
\hline & & & Fuel-Tunnel & lb & 0.0859 & 0.55941 & 1.73097 & 2.31075 & 0.68891 & 2.08627 \\
\hline & & & Fuel-Scale & lb & 0 & 0 & 0 & 0 & 0 & 0 \\
\hline & & & bsFC & lb/bhp-hr & - & 0.3344 & 0.3050 & 0.3009 & 0.3575 & 0.3133 \\
\hline & & & bsHC & g/bhp-hr & 4.7571 & 0.0811 & 0.0196 & 0.0177 & 0.0827 & 0.0163 \\
\hline & & & bsHC2 & g/bhp-hr & 3.3964 & 0.0779 & 0.0188 & 0.0172 & 0.0801 & 0.0157 \\
\hline & & & bsLoCO & g/bhp-hr & 111.7922 & 0.6584 & 1.6194 & 1.2612 & 0.7026 & 6.013 \\
\hline & & & bsHiCO & g/bhp-hr & 96.7363 & 0.6259 & 1.57 & 1.2227 & 0.6719 & 6.3942 \\
\hline & & & bsCO 2 & g/bhp-hr & 14709.89 & 481.52 & 437.68 & 432.36 & 514.73 & 442.19 \\
\hline & & & bsNOx & g/bhp-hr & 354.074 & 10.426 & 6.279 & 4.321 & 10.560 & 5.127 \\
\hline & & & bsNOx2 & g/bhp-hr & 334.786 & 10.634 & 6.975 & 6.735 & 10.817 & 5.720 \\
\hline & & & bsNO_2 & g/bhp-hr & 299.588 & 10.003 & 6.757 & 6.546 & 10.392 & 5.518 \\
\hline & & & bsTPM & g/bhp-hr & 0.7292 & 0.1406 & 0.0620 & 0.0589 & 0.1156 & 0.1788 \\
\hline
\end{tabular}


Table 8-54 Summary of Cerion 1 for DDC STeady State

\begin{tabular}{|l|l|l|l|l|r|r|r|r|r|r|}
\hline \multicolumn{4}{|c}{ Cerion 1 } & Mode: & $\mathbf{1}^{*}$ & $\mathbf{2}$ & $\mathbf{3}$ & $\mathbf{4}$ & $\mathbf{5}$ & $\mathbf{6}$ \\
\hline Date & Time & Test \# & Work & bhp-hr & 0 & 1.665 & 5.673 & 7.52 & 1.931 & 6.466 \\
\hline $3 / 28 / 2009$ & $4: 11: 35$ & E02606-02 & Fuel-Meter & lb & 0.11565 & 0.28567 & 1.75374 & 2.3386 & 0.66864 & 2.13724 \\
\hline & & & Fuel-Tunnel & lb & 0.08376 & 0.55855 & 1.76555 & 2.32629 & 0.70257 & 2.14419 \\
\hline & & & Fuel-Scale & lb & 0 & 0 & 0 & 0 & 0 & 0 \\
\hline & & & bsFC & lb/bhp-hr & - & 0.3355 & 0.3112 & 0.3093 & 0.3638 & 0.3316 \\
\hline & & & bsHC & g/bhp-hr & 6.7096 & 0.0810 & 0.0236 & 0.0270 & 0.0687 & 0.0121 \\
\hline & & & bsHC2 & g/bhp-hr & 5.4118 & 0.0779 & 0.0228 & 0.0266 & 0.0663 & 0.0115 \\
\hline & & & bsLoCO & g/bhp-hr & 104.2873 & 0.6157 & 2.4094 & 2.0495 & 0.4381 & 6.1754 \\
\hline & & & bsHiCO & g/bhp-hr & 91.5636 & 0.5867 & 2.3508 & 1.998 & 0.4159 & 10.1772 \\
\hline & & & bsCO 2 & g/bhp-hr & 14340.86 & 482.94 & 445.45 & 443.3 & 524.29 & 462.62 \\
\hline & & & bsNOx & g/bhp-hr & 365.649 & 10.702 & 6.259 & 4.380 & 12.594 & 5.220 \\
\hline & & & bsNOx2 & g/bhp-hr & 350.937 & 10.921 & 7.506 & 8.356 & 12.891 & 6.144 \\
\hline & & & bsNO_2 & g/bhp-hr & 309.319 & 10.255 & 7.246 & 8.076 & 12.467 & 5.893 \\
\hline & & & bsTPM & g/bhp-hr & 0.0400 & 0.1167 & 0.0709 & 0.0705 & 0.0536 & 0.2994 \\
\hline
\end{tabular}


Table 8-55 Summary of NanoBonus for DDC Steady State

\begin{tabular}{|l|l|l|l|l|r|r|r|r|r|r|}
\hline \multicolumn{4}{|c}{ NanoBonus } & Mode: & $\mathbf{1}^{*}$ & $\mathbf{2}$ & $\mathbf{3}$ & $\mathbf{4}$ & $\mathbf{5}$ & $\mathbf{6}$ \\
\hline Date & Time & Test \# & Work & bhp-hr & 0 & 1.673 & 5.684 & 7.688 & 1.931 & 6.664 \\
\hline $3 / 28 / 2009$ & $7: 51: 34$ & E02608-01 & Fuel-Meter & lb & 0.1297 & 0.4531 & 1.57182 & 2.42977 & 0.67986 & 2.1623 \\
\hline & & & Fuel-Tunnel & lb & 0.08742 & 0.56125 & 1.73259 & 2.31128 & 0.69097 & 2.07969 \\
\hline & & & Fuel-Scale & lb & 0 & 0 & 0 & 0 & 0 & 0 \\
\hline & & & bsFC & lb/bhp-hr & - & 0.3355 & 0.3048 & 0.3006 & 0.3578 & 0.3121 \\
\hline & & & bsHC & g/bhp-hr & 7.9345 & 0.0978 & 0.0211 & 0.0179 & 0.0829 & 0.0179 \\
\hline & & & bsHC2 & g/bhp-hr & 7.1192 & 0.0959 & 0.0206 & 0.0176 & 0.0814 & 0.0175 \\
\hline & & & bsLoCO & g/bhp-hr & 115.1613 & 0.7137 & 1.6098 & 1.1648 & 0.6942 & 5.9009 \\
\hline & & & bsHiCO & g/bhp-hr & 106.5165 & 0.691 & 1.5614 & 1.1295 & 0.6698 & 6.1248 \\
\hline & & & bsCO 2 & g/bhp-hr & 14946.28 & 482.69 & 437.5 & 432.12 & 515.17 & 440.78 \\
\hline & & & bsNOx & g/bhp-hr & 356.930 & 10.417 & 6.254 & 4.187 & 10.507 & 5.121 \\
\hline & & & bsNOx2 & g/bhp-hr & 343.104 & 10.657 & 6.999 & 6.722 & 10.776 & 5.723 \\
\hline & & & bsNO_2 & g/bhp-hr & 296.690 & 9.973 & 6.777 & 6.529 & 10.347 & 5.517 \\
\hline & & & bsTPM & g/bhp-hr & 0.1976 & 0.1826 & 0.0583 & 0.0601 & 0.1103 & 0.1749 \\
\hline
\end{tabular}


Table 8-56 Summary of NanoBonus for DDC Steady State

\begin{tabular}{|l|l|l|l|l|r|r|r|r|r|r|}
\hline \multicolumn{4}{|c}{ NanoBonus } & Mode: & \multicolumn{1}{|l}{$\mathbf{1}^{*}$} & $\mathbf{2}$ & $\mathbf{3}$ & $\mathbf{4}$ & $\mathbf{5}$ & $\mathbf{6}$ \\
\hline Date & Time & Test \# & Work & bhp-hr & 0 & 1.662 & 5.674 & 7.678 & 1.932 & 6.666 \\
\hline $3 / 28 / 2009$ & $8: 38: 08$ & E02608-02 & Fuel-Meter & lb & 0.13516 & 0.30559 & 1.74619 & 2.44396 & 0.69368 & 2.15797 \\
\hline & & & Fuel-Tunnel & lb & 0.0869 & 0.56007 & 1.73153 & 2.30724 & 0.68854 & 2.08295 \\
\hline & & & Fuel-Scale & lb & 0 & 0 & 0 & 0 & 0 & 0 \\
\hline & & & bsFC & lb/bhp-hr & - & 0.3370 & 0.3052 & 0.3005 & 0.3564 & 0.3125 \\
\hline & & & bsHC & g/bhp-hr & 3.7040 & 0.0882 & 0.0191 & 0.0160 & 0.0705 & 0.0156 \\
\hline & & & bsHC2 & g/bhp-hr & 3.1715 & 0.0869 & 0.0188 & 0.0158 & 0.0695 & 0.0154 \\
\hline & & & bsLoCO & g/bhp-hr & 120.7351 & 0.7122 & 1.6696 & 1.2103 & 0.6836 & 5.9885 \\
\hline & & & bsHiCO & g/bhp-hr & 109.8578 & 0.6839 & 1.6183 & 1.1744 & 0.6552 & 6.433 \\
\hline & & & bsCO & g/bhp-hr & 14866.11 & 484.89 & 437.92 & 431.84 & 513.15 & 440.91 \\
\hline & & & bsNOx & g/bhp-hr & 359.105 & 10.516 & 6.368 & 4.385 & 10.595 & 5.211 \\
\hline & & & bsNOx2 & g/bhp-hr & 339.926 & 10.734 & 6.932 & 6.683 & 10.836 & 5.731 \\
\hline & & & bsNO_2 & g/bhp-hr & 302.935 & 10.090 & 6.731 & 6.491 & 10.411 & 5.528 \\
\hline & & & bsTPM & g/bhp-hr & 0.7655 & 0.1721 & 0.0572 & 0.0589 & 0.1496 & 0.1752 \\
\hline & & & & & & & & & \\
\hline
\end{tabular}


Table 8-57 Summary of Baseline for NanoBonus for DDC Steady State

\begin{tabular}{|l|l|l|l|l|l|r|r|r|r|r|}
\hline \multicolumn{4}{|c}{ Haltermann } & Mode: & \multicolumn{1}{|c|}{$\mathbf{1}^{*}$} & $\mathbf{2}$ & $\mathbf{3}$ & $\mathbf{4}$ & $\mathbf{5}$ & $\mathbf{6}$ \\
\hline Date & Time & Test \# & Work & bhp-hr & 0 & 1.664 & 5.674 & 7.688 & 1.919 & 6.657 \\
\hline 3/28/2009 & $23: 58: 16$ & E02610-01 & Fuel-Meter & lb & 0.13058 & 0.42124 & 1.64893 & 2.4473 & 0.68628 & 2.15804 \\
\hline & & & Fuel-Tunnel & lb & 0.08499 & 0.55802 & 1.72639 & 2.31556 & 0.68693 & 2.08219 \\
\hline & & & Fuel-Scale & lb & 0 & 0 & 0 & 0 & 0 & 0 \\
\hline & & & bsFC & lb/bhp-hr & - & 0.3353 & 0.3043 & 0.3012 & 0.3580 & 0.3128 \\
\hline & & & bsHC & g/bhp-hr & 7.1178 & 0.1057 & 0.0240 & 0.0216 & 0.0859 & 0.0188 \\
\hline & & & bsHC2 & g/bhp-hr & 6.6502 & 0.1046 & 0.0238 & 0.0214 & 0.0850 & 0.0186 \\
\hline & & & bsLoCO & g/bhp-hr & 126.759 & 0.7247 & 1.8449 & 1.4632 & 0.7107 & 5.9592 \\
\hline & & & bsHiCO & g/bhp-hr & 116.4103 & 0.691 & 1.79 & 1.42 & 0.68 & 6.6637 \\
\hline & & & bsCO & g/bhp-hr & 14513.46 & 482.58 & 436.27 & 432.45 & 515.44 & 440.94 \\
\hline & & & bsNOx & g/bhp-hr & 358.114 & 10.615 & 6.260 & 4.288 & 10.822 & 5.064 \\
\hline & & & bsNOx2 & g/bhp-hr & 341.134 & 10.856 & 6.912 & 6.659 & 11.054 & 5.679 \\
\hline & & & bsNO_2 & g/bhp-hr & 300.754 & 10.174 & 6.693 & 6.468 & 10.641 & 5.474 \\
\hline & & & bsTPM & g/bhp-hr & 0.1160 & 0.1587 & 0.0666 & 0.0779 & 0.0970 & 0.1928 \\
\hline & & & & & & & & \\
\hline
\end{tabular}


Table 8-58 Summary of Baseline for NanoBonus for DDC Steady State

\begin{tabular}{|l|l|l|l|l|l|r|r|r|r|r|}
\hline \multicolumn{4}{|c}{ Haltermann } & Mode: & $\mathbf{1}^{*}$ & $\mathbf{2}$ & $\mathbf{3}$ & $\mathbf{4}$ & $\mathbf{5}$ & $\mathbf{6}$ \\
\hline Date & Time & Test \# & Work & bhp-hr & 0 & 1.661 & 5.673 & 7.689 & 1.926 & 6.663 \\
\hline $3 / 29 / 2009$ & $0: 32: 07$ & E02610-02 & Fuel-Meter & lb & 0.12667 & 0.2576 & 1.78248 & 2.43167 & 0.6888 & 2.15314 \\
\hline & & & Fuel-Tunnel & lb & 0.08731 & 0.55842 & 1.72785 & 2.3077 & 0.68658 & 2.08295 \\
\hline & & & Fuel-Scale & lb & 0 & 0 & 0 & 0 & 0 & 0 \\
\hline & & & bsFC & lb/bhp-hr & \#DIV/0! & 0.3362 & 0.3046 & 0.3001 & 0.3565 & 0.3126 \\
\hline & & & bsHC & g/bhp-hr & 7.9746 & 0.0928 & 0.0233 & 0.0188 & 0.0839 & 0.0186 \\
\hline & & & bsHC2 & g/bhp-hr & 8.4780 & 0.0940 & 0.0236 & 0.0190 & 0.0848 & 0.0189 \\
\hline & & & bsLoCO & g/bhp-hr & 114.1351 & 0.6315 & 1.7371 & 1.2758 & 0.6615 & 5.96 \\
\hline & & & bsHiCO & g/bhp-hr & 108.5748 & 0.621 & 1.6857 & 1.2387 & 0.6422 & 6.5516 \\
\hline & & & bsCO & g/bhp-hr & 14923.87 & 483.89 & 436.94 & 431.24 & 513.25 & 440.92 \\
\hline & & & bsNOx & g/bhp-hr & 353.324 & 10.534 & 6.204 & 4.247 & 10.653 & 5.064 \\
\hline & & & bsNOx2 & g/bhp-hr & 321.332 & 10.735 & 6.907 & 6.641 & 10.906 & 5.693 \\
\hline & & & bsNO_2 & g/bhp-hr & 295.962 & 10.150 & 6.701 & 6.447 & 10.498 & 5.486 \\
\hline & & & bsTPM & g/bhp-hr & 0.2983 & 0.1341 & 0.0573 & 0.0679 & 0.0946 & 0.1904 \\
\hline & & & & & & & & & \\
\hline
\end{tabular}




\subsubsection{Cummins Testing Summaries}

Table 8-59 Summary of Baseline Testing on Cummins

\begin{tabular}{|c|c|c|c|c|c|c|c|c|c|c|c|}
\hline Fuel: & Guttman & & & Work & Fuel Rec. & bsFC & bsTHC & bsCO & $\mathrm{bsCO}_{2}$ & bsNOx & bsTPM \\
\hline Date & Time & Test No. & Start Type & bhp-hr & $\mathrm{g}$ & lb/bhp-hr & g/bhp-hr & g/bhp-hr & g/bhp-hr & g/bhp-hr & mg/bhp-hr \\
\hline $1 / 7 / 09$ & $0: 25$ & 0014-001-01 & Warm Start & 26.16 & 4291.914 & 0.3617 & 0.0800 & 0.871 & 520.6 & 3.626 & 59.0 \\
\hline $1 / 7 / 09$ & $1: 45$ & 0014-001-03 & Hot Start & 26.16 & 4593.164 & 0.3870 & 0.2439 & 0.965 & 556.6 & 4.144 & 63.4 \\
\hline $1 / 7 / 09$ & $2: 25$ & 0014-001-04 & Hot Start & 26.14 & 4582.213 & 0.3864 & 0.2355 & 0.969 & 555.8 & 4.127 & 70.1 \\
\hline $1 / 7 / 09$ & $4: 25$ & 0014-001-07 & Hot Start & 26.16 & 4592.206 & 0.3871 & 0.2410 & 0.991 & 556.6 & 4.116 & 61.5 \\
\hline Comments: & Did Not Use & & & & & & & & & & \\
\hline
\end{tabular}

Table 8-60 Summary of Cerion 1 Testing on Cummins

\begin{tabular}{|c|c|c|c|c|c|c|c|c|c|c|c|}
\hline Fuel: & Cerion 1 & & & Work & Fuel Rec. & bsFC & bsTHC & $\mathrm{bsCO}$ & $\mathrm{bsCO}_{2}$ & bsNOx & bsTPM \\
\hline Date & Time & Test No. & Start Type & bhp-hr & $\mathrm{g}$ & lb/bhp-hr & g/bhp-hr & g/bhp-hr & g/bhp-hr & g/bhp-hr & g/bhp-hr \\
\hline $1 / 7 / 09$ & $20: 12$ & 0014-002-01 & Warm Start & 26.16 & 4604.585 & 0.3881 & 0.2228 & 0.987 & 558.2 & 4.100 & 58.4 \\
\hline $1 / 7 / 09$ & $20: 52$ & $0014-002-02$ & Hot Start & 26.15 & 4601.966 & 0.3880 & 0.2329 & 0.975 & 558.1 & 4.096 & 60.1 \\
\hline $1 / 7 / 09$ & $21: 32$ & 0014-002-03 & Hot Start & 26.14 & 4595.903 & 0.3876 & 0.2326 & 0.945 & 557.6 & 4.125 & 53.9 \\
\hline $1 / 7 / 09$ & $22: 12$ & 0014-002-04 & Hot Start & 26.15 & 4587.578 & 0.3868 & 0.2350 & 0.942 & 556.3 & 4.107 & 55.8 \\
\hline $1 / 7 / 09$ & $22: 52$ & 0014-002-05 & Hot Start & 26.15 & 4585.139 & 0.3866 & 0.2346 & 0.937 & 556.1 & 4.136 & 61.4 \\
\hline $1 / 7 / 09$ & $23: 33$ & 0014-002-06 & Hot Start & 26.16 & 4588.538 & 0.3867 & 0.2350 & 0.928 & 556.2 & 4.120 & 55.7 \\
\hline $1 / 7 / 09$ & $0: 14$ & $0014-002-07$ & Hot Start & 26.19 & 4603.136 & 0.3875 & 0.2290 & 0.933 & 557.4 & 4.121 & 61.6 \\
\hline
\end{tabular}


Table 8-61 Summary of Baseline for Cerion 1 Testing on Cummins

\begin{tabular}{|c|c|c|c|c|c|c|c|c|c|c|c|}
\hline Fuel: & Guttman & & & Work & Fuel Rec. & bsFC & bsTHC & bsCO & $\mathrm{bsCO}_{2}$ & bsNOx & bsTPM \\
\hline Date & Time & Test No. & Start Type & bhp-hr & $g$ & lb/bhp-hr & g/bhp-hr & g/bhp-hr & g/bhp-hr & g/bhp-hr & mg/bhp-hr \\
\hline $1 / 8 / 09$ & $1: 41$ & 0014-002-08 & Warm Start & 26.13 & 4584.474 & 0.3868 & 0.2092 & 0.919 & 556.5 & 4.159 & 58.8 \\
\hline $1 / 8 / 09$ & $2: 21$ & 0014-002-09 & Hot Start & 26.14 & 4589.437 & 0.3870 & 0.2278 & 0.908 & 556.7 & 4.150 & 50.5 \\
\hline $1 / 8 / 09$ & $3: 02$ & 0014-002-10 & Hot Start & 26.15 & 4585.819 & 0.3866 & 0.2291 & 0.904 & 556.2 & 4.125 & 60.0 \\
\hline $1 / 8 / 09$ & $3: 42$ & 0014-002-11 & Hot Start & 26.15 & 4580.065 & 0.3862 & 0.2285 & 0.906 & 555.6 & 4.167 & 57.2 \\
\hline Comments: & Baseline for Cerion 1 & & & & & & & & & & \\
\hline
\end{tabular}

Table 8-62 Summary of Baseline for H2Oil 1 Testing on Cummins

\begin{tabular}{|c|c|c|c|c|c|c|c|c|c|c|c|}
\hline Fuel: & Guttman & & & Work & Fuel Rec. & bsFC & bsTHC & bsCO & bsCO & bsNOx & bsTPM \\
\hline Date & Time & Test No. & Start Type & bhp-hr & $\mathrm{g}$ & lb/bhp-hr & $\mathrm{g} / \mathrm{bhp}-\mathrm{hr}$ & $\mathrm{g} / \mathrm{bhp}-\mathrm{hr}$ & $\mathrm{g} / \mathrm{bhp}-\mathrm{hr}$ & $\mathrm{g} / \mathrm{bhp}-\mathrm{hr}$ & $\mathrm{mg} / \mathrm{bhp}-\mathrm{hr}$ \\
\hline $1 / 9 / 09$ & $3: 40$ & $0014-003-07$ & Warm Start & 26.13 & 4612.791 & 0.3891 & 0.2155 & 0.805 & 560.0 & 4.112 & 51.1 \\
\hline $1 / 9 / 09$ & $4: 20$ & $0014-003-08$ & Hot Start & 26.14 & 4605.142 & 0.3884 & 0.2281 & 0.812 & 558.9 & 4.089 & 50.5 \\
\hline $1 / 9 / 09$ & $5: 00$ & $0014-003-09$ & Hot Start & 26.15 & 4613.296 & 0.3890 & 0.2311 & 0.810 & 559.7 & 4.107 & 50.9 \\
\hline $1 / 9 / 09$ & $5: 40$ & $0014-003-10$ & Hot Start & 26.14 & 4608.3 & 0.3886 & 0.2304 & 0.803 & 559.2 & 4.105 & 50.6 \\
\hline Comments: & Baseline for H2Oil 1 & & & & & & & & & & \\
\hline
\end{tabular}


Table 8-63 Summary of H2Oil 1 Testing on Cummins

\begin{tabular}{|c|c|c|c|c|c|c|c|c|c|c|c|}
\hline Fuel: & H2Oil 1 & & & Work & Fuel Rec. & bsFC & bsTHC & bsCO & $\mathrm{bsCO}_{2}$ & bsNOx & bsTPM \\
\hline Date & Time & Test No. & Start Type & bhp-hr & $g$ & lb/bhp-hr & g/bhp-hr & g/bhp-hr & g/bhp-hr & g/bhp-hr & mg/bhp-hr \\
\hline $1 / 8 / 09$ & - & 0014-003-01 & Warm Start & 26.13 & 4657.183 & 0.3929 & 0.2208 & 0.911 & 565.2 & 4.287 & 51.8 \\
\hline $1 / 9 / 09$ & $0: 19$ & 0014-003-03 & Hot Start & 26.15 & 4598.150 & 0.3877 & 0.2383 & 0.834 & 557.8 & 4.091 & 52.4 \\
\hline $1 / 9 / 09$ & $1: 39$ & 0014-003-05 & Hot Start & 26.14 & 4602.466 & 0.3881 & 0.2350 & 0.825 & 558.4 & 4.091 & 52.2 \\
\hline $1 / 9 / 09$ & $2: 20$ & 0014-003-06 & Hot Start & 26.14 & 4600.059 & 0.3880 & 0.2344 & 0.826 & 558.3 & 4.080 & 54.1 \\
\hline
\end{tabular}

Table 8-64 Summary of Baseline for NanoBonus Testing on Cummins

\begin{tabular}{|c|c|c|c|c|c|c|c|c|c|c|c|}
\hline Fuel: & Guttman & & & Work & Fuel Rec. & bsFC & bsTHC & bsCO & $\mathrm{bsCO}_{2}$ & bsNOx & bsTPM \\
\hline Date & Time & Test No. & Start Type & bhp-hr & $\mathrm{g}$ & lb/bhp-hr & g/bhp-hr & g/bhp-hr & g/bhp-hr & g/bhp-hr & mg/bhp-hr \\
\hline $1 / 10 / 09$ & $0: 41$ & 0014-004-07 & Warm Start & 26.15 & 4629.791 & 0.3904 & 0.2169 & 0.828 & 561.8 & 4.131 & 53.2 \\
\hline $1 / 10 / 09$ & 2:01 & 0014-004-09 & Hot Start & 26.14 & 4622.929 & 0.3899 & 0.2321 & 0.836 & 561.0 & 4.104 & 55.2 \\
\hline $1 / 10 / 09$ & $2: 41$ & 0014-004-10 & Hot Start & 26.14 & 4626.824 & 0.3902 & 0.2325 & 0.844 & 561.4 & 4.122 & 57.6 \\
\hline
\end{tabular}


Table 8-65 Summary of NanoBonus Test on Cummins

\begin{tabular}{|c|c|c|c|c|c|c|c|c|c|c|c|}
\hline Fuel: & NanoBonus & & & Work & Fuel Rec. & bsFC & bsTHC & bsCO & $\mathrm{bsCO}_{2}$ & bsNOx & bsTPM \\
\hline Date & Time & Test No. & Start Type & bhp-hr & $\mathrm{g}$ & lb/bhp-hr & g/bhp-hr & g/bhp-hr & g/bhp-hr & g/bhp-hr & mg/bhp-hr \\
\hline $1 / 9 / 09$ & - & 0014-004-01 & Warm Start & 26.161 & 4641.439 & 0.391 & 0.2124 & 0.795 & 562.9 & 4.184 & 52.7 \\
\hline $1 / 9 / 09$ & $21: 31$ & 0014-004-04 & Hot Start & 26.159 & 4618.972 & 0.389 & 0.2290 & 0.817 & 560.2 & 4.134 & 50.4 \\
\hline $1 / 9 / 09$ & $22: 11$ & 0014-004-05 & Hot Start & 26.157 & 4618.207 & 0.389 & 0.2283 & 0.834 & 560.1 & 4.129 & 50.5 \\
\hline $1 / 9 / 09$ & $22: 51$ & 0014-004-06 & Hot Start & 26.154 & 4619.547 & 0.389 & 0.2363 & 0.828 & 560.3 & 4.135 & 55.8 \\
\hline
\end{tabular}

\subsubsection{AM General Testing Summaries}

Table 8-66 Summary of Baseline for NanoBonus Test on AM General

\begin{tabular}{|c|c|c|c|c|c|c|c|c|c|c|c|c|}
\hline Fuel: & JP8 & & & Work & Fuel Rec. & bsFC & bsTHC & bsCO & $\mathrm{bsCO}_{2}$ & bsNOx & bsNOx 2 & bsTPM \\
\hline Date & Time & Test No. & Start Type & bhp-hr & $\mathrm{g}$ & lb/bhp-hr & g/bhp-hr & g/bhp-hr & g/bhp-hr & g/bhp-hr & g/bhp-hr & $\mathrm{mg} / \mathrm{bhp}-\mathrm{hr}$ \\
\hline 4/27/09 & $10: 39$ & $0019-002-54$ & Warm & 9.913 & 0.003 & 0.0028 & 0.000343 & -0.00831 & 4.103215 & -0.00718 & -0.00077 & 349.1 \\
\hline $4 / 27 / 09$ & $11: 23$ & $0019-002-55$ & Warm & 9.906 & 2178.454 & 0.4848 & 0.115095 & 1.382425 & 697.3848 & 9.414841 & 8.821278 & 234.8 \\
\hline $4 / 27 / 09$ & $12: 08$ & $0019-002-56$ & Hot & 9.909 & 2170.324 & 0.4829 & 0.1175 & 1.370 & 694.6 & 9.291 & 8.750 & 243.7 \\
\hline $4 / 27 / 09$ & $12: 53$ & 0019-002-57 & Hot & 9.906 & 2167.375 & 0.4824 & 0.1232 & 1.358 & 693.9 & 9.271 & 8.725 & 256.5 \\
\hline 4/27/09 & $13: 37$ & $0019-002-58$ & Hot & 9.910 & 2160.53 & 0.4807 & 0.1217 & 1.386 & 691.4 & 8.816 & 8.256 & 255.8 \\
\hline Comments: & Baseline for & NanoBonus & & & & & & & & & & \\
\hline
\end{tabular}


Table 8-67 Summary of NanoBonus Test on AM General

\begin{tabular}{|c|c|c|c|c|c|c|c|c|c|c|c|c|}
\hline Fuel: & NanoE & onus & & Work & Fuel Rec. & bsFC & bsTHC & $\mathrm{bsCO}$ & $\mathrm{bsCO}_{2}$ & bsNOx & bsNOx 2 & bsTPM \\
\hline Date & Time & Test No. & Start Type & bhp-hr & $\mathrm{g}$ & lb/bhp-hr & g/bhp-hr & g/bhp-hr & g/bhp-hr & g/bhp-hr & g/bhp-hr & mg/bhp-hr \\
\hline 4/28/09 & $16: 02$ & 0019-003-05 & Warm & 9.925 & 2168.607 & 0.4818 & 0.1079 & 1.360 & 693.0 & 9.181 & 8.545 & 212.5 \\
\hline $4 / 28 / 09$ & $16: 47$ & 0019-003-06 & Hot & 9.911 & 2170.336 & 0.4829 & 0.1197 & 1.352 & 694.5 & 9.211 & 8.511 & 229.2 \\
\hline $4 / 28 / 09$ & $17: 33$ & 0019-003-07 & Hot & 9.900 & 2177.762 & 0.4850 & 0.1288 & 1.420 & 697.5 & 9.175 & 8.432 & 250.3 \\
\hline $4 / 28 / 09$ & $18: 18$ & 0019-003-08 & Hot & 9.891 & 2178.502 & 0.4856 & 0.1320 & 1.404 & 698.4 & 9.255 & 8.458 & 259.4 \\
\hline Comments: & & & & & & & & & & & & \\
\hline
\end{tabular}

Table 8-68 Summary of Baseline for H2Oil 2 Test on AM General

\begin{tabular}{|c|c|c|c|c|c|c|c|c|c|c|c|c|}
\hline Fuel: & JP8 & & & Work & Fuel Rec. & bsFC & bsTHC & bsCO & $\mathrm{bsCO}_{2}$ & bsNOx & bsNOx 2 & bsTPM \\
\hline Date & Time & Test No. & Start Type & bhp-hr & $\mathrm{g}$ & lb/bhp-hr & g/bhp-hr & g/bhp-hr & g/bhp-hr & g/bhp-hr & g/bhp-hr & mg/bhp-hr \\
\hline $4 / 29 / 09$ & $18: 26$ & 0019-002-75 & Warm & 9.902 & 2178.005 & 0.4849 & 0.0750 & 1.355 & 697.7 & 9.187 & 8.587 & 202.8 \\
\hline $4 / 29 / 09$ & 19:11 & 0019-002-76 & Hot & 9.894 & 2185.683 & 0.4871 & 0.1245 & 1.419 & 700.5 & 9.268 & 8.634 & 226.8 \\
\hline $4 / 29 / 09$ & $19: 56$ & 0019-002-77 & Hot & 9.883 & 2189.625 & 0.4885 & 0.1294 & 1.437 & 702.6 & 9.347 & 8.643 & 247.0 \\
\hline 4/29/09 & $20: 42$ & 0019-002-78 & Hot & 9.889 & 2185.307 & 0.4873 & 0.1350 & 1.452 & 700.7 & 9.364 & 8.697 & 248.1 \\
\hline Comments: & Baseliı & e for $\mathrm{H} 2 \mathrm{O}$ il 2 & & & & & & & & & & \\
\hline
\end{tabular}


Table 8-69 Summary of H2Oil 2 Test on AM General

\begin{tabular}{|c|c|c|c|c|c|c|c|c|c|c|c|c|}
\hline Fuel: & H2Oil 2 & & & Work & Fuel Rec. & bsFC & bsTHC & bsCO & $\mathrm{bsCO}_{2}$ & bsNOx & bsNOx 2 & bsTPM \\
\hline Date & Time & Test No. & Start Type & bhp-hr & $g$ & lb/bhp-hr & g/bhp-hr & g/bhp-hr & g/bhp-hr & g/bhp-hr & g/bhp-hr & mg/bhp-hr \\
\hline $5 / 1 / 09$ & $8: 31$ & 0019-004-01 & Warm & 9.895 & 2170.449 & 0.4836 & 0.0913 & 1.360 & 695.7 & 9.091 & 8.541 & 214.7 \\
\hline $5 / 1 / 09$ & $9: 16$ & 0019-004-02 & Hot & 9.893 & 2176.941 & 0.4852 & 0.1107 & 1.399 & 697.8 & 9.236 & 8.533 & 232.5 \\
\hline $5 / 1 / 09$ & 10:01 & 0019-004-03 & Hot & 9.890 & 2174.182 & 0.4847 & 0.1225 & 1.385 & 697.1 & 9.324 & 8.612 & 240.0 \\
\hline $5 / 1 / 09$ & $10: 46$ & 0019-004-04 & Hot & 9.887 & 2174.086 & 0.4848 & 0.1254 & 1.403 & 697.3 & 9.344 & 8.622 & 247.1 \\
\hline Comments: & & & & & & & & & & & & \\
\hline
\end{tabular}

Table 8-70 Summary of Baseline Test on AM General

\begin{tabular}{|c|c|c|c|c|c|c|c|c|c|c|c|c|}
\hline Fuel: & JP8 & & & Work & Fuel Rec. & bsFC & bsTHC & $\mathrm{bsCO}$ & $\mathrm{bsCO}_{2}$ & bsNOx & bsNOx 2 & bsTPM \\
\hline Date & Time & Test No. & Start Type & bhp-hr & g & lb/bhp-hr & g/bhp-hr & g/bhp-hr & g/bhp-hr & g/bhp-hr & g/bhp-hr & $\mathrm{mg} / \mathrm{bhp}-\mathrm{hr}$ \\
\hline $5 / 4 / 09$ & $11: 35$ & 0019-002-96 & Warm & 9.899 & 2174.663 & 0.4843 & 0.0902 & 1.355 & 696.8 & 9.065 & 8.506 & 212.7 \\
\hline $5 / 4 / 09$ & $12: 20$ & $0019-002-97$ & Hot & 9.891 & 2175.953 & 0.4851 & 0.1103 & 1.399 & 697.6 & 9.208 & 8.540 & 225.8 \\
\hline $5 / 4 / 09$ & 13:05 & $0019-002-98$ & Hot & 9.886 & 2175.307 & 0.4851 & 0.1183 & 1.414 & 697.7 & 9.155 & 8.532 & 243.0 \\
\hline $5 / 4 / 09$ & $13: 50$ & 0019-002-99 & Hot & 9.888 & 2184.956 & 0.4872 & 0.1250 & 1.404 & 700.7 & 9.247 & 8.603 & 222.8 \\
\hline Comments: & Not Used & & & & & & & & & & & \\
\hline
\end{tabular}


Table 8-71 Summary of Cerion 1 Test on AM General

\begin{tabular}{|c|c|c|c|c|c|c|c|c|c|c|c|c|}
\hline Fuel: & Cerion 1 & & & Work & Fuel Rec. & bsFC & bsTHC & bsCO & $\mathrm{bsCO}_{2}$ & bsNOx & bsNOx 2 & bsTPM \\
\hline Date & Time & Test No. & Start Type & bhp-hr & $\mathrm{g}$ & $\mathrm{lb} / \mathrm{bhp}-\mathrm{hr}$ & g/bhp-hr & g/bhp-hr & g/bhp-hr & g/bhp-hr & g/bhp-hr & mg/bhp-hr \\
\hline $5 / 6 / 09$ & $19: 56$ & 0019-005-01 & Warm & 9.901 & 2171.648 & 0.4836 & 0.0846 & 1.255 & 695.9 & 9.075 & 8.611 & - \\
\hline $5 / 6 / 09$ & $20: 41$ & 0019-005-02 & Hot & 9.905 & 2176.639 & 0.4845 & 0.0961 & 1.333 & 697.0 & 9.329 & 8.805 & 241.7 \\
\hline $5 / 6 / 09$ & $21: 27$ & 0019-005-03 & Hot & 9.903 & 2178.591 & 0.4851 & 0.1034 & 1.380 & 697.7 & 9.416 & 8.870 & 254.7 \\
\hline $5 / 6 / 09$ & $22: 12$ & 0019-005-04 & Hot & 9.889 & 2180.082 & 0.4861 & 0.1037 & 1.339 & 699.2 & 9.541 & 8.918 & 251.7 \\
\hline Comments: & & & & & & & & & & & & \\
\hline
\end{tabular}

Table 8-72 Summary of Baseline for Cerion 1 Test on AM General

\begin{tabular}{|c|c|c|c|c|c|c|c|c|c|c|c|c|}
\hline Fuel: & JP8 & & & Work & Fuel Rec. & bsFC & bsTHC & $\mathrm{bsCO}$ & $\mathrm{bsCO}_{2}$ & bsNOx & bsNOx 2 & bsTPM \\
\hline Date & Time & Test No. & Start Type & bhp-hr & $\mathrm{g}$ & lb/bhp-hr & g/bhp-hr & g/bhp-hr & g/bhp-hr & g/bhp-hr & g/bhp-hr & mg/bhp-hı \\
\hline $5 / 7 / 09$ & $18: 49$ & 0019-002-117 & Hot & 9.908 & 2173.816 & 0.4837 & 0.1029 & 1.331 & 695.9 & 9.147 & 8.625 & 226.1 \\
\hline $5 / 7 / 09$ & 19:35 & 0019-002-118 & Hot & 9.900 & 2174.541 & 0.4842 & 0.1072 & 1.363 & 696.6 & 9.003 & 8.420 & 233.3 \\
\hline $5 / 7 / 09$ & $20: 20$ & 0019-002-119 & Hot & 9.894 & 2180.1 & 0.4858 & 0.1088 & 1.369 & 698.8 & 9.191 & 8.616 & 236.7 \\
\hline Comments: & Baselir & e for Cerion 1 & & & & & & & & & & \\
\hline
\end{tabular}


Table 8-73 Mode A Baseline for NanoBonus Steady State Test on AM General

\begin{tabular}{|c|c|l|c|c|c|c|c|c|c|c|c|}
\hline Fuel: & JP8 & & Work & Fuel Rec. & bsFC & bsTHC & bsCO & bsCO $_{2}$ & bsNOx & bsNOx 2 & bsTPM \\
\hline Date & Test No. & Start Type & bhp-hr & $\mathrm{g}$ & lb/bhp-hr & g/bhp-hr & g/bhp-hr & g/bhp-hr & g/bhp-hr & g/bhp-hr & mg/bhp-hr \\
\hline 4/28 & $0019-002-71$ & Hot & 5.06 & 912.453 & 0.3973 & 0.0552 & 0.452 & 572.7 & 7.070 & 6.778 & 165.82 \\
\hline $4 / 28$ & $0019-002-72$ & Hot & 5.17 & 927.3323 & 0.3954 & 0.0579 & 0.472 & 569.8 & 7.062 & 6.734 & 96.98996 \\
\hline $4 / 28$ & $0019-002-73$ & Hot & 5.16 & 927.4846 & 0.3964 & 0.0631 & 0.487 & 571.3 & 7.126 & 6.778 & 107.6775 \\
\hline
\end{tabular}

\section{Table 8-74 Mode A NanoBonus Steady State Test on AM General}

\begin{tabular}{|c|c|c|c|c|c|c|c|c|c|c|c|}
\hline Fuel: & NanoBonus & & Work & Fuel Rec. & bsFC & bsTHC & bsCO & $\mathrm{bsCO}_{2}$ & bsNOx & bsNOx 2 & bsTPM \\
\hline Date & Test No. & Start Type & bhp-hr & $\mathrm{g}$ & lb/bhp-hr & g/bhp-hr & g/bhp-hr & g/bhp-hr & g/bhp-hr & g/bhp-hr & mg/bhp-hr \\
\hline $4 / 29$ & 0019-003-19 & Hot & 5.12 & 925.0867 & 0.3980 & 0.0959 & 0.444 & 573.6 & 6.901 & 6.577 & 117.0589 \\
\hline $4 / 29$ & 0019-003-20 & Hot & 5.07 & 919.4395 & 0.3996 & 0.0678 & 0.462 & 575.9 & 7.193 & 6.872 & 94.39073 \\
\hline $4 / 29$ & 0019-003-21 & Hot & 5.07 & 922.8994 & 0.4011 & 0.0664 & 0.502 & 578.0 & 7.297 & 6.959 & 105.1049 \\
\hline
\end{tabular}

Table 8-75 Mode A Baseline for H2Oil 2 Steady State Test on AM General

\begin{tabular}{|c|c|l|c|c|c|c|c|c|c|c|c|}
\hline Fuel: & JP8 & & Work & Fuel Rec. & bsFC & bsTHC & bsCO & bsCO $_{2}$ & bsNOx & bsNOx 2 & bsTPM \\
\hline Date & Test No. & Start Type & bhp-hr & $\mathrm{g}$ & lb/bhp-hr & g/bhp-hr & g/bhp-hr & g/bhp-hr & g/bhp-hr & g/bhp-hr & mg/bhp-hr \\
\hline $4 / 30$ & $0019-002-93$ & Hot & 5.14 & 918.7886 & 0.3944 & 0.0728 & 0.436 & 568.4 & 7.021 & 6.688 & 92.11451 \\
\hline $4 / 30$ & $0019-002-94$ & Hot & 5.17 & 924.7422 & 0.3944 & 0.0610 & 0.493 & 568.4 & 7.176 & 6.853 & 105.8683 \\
\hline $4 / 30$ & $0019-002-95$ & Hot & 5.11 & 917.527 & 0.3962 & 0.0673 & 0.495 & 571.0 & 7.335 & 6.981 & 103.1266 \\
\hline
\end{tabular}


Table 8-76 Mode A H2Oil 2 Steady State Test on AM General

\begin{tabular}{|c|c|c|c|c|c|c|c|c|c|c|c|}
\hline Fuel: & H2Oil 2 & & Work & Fuel Rec. & bsFC & bsTHC & bsCO & $\mathrm{bsCO}_{2}$ & bsNOx & bsNOx 2 & bsTPM \\
\hline Date & Test No. & Start Type & bhp-hr & $\mathrm{g}$ & lb/bhp-hr & g/bhp-hr & g/bhp-hr & g/bhp-hr & g/bhp-hr & g/bhp-hr & $\mathrm{mg} / \mathrm{bhp}-\mathrm{hr}$ \\
\hline $5 / 1$ & 0019-004-17 & Hot & 5.09 & 915.6958 & 0.3968 & 0.0912 & 0.429 & 572.0 & 6.840 & 6.528 & 112.2166 \\
\hline $5 / 1$ & 0019-004-18 & Hot & 5.12 & 921.4406 & 0.3971 & 0.0640 & 0.470 & 572.3 & 7.124 & 6.820 & 103.0735 \\
\hline $5 / 1$ & 0019-004-19 & Hot & 5.13 & 923.283 & 0.3965 & 0.0635 & 0.475 & 571.4 & 7.003 & 6.703 & 98.73892 \\
\hline $5 / 1$ & 0019-004-20 & Hot & 5.16 & 931.6815 & 0.3980 & 0.0618 & 0.476 & 573.6 & 6.981 & 6.708 & 100.2439 \\
\hline
\end{tabular}

Table 8-77 Mode A Baseline for Cerion 1 Steady State Test on AM General

\begin{tabular}{|c|c|c|c|c|c|c|c|c|c|c|c|}
\hline Fuel: & JP8 & & Work & Fuel Rec. & bsFC & bsTHC & bsCO & $\mathrm{bsCO}_{2}$ & bsNOx & bsNOx 2 & bsTPM \\
\hline Date & Test No. & Start Type & bhp-hr & $\mathrm{g}$ & lb/bhp-hr & g/bhp-hr & g/bhp-hr & g/bhp-hr & g/bhp-hr & g/bhp-hr & $\mathrm{mg} / \mathrm{bhp}-\mathrm{hr}$ \\
\hline $5 / 4$ & 0019-002-111 & Hot & 5.08 & 914.9978 & 0.3971 & 0.0846 & 0.432 & 572.3 & 6.735 & 6.457 & 113.116 \\
\hline $5 / 4$ & 0019-002-112 & Hot & 5.18 & 929.3132 & 0.3958 & 0.0630 & 0.466 & 570.4 & 6.869 & 6.572 & 86.26686 \\
\hline $5 / 4$ & 0019-002-113 & Hot & 5.14 & 924.9169 & 0.3964 & 0.0600 & 0.463 & 571.4 & 6.946 & 6.645 & 90.03258 \\
\hline $5 / 4$ & 0019-002-114 & Hot & 5.08 & 916.51 & 0.3977 & 0.0628 & 0.482 & 573.2 & 6.994 & 6.686 & 92.70903 \\
\hline
\end{tabular}

Table 8-78 Mode A Cerion 1 Steady State Test on AM General

\begin{tabular}{|c|c|c|c|c|c|c|c|c|c|c|c|}
\hline Fuel: & Cerion 1 & & Work & Fuel Rec. & bsFC & bsTHC & $\mathrm{bsCO}$ & $\mathrm{bsCO}_{2}$ & bsNOx & bsNOx 2 & bsTPM \\
\hline Date & Test No. & Start Type & bhp-hr & $\mathrm{g}$ & lb/bhp-hr & g/bhp-hr & g/bhp-hr & g/bhp-hr & g/bhp-hr & g/bhp-hr & $\mathrm{mg} / \mathrm{bhp}-\mathrm{hr}$ \\
\hline $5 / 7$ & 0019-005-15 & Hot & 5.04 & 910.5464 & 0.3980 & 0.0758 & 0.435 & 573.6 & 6.546 & 6.312 & 102.9357 \\
\hline $5 / 7$ & 0019-005-16 & Hot & 5.09 & 920.078 & 0.3982 & 0.0592 & 0.491 & 573.9 & 6.609 & 6.381 & 84.90544 \\
\hline $5 / 7$ & 0019-005-17 & Hot & 5.10 & 919.8685 & 0.3980 & 0.0581 & 0.506 & 573.6 & 6.920 & 6.671 & 91.96954 \\
\hline
\end{tabular}


Table 8-79 Mode B Baseline for NanoBonus Steady State Test on AM General

\begin{tabular}{|c|c|l|c|c|c|c|c|c|c|c|c|}
\hline Fuel: & JP8 & & Work & Fuel Rec. & bsFC & bsTHC & bsCO & bsCO $_{2}$ & bsNOx & bsNOx 2 & bsTPM \\
\hline Date & Test No. & Start Type & bhp-hr & $\mathrm{g}$ & lb/bhp-hr & $\mathrm{g} / \mathrm{bhp}-\mathrm{hr}$ & $\mathrm{g} / \mathrm{bhp}-\mathrm{hr}$ & $\mathrm{g} / \mathrm{bhp}-\mathrm{hr}$ & $\mathrm{g} / \mathrm{bhp}-\mathrm{hr}$ & $\mathrm{g} / \mathrm{bhp}-\mathrm{hr}$ & $\mathrm{mg} / \mathrm{bhp}-\mathrm{hr}$ \\
\hline $4 / 28$ & $0019-002-71$ & Hot & 2.94 & 758.2806 & 0.5678 & 0.4281 & 2.800 & 814.3 & 7.164 & 6.567 & 2.529927 \\
\hline $4 / 28$ & $0019-002-72$ & Hot & 2.99 & 766.7331 & 0.5648 & 0.4164 & 2.938 & 809.8 & 7.071 & 6.426 & 138.5116 \\
\hline $4 / 28$ & $0019-002-73$ & Hot & 2.94 & 759.9894 & 0.5690 & 0.4475 & 2.931 & 815.8 & 7.182 & 6.523 & 144.3128 \\
\hline
\end{tabular}

Table 8-80 Mode B NanoBonus Steady State Test on AM General

\begin{tabular}{|c|c|l|c|c|c|c|c|c|c|c|c|}
\hline Fuel: & NanoBonus & & Work & Fuel Rec. & bsFC & bsTHC & bsCO & bsCO $_{2}$ & bsNOx & bsNOx 2 & bsTPM \\
\hline Date & Test No. & Start Type & bhp-hr & $g$ & lb/bhp-hr & g/bhp-hr & g/bhp-hr & g/bhp-hr & g/bhp-hr & g/bhp-hr & mg/bhp-hr \\
\hline $4 / 29$ & $0019-003-19$ & Hot & 2.95 & 764.9445 & 0.5716 & 0.5591 & 3.131 & 819.0 & 7.311 & 6.751 & 197.6911 \\
\hline $4 / 29$ & $0019-003-20$ & Hot & 3.04 & 780.4608 & 0.5658 & 0.3365 & 1.823 & 813.2 & 6.223 & 5.784 & 126.1841 \\
\hline $4 / 29$ & $0019-003-21$ & Hot & 2.95 & 769.299 & 0.5744 & 0.4285 & 2.130 & 824.9 & 6.294 & 5.784 & 124.2913 \\
\hline
\end{tabular}

Table 8-81 Mode B Baseline for H2Oil 2 Steady State Test on AM General

\begin{tabular}{|c|c|c|c|c|c|c|c|c|c|c|c|}
\hline Fuel: & JP8 & & Work & Fuel Rec. & bsFC & bsTHC & bsCO & $\mathrm{bsCO}_{2}$ & bsNOx & bsNOx 2 & bsTPM \\
\hline Date & Test No. & Start Type & bhp-hr & $g$ & lb/bhp-hr & g/bhp-hr & g/bhp-hr & g/bhp-hr & g/bhp-hr & g/bhp-hr & mg/bhp-hr \\
\hline $4 / 30$ & 0019-002-93 & Hot & 2.95 & 766.034 & 0.5721 & 0.3797 & 2.280 & 821.4 & 6.327 & 5.863 & 129.5085 \\
\hline $4 / 30$ & 0019-002-94 & Hot & 2.90 & 756.315 & 0.5744 & 0.4131 & 2.291 & 824.7 & 6.292 & 5.772 & 119.6456 \\
\hline $4 / 30$ & 0019-002-95 & Hot & 2.92 & 755.0692 & 0.5704 & 0.3175 & 1.766 & 819.9 & 6.441 & 5.959 & 119.9206 \\
\hline
\end{tabular}


Table 8-82 Mode B H2Oil 2 Steady State Test on AM General

\begin{tabular}{|c|c|c|c|c|c|c|c|c|c|c|c|}
\hline Fuel: & H2Oil 2 & & Work & Fuel Rec. & bsFC & bsTHC & bsCO & $\mathrm{bsCO}_{2}$ & bsNOx & bsNOx 2 & bsTPM \\
\hline Date & Test No. & Start Type & bhp-hr & $\mathrm{g}$ & lb/bhp-hr & g/bhp-hr & g/bhp-hr & g/bhp-hr & g/bhp-hr & g/bhp-hr & mg/bhp-hr \\
\hline $5 / 1$ & 0019-004-17 & Hot & 2.99 & 775.5 & 0.5718 & 0.3500 & 1.960 & 820.9 & 6.330 & 5.950 & \\
\hline $5 / 1$ & 0019-004-18 & Hot & 2.94 & 765.6193 & 0.5734 & 0.4131 & 2.193 & 823.4 & 6.405 & 5.922 & 125.741 \\
\hline $5 / 1$ & 0019-004-19 & Hot & 2.96 & 765.3519 & 0.5705 & 0.4576 & 2.928 & 818.0 & 7.100 & 6.499 & 132.3394 \\
\hline $5 / 1$ & $0019-004-20$ & Hot & 2.94 & 768.8337 & 0.5771 & 0.4238 & 2.282 & 828.6 & 6.269 & 5.776 & 117.4831 \\
\hline
\end{tabular}

Table 8-83 Mode B Baseline for Cerion 1 Steady State Test on AM General

\begin{tabular}{|c|c|c|c|c|c|c|c|c|c|c|c|}
\hline Fuel: & JP8 & & Work & Fuel Rec. & bsFC & bsTHC & $\mathrm{bsCO}$ & $\mathrm{bsCO}_{2}$ & bsNOx & bsNOx 2 & bsTPM \\
\hline Date & Test No. & Start Type & bhp-hr & $\mathrm{g}$ & lb/bhp-hr & g/bhp-hr & g/bhp-hr & g/bhp-hr & g/bhp-hr & g/bhp-hr & mg/bhp-hr \\
\hline $5 / 4$ & 0019-002-111 & Hot & 2.94 & 767.5704 & 0.5760 & 0.3815 & 1.959 & 827.6 & 6.385 & 6.002 & 178.9519 \\
\hline $5 / 4$ & 0019-002-112 & Hot & 2.94 & 767.8915 & 0.5751 & 0.3663 & 1.942 & 826.3 & 6.389 & 5.925 & 121.0563 \\
\hline $5 / 4$ & 0019-002-113 & Hot & 2.92 & 766.9483 & 0.5785 & 0.4094 & 2.215 & 830.7 & 6.449 & 5.917 & 120.769 \\
\hline $5 / 4$ & 0019-002-114 & Hot & 2.94 & 768.9999 & 0.5766 & 0.4323 & 2.331 & 827.8 & 6.447 & 5.888 & 120.8579 \\
\hline
\end{tabular}

Table 8-84 Mode B Cerion 1 Steady State Test on AM General

\begin{tabular}{|r|c|l|c|c|c|c|c|c|c|c|c|}
\hline Fuel: & Cerion 1 & & Work & Fuel Rec. & bsFC & bsTHC & bsCO & bsCO $_{2}$ & bsNOx & bsNOx 2 & bsTPM \\
\hline Date & Test No. & Start Type & bhp-hr & $\mathrm{g}$ & $\mathrm{lb} / \mathrm{bhp}-\mathrm{hr}$ & $\mathrm{g} / \mathrm{bhp}-\mathrm{hr}$ & $\mathrm{g} / \mathrm{bhp}-\mathrm{hr}$ & $\mathrm{g} / \mathrm{bhp}-\mathrm{hr}$ & $\mathrm{g} / \mathrm{bhp}-\mathrm{hr}$ & $\mathrm{g} / \mathrm{bhp}-\mathrm{hr}$ & $\mathrm{mg} / \mathrm{bhp}-\mathrm{hr}$ \\
\hline $5 / 7$ & $0019-005-15$ & Hot & 2.97 & 772.1116 & 0.5736 & 0.4588 & 2.800 & 822.7 & 6.902 & 6.452 & 164.7574 \\
\hline $5 / 7$ & $0019-005-16$ & Hot & 2.96 & 773.2404 & 0.5756 & 0.3885 & 2.345 & 826.4 & 6.463 & 5.995 & 117.2012 \\
\hline $5 / 7$ & $0019-005-17$ & Hot & 2.94 & 769.5666 & 0.5770 & 0.4341 & 2.590 & 828.0 & 6.684 & 6.148 & 113.4699 \\
\hline
\end{tabular}

John

$\mathrm{H}$. (alysigned by yohn

Hagen 